\title{
Biomechanical Comparison of Wire Circlage and Rigid Plate Fixation for Median Sternotomy Closure in Human Cadaver Specimens
}

\author{
A Thesis \\ Presented to \\ the Faculty of California Polytechnic State University, \\ San Luis Obispo \\ In Partial Fulfillment \\ Of the Requirements for the Degree \\ Master of Science in Biomedical Engineering
}

By

Mark Steven Wong

April 2010 
(C) 2010

Mark Steven Wong

ALL RIGHTS RESERVED 


\section{COMMITTEE MEMBERSHIP}

TITLE: $\quad$ Biomechanical Comparison of Wire Circlage and Rigid Plate Fixation for Median Sternotomy Closure in Human Cadaver Specimens

AUTHOR: $\quad$ Mark Wong

DATE SUBMITTED: $\quad$ April $19^{\text {th }} 2010$

COMMITTEE CHAIR: $\quad$ Dr. Lanny Griffin, Department Chair - Biomedical Engineering

COMMITTEE MEMBER: Dr. Dan Walsh, Senior Associate Dean

COMMITTEE MEMBER: Dr. Scott Hazelwood, Associate Professor 


\begin{abstract}
Biomechanical Comparison of Wire Circlage and Rigid Plate Fixation for Median Sternotomy Closure in Human Cadaver Specimens

By: Mark Steven Wong
\end{abstract}

\title{
Background:
}

Over 700,000 patients per year undergo open-heart surgery. Healing complication rates can be up to $5 \%$ of patients who undergo this procedure, with a morbidity rate of $50 \%$ if mediastinitis supervenes. A secure and rigid fixation of surgically divided sternum is critical to avoid healing complications. The purpose of this study was to compare the yield load, construct stiffness, ultimate load, displacement at ultimate load, and post-yield behavior of three sternotomy closure methods (Peristernal wires or Sternalock titanium plates) when stressed in each of three directions: lateral distraction, rostro-caudal (longitudinal) shear distraction, and anterior-posterior (transverse) shear in a cadaveric model.

Methods:

Forty-two fresh cadaver models were divided into three test groups: group A, B, and C. A cardiothoracic surgeon divided each cadaveric sternum longitudinally and repaired peristernal wires or one of two Sternalock configurations. Tests were performed using a materials testing system that applied force at a constant displacement rate in a uniaxial direction until the construct catastrophically failed. Mechanical behavior was monitored using a 3D texture correlation system to create a real-time three-dimensional representation of strain directions. The resulting displacement pattern is analogous to a finite element contour plot of displacements, Lagrange Strain, or velocity. Statistical analysis was used to show the different mechanical properties of each closure method.

Results:

When loaded in lateral distraction, both Sternalock configurations surpassed the rigidity of peristernal wires by $600 \%$. Some evidence was also found linking Sternalock with stiffer behavior in the rostro-caudal direction. Though not statistically significant, a trend was observed showing that constructs using the Sternalock also had higher yield loads, as well as, less post-yield displacement when compared to peristernal wires.

Conclusions:

Data gathered showed the superior performance of the Sternalock system in stiffness in both longitudinal distraction and rostro-caudal shear. Implications for use of the Sternalock system are faster healing times, lower complication rates, and success of the procedure. 


\section{ACKNOWLEDGMENTS}

This research project was made possible with the guidance and direction from Dr. Lanny Griffin, thank you for all of your help. Thank you, Biomet Microfixation, for providing equipment and specimens to conduct the research. Thank you, Daniel Kim for putting in long hours in the lab to help me conduct research. 


\section{Table of Contents}

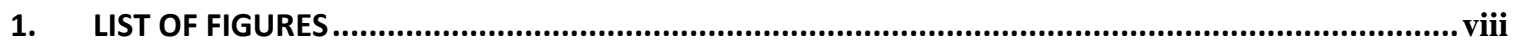

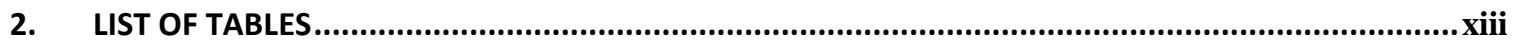

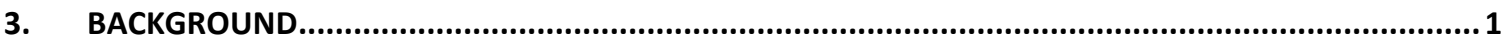

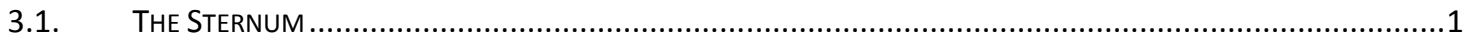

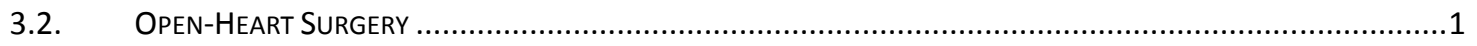

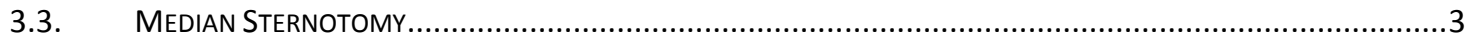

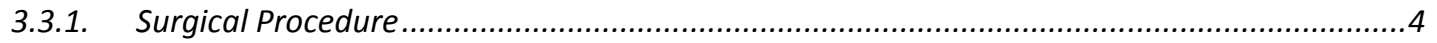

3.3.2. Sternal closure after a median sternotomy .....................................................................

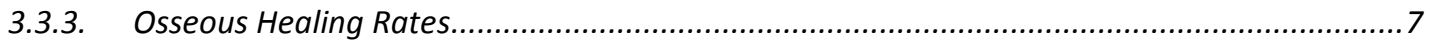

3.3.4. Advantages of the median sternotomy

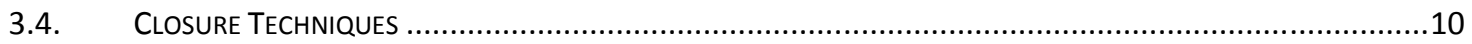

3.4.1. Stainless steel wire fixation ..................................................................................... 10

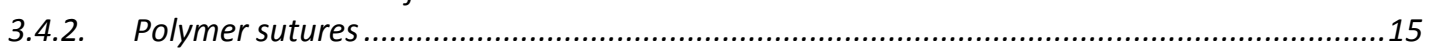

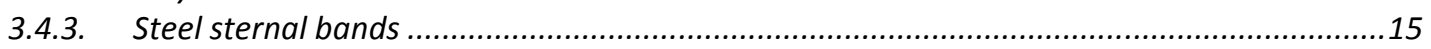

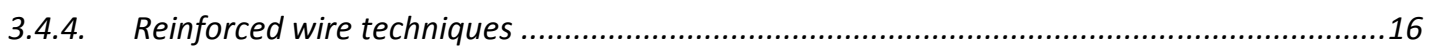

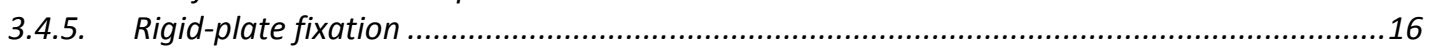

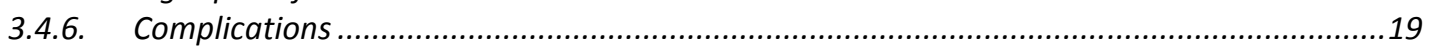

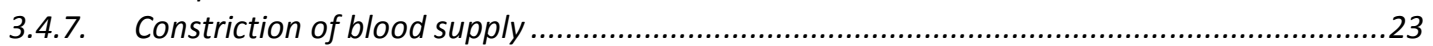

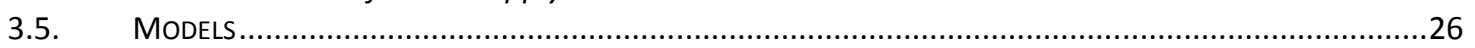

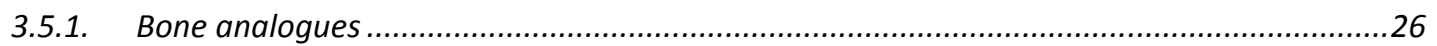

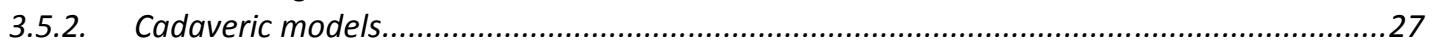

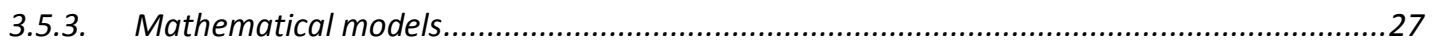

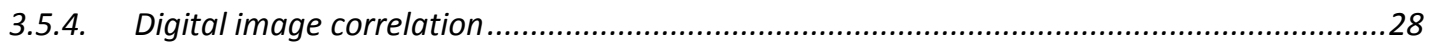

4. OBJECTIVES

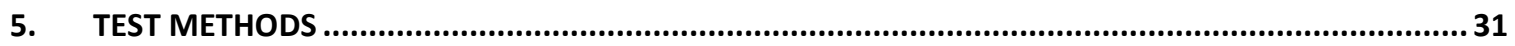

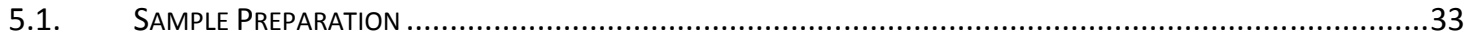

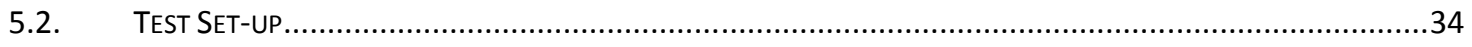

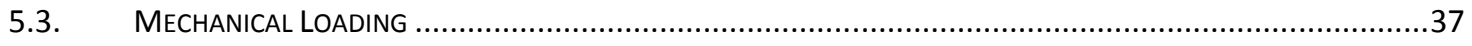

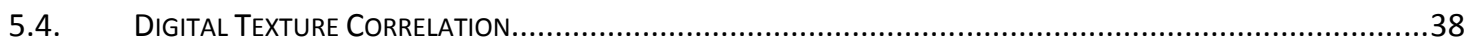

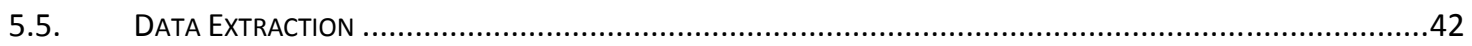

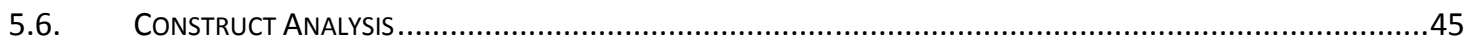

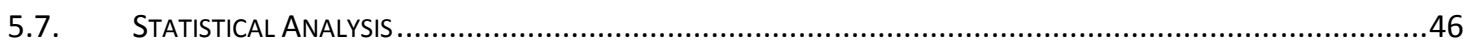

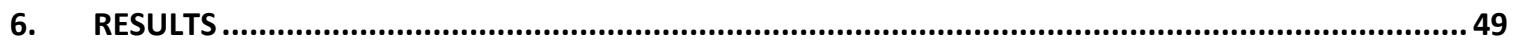

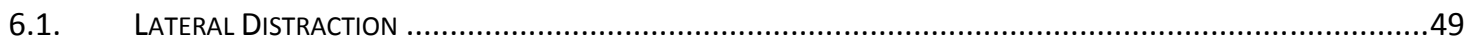

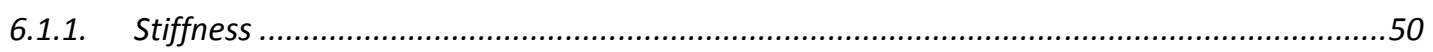

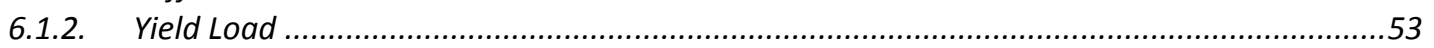

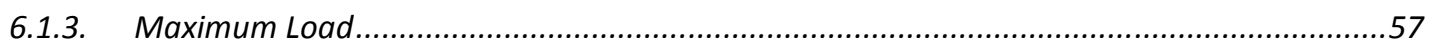

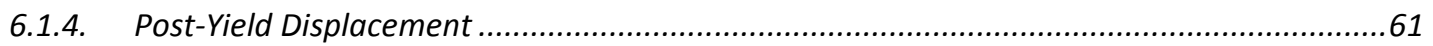

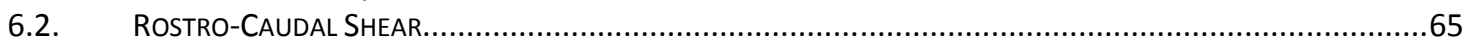

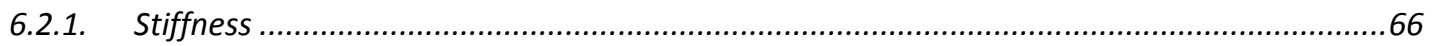

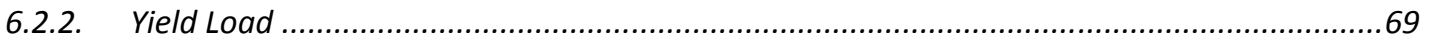

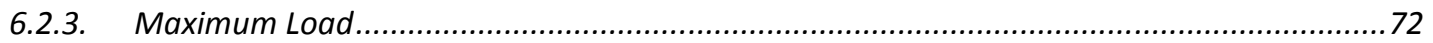

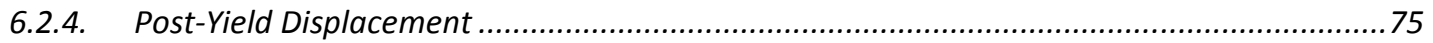

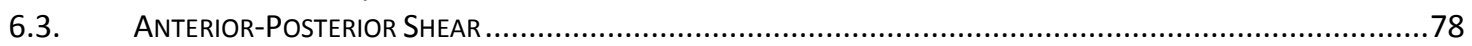

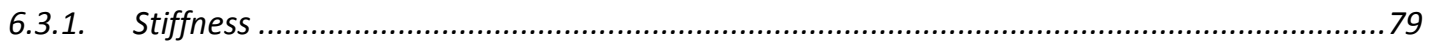

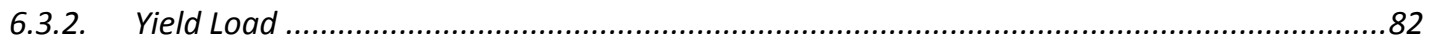

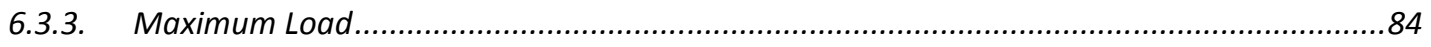




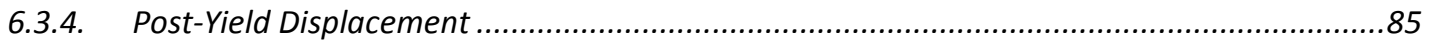

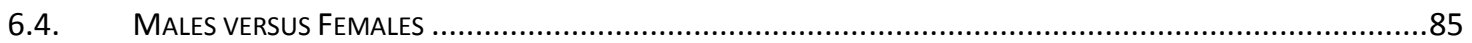

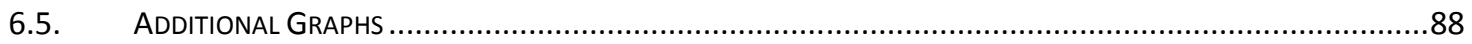

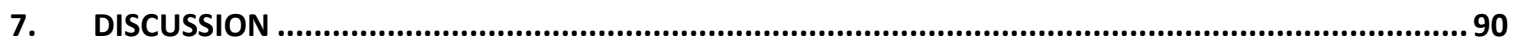

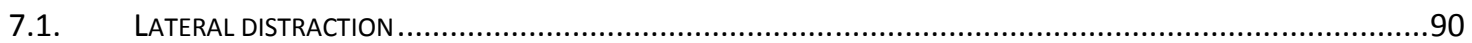

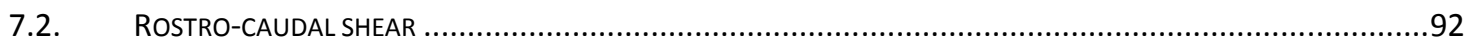

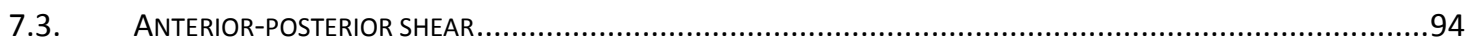

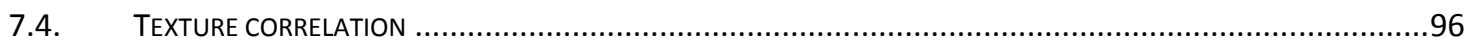

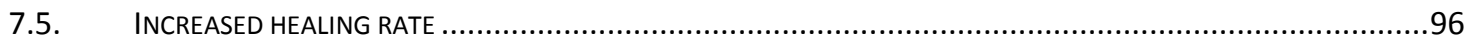

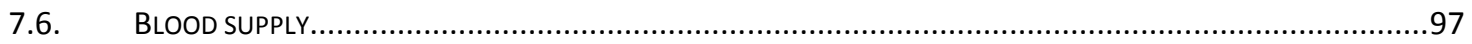

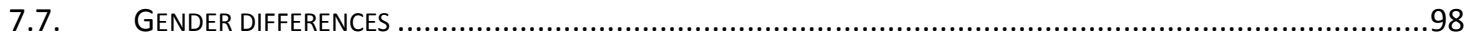

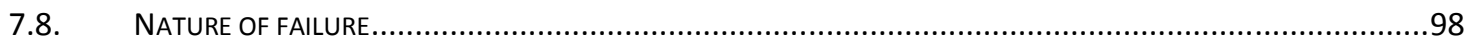

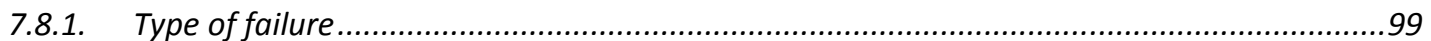

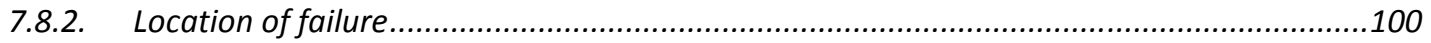

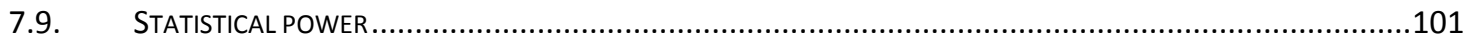

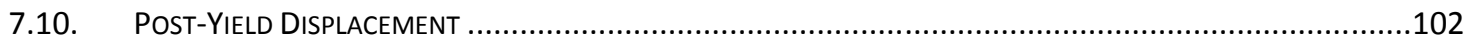

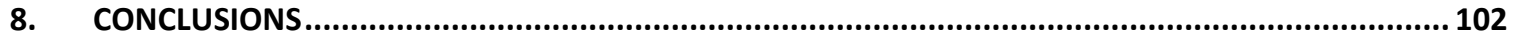

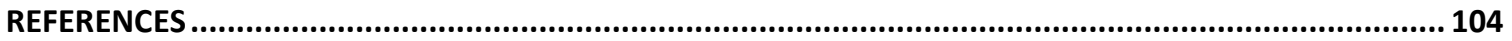

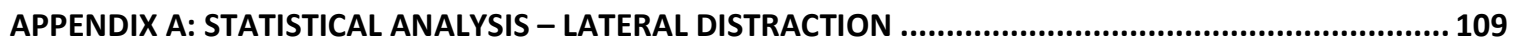

APPENDIX B: STATISTICAL ANALYSIS - ROSTRO-CAUDAL SHEAR ................................................ 123

APPENDIX C: STATISTICAL ANALYSIS - ANTERIOR-POSTERIOR SHEAR ......................................... 


\section{List of Figures}

FIGURE 3.1: A COMPLETE VERTICAL INCISION ALONG THE STERNUM USING AN OSCILLATING POWER SAW

[3].

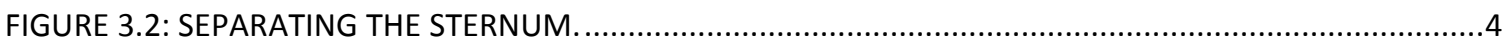

FIGURE 3.3: A CLAMP IS USED TO HOLD OPEN THE STERNUM AND EXPOSE THE PERICARDIUM.................5

FIGURE 3.4: UPPER ROW: SINGLE TRANSSTERNAL, SINGLE PERISTERNAL, ALTERNATING TRANS AND PERISTERNAL LOWER ROW: FIGURE-EIGHT PERISTERNAL, FIGURE-EIGHT PERICOSTAL, AND ROBICSEK

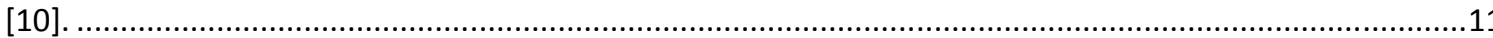

FIGURE 3.5: ILLUSTRATION OF A TRANSTERNAL WIRE CLOSURE [18] ...................................................13

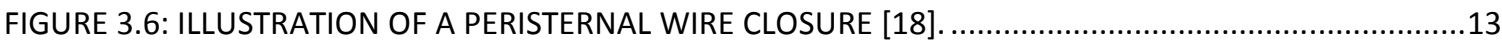

FIGURE 3.7: ILLUSTRATION OF A PERICOSTAL FIGURE-OF-EIGHT WIRE CLOSURE[18] ..............................14

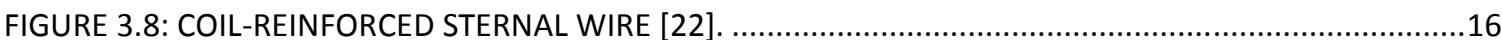

FIGURE 3.9: STERNAL REINFORCEMENT DEVICE DSS: STERNAL SYNTHESIS DEVICE (MIKAI SPA, VINCENZA,

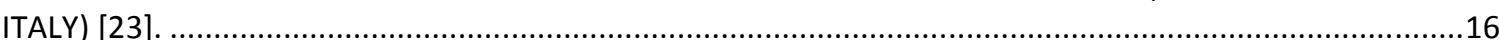

FIGURE 3.10: PHOTOGRAPH OF A CUSTOMIZED 2.3MM, FOUR-HOLE TITANIUM ALLOY H-PLATE (KLS-

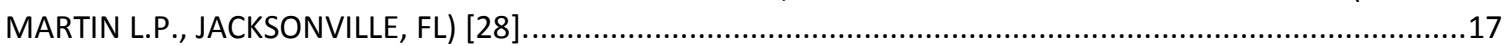

FIGURE 3.11: AN ARTIST'S DRAWING OF A STERNUM FIXED WITH WIRES AND RIGID PLATES[29]............19

FIGURE 3.12: TISSUE IMMEDIATELY SURROUNDING THE INFECTED AREA IS REMOVED [42] .....................22

FIGURE 3.13: RADIOGRAPH OF WHOLE INJECTED STERNOCHONDRAL SPECIMEN. IMA - INTERNAL MAMMARY ARTERY, SEA - SUPERIOR EPIGASTRIC ARTERY, MPA - MUSCULOPHRENIC ARTERY [43] .......24

FIGURE 3.14: SIMPLIFIED DIAGRAM OF STERNUM, ILLUSTRATING BLOOD SUPPLY VIA INTERNAL MAMMARY ARTERIES. IMA - INTERNAL MAMMARY ARTERY, S - STERNAL BRANCH, GS - GIGLI SAW, PD PERIOSTEAL DIATHERMY [43].

FIGURE 3.15: IDEALIZED DRAWING OF CROSS-SECTIONAL VIEW OF A STERNUM AND ITS BLOOD SUPPLY. IMA - INTERNAL MAMMARY ARTERY, P - PERFORATING BRANCH, M - MEDIAL, S - STERNUM, PM PECTORALIS MAJOR [43].

FIGURE 3.16: EXAMPLE ANALYSIS OF THE HUMAN STERNUM BY A NUMERICAL METHOD [45]. .28

FIGURE 3.17: THE DIGITAL IMAGE CORRELATION SYSTEM TRACKS THE GREY VALUE PATTERN, OR 'SPECKLE,' IN SMALL SUBSETS DURING DEFORMATION .28

FIGURE 5.1: THE TEST FRAME USED IN THIS STUDY (BOSE SMARTTEST SP, EDEN PRAIRIE, MN).

FIGURE 5.2: PICTURES OF THE THREE CLOSURE TECHNIQUES USED IN THE STUDY. A) PERISTERNAL WIRES, B) STERNALOCK WITH L-PLATE, C) STERNALOCK WITH BOX-PLATE.

FIGURE 5.3: THE CADAVERIC STERNUM MUST BE COATED WITH A SPECIAL HIGH-CONTRAST "SPECKLE" TO RECORD AN ACCEPTABLE AMOUNT OF DATA.

FIGURE 5.4: PICTURE OF THE ALIGNMENT TOOL DESIGNED FOR THIS PROJECT WITH ONE SIDE OF THE SPIKED CLAMPS IN POSITION. . .36

FIGURE 5.5: A PICTURE OF THE TEST SET-UP USED. A LOAD FRAME TRANSFERS TENSION TO THE STERNAL CONSTRUCT VIA A SET OF SPIKED CLAMPS. AN ARRAY OF CAMERAS RECORD DATA THROUGHOUT THE TEST.

FIGURE 5.6: PHOTOGRAPHS OF EACH DIRECTION TESTED IN THE STUDY. STARTING FROM TOP LEFT FIGURE - A) LATERAL DISTRACTION, B) ROSTRO-CAUDAL SHEAR, C) ANTERIOR-POSTERIOR SHEAR. 
FIGURE 5.7: AN EXAMPLE 3-DIMENSIONAL SHAPE CONSTRUCTED BY VIC-3D USING AN ARRAY OF OPTICAL CAMERAS. .38

FIGURE 5.8: EXAMPLE COLORATIONS OF STRESS CONCENTRATIONS IN A) LATERAL DISTRACTION AND B) LONGITUDINAL SHEAR.

FIGURE 5.9: A RECTANGLE IS DRAWN ON THE TOP HALF OF THE STERNUM INDICATING THE AREA THAT DATA WAS EXTRACTED FROM.

FIGURE 5.10: A RECTANGLE IS DRAWN ON THE BOTTOM HALF OF THE STERNUM INDICATING THE AREA THAT DATA WAS EXTRACTED FROM.

FIGURE 5.11: LOAD-DISPLACEMENT CURVE AND DEFINITIONS OF TERMS. STIFFNESS IS

FIGURE 6.1: RIGIDITY (STIFFNESS) OF THE VARIOUS FIXATION METHODS TESTED IN LATERAL DISTRACTION. DATA DENOTED BY AN ASTERISK ARE SIGNIFICANT (P<0.05). COLUMNS DENOTE MEAN VALUES. STIFFNESS IS MEASURED IN NEWTONS OF FORCE PER MILLIMETER DISPLACEMENT. ERROR BARS INDICATE ONE STANDARD DEVIATION.

FIGURE 6.2: RIGIDITY (STIFFNESS) OF THE VARIOUS FIXATION METHODS TESTED IN LATERAL DISTRACTION SEPARATED BY GENDER. COLUMNS DENOTE MEAN VALUES. STIFFNESS IS MEASURED IN NEWTONS OF FORCE PER MILLIMETER DISPLACEMENT. ERROR BARS INDICATE ONE STANDARD DEVIATION. COLUMNS DENOTED WITH LETTER ' $C$ ' ARE STATISTICALLY DIFFERENT $(P<0.05)$ THAN COLUMNS DENOTED WITH THE LETTER 'A,' LIKEWISE 'B' IS DIFFERENT THAN 'D.'

FIGURE 6.3: SIDE BY SIDE COMPARISON PLOT OF MAIN EFFECTS WITH REGARDS TO CONSTRUCT STIFFNESS TESTED IN LATERAL DISTRACTION.

FIGURE 6.4: INTERACTION PLOT DESCRIBING THE EFFECT OF GENDER ON EACH CONSTRUCT IN REGARDS TO STIFFNESS TESTED IN LATERAL DISTRACTION.

FIGURE 6.5: YIELD STRENGTH OF THE VARIOUS FIXATION METHODS TESTED IN LATERAL DISTRACTION. COLUMNS DENOTE MEAN VALUES. YIELD STRENGTH IS MEASURED IN NEWTONS OF FORCE. ERROR BARS INDICATE ONE STANDARD DEVIATION.

FIGURE 6.6: YIELD STRENGTH OF THE VARIOUS FIXATION METHODS TESTED IN LATERAL DISTRACTION SEPARATED BY GENDER. COLUMNS DENOTE MEAN VALUES. YIELD STRENGTH IS MEASURED IN NEWTONS OF FORCE. ERROR BARS INDICATE ONE STANDARD DEVIATION.......

FIGURE 6.7: SIDE BY SIDE COMPARISON PLOT OF MAIN EFFECTS WITH REGARDS TO YIELD STRENGTH TESTED IN LATERAL DISTRACTION.

FIGURE 6.8: INTERACTION PLOT DESCRIBING THE EFFECT OF GENDER ON EACH CONSTRUCT IN REGARDS TO YIELD STRENGTH TESTED IN LATERAL DISTRACTION.

FIGURE 6.9: MAXIMUM STRENGTH OF THE VARIOUS FIXATION METHODS TESTED IN LATERAL DISTRACTION. COLUMNS DENOTE MEAN VALUES. MAXIMUM STRENGTH IS MEASURED IN NEWTONS OF FORCE. ERROR BARS INDICATE ONE STANDARD DEVIATION.....

FIGURE 6.10: MAXIMUM STRENGTH OF THE VARIOUS FIXATION METHODS TESTED IN LATERAL DISTRACTION SEPARATED BY GENDER. COLUMNS DENOTE MEAN VALUES. MAXIMUM STRENGTH IS MEASURED IN NEWTONS OF FORCE. ERROR BARS INDICATE ONE STANDARD DEVIATION......

FIGURE 6.11: SIDE BY SIDE COMPARISON PLOT OF MAIN EFFECTS WITH REGARDS TO MAXIMUM STRENGTH TESTED IN LATERAL DISTRACTION.

FIGURE 6.12: INTERACTION PLOT DESCRIBING THE EFFECT OF GENDER ON EACH CONSTRUCT IN REGARDS TO YIELD STRENGTH TESTED IN LATERAL DISTRACTION. 
FIGURE 6.13: POST-YIELD BEHAVIOR OF THE VARIOUS FIXATION METHODS TESTED IN LATERAL DISTRACTION. COLUMNS DENOTE MEAN VALUES. POST-YIELD DISPLACEMENT IS MEASURED IN MILLIMETERS. ERROR BARS INDICATE ONE STANDARD DEVIATION.

FIGURE 6.14: POST-YIELD BEHAVIOR OF THE VARIOUS FIXATION METHODS TESTED IN LATERAL DISTRACTION SEPARATED BY GENDER. COLUMNS DENOTE MEAN VALUES POST-YIELD DISPLACEMENT IS MEASURED IN MILLIMETERS. ERROR BARS INDICATE ONE STANDARD DEVIATION...

FIGURE 6.15: SIDE BY SIDE COMPARISON PLOT OF MAIN EFFECTS WITH REGARDS TO POST-YIELD DISPLACEMENT TESTED IN LATERAL DISTRACTION...

FIGURE 6.16: INTERACTION PLOT DESCRIBING THE EFFECT OF GENDER ON EACH CONSTRUCT IN REGARDS TO POST-YIELD DISPLACEMENT TESTED IN LATERAL DISTRACTION. .64

FIGURE 6.17: RIGIDITY (STIFFNESS) OF THE VARIOUS FIXATION METHODS TESTED IN LONGITUDINAL SHEAR. COLUMNS DENOTE MEAN VALUES. STIFFNESS IS MEASURED IN NEWTONS OF FORCE PER MILLIMETER DISPLACEMENT. ERROR BARS INDICATE ONE STANDARD DEVIATION. 66

FIGURE 6.18: RIGIDITY (STIFFNESS) OF THE VARIOUS FIXATION METHODS TESTED IN LONGITUDINAL SHEAR SEPARATED BY GENDER. COLUMNS DENOTE MEAN VALUES. STIFFNESS IS MEASURED IN NEWTONS OF FORCE PER MILLIMETER DISPLACEMENT. ERROR BARS INDICATE ONE STANDARD DEVIATION.

FIGURE 6.19: SIDE BY SIDE COMPARISON PLOT OF MAIN EFFECTS WITH REGARDS TO STIFFNESS TESTED IN LONGITUDINAL SHEAR.

FIGURE 6.20: INTERACTION PLOT DESCRIBING THE EFFECT OF GENDER ON EACH CONSTRUCT IN REGARDS STIFFNESS TESTED IN LONGITUDINAL SHEAR.

FIGURE 6.21: YIELD STRENGTH OF THE VARIOUS FIXATION METHODS TESTED IN LONGITUDINAL SHEAR. COLUMNS DENOTE MEAN VALUES. YIELD STRENGTH IS MEASURED IN NEWTONS OF FORCE. ERROR BARS INDICATE ONE STANDARD DEVIATION..

FIGURE 6.22: YIELD STRENGTH OF THE VARIOUS FIXATION METHODS TESTED IN LONGITUDINAL SHEAR SEPARATED BY GENDER. COLUMNS DENOTE MEAN VALUES. YIELD STRENGTH IS MEASURED IN NEWTONS OF FORCE. ERROR BARS INDICATE ONE STANDARD DEVIATION.

FIGURE 6.23: SIDE BY SIDE COMPARISON PLOT OF MAIN EFFECTS WITH REGARDS TO YIELD STRENGTH TESTED IN LONGITUDINAL SHEAR.

FIGURE 6.24: INTERACTION PLOT DESCRIBING THE EFFECT OF GENDER ON EACH CONSTRUCT IN REGARDS YIELD STRENGTH TESTED IN LONGITUDINAL SHEAR.

FIGURE 6.25: MAXIMUM STRENGTH OF THE VARIOUS FIXATION METHODS TESTED IN LONGITUDINAL SHEAR. COLUMNS DENOTE MEAN VALUES. MAXIMUM STRENGTH IS MEASURED IN NEWTONS OF FORCE. ERROR BARS INDICATE ONE STANDARD DEVIATION.....

FIGURE 6.26: MAXIMUM STRENGTH OF THE VARIOUS FIXATION METHODS TESTED IN LONGITUDINAL SHEAR SEPARATED BY GENDER. COLUMNS DENOTE MEAN VALUES. MAXIMUM STRENGTH IS MEASURED IN NEWTONS OF FORCE. ERROR BARS INDICATE ONE STANDARD DEVIATION.

FIGURE 6.27: SIDE BY SIDE COMPARISON PLOT OF MAIN EFFECTS WITH REGARDS TO MAXIMUM STRENGTH TESTED IN LONGITUDINAL SHEAR.

FIGURE 6.28: INTERACTION PLOT DESCRIBING THE EFFECT OF GENDER ON EACH CONSTRUCT IN REGARDS MAXIMUM STRENGTH TESTED IN LONGITUDINAL SHEAR.....

FIGURE 6.29: POST-YIELD BEHAVIOR OF THE VARIOUS FIXATION METHODS TESTED IN LONGITUDINAL SHEAR. COLUMNS DENOTE MEAN VALUES. POST-YIELD DISPLACEMENT IS MEASURED IN MILLIMETERS. ERROR BARS INDICATE ONE STANDARD DEVIATION. 
FIGURE 6.30: POST-YIELD OF THE VARIOUS FIXATION METHODS TESTED IN LONGITUDINAL SHEAR SEPARATED BY GENDER. COLUMNS DENOTE MEAN VALUES. POST-YIELD DISPLACEMENT IS MEASURED IN MILLIMETERS. ERROR BARS INDICATE ONE STANDARD DEVIATION.

FIGURE 6.31: SIDE BY SIDE COMPARISON PLOT OF MAIN EFFECTS WITH REGARDS TO POST-YIELD DISPLACEMENT TESTED IN LONGITUDINAL SHEAR.

FIGURE 6.32: INTERACTION PLOT DESCRIBING THE EFFECT OF GENDER ON EACH CONSTRUCT IN REGARDS POST-YIELD DISPLACEMENT TESTED IN LONGITUDINAL SHEAR. . .78

FIGURE 6.33: RIGIDITY (STIFFNESS) OF THE VARIOUS FIXATION METHODS TESTED IN TRANSVERSE SHEAR. COLUMNS DENOTE MEAN VALUES. STIFFNESS IS MEASURED IN NEWTONS OF FORCE PER MILLIMETER DISPLACEMENT. ERROR BARS INDICATE ONE STANDARD DEVIATION.

FIGURE 6.34: RIGIDITY (STIFFNESS) OF THE VARIOUS FIXATION METHODS TESTED IN LONGITUDINAL SHEAR SEPARATED BY GENDER. COLUMNS DENOTE MEAN VALUES. STIFFNESS IS MEASURED IN NEWTONS OF FORCE PER MILLIMETER DISPLACEMENT. ERROR BARS INDICATE ONE STANDARD DEVIATION.

FIGURE 6.35: SIDE BY SIDE COMPARISON PLOT OF MAIN EFFECTS WITH REGARDS TO STIFFNESS TESTED IN TRANSVERSE SHEAR.

FIGURE 6.36: INTERACTION PLOT DESCRIBING THE EFFECT OF GENDER ON EACH CONSTRUCT IN REGARDS STIFFNESS TESTED IN TRANSVERSE SHEAR.

FIGURE 6.37: YIELD STRENGTH OF THE VARIOUS FIXATION METHODS TESTED IN LONGITUDINAL SHEAR. COLUMNS DENOTE MEAN VALUES. YIELD STRENGTH IS MEASURED IN NEWTONS OF FORCE. ERROR BARS INDICATE ONE STANDARD DEVIATION

FIGURE 6.38: YIELD STRENGTH OF THE VARIOUS FIXATION METHODS TESTED IN LONGITUDINAL SHEAR SEPARATED BY GENDER. COLUMNS DENOTE MEAN VALUES. YIELD STRENGTH IS MEASURED IN NEWTONS OF FORCE. ERROR BARS INDICATE ONE STANDARD DEVIATION..

FIGURE 6.39: COMPARING STIFFNESS BETWEEN MALE AND FEMALE SPECIMEN. COLUMNS DENOTE CUMULATIVE VALUES FOR ALL FIXATION METHODS.

FIGURE 6.40: COMPARING YIELD STRENGTH BETWEEN MALE AND FEMALE SPECIMEN. COLUMNS DENOTE CUMULATIVE VALUES FOR ALL FIXATION METHODS. AN ASTERISK INDICATES STATISTICALLY SIGNIFICANCE BETWEEN MALE AND FEMALE SPECIMEN.

FIGURE 6.41: COMPARING MAXIMUM STRENGTH BETWEEN MALE AND FEMALE SPECIMEN. COLUMNS DENOTE CUMULATIVE VALUES FOR ALL FIXATION METHODS.

FIGURE 6.42: COMPARING POST-YIELD DISPLACEMENT BETWEEN MALE AND FEMALE SPECIMEN. COLUMNS DENOTE CUMULATIVE VALUES FOR ALL FIXATION METHODS.

FIGURE 6.43: RIGIDITY (STIFFNESS) OF THE VARIOUS FIXATION METHODS TESTED IN VARIOUS DIRECTIONS AND SEPARATED BY GENDER. COLUMNS DENOTE MEAN VALUES. STIFFNESS IS MEASURED IN NEWTONS OF FORCE PER MILLIMETER DISPLACEMENT. ERROR BARS INDICATE ONE STANDARD DEVIATION. 88

FIGURE 6.44: YIELD STRENGTH OF THE VARIOUS FIXATION METHODS TESTED IN VARIOUS DIRECTIONS AND SEPARATED BY GENDER. COLUMNS DENOTE MEAN VALUES. YIELD STRENGTH IS MEASURED IN NEWTONS OF FORCE. ERROR BARS INDICATE ONE STANDARD DEVIATION.

FIGURE 6.45: MAXIMUM STRENGTH OF THE VARIOUS FIXATION METHODS TESTED IN VARIOUS DIRECTIONS AND SEPARATED BY GENDER. COLUMNS DENOTE MEAN VALUES. MAXIMUM STRENGTH IS MEASURED IN NEWTONS OF FORCE. ERROR BARS INDICATE ONE STANDARD DEVIATION.

FIGURE 6.46: POST-YIELD DISPLACEMENT OF THE VARIOUS FIXATION METHODS TESTED IN VARIOUS DIRECTIONS AND SEPARATED BY GENDER. COLUMNS DENOTE MEAN VALUES. POST-YIELD DISPLACEMENT IS MEASURED MILLIMETERS. ERROR BARS INDICATE ONE STANDARD DEVIATION. 
FIGURE 7.1: PICTURE TAKEN AT MAXIMUM DISPLACEMENT IN THE LATERAL DISTRACTION DIRECTION. SEPARATION CAN BE OBSERVED AT THE MIDLINE AND RIB FRACTURES CAN BE SEEN ALONG THE BOTTOM

CLAMP.

FIGURE 7.2: PICTURE TAKEN AT MAXIMUM DISPLACEMENT IN THE LONGITUDINAL DIRECTION. SLANTED WIRES INDICATE PLASTIC DEFORMATION AT THE MIDLINE.

FIGURE 7.3: PICTURE TAKEN AT MAXIMUM DISPLACEMENT IN THE TRANSVERSE DIRECTION. FAILURE DID NOT OCCUR DURING THIS TEST.

FIGURE 7.4: PICTURE TAKEN FROM A CAMERA USED IN THE DIGITAL IMAGE CORRELATION CAPTURE SYSTEM.

FIGURE 7.5: PICTURE TAKEN AFTER FAILURE OF THE DEVICE OCCURRED. A SCREW THAT FASTENED THE PLATE TO THE STERNUM BECAME DISLODGED.

FIGURE 7.6: PICTURE TAKEN AFTER CLAMPS WERE REMOVED FROM THE STERNUM. OBVIOUS TEARING OF THE INTERCOSTAL MUSCLES HAD TAKEN PLACE, AS WELL AS FRACTURE OF ASSOCIATED RIBS IN THE AREA. 


\section{List of Tables}

TABLE 5.1: TEST DESIGN FOR THE OVERALL STUDY.

TABLE 6.1: DESCRIPTION OF THE SAMPLE GROUP TESTED IN LATERAL DISTRACTION WITH VALUES FOR EACH BIOMECHANICAL PROPERTY.

TABLE 6.2: MEAN STIFFNESS VALUES FOR EACH STERNAL-CLOSURE TECHNIQUE TESTED IN LATERAL DISTRACTION, SEPARATED BY GENDER.

TABLE 6.3: MEAN YIELD VALUES FOR EACH STERNAL-CLOSURE TECHNIQUE TESTED IN LATERAL DISTRACTION, SEPARATED BY GENDER.

TABLE 6.4: MEAN MAXIMUM-LOAD VALUES FOR EACH STERNAL-CLOSURE TECHNIQUE TESTED IN LATERAL DISTRACTION, SEPARATED BY GENDER.

TABLE 6.5: MEAN POST-YIELD VALUES FOR EACH STERNAL-CLOSURE TECHNIQUE TESTED IN LATERAL DISTRACTION, SEPARATED BY GENDER.

TABLE 6.6: DESCRIPTION OF THE SAMPLE GROUP TESTED IN THE LONGITUDINAL DISTRACTION WITH VALUES FOR EACH BIOMECHANICAL PROPERTY

TABLE 6.7: MEAN STIFFNESS VALUES FOR EACH STERNAL-CLOSURE TECHNIQUE TESTED IN LONGITUDINAL SHEAR, SEPARATED BY GENDER.

TABLE 6.8: MEAN YIELD VALUES FOR EACH STERNAL-CLOSURE TECHNIQUE TESTED IN LONGITUDINAL SHEAR, SEPARATED BY GENDER.

TABLE 6.9: MEAN MAXIMUM-LOAD VALUES FOR EACH STERNAL-CLOSURE TECHNIQUE TESTED IN LONGITUDINAL SHEAR, SEPARATED BY GENDER.

TABLE 6.10: MEAN POST-YIELD VALUES FOR EACH STERNAL-CLOSURE TECHNIQUE TESTED IN LONGITUDINAL SHEAR, SEPARATED BY GENDER.

TABLE 6.11: DESCRIPTION OF THE SAMPLE GROUP TESTED IN THE TRANSVERSE DISTRACTION WITH VALUES FOR EACH BIOMECHANICAL PROPERTY.

TABLE 6.12: MEAN STIFFNESS VALUES FOR EACH STERNAL-CLOSURE TECHNIQUE TESTED IN TRANSVERSE SHEAR, SEPARATED BY GENDER.

TABLE 6.13: MEAN YIELD VALUES FOR EACH STERNAL-CLOSURE TECHNIQUE TESTED IN TRANSVERSE SHEAR, SEPARATED BY GENDER.

TABLE 6.14: MEAN YIELD VALUES FOR EACH STERNAL-CLOSURE TECHNIQUE TESTED IN TRANSVERSE SHEAR. 


\section{Background}

\subsection{The Sternum}

Also known as the breastplate, the sternum is located in the mid-thoracic (chest) region of the human body. The sternum is an elongated flat bone that makes up the core of the anterior thoracic wall. The clavicles, ribs, and muscle all make critical attachments to the sternum. The sternum provides a strong structural foundation for the entire thoracic region for different components that provide protection for vital organs and a means for skeletal movement. Thus, the sternum is the most critical component of structural support to the entire thorax.

The sternum is made up of three regions: the manubrium, gladiolus, and xiphoid process. The manubrium is thick, broad, and makes up the upper part of the sternum. The manubrium supports the first two ribs, as well as, the clavicles and transitions into the main body of the sternum. The gladiolus or body of the sternum is a long flat bone thinner than the manubrium that connects the second through sixth ribs via cartilage. The xiphoid process makes up the bottom region of the sternum, articulating the seventh costal cartilage. The xiphoid is the thinnest and inherently weakest component of the sternum.

\subsection{Open-Heart Surgery}

Open-heart surgery is the often directly associated with a median sternotomy, though not a median sternotomy can technically be utilized in other operations. Still, open-heart surgery makes up the vast majority of operations requiring a median sternotomy. 
699,000 open-heart procedures were performed in United States in 2005[1]; this number has grown from 666,000 in 2003 . This number is projected to grow in the future due to an aging population with increasing rates of obesity and cardiovascular disease. Of the 699,000 surgeries in 2005, this included 106,000 valve replacements, 469,000 bypass surgeries, and 2,192 heart transplants. Healing complication rates are between $0.3 \%$ and $5 \%$ of cases and mortality rates can be up to $47 \%$ if mediastinitis supervenes[2]. From to these statistics, we find that up to 34,950 complications, and up to 16,427 mortalities are associated with open-heart surgeries each year.

Open-heart surgery is defined as a procedure that involves sternal division and a subsequent incision along the pericardium. However, a significant number of procedures require division of the sternum without the need to access the pericardium (open-chest surgery), for example, revision surgeries required by $5 \%$ of open-heart surgery patients who develop postoperative healing complications. Therefore, the actual quantities of operations that require anterior access of the chest via sternal division exceed the 699,000 open heart surgeries.

The most common procedure requiring a midline sternotomy is coronary artery bypass grafting $(\mathrm{CABG})$. During this procedure a midline incision is used to gain access to the heart and aorta. In a traditional CABG, a heart-lung machine is used to bypass blocked blood vessels, as well as oxygenate and circulate blood during surgery while heart muscle is stopped. 
The median sternotomy incision remains an extremely popular incision used by cardiac surgeons. The vast number of these surgeries performed each year outnumbers that of any other cardiac procedure. Although they have a low probability of occurrence, a large amount of healing complications have been associated with surgeries requiring sternal division; these complications have been directly linked to an uncomfortable rate of mortality. A closer analysis should be done to understand the shortcomings of sternal closure techniques and how we can improve the postoperative healing process.

\subsection{Median Sternotomy}

A large proportion of surgical operations require access into vital organs in the thoracic cage. The sternum is a commonly used access point to vital organs in surgical procedures. The median sternotomy is a preferred option because of its excellent exposure of vital organs and it is perceived to be well tolerated by most patients.

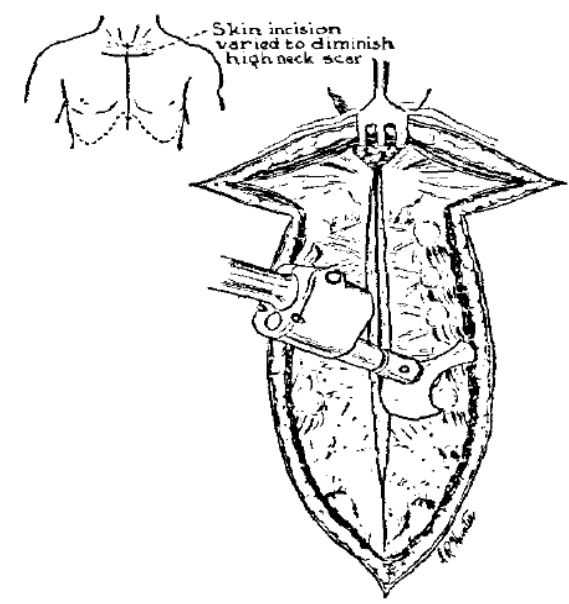

Figure 3.1: A complete vertical incision along the sternum using an oscillating power saw [3].

A complete vertical division was first used by Milton in 1897 to gain access to the posterior mediastinum. This approach was used sporadically for various purposes until 
the complete vertical incision was popularized by Julian in 1957, which he favored over a similar transverse bilateral thoracotomy. Since then the median sternotomy has grown to be the most popular incision performed by cardiac surgeons.

\subsubsection{Surgical Procedure}

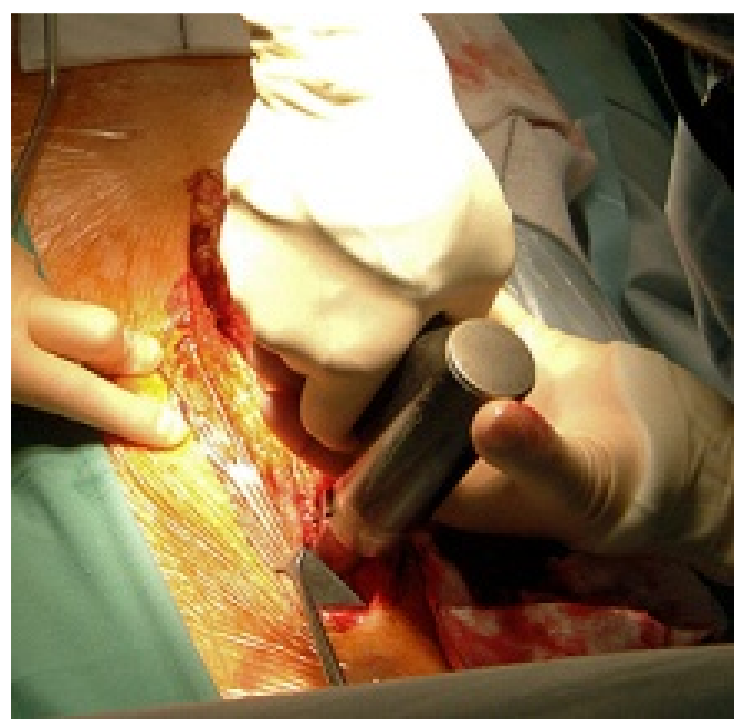

Figure 3.2: Separating the sternum.

During a median sternotomy, the patient is placed on his back and a vertical, midline incision is made from above the sternal notch to well past the xiphoid region. To minimize visible scars, a transverse skin incision can be made at the third intercostal space. An incision is made along the linea alba through the lower part of the incision, and an oscillating saw is used to divide the sternum down its midline. The incision made by the saw is carried upward into the deep cervical fascia and must intersect the interclavicular ligament. The pericardium can then be opened between the pleural reflections[3]. 


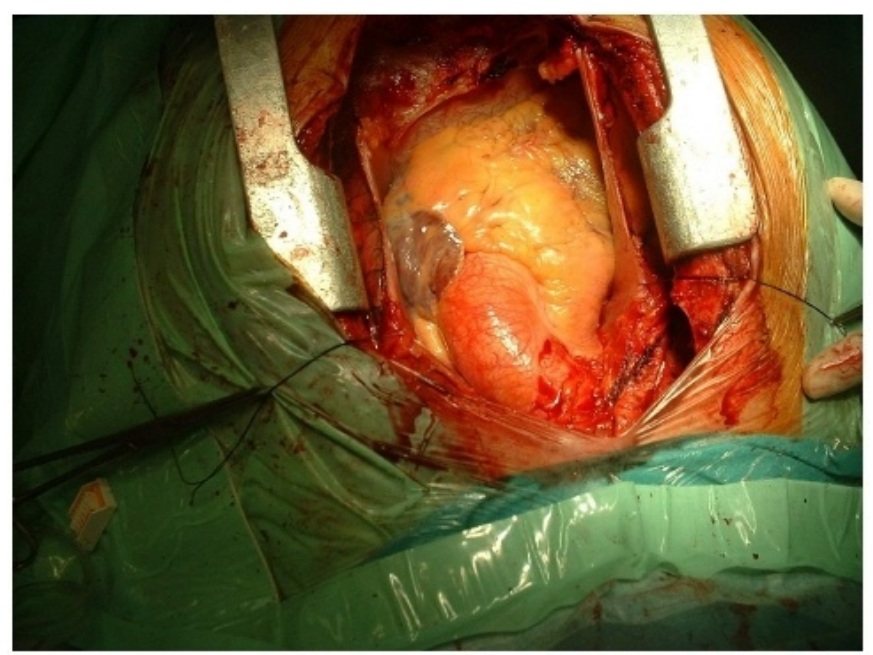

Figure 3.3: A clamp is used to hold open the sternum and expose the pericardium.

\subsubsection{Sternal closure after a median sternotomy}

After the particular cardiac surgery involving the median sternotomy is completed, the two halves of sternum need to be secured. This is called the closure technique and its purpose is to unify the divided sternum to allow for osseous healing. Various methods are utilized to accomplish this, including different configurations of stainless steel sutures, steel coils, steel bands, reinforced wire configurations, nylon bands, and rigidfixation plates.

In his initial evaluation of the procedure in 1957, Julian immediately recognized: "The solidity of the closure is important because it completely immobilizes the chest from abnormal movements and renders the postoperative period more comfortable. The security of wire sutures is essential[3].”

In the four cases used in Julian's evaluation, the second case resulted in the death of the patient due to wound disruption. The sensitivity of the sternum in the postoperative 
healing phase has been a major problem since the early evaluation phase in the history of this procedure; the period of time immediately following a median sternotomy remains to be a prime concern when considering candidates for surgery.

A secure and rigid fixation of the sternum is critical to avoiding healing complications. Without sufficient stability at the osteotomy site, patients can suffer from pain, respiratory problems, wound leakage, sternal non-union or malunion, osteomyelitis, pseudoarthrosis, dehiscence, and mediastinitis. Patients often require corrective surgery when sufficient a secure sternal union cannot be achieved several days after operation. In severe cases, patients require sternal debridement and reconstructive surgery. Additional procedures required in ensuring a stable fixation and correct healing of the sternum introduces unnecessary risk to complications like infection, as well as added cost and lengthened time required in the hospital.

Alternative closure techniques continue to be explored due to the inadequate performance of current devices. It has been shown that a fixation technique which is more effective at providing a rigid construct of sternum postoperatively will result in earlier union of the sternal halves with typical cellular elements and stromal tissue at the osteotomy site [4]. Insufficient postoperative sternal rigidity or sternal instability in the early postoperative period has been associated with a two to four times greater incidence of wound complications, mediastinitis, and chronic sternal infections [5]. Separate reports have also claimed that this insufficient stability is one of the most important factors 
influencing the development of mediastinitis [6]. It is statistically shown that in cases where mediastinitis supervenes, $47 \%$ of patients die [2].

\subsubsection{Osseous Healing Rates}

Immediately after a fracture, blood vessels in the immediate area constrict to prevent any further bleeding. Soon after, a blood clot forms around the injury site and between bone fragments as a result of hematoma. All cells inside and around the blood clot deteriorate, leaving only inflammatory cells to populate the area. These inflammatory cells include macrophages, monocytes, lymphocytes, and fibroblasts; they form a matrix called granulation tissue. Still not vascularized, oxygen is taken from exposed muscle and bone directly around the injury site. As leukocytes remove the blood clot, vascular ingrowth advances and replaces collagen.

On average of six weeks after an injury, a fibrocartilage callus can be observed, formed temporarily from fibroblasts and chondroblasts to cover the length of the bone fracture. Introduced osteoids form woven bone, which consist of a large amount of osteocytes and grows very quickly. However, woven bone is significantly weaker to the slow growing lamellar bone because it only contains a smaller number of randomly oriented collagen fibers where lamellar bone consists of highly organized sheets of fibers with high collagen content. Woven bone is eventually mineralized and is completely replaced by lamellar bone. Three months after injury, mineralized bone can usually be observed. Bone fracture healing is completed when bone remodeling restores the original shape and mechanical strength. 
The early postoperative phase is critical because any movement around the fracture could result in severed blood vessels, or damaging the fragile granulation tissue. Also, extended amounts of time that bone is left unhealed increased the risk for infection. Treatment of any bone damage is therefore aimed at stabilization of the injury, particularly in the early postoperative phase. This is achieved by completely immobilizing the injury site and the surrounding area throughout the entire healing process.

Bitkover conducted a study evaluating computed tomography images of mainstream steel suture closure techniques. These images revealed that the bone callus involved in healing was not found in images three months after operation. Cortical bone growth bridging the length of the sternotomy was not visible until six months post-operation. Therefore, from this study, no specific timeline was found determining when the callus, or woven bone begins to form between three and six months after the sternotomy was performed [7]. This longer-than-average time observed in the formation of the fibrocartilage callus and mineralized bone suggests that the osteotomy site is not sufficiently stabilized and allowing disruption during the healing phase. The implication of this study is that there is a large amount of room to improve the efficiency of the closure technique used (stainless steel wire sutures).

In a study conducted by Sargent using baboons, the presence of woven bone was found eight weeks after operation using popular wire closure techniques [4]. The interesting 
finding from this study is that using an alternative, more stable rigid fixation method, the presence of woven bone could be found only four weeks after operation. This reveals how much the closure technique can effect osseous healing, and how crucial it is to completely immobilize the osteotomy site. Some consideration should be made on the implications of any physiological differences between baboons and human patients, but the study does reveal the potential of a more efficient closure technique.

\subsubsection{Advantages of the median sternotomy}

Minimally invasive surgeries such as minimally invasive direct coronary bypass (MIDCAB), off-pump coronary artery bypass (OPCAB), and robotic assisted coronary artery bypass (RACAB) have gained popularity because it can be performed without while the heart is still beating and using a much smaller incision, which often translates to shorter hospital stays. However, a complete midline sternotomy remains the more popular method because it can be performed quickly, is a familiar procedure to surgeons, provides access and exposure to chest structures, and is well tolerated by most patients [8, 9]. Surgeons have clear access to observe vital organs and to perform any intervention necessary. Also, many procedures may be more difficult to perform on a beating heart than on a still heart. In most cases, the procedure is relatively painless and heals well.

Minimally invasive cardiac surgeries decrease visualization of the operative site, and are technically more difficult. Postoperative pain is not always decreased when compared to a median sternotomy. Multiple incisions may also be required with a less invasive approach, decreasing the cosmetic appeal of minimally invasive techniques. 


\subsection{Closure Techniques}

Many different methods and approaches in ensuring a stable and reliable sternal closure have been explored. These include nylon bands, stainless steel wires, reinforced steel wires, steel bands, and rigid plate fixation. Different hospitals in different regions have their own procedural guidelines, while some wait to choose their method after observation of the sternum. Inside this, each surgeon has their own preferences to each particular method. Concerns surrounding each method include stability, reliability, cost, ease of use, speed, complexity in removing the device in the event of a complication, and familiarity.

\subsubsection{Stainless steel wire fixation}

Stainless steel wires wrap around or thread through sternal halves to combat physiologic forces from transversely separating the surgically divided sternum. Tension is applied by twisting the two ends into a knot and the resulting compressive force prevents any unwanted movement of the sternum during the healing phase. The tension of the knot is estimated by the surgeon, determined by hand. This part of the procedure is relatively simple and can be completed quickly. 

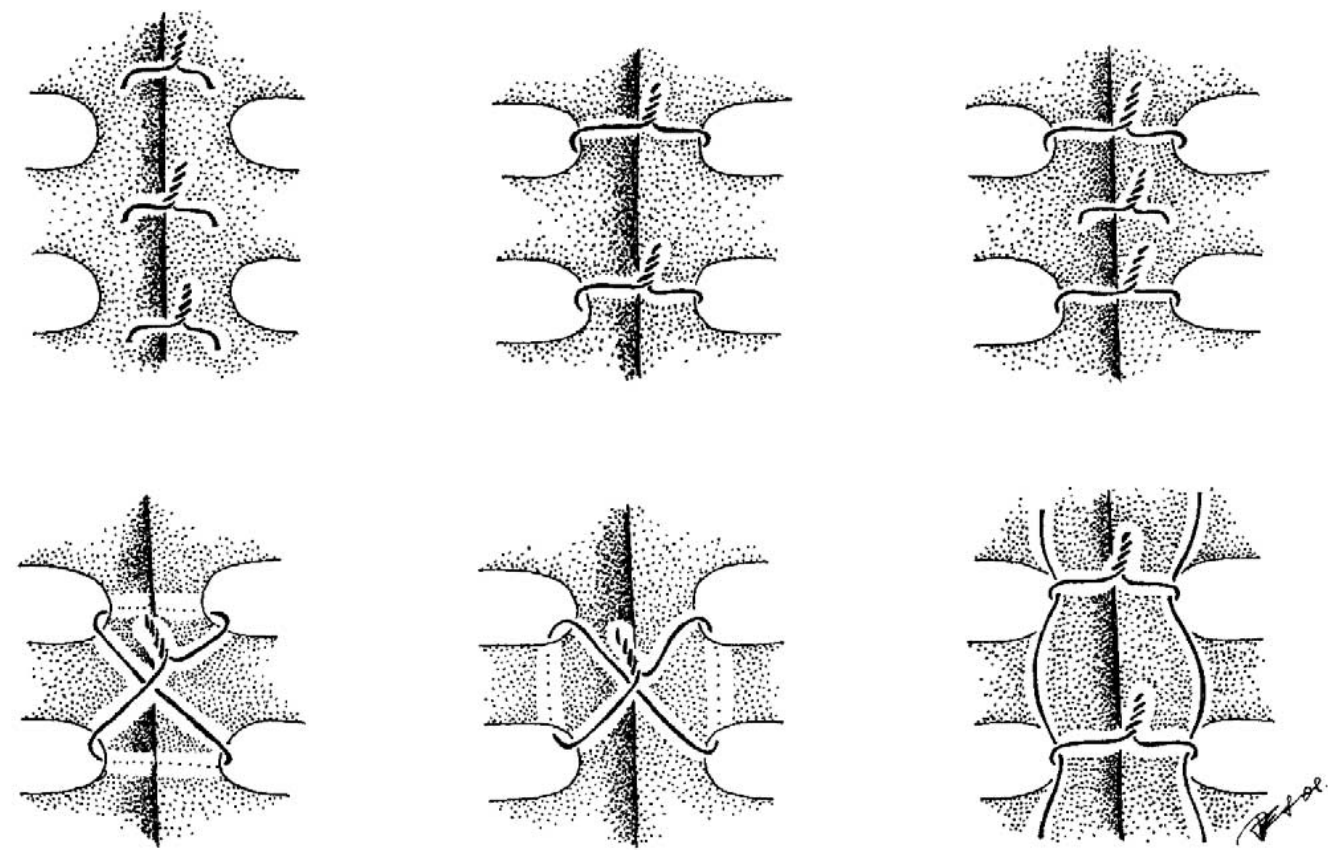

Figure 3.4: Upper row: single transsternal, single peristernal, alternating trans and peristernal Lower row: figure-eight peristernal, figure-eight pericostal, and Robicsek [10].

Previous studies have shown the efficacy of this closure technique, as well as its superiority over other non-rigid closure methods [11, 12]. Stainless steel wire closure techniques are the most popular closure technique used by cardiac surgeons. Steel wires have been the primary closure method since Julian's initial evaluation of the procedure in 1957. Because of this familiarity, cardiac surgeons have been extremely reluctant to institute alternative techniques. In addition, steel wires are very cost effective and simple to manage in the event of revision surgery.

Wire failures are usually characterized with wire cutting through bone rather than the wire breaking or unraveling [13]. If the wire cuts into the bone, the wire is no longer tight and in contact at all pointed with bone. There are less compressive forces acting against the bone and repetitive respiratory motion of the chest wall will further loosen wires and cut the sternum into segments [14]. However, this is not the only complication 
that exists, during mechanical testing unwinding of the knot is a common issue, and in canine studies, wire breakage is a fairly common occurrence [15]. Wire breakage, however, is not a primary concern unless tightened to the point where the material is compromised. Also, an underlying issue is that cadaver models are unable to identify pain associated with the wire knot under the skin [13].

Comparing stainless steel wire fixation with alternative techniques in an accurate and encompassing characterization is extremely difficult because countless configurations and combinations exist. Among steel wire techniques, every hospital and surgeon has their own preferred method. Also, different configurations are more suited for different applications, for example the Robicsek technique has been found to be particularly effective in stabilizing cases where other methods have previously failed [16].

\subsubsection{Transternal wires}

The standard closure of the sternum after sternotomy utilizes surgical steel sutures passed through the sternum approximately $1 \mathrm{~cm}$ on each side [17]. After passing through the sternum, the loose suture wires are then crossed, pulled, and twisted several times to apply a compressive force on the sternal halves. The wire sutures may easily cut through the bone under simultaneous load from several directions [18]. Several modifications have been explored to prevent penetration of the bone, including, combinations of mattress and wires, figure-eight configurations, double-cross wires, and interlocking multitwisted wires [18]. 


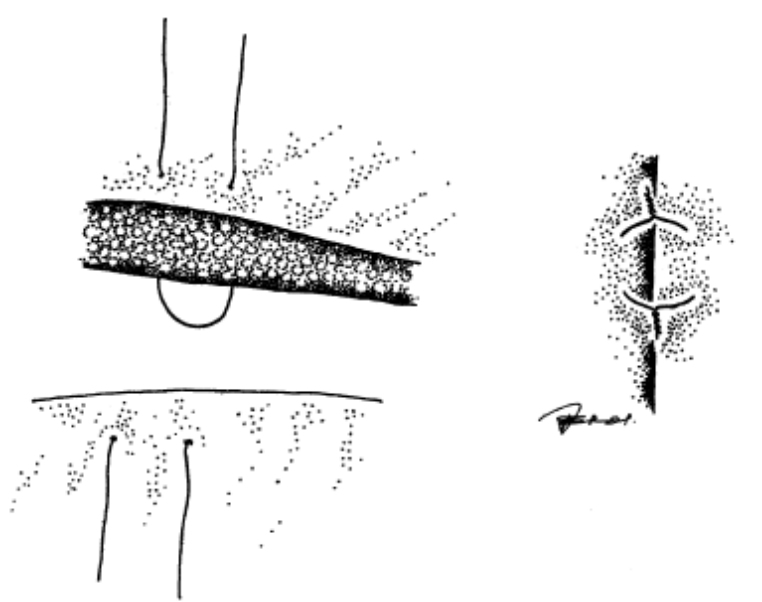

Figure 3.5: Illustration of a transternal wire closure [18].

\subsubsection{Peristernal wires}

Peristernal sutures reinforce the lateral table of the sternum by wrapping around the whole sternal body. This allows tighter closures with less likelihood of the wires cutting through cortical bone [18]. Advantages for single sutures have been published [19] but most surgeons have adopted figure-eight interlocking closures [20, 21]. Figure-eight peristernal wires are faster, simpler, and more reliable than similarly configured transternal wires [18, 20, 21].

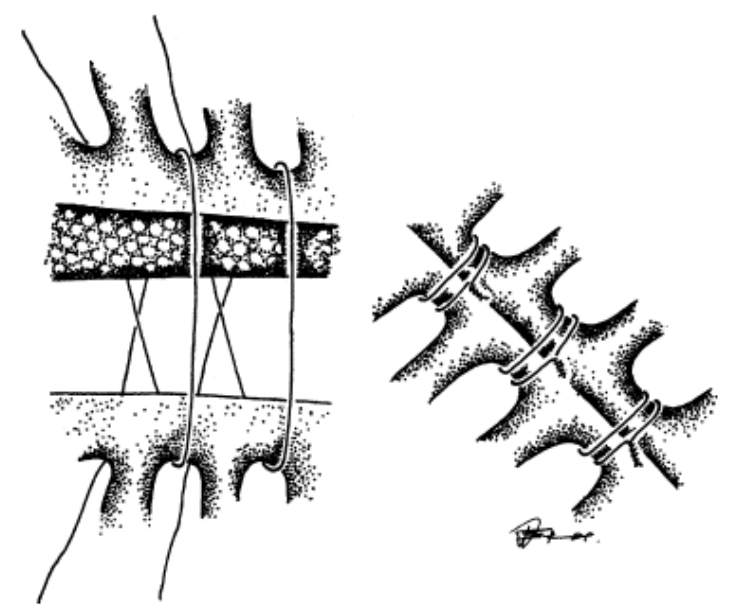

Figure 3.6: Illustration of a peristernal wire closure [18]. 


\subsubsection{Pericostal wires}

Pericostal wire closure techniques rely upon the costal cartilages outside the operative area by wrapping around a single rib [18].

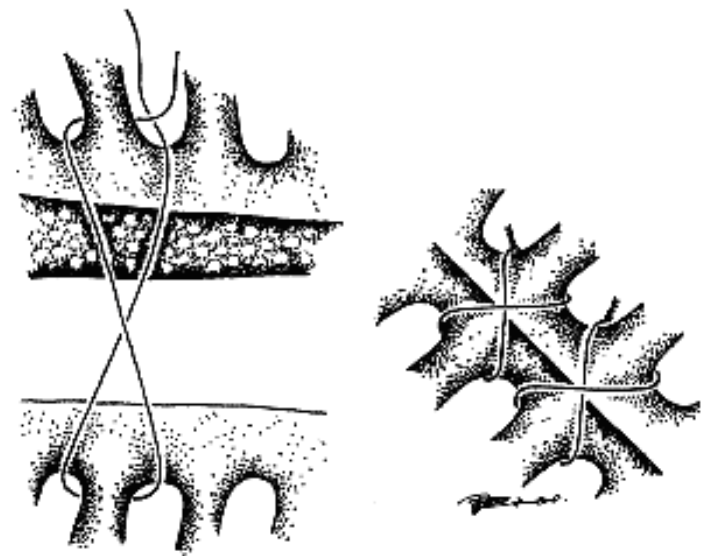

Figure 3.7: Illustration of a pericostal figure-of-eight wire closure[18].

\subsubsection{Figure-of-eight}

A figure-of-eight closure is characterized by steel wire wrapped around the manubrium in the shape of an 8. A series of figure-eight is the closure choice for the most human cardiothoracic surgeons [15].

The configuration that is optimal for clinical use has been a disputed topic. One claim asserts that figure-eight pericostal closure (Figure 3.7) has the highest failure rate compared to other popular steel wire methods [10], while others claim that figure-eight suturing is safer than simple wires [6] and have the least permanent displacement under load [15]. Clinical observation suggests that figure-of-eight, results in uneven tension. The advantage of this method is that the force that it applies on bone is distributed over a larger surface area and reinforces sternal segments [15]. 


\subsubsection{Polymer sutures}

Performed in the same manner as steel sutures, nylon bands have been ruled out as an effective technique. The nominal gauge of steel wires and polyester bands are identical and therefore are characterized by the same surface area. The high elastic modulus allows it to stretch under load, and the actual diameter of the polyester suture shrinks. This means that the force applied on the manubrium is distributed under a decreased surface area and is more likely to cut through bone [8]. This also correlates to clinical data in which the good results of steel closures were not replicated with the use of nylon bands and cuts through bone at over four times the rate of standard steel wire closures [2, $8]$.

\subsubsection{Steel sternal bands}

Steel sternal bands are used to achieve a larger force distribution by wrapping a wide steel band peristernally around the manubrium. In practice, more wires are usually involved in a sternal closure than bands, but this can also be attributed to its larger size. Because of the larger size of sternal bands, they risk traumatizing surrounding tissue and cannot be placed through the manubrium or around the rest of the sternum [22].

In applications that allow for this device to be used, sternal bands are particularly effective. They cut through bone at a quarter of the rate of standard steel wire closures and are twice as rigid. The use of a more reliable, rigid closure can result in the reduction in postoperative pain and postoperative hospital stay [8]. 


\subsubsection{Reinforced wire techniques}

The exposed weakness of the stainless steel wire technique is the wire's ability to cut through bone and its dependence on bone strength. To correct this, techniques have been developed to allow for forces to be distributed over larger surface areas while retaining the simplicity of standard steel wire closures and therefore allowing less dependence on bone strength. Examples of this include coil jacketed wires and titanium sheets strategically placed under the wire on either side of the sternum.

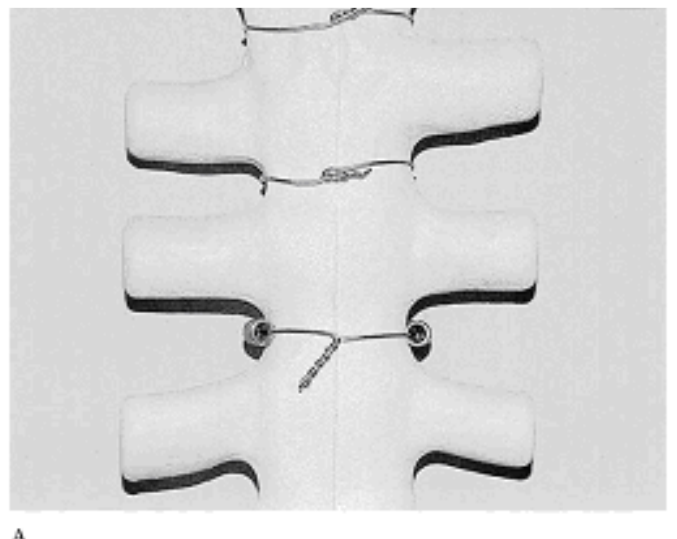

A

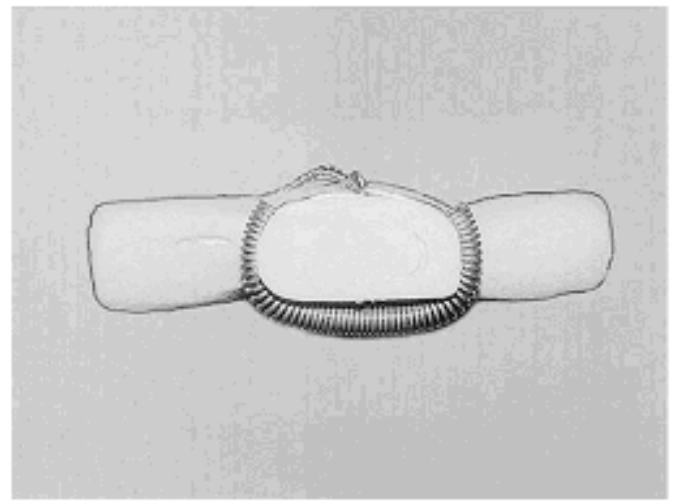

Figure 3.8: Coil-reinforced sternal wire [22].
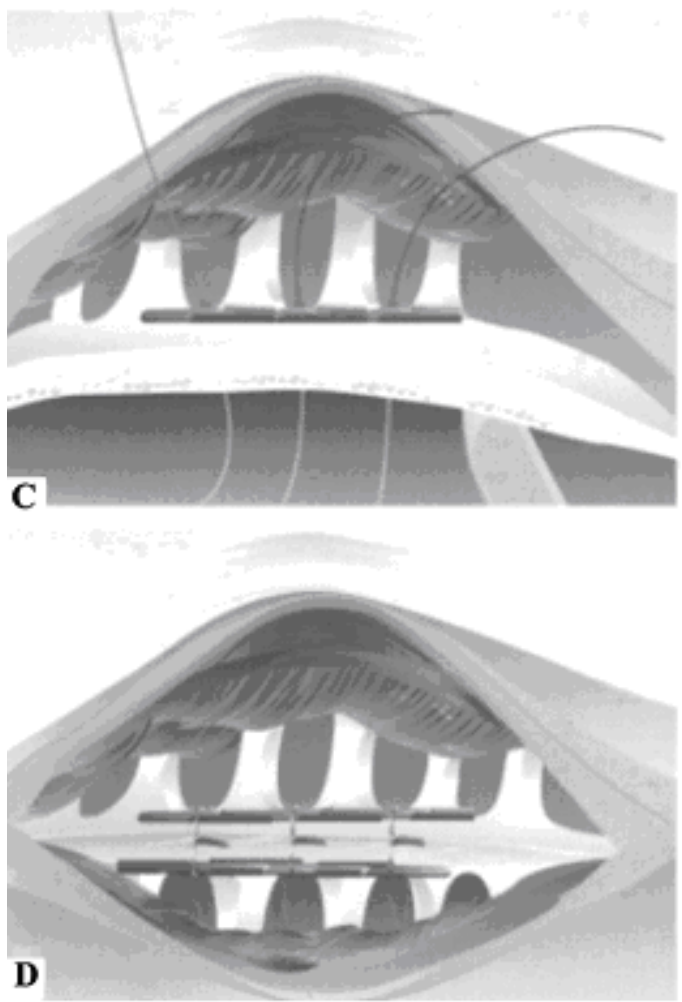

Figure 3.9: Sternal reinforcement device DSS: Sternal Synthesis Device (Mikai SpA, Vincenza, Italy) [23].

\subsubsection{Rigid-plate fixation}

Craniomaxillofacial and orthopedic surgeons have historically used wires for bone fixation, similar to cardiothoracic surgeons. Morbidity and complications associated with wire fixation of these other two applications were also similar, including infection, 
separation, instability, motion, non-union, and delayed healing. Rigid fixation techniques have been developed to provide superior stiffness at an injury site to aid in osseous healing rates and reduced complication rates. The implementation of rigid fixation techniques has significantly reduced bone healing complications in the areas of craniomaxillofacial and orthopedic surgery [24-27]. This translates to fewer hospitalization days and an earlier return to normal function. The advantages of rigid fixation have led to the near-complete replacement of wire fixation in orthopedic, craniomaxillofacial, otolaryngologic, oral, and neurologic surgery [28].

\subsubsection{H-shaped titanium plates}

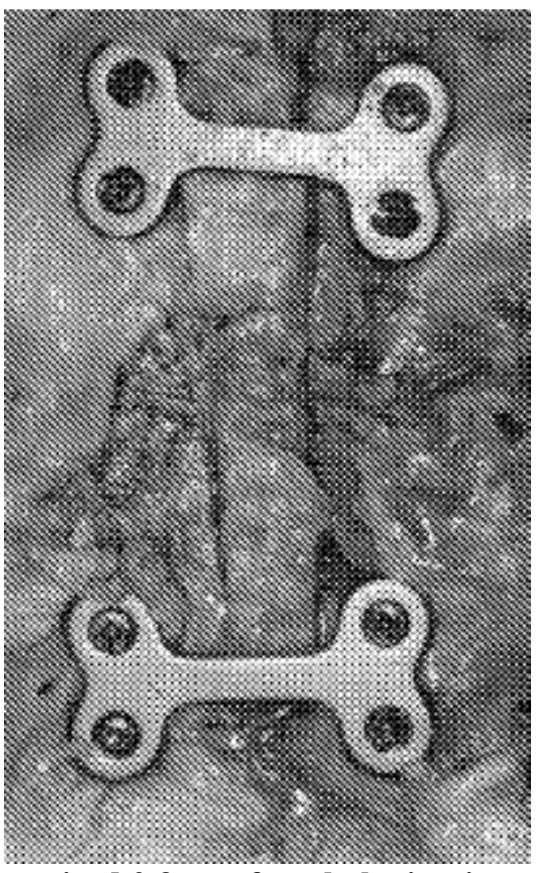

Figure 3.10: Photograph of a customized 2.3mm, four-hole titanium alloy H-plate (KLS-Martin L.P., Jacksonville, FL) [28].

Ozaki et al. cited compelling advantages of rigid fixation over wire fixation in promoting good bone healing. H-plates made from a titanium alloy were developed to experiment on a rigid fixation technique to close a median sternotomy. The study obtained results 
showing that the H-plates developed had a statistically significant sternal stiffness, less sternal motion, and fewer failures when compared to sternum closed with wires [28].

The mechanical behavior of the device-cadaver construct is not entirely dependent on the rigid plate on screws, but also largely dependent on the bone that they are screwed into. Screws must be placed into the thickest and densest possible bone, properly drilled with appropriately sized screws. Concerns with this new technology included the high cost of the plates and damage of underlying structures by the drill.

\subsubsection{The Biomet Sternalock}

Originally developed by Walter Lorenz Inc, the Sternalock system is a titanium plating system, screwing directly into divided the manubrium to fasten itself. The system utilizes two X-plates at the mid-body and one L-plate as inferiorly on the sternum as possible, in conjunction with wires at the manubrium and xiphoid for extra stability in

physiologically weaker areas. Implant time for this device has been claimed to be shorter than wire closure techniques [29]. 


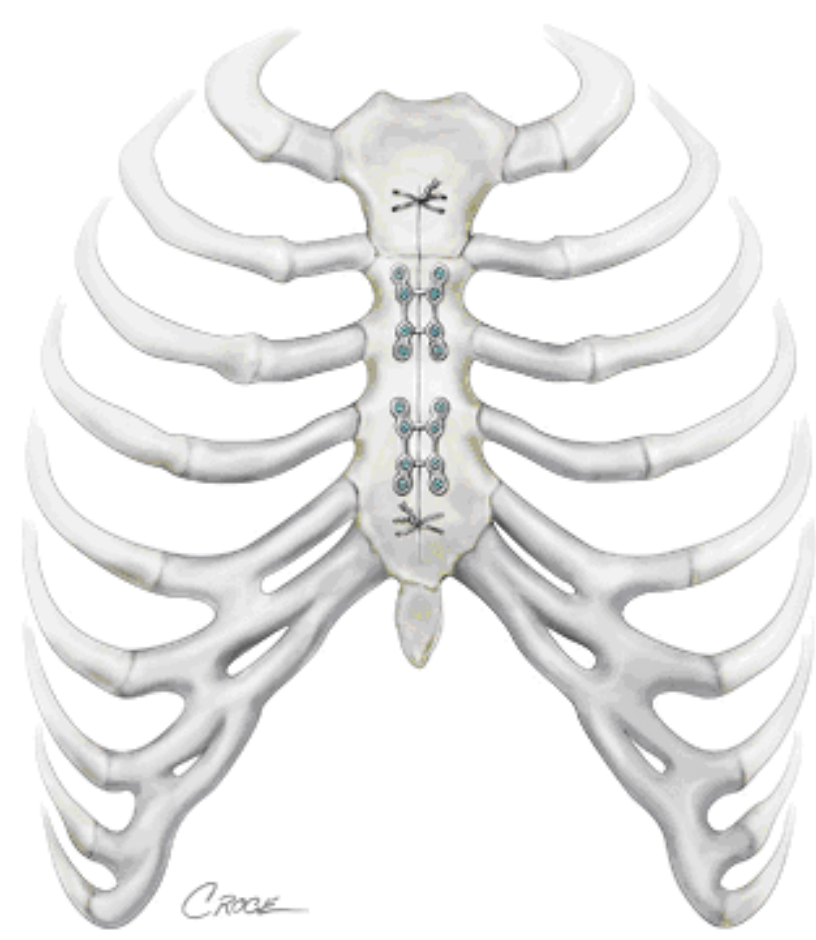

Figure 3.11: An artist's drawing of a sternum fixed with wires and rigid plates[29].

\subsubsection{Complications}

Potential healing complications that can develop after a median sternotomy include sternal mal-union and non-union, dehiscence, mediastinitis, and lingering incision pain. The presence of an individual complication is associated with the presence of additional complications, as well as directly related to sternal instability, or insufficient sternal approximation [30]. The presence of healing complications may lead to hardware failure and occasionally, death $[5,7,12,31-33]$.

A surgical debridement would be performed as soon as possible in the event of dehiscence or mediastinitis [34]. In a procedure first described by Schumacker and Mandelbaum in 1963, the infected area undergoes debridement, sternal reclosure and mediastinal antibiotic irrigation [35]. The average additional hospital cost to treat post 
sternotomy mediastinitis is $\$ 500,000$ [36]. The alternate cost of a better closure technique is extremely cheap in comparison. Prevention of postoperative complications is fiscally sound, and more importantly, it has the potential to save lives.

Increased motion at the sternotomy site can worsen a patient's postoperative sternal pain, which may lead to atelectasis and pneumonia secondary to a decreased inspiratory effort [28].

\subsubsection{Increased risk factors}

A thorough understanding of risk factors can aid in predicting the incidence of serious complications. Postoperative healing complications can occur in up to $5 \%$ of patients [2, $11,18,37]$, and historical data has revealed that the use of sternal wires on a select group of patients exhibiting "high risk factors" is insufficient as a closure technique [38]. Univariate risk factors include: insulin-dependent diabetes, obesity, postoperative bleeding, prolonged ventilation, surgical reexploration, use of one or two internal mammary artery (IMA) grafts, number of diseased vessels, postoperative intra-aortic balloon pump (IABP) use, blood transfusions, and female gender [39]. Multivariate analysis revealed five independent risk factors including obesity, insulin-dependent diabetes, IMA grafting, blood transfusions, and surgical reexploration [39].

\subsubsection{Sternal mal-union and non-union}

When the rigidity of the closure technique is insufficient and a degree of motion is allowed between the sternal halves, bone healing is interrupted. This interruption results 
in delayed healing, and in some cases the bone continues to heal as two individual pieces rather than in union. This can occur in partial areas of the sternum, yielding a partial joining of the separated sternum, or sternal mal-union. In more severe cases, this takes place along the entire incision line, resulting in a complete sternal non-union.

The sternum is relied upon for structural support by many major organs and undergoes repeated stress cycles from menial physical tasks. From respiration alone the sternum goes under approximately 20 loading and unloading cycles, coughing caused by other conditions can dramatically increase loading characteristics. In a healthy individual, external forces act upon the thorax and the structural support created by the ribcage prevents the majority of the force to be transmitted to vital organs. Likewise, forces produced from respiration are contained by the firm encapsulation of bone.

When the structural integrity of the thorax is incomplete or severely compromised, the patient experiences an incapacitating pain. Patients are overcome with pain during everyday tasks and their lifestyles become increasingly limited.

\subsubsection{Dehiscence}

Dehiscence is defined as a reopening of a wound that was previously closed, as is the case in postoperative sternotomy patients. The wound ruptures along the sutured incision line often with discharge. Dehiscence is a result of poor wound healing and often occurs within the first 2 weeks postoperatively before significant bone healing [30]. 
"Dehiscence occurs when failure stress of the sternum is exceeded as forces such as those produced by coughing are applied to the sternotomy [40]."

Dehiscence is the most commonly reference healing complication in median-sternotomy related literature and the largest postoperative concern when a median sternotomy is performed. Dehiscence is directly related to a life-threatening complication known as mediastinitis; in all cases of mediastinitis developing in patients, dehiscence was present.

\subsubsection{Mediastinitis}

Mediastinitis is an infection involving the mediastinum, or thorax. This condition is characterized by a bacterial infection causing inflammation and a rupture of the wound. As infections can progress rapidly in this region, mediastinitis must be treated immediately. Mediastinitis is the most serious postoperative healing complication that can occur. As previously stated, it has been shown that in a statistical sample, $47 \%$ of patients who develop this serious complication die [2, 16, 31, 38, 41].

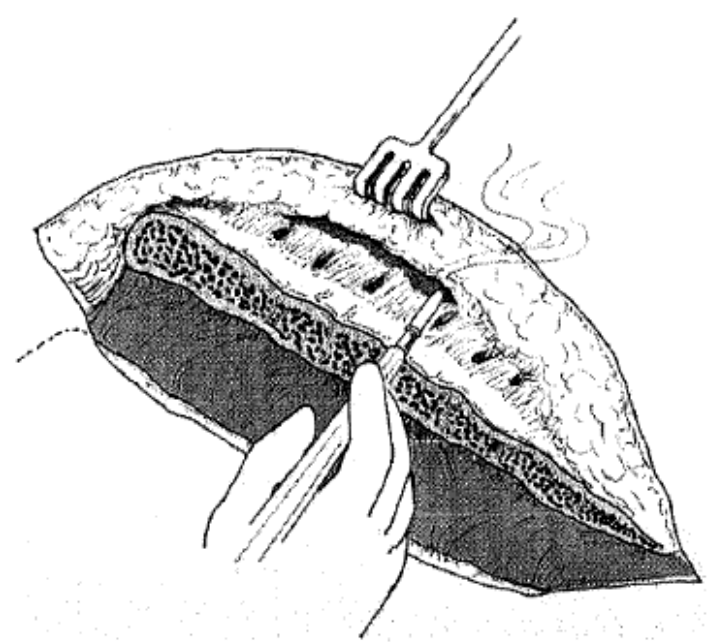

Figure 3.12: Tissue immediately surrounding the infected area is removed [42]. 
If not treated immediately, infection will rapidly spread and further complications, such as, sepsis, respiratory insufficiency, or multi-organ failure can occur [42]. Treatment of mediastinitis and dehiscence alike involves removal of compromised tissue and prevention of any infection from progressing. Specifically, this entails an array of antibiotics and an immediate sternal debridement without the removal of bone, and in advanced cases of mediastinitis a complete sternal debridement was carried out. Even with proper treatment, the likelihood of patient survival is limited.

Typically mediastinitis occurs in conjunction with dehiscence and rarely develops independently. This has been observed in multiple studies. Such is the basis for theorizing that eliminating sternal dehiscence, or preserving wound closure integrity, advances in mediastinitis prevention can be made.

\subsubsection{Constriction of blood supply}

The arterial blood supply of the adult human sternum is only significantly derived from its periosteal plexus fed by segmental sternal branches of the internal mammary artery. When the periosteal arterial plexus is obliterated or isolated, no collateral blood supply is available to the cortical sternal bone [43]. 


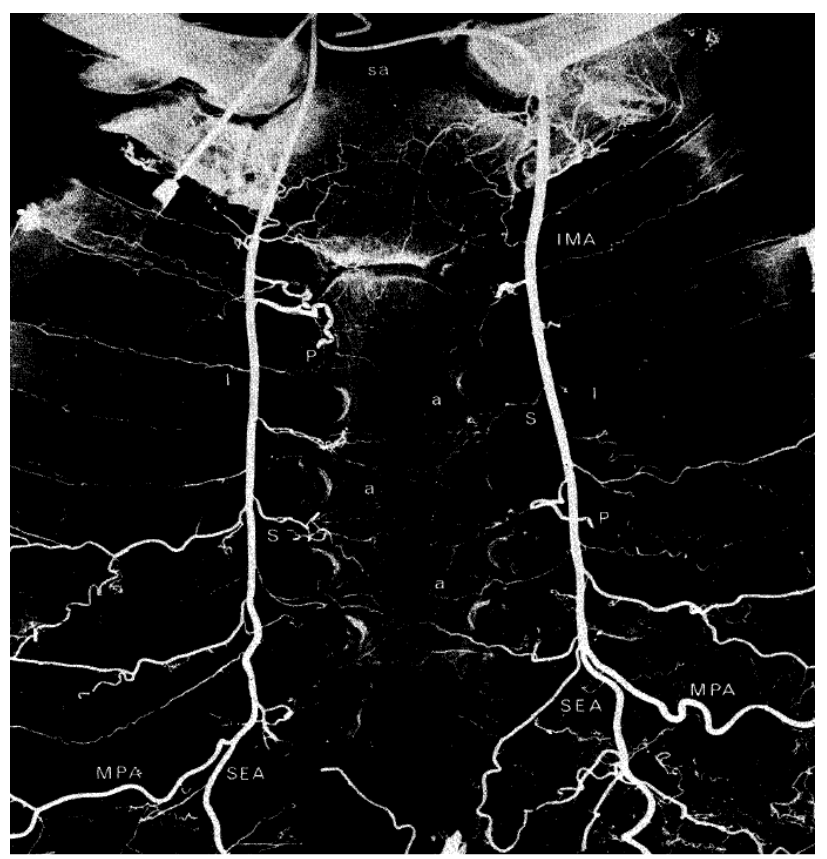

Figure 3.13: Radiograph of whole injected sternochondral specimen. IMA - internal mammary artery, SEA - superior epigastric artery, MPA - Musculophrenic artery [43].

Internal mammary arteries (IMA) run along the length of the sternum supplying blood to the entire area and supply slender arteries which run between fascicles of the intercostal muscles. A perforating branch is given off at almost all of the first five intercostal spaces and present as much smaller vessels below the fifth space. This branch passes forward through internal intercostal muscle and supply overlying subcutaneous fat and skin.

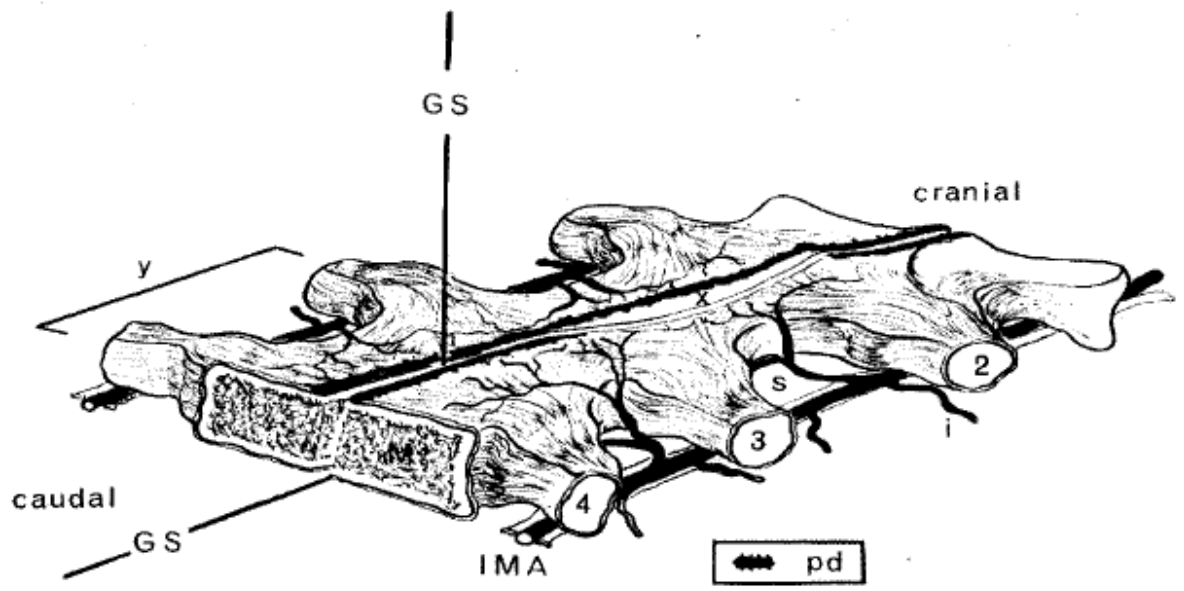

Figure 3.14: Simplified diagram of sternum, illustrating blood supply via Internal mammary arteries. IMA - internal mammary artery, s - sternal branch, GS - Gigli saw, pd - Periosteal diathermy [43]. 
Sternal branches exist in each interchondral space and pass medially toward the sternum from both sides. Each branch bifurcates into an upper and lower branch, running across the sternum. The upper and lower branches anastomose, or rejoin with each other, then again with their counterparts on the opposite side. Sternal branches run across the sternum parallel to bone and taper off very rapidly, disappearing within the peripheral marrow cavity.

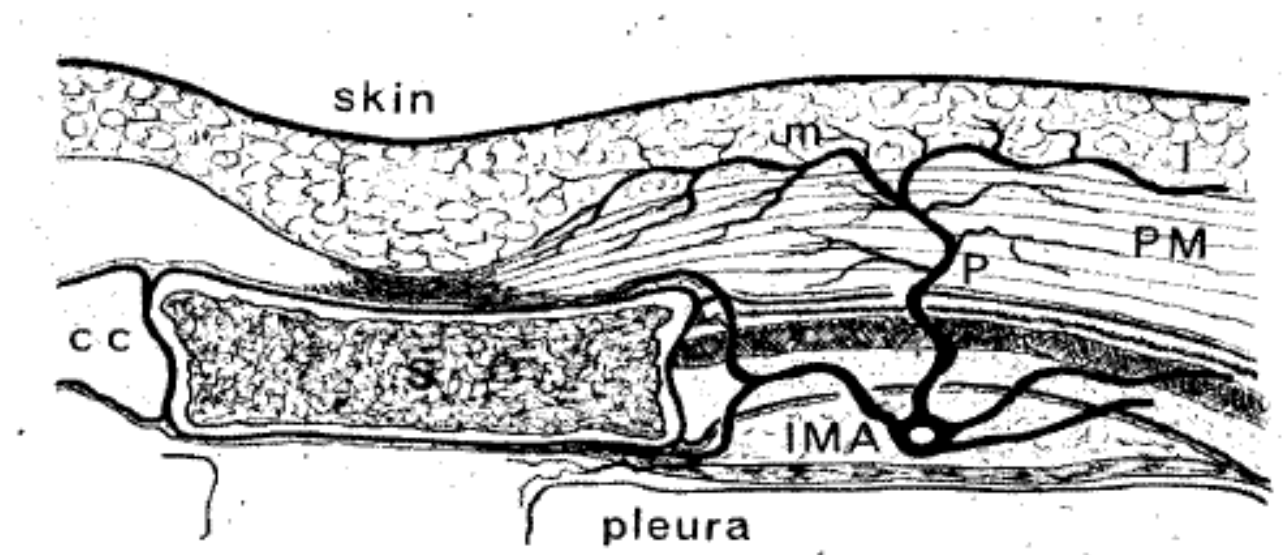

Figure 3.15: Idealized drawing of cross-sectional view of a sternum and its blood supply. IMA - internal mammary artery, P - Perforating branch, m - Medial, S - Sternum, PM - Pectoralis major [43].

In a study conducted by Arnold, three peristernal tapes were secured circumferentially at the second, fourth, and sixth spaces. These peristernal tapes were found to interrupt the IMA on either side of the sternum and reduce vessel density in the adjoining periosteum [43]. Interruption of vasculature supplying the manubrium will undoubtedly decrease bone healing rates and may give way to numerous other complications. Contact area around the manubrium should be minimized to allow for optimal blood supply during healing. Compounded with the main shortcoming of the median sternotomy, insufficient rigidity of the construct, the result is an extremely difficult problem to fix. With current 
technology, more wires must be added to achieve a stiffer construct, however this increased surface contact area around the manubrium will further interrupt its blood supply.

\subsection{Models}

All bench-top and in-vitro testing do not have been proven to provide any direct clinical correlation to how sternotomy closure devices will behave. These due diligence tests that provide data before clinical trials can provide insights to strengths and weaknesses of particular closure methods. While different modeling techniques have strengths and weaknesses, bench-top models are a necessary step in developing a viable sternotomy closure device.

\subsubsection{Bone analogues}

Cohen and Griffin conducted a study comparing three sternotomy closure techniques with the use of a synthesized polyurethane foam model [31]. In an effort to thoroughly evaluate the mechanical properties of the devices included in the study and minimize any inconsistency in the model, they used a bone analogue. They cited the large variability in bone density, sternal size, and sternal thickness when using cadaveric specimen. Also, animal models possess size and shape differences that cannot be ignored. Compressed foam has been developed to simulate cancellous and cortical bone [44]. 


\subsubsection{Cadaveric models}

Although supportive data from animal and bone analogues are beneficial in obtaining a good understanding of how a closure technique will behave, nothing can replace data from a human cadaveric study. Because of the unique shape of the human sternum, the use of a cadaver is the best way to assess the sternal closure stability. The configuration that a wire assumes around the sternum influences the way in which tension is applied to the sternum and thus affects stability [11].

\subsubsection{Mathematical models}

The finite element method is widely used for structural analysis problems in engineering research and practice. A numerical technique analyzing different sternal closure techniques was attempted by Bruhin et al. to investigate displacement and stress distribution of the sternum embedded in the human chest. Acquiring an in depth knowledge of the strain and stress distributions and force transfer was seen as an opportunity to determine the optimal sternal closure technique. The advantage of a numerical technique was that realistic conditions regarding traction forces at any point of the sternum could be mimicked quantitatively [45]. 


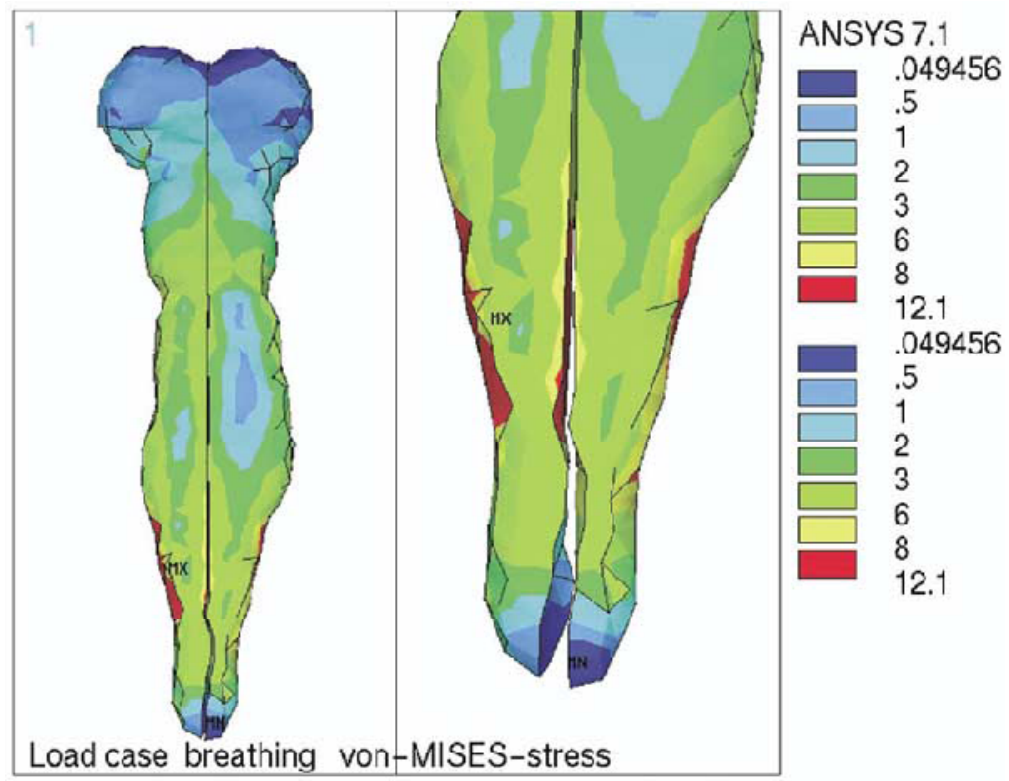

Figure 3.16: Example analysis of the human sternum by a numerical method [45].

\subsubsection{Digital image correlation}

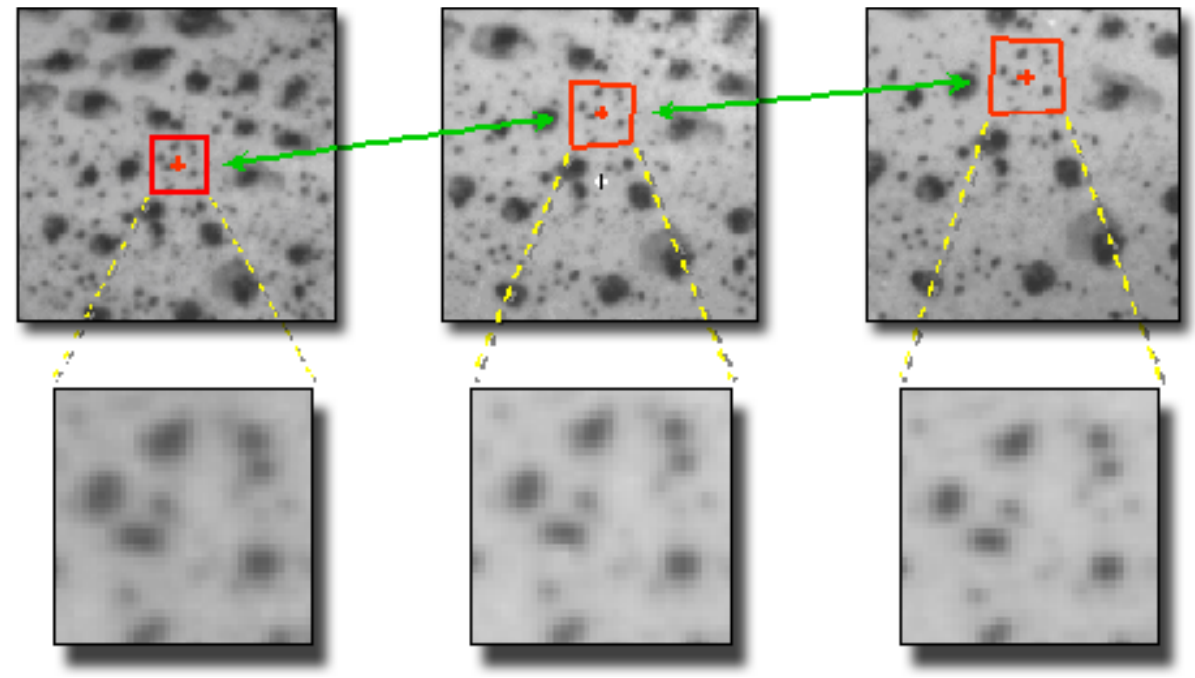

Figure 3.17: The digital image correlation system tracks the grey value pattern, or 'speckle,' in small subsets during deformation

Measuring deformation can be easily done by tracking the displacement of markers on the surface of the sample. Each marker is treated as a node with an associate finite element. The difference in position for each marker defines a displacement vector. Digital image correlation is a well developed technique widely used for other areas of engineering research[46-48]. To enhance the resolution of the technique, a "speckle" can 
be applied to increase the amount of points identified by the computer. Limited applications of biomechanics have been attempted, such as, the analysis bone surfaces and soft tissue. 


\section{Objectives}

The objective of this study is to compare the performance of the Biomet Microfixation (Jacksonville, Florida) Sternalock plating system and an established peristernal wire closure technique in a mechanical system. Results of this study will evaluate whether this rigid fixation technique is significantly superior to mainstream methods and worth further evaluation and implementation.

The prevalence of healing complications and the high rate of mortality associated with these problems continue to harm up to $47 \%$ of patients undergoing median sternotomies each year [2]. These healing complications are directly linked to closure techniques that do not meet necessary stiffness requirements. Therefore, the most appropriate way to fix this problem is to do our best to prevent all complications as best as we can - a more stiff closure technique.

Specific Aim: evaluate the relative mechanical performance of the Sternalock plating system when compared with an established peristernal wire closure techniques when applied to a median sternotomy.

Hypothesis: Biomet Microfixation's Sternalock plating system will provide a more stiff structure with more strength to separated sternal halves when compared to peristernal wire closure techniques. 


\section{Test Methods}

Forty-two fresh human cadaveric sterna were obtained from Biomet Microfixation in Jacksonville, Florida. Each sternum sample was accompanied by CT scans, a seven-digit specimen number, and the age and sex of the donor. Each sternum was divided along the midline and closed with peristernal wires or Sternalock plates, consistent with a sternotomy procedure. Sterna were received surgically divided and closure technique applied and stored at $-20^{\circ}$ Celsius. Samples were separated into the three groups of closure techniques and numbered from 1-42.

Figure 5.1 shows the servopneumatic materials testing system (Bose SmartTest SP, Eden Prairie, MN) used for this study. A constant displacement of $25 \mathrm{~mm} / \mathrm{min}$ was applied by using WinTest Digital Control Electronics and WinTest Software (Bose Corporation, Minnetonka, MN).

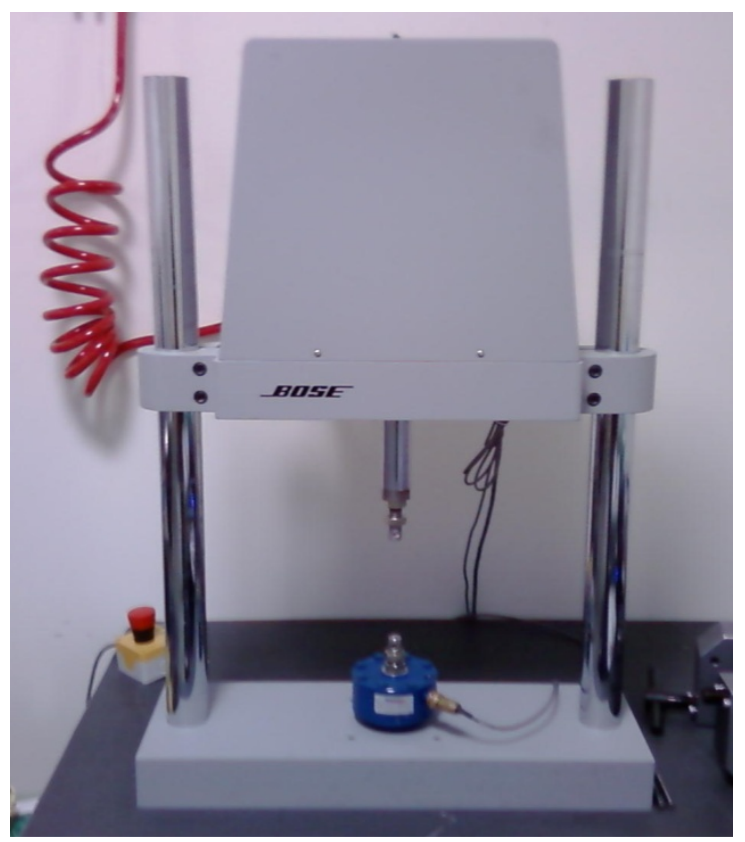

Figure 5.1: The test frame used in this study (Bose SmartTest SP, Eden Prairie, MN). 
The study utilized a human cadaveric sternum to model the biomechanical behavior under stress. Griffin studied the efficacy of the use of a polyurethane foam bone analogue in modeling cancellous bone to provide reproducibility in testing [31]. However, a human cadaveric model is uniquely suited to provide a clinical representation of biomechanical behavior, due to the overwhelming complexity of the biological composite structure of the thorax. Variability in bone density, sternal size, cortical bone thickness, and sternal thickness experienced in clinical settings can be accounted for with the use of a human cadaveric model.

42 fresh cadaver models were divided into three test groups. Group A employed a mainstream wire closure technique. Group B and group C utilized the Sternalock plating technique (Biomet Microfixation, Jacksonville Florida). Figure 5.2a shows an example of a group A sternum, closed with three peristernal wires at the manubrium and five trans-sternal wires along the body of the sterna. Group B was characterized by two " $\mathrm{X}$ " plates on the sternum body and an "L" plate at the manubrium, as well as, 3 wires at the manubrium and two additional wires at the xiphoid process (Figure 5.2b). Group C sterna were closed with a "Box" plate and 2 wires at the manubrium and two "X" plates at the sternum body with two wires at the xiphoid process, shown in Figure 5.2c. 

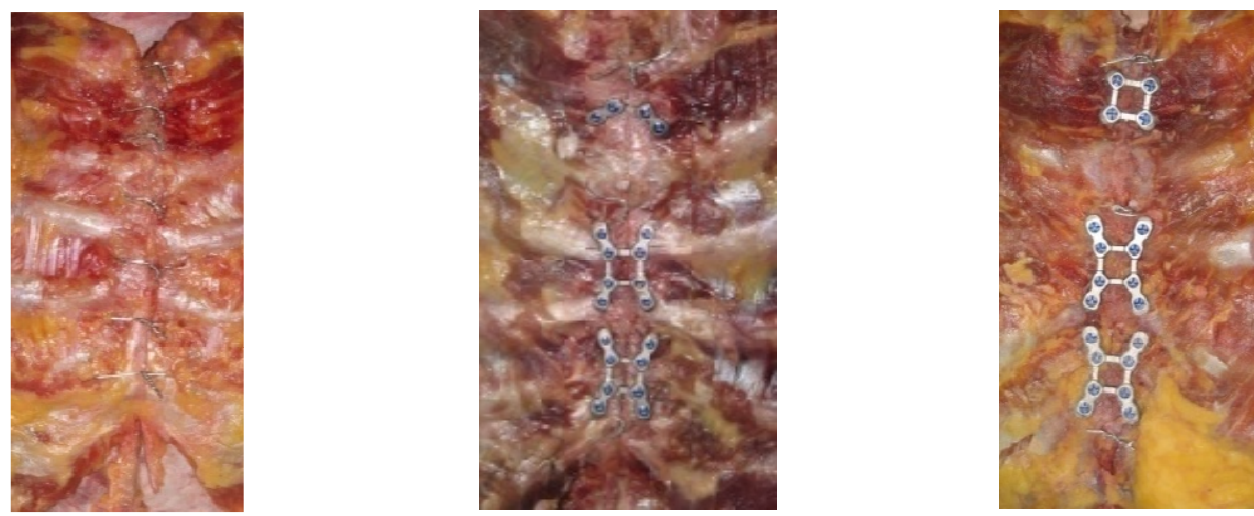

Figure 5.2: Pictures of the three closure techniques used in the study. a) peristernal wires, b) Sternalock with L-plate, c) Sternalock with box-plate.

\subsection{Sample Preparation}

Samples were removed from the $-20^{\circ} \mathrm{C}$ deep freeze a day before testing and placed into a standard freezer. The night prior to testing, the specimen were allowed to completely thaw in a refrigerator. Then, several hours prior to testing, samples were placed in a room-temperature lab.

When the specimen reached room-temperature it was dried with a paper towel and a coat of white shoe polish (Meltonian Boot \& Shoe Cream polish) was applied in a 3 inch area on either side of the incision line. This coat was allowed to dry for 20 minutes. A "speckle" pattern was then applied over the white area-of-interest by sprinkling black ink (Sanford: Higgins Black Magic) and allowed to dry for 30 minutes (Figure 5.3). The desired size of black-ink "speckles" were 1 millimeter in diameter. The combination of the white polish and black waterproof ink was designed to provide added contrast to aid in data collection to increase the resolution of the digital image correlation system. 


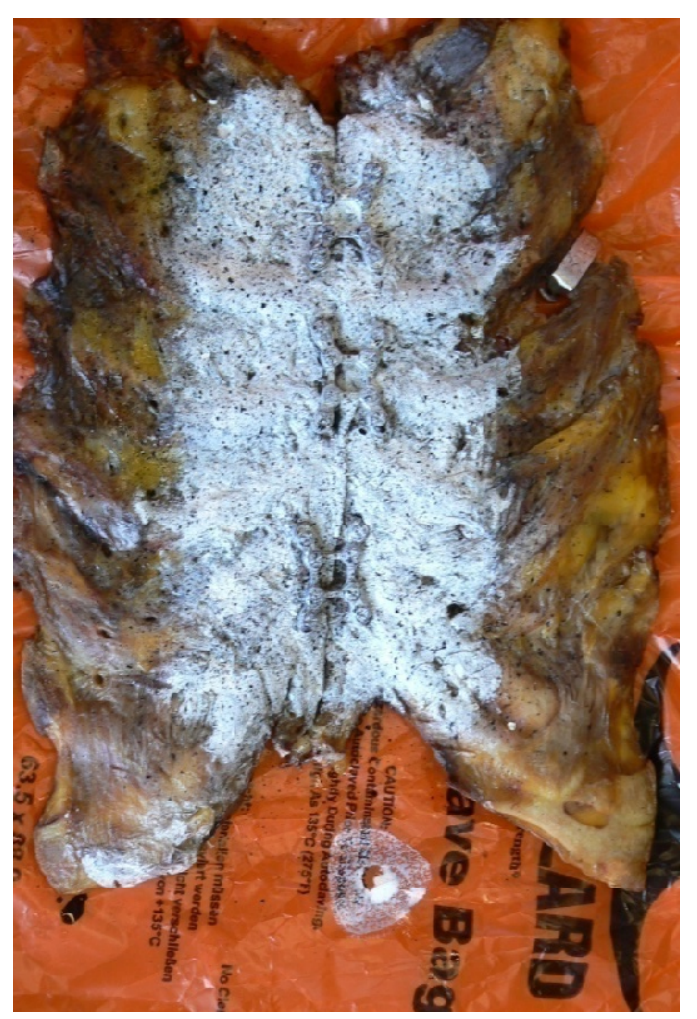

Figure 5.3: The cadaveric sternum must be coated with a special high-contrast "speckle" to record an acceptable amount of data.

A polish was chosen for this application because it demonstrated good adhesion qualities with the fresh cadaver model and did not crack during high mechanical loads, characterized by large displacement values. The black waterproof drawing ink was used in combination with the shoe wax because it produced the most opacity after drying, and subsequently a higher contrast.

\subsection{Test Set-up}

To grip the sterna, a set of aluminum clamps were constructed. These clamps were machined from aluminum blocks with tapped holes that held and array of $65 \mathrm{~mm}$ length cranial screws, designed to firmly hold tissue and bone to withstand applied directional forces. Larger bolts were passed through a set of analogous clearance holes on either 
sides of the clamp to hold the clamp in place over the sample. $1 / 4$ inch bolts were used to secure the clamps to the mechanical test frame. The sternotomy line being parallel to the clamp plates was verified prior to each test, as well as top plate parallel to the bottom plate.

Three sets of test fixtures were used, each designed to apply load in a different load on the construct. Figure 5.6a shows the intended configuration to apply lateral distraction, Figure 5.6b - longitudinal shear, and Figure 5.5c - transverse shear.

Alignment of the cadaver model with the test fixture and subsequent application of force is a highly emphasized parameter. The midline of the sternum must be parallel to the spiked clamps to achieve uniform application of force along the entire length of the osteotomy site. The midline and clamps must also be perpendicular to the displacement of the test frame. The bulk head of the test frame should also intersect the sternum with an approximately equal length on either side to minimize any rotational effects during testing. Therefore, an alignment tool was made to aid in loading the sternum onto spiked clamps that were designed to firmly hold ribs and flesh during mechanical testing. This alignment tool regulated the distance at which clamps gripped the sternum from the midline. The tool also ensured that the clamps gripped the sample parallel to the midline in every case. This was further adjusted as needed to ensure that alignment was achieved for every test. 
The alignment tool was placed on a table-top and one side of each of the spiked clamps was positioned on top of the tool (Figure 5.4). A sternum was then placed -on top of the open clamps with the posterior side of the sternum facing up. From this view, it could be verified that the sternotomy line was parallel to the clamps. The matching second side of each spiked clamps where then positioned using the tool, and tightened around the sternum. Each screw located on the clamps was then tightened by hand to ensure that a firm grip on the ribs was achieved.

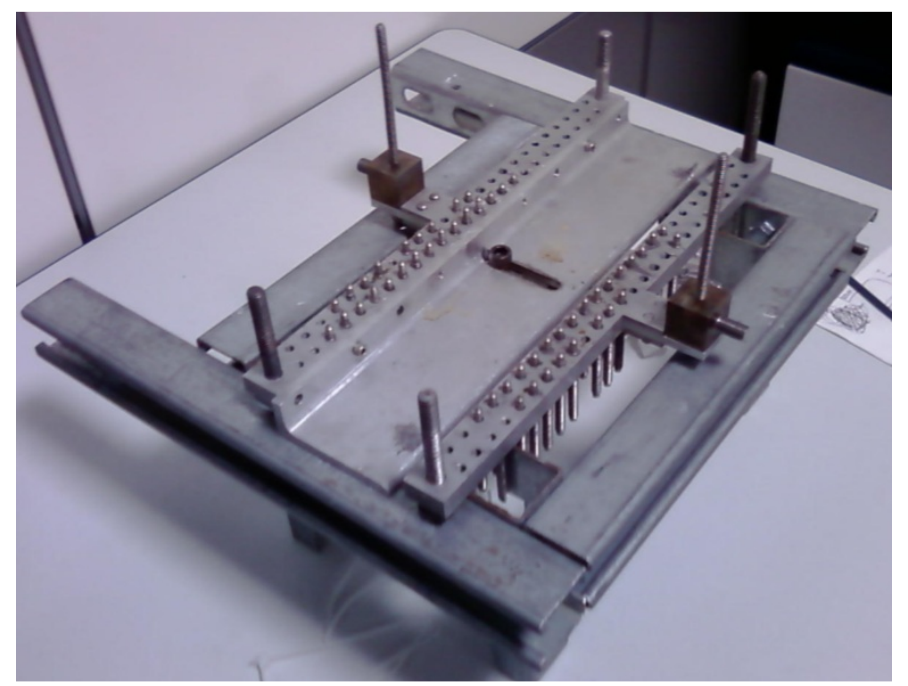

Figure 5.4: Picture of the alignment tool designed for this project with one side of the spiked clamps in position. 


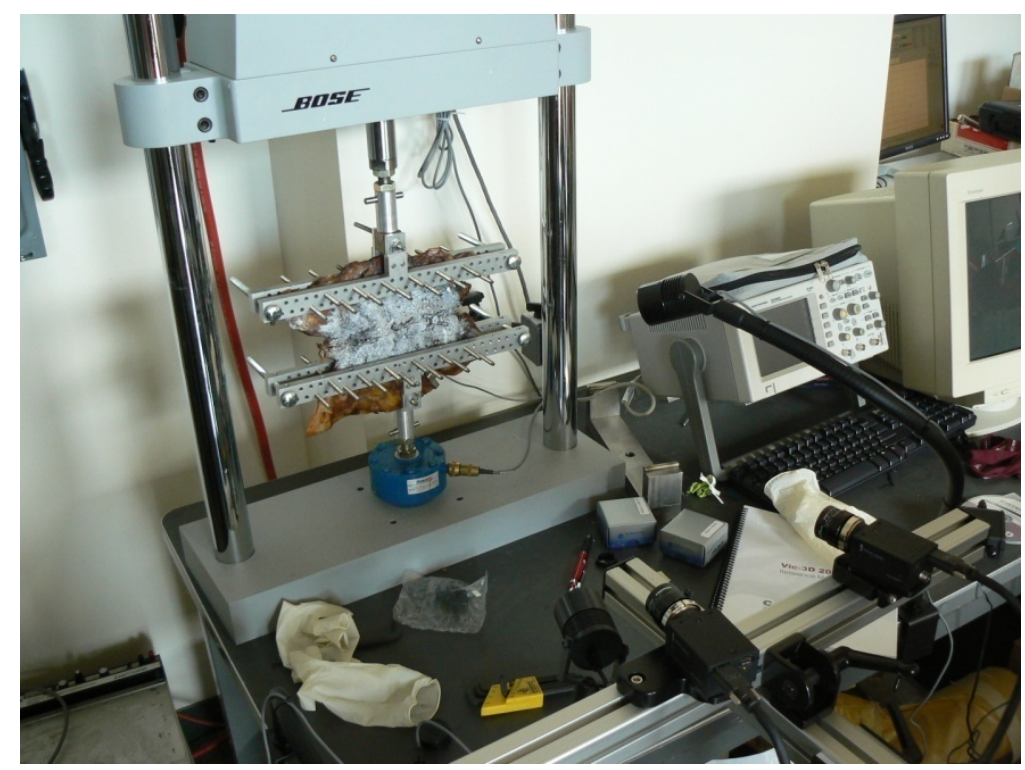

Figure 5.5: A picture of the test set-up used. A load frame transfers tension to the sternal construct via a set of spiked clamps. An array of cameras record data throughout the test.

The specimen was properly loaded inside the clamps with appropriate accessories for each differing test and attaching the clamps to the load frame, shown in Figure 5.5. Data was captured by Vic-3D (Correlated Solutions Inc, Columbia, SC), a digital image correlation system. This system utilized two optical cameras along with 3-D correlation algorithms to provide full-field 3-D shape, displacement and strain data for mechanical testing.

\subsection{Mechanical Loading}

The cadaver model was stressed in three different modes to rigorously test the biomechanical properties of the sternotomy closure technique: lateral distraction, longitudinal shear, and transverse shear. In each of these directions, a monotonic materials test was used in this application, pulling the construct at a constant $25 \mathrm{~mm} / \mathrm{min}$ until failure. Failure is defined as $2 \mathrm{~mm}$ of displacement at the midline, fracture of the sternum, fracture of ribs, or tearing of intercostals muscles resulting in loss of grip. 


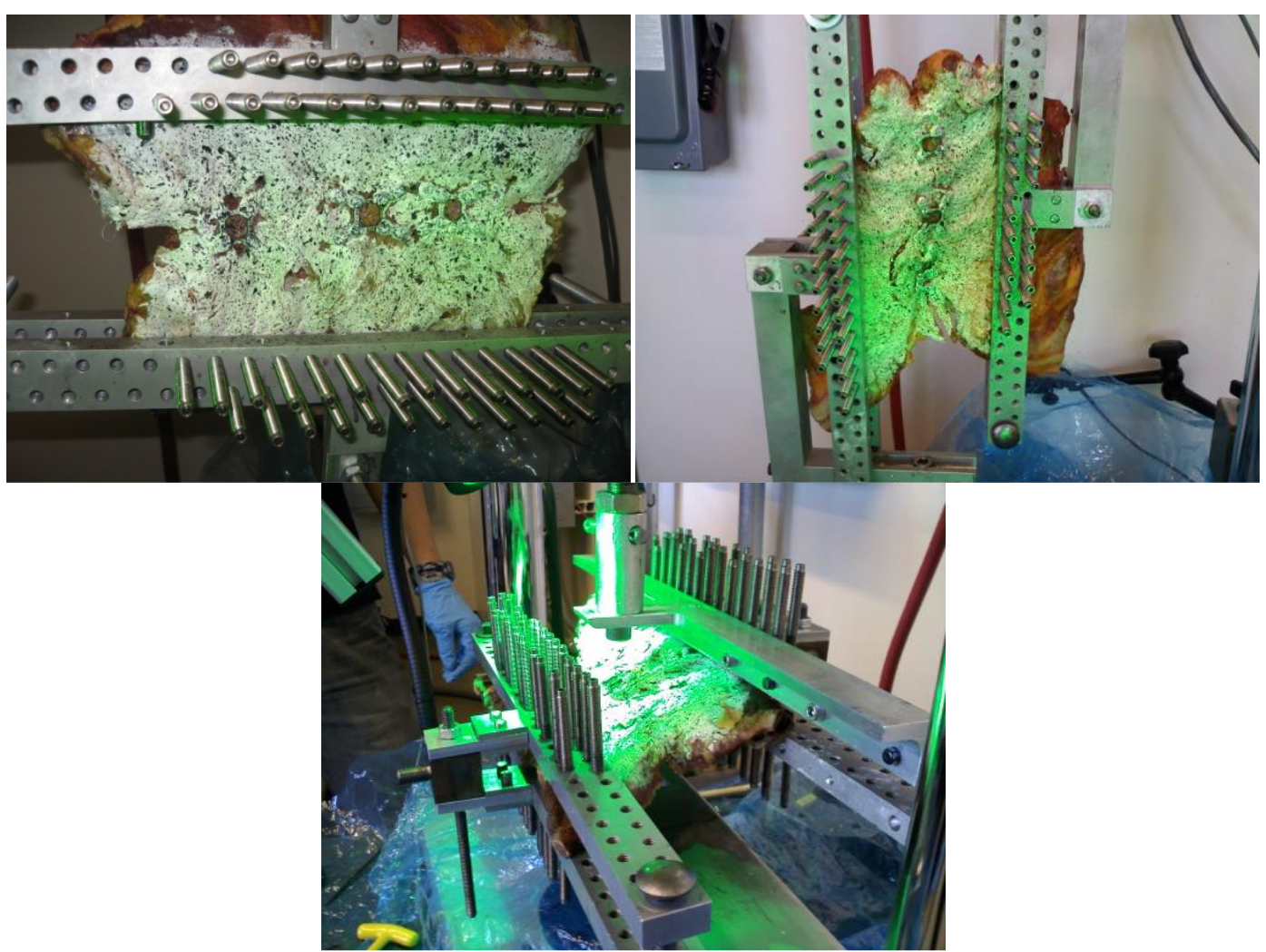

Figure 5.6: Photographs of each direction tested in the study. Starting from top left figure - a) lateral distraction, b) rostro-caudal shear, c) anterior-posterior shear.

\subsection{Digital Texture Correlation}

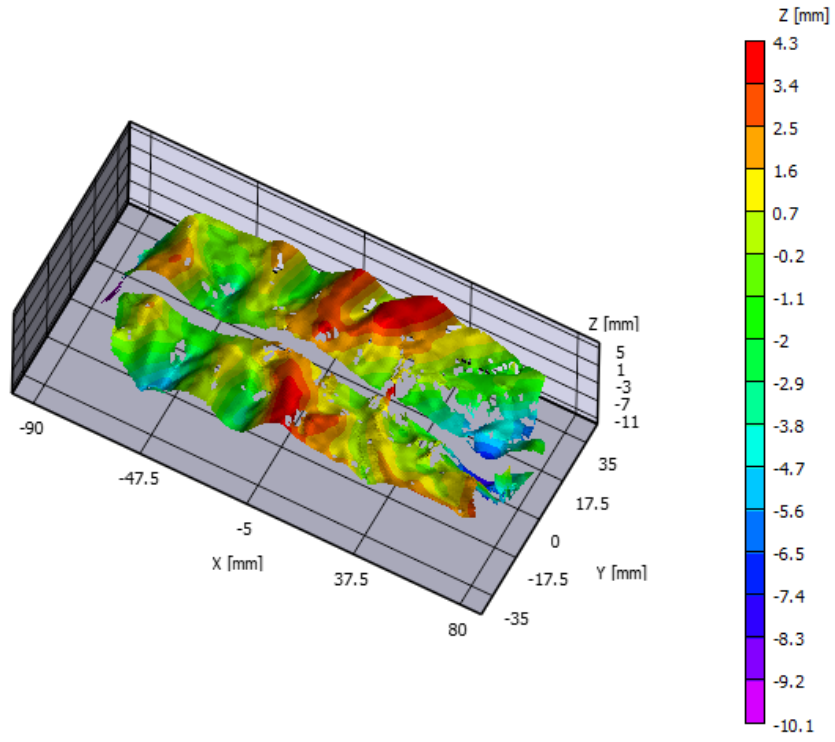

Figure 5.7: An example 3-dimensional shape constructed by Vic-3D using an array of optical cameras. 
Vic-3D (Correlated Solutions Inc, Columbia, SC), a Digital Image Correlation system was used to capture images at 3 frames per second of the sternum during mechanical loading. The system utilized two cameras placed at approximately 10 degrees to the left and right of the sample. The 3-D correlation algorithms processed the images to provide full-field 3-D shape, displacement and strain data of the cadaver construct during mechanical testing, shown by Figure 5.7. The resulting displacement pattern is analogous to a finite element contour plot of displacements, Lagrange Strain, or velocity.

The "speckle" pattern that was previously applied consisted of a non-shine shoe-wax and small drops of waterproof black ink. This "speckle" pattern provides assistance to the digital image correlation software by providing the extra contrast needed to track pixel displacement during testing.

For group A, two "areas-of-interest" were established in Vic-3D, one for each sternal half around the speckled area and separated along the incision line. Figure 5.8 shows examples of a sternum closed with peristernal wires stressed in both lateral distraction and longitudinal shear with coloration for strain rates, red indicates high displacement. For group B and group C, an "area-of-interest" was also drawn for each of the sternum halves, but also around the titanium plates. This was done to instruct the texture correlation software that there are two separate solid materials under stress. 

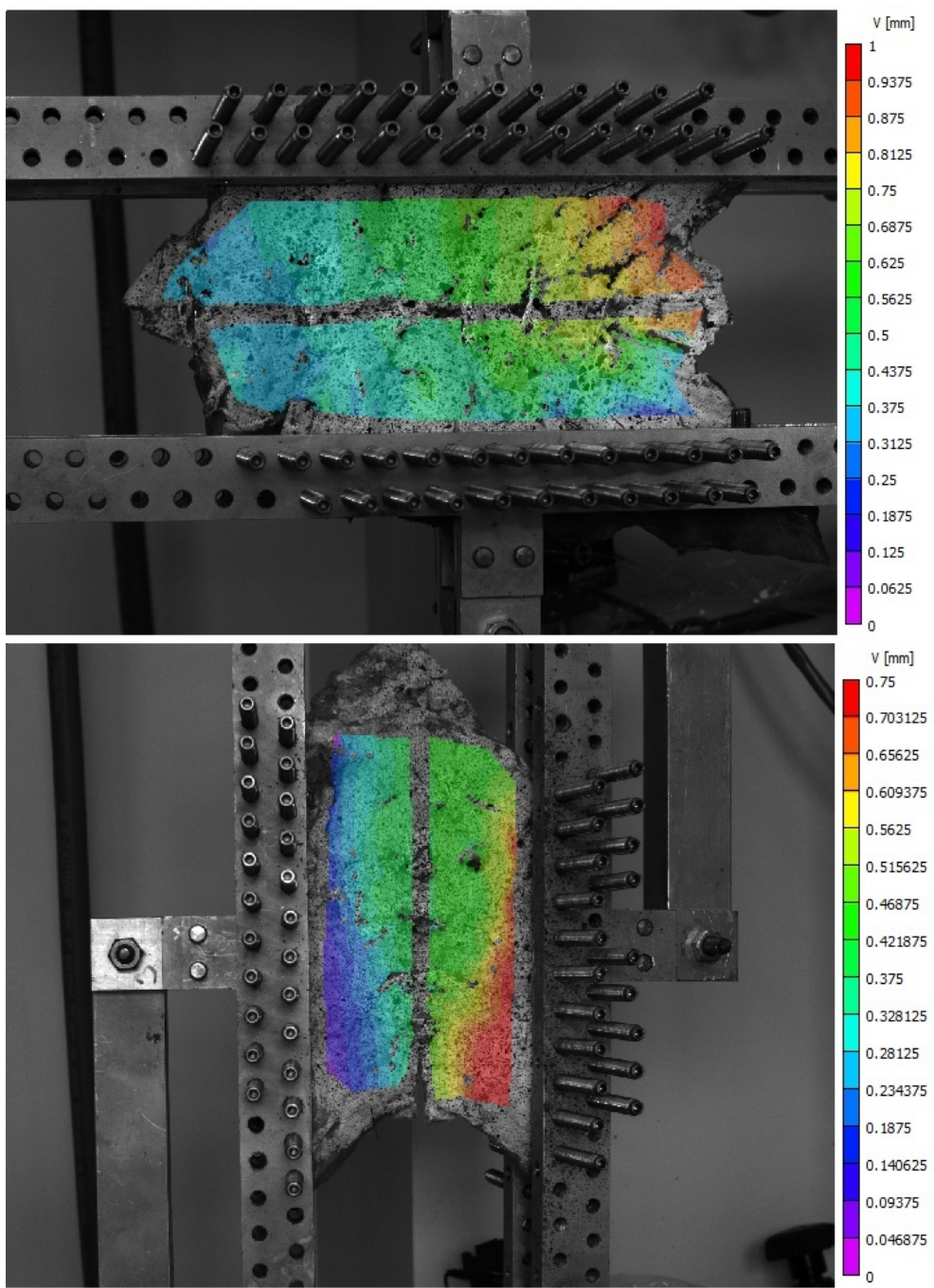

Figure 5.8: Example colorations of stress concentrations in a) lateral distraction and b) longitudinal shear.

The texture correlation system captured images at an interval of 0.3 seconds, or 3.33

frames per second. Average rate of vertical displacement between the sternal halves was found on either side of the midline incision. With this data, a force by displacement graph was constructed for each area between titanium plates.

A rectangle was drawn that included the length of the sternal body, approximately 5 millimeters away from the midline on either side, shown in Figure 5.9 and Figure 5.10. 
Inside this rectangle, the vertical movement of each pixel inside this defined rectangle is averaged at each point in time. The manubrium and xiphoid regions were ignored due to issues of reproducibility. The behavior of the manubrium always showed zero displacement at the midline, and therefore, an infinite stiffness, before failure was observed in the construct. The xiphoid region universally showed displacement at the midline first. However, the steel wire placed in this area to further stabilize the xiphoid in sterna closed with Sternalock plates caused cutting of bone and subsequent erratic behavior.

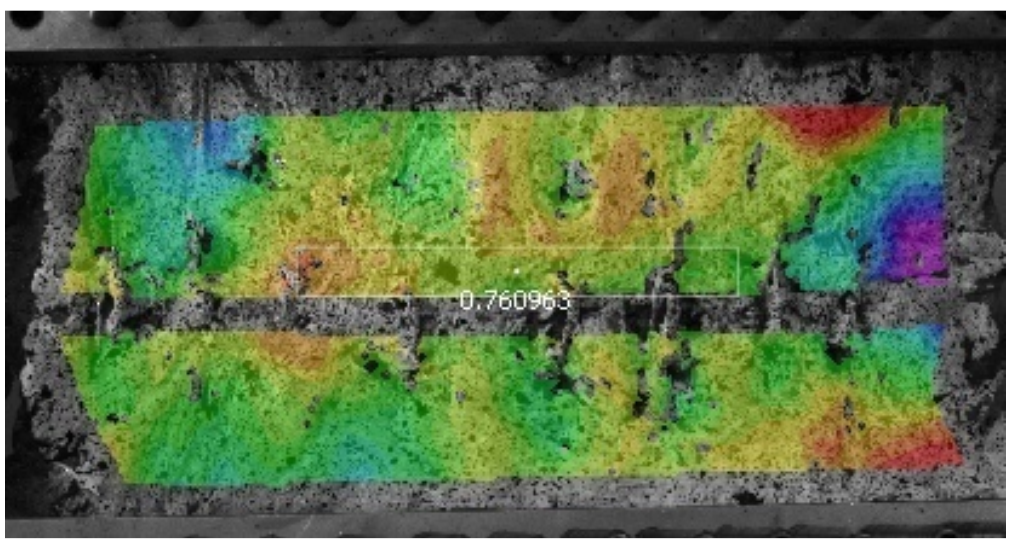

Figure 5.9: A rectangle is drawn on the top half of the sternum indicating the area that data was extracted from.

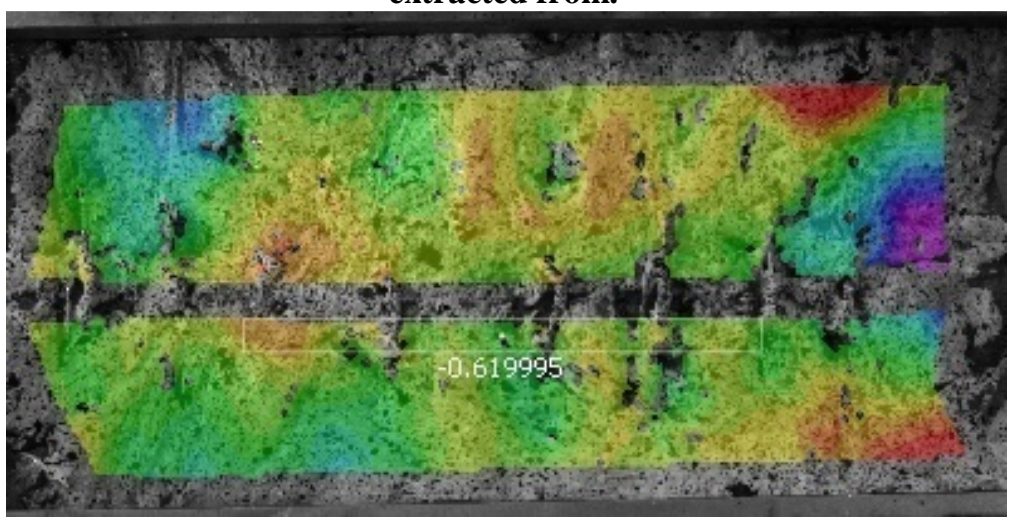

Figure 5.10: A rectangle is drawn on the bottom half of the sternum indicating the area that data was extracted from. 


\subsection{Data Extraction}

Samples were stressed monotonically in one of three directions until they broke using a servopneumatic testing system. Data collected during this test constructs a Force vs.

Displacement graph similar to Figure 5.11.

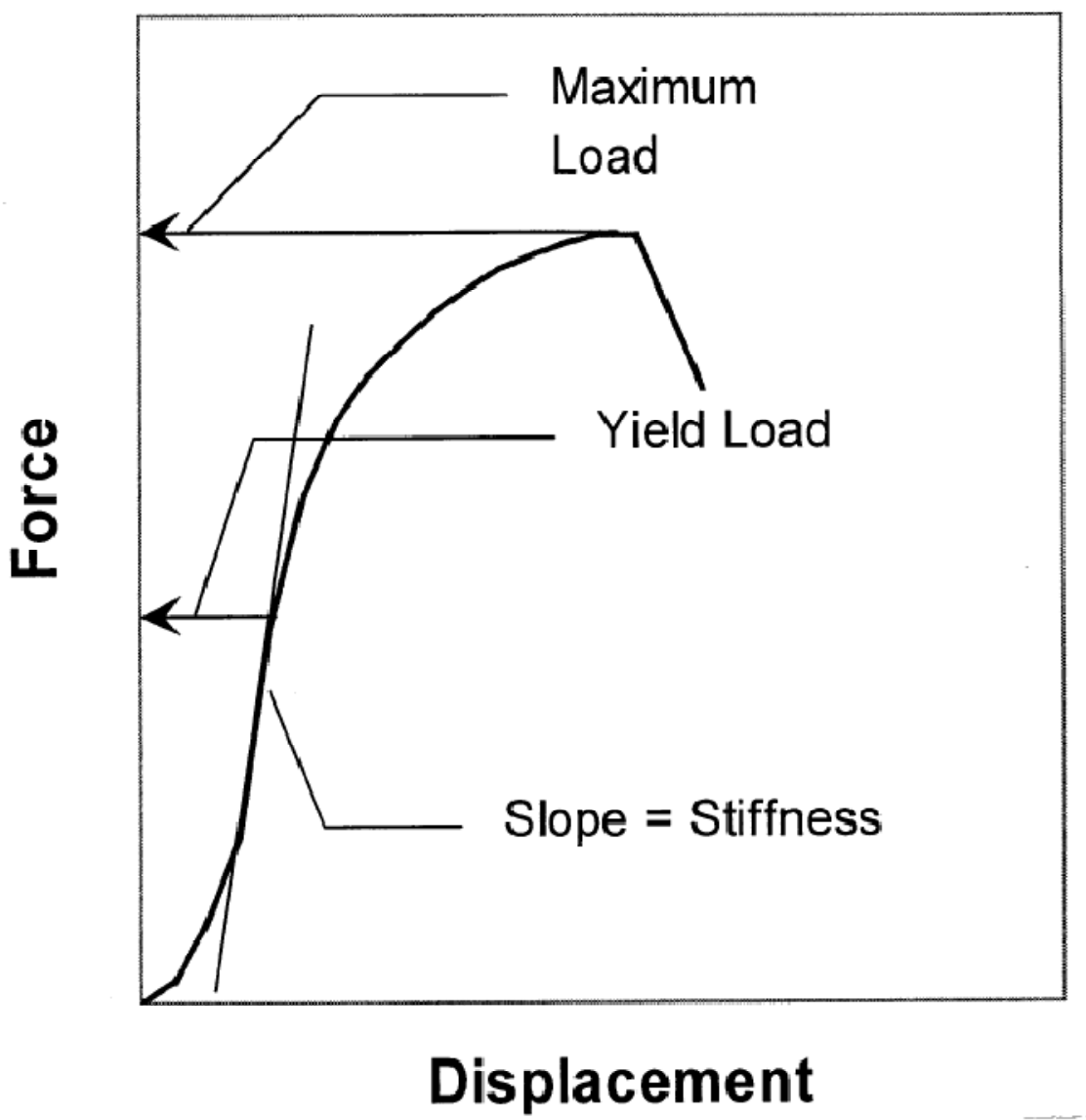

Figure 5.11: Load-displacement curve and definitions of terms. Stiffness is the slope of the linear portion of the curve. The yield load is the force applied that causes the curve to become nonlinear. Above this point of the curve, displacement is at least partially irreversible after removing the force. Maximum load is the force required to cause catastrophic failure of the system.

These unidirectional tests evaluated the biomechanical properties in lateral distraction, longitudinal shear, or transverse shear. From the force vs. displacement graph constructed by the data output, values for construct stiffness, yield load, and ultimate load 
could be calculated. With these values, the displacement at yield load and post-yield displacement could be found from the given data points.

Stiffness is the resistance to elastic deformation when force is applied. The upward linear portion of the graph is characterized by elastic deformation, in other words, the construct will return to its original state when the applied force is removed. The slope of this linear portion is referred to as Young's Modulus or modulus of elasticity and is the measure of stiffness of a material or construct, more specifically the ratio of stress to strain during elastic deformation. This equation is in the form of $y=m x+b$, with " $m$ " representing the slope and stiffness of the construct. An algorithm was developed to calculate the modulus of elasticity. 60 consecutive data points were isolated within the upward linear section of the graph starting at point 1 . If the linear trend fit to these points did not have an $\mathrm{R}^{2}$ value over 0.96 , the next set of 60 consecutive data points were taken with an increment of 1 data point, in other words, points 2-62. A negative slope could not be accepted, and a negative stiffness cannot exist. If a negative slope was found in a region of the sternum, the stiffness was taken to be infinite and quantified as zero displacement at that region. This method ensured that the largest and most linear slope was chosen for each region.

The yield load is the stress capacity of the construct before permanent damage is inflicted to the sternum or device. This is also known as the stress limit associated with elastic deformation, or the ability to return to the original state. Elastic deformation is characterized by the upward linear section of the force vs. displacement graph. To find 
the yield load, a secant slope method was used. An interval of 60 data points were used to best represent linear portion to calculate the modulus of elasticity. Multiplying this previously found slope or stiffness by 0.95 , a line was then extrapolated over the force vs. displacement graph. The point of intersection between the two lines defined as departure from linearity and taken to be the yield load for the construct of divided sternum and closure technique.

The ultimate load is absolute maximum load that can be sustained without failure of the construct. In our model, the ultimate load refers to the load experienced by the construct immediately before catastrophic failure. Failure can be characterized by breakage of the ribs, tearing of intercostal muscles, wire fracture, plate fracture, or loss of screw fixation. Also, failure can occur at the area the clamp gripped the sternum, in the ribs, where the ribs meet the sternum body, and on the sternum body.

Post-yield displacement is evidence of wires cutting into the cadaveric sternum model, or other damage to bone. This leads to sterna malunion and nonunion of the sternotomy and is not a desirable outcome. Post-yield displacement was found by recording the displacement at the midline when the yield and ultimate loads were met; these values were subtracted to quantify how much more the construct in-elastically displaced before catastrophic failure. 


\subsection{Construct Analysis}

As the sternum is pulled upward, the sternal halves displace at different rates, depending on the construct stiffness. If the closure is not stiff enough, the upper half of the sternum will displace at a rate higher that the corresponding half and a gap at the sternotomy line can be observed. With an exceptionally stiff construct, there will be no relative displacement immediately surrounding the incision line and no gap can be observed. The closure technique keeps the sternal halves together and moves in union. Overall, the specimen is still displacing at the same rate, but that strain is transferred to ribs and fascia. However, our concern is the device and its interaction with the specimen.

Relative displacement between the sternal halves is the desired output, and what we use in our force vs. displacement graph. This is calculated by first analyzing the vertical displacement or $\mathrm{V}(\mathrm{mm})$ of the top sternal half and subtracting that by the vertical displacement of the lower sternal half. These vertical displacement values were analyzed for every frame throughout the entirety of the test in real-time.

Instead of picking one point on the top half and one point on the bottom half and tracking the vertical displacement of those points throughout the duration of the test, we took the average vertical displacement inside a defined area on both sides of the sternum. After capturing the images taken during the test, the digital texture correlation software has the capability of defining these areas in the form of rectangles, and extracting data pertaining to the vertical displacement within the defined area. The resulting .csv file with the 
extracted values contains the image-frame number and an associated vertical displacement value.

For Group A, consisting of sternum closed by pericostal wires, two rectangles were drawn to include the immediate area around the entire length of the incision line. One rectangle included the top half, and another incorporated the bottom half. The difference in the two values resulted in the total vertical displacement around the sternotomy line.

Group B was characterized by sternum closed by Biomet SternaLock plates. Because of the size and complex geometry of the titanium plates, the texture correlation software was unable to gather data on the plates or the immediate area surrounding them. Small rectangular areas were defined between each plate and on the ends for the top and bottom half of the sternum, totally four sections for each sternal half. Analysis of vertical displacement data extracted from these four rectangular areas resulted in relative vertical displacement values for each of the four sections. Each of these vertical displacements was graphed on a force vs. displacement graph.

\subsection{Statistical Analysis}

A total of 42 cadaveric models were tested, approximately 5 models per group for each direction of force applied on the construct, shown in table 1. Each biomechanical parameter (stiffness, yield load, and maximum load) were evaluated using an ANOVA model (Minitab, v15.2, State College, PA). Each of the biomechanical parameters was modeled as dependent variables, with fixation method, gender, and first order interaction 
Biomechanical Comparison of Wire Circlage and Rigid Plate Fixation for Median Sternotomy Closure in Human Cadaver Specimens

as factors. Age was used as a covariate. Tukey post-hoc testing was performed and strong statistical evidence was reported when $\mathrm{p}<0.05$. 
Table 5.1: Test Design for the overall study.

\begin{tabular}{|c|c|c|c|c|c|}
\hline \# & $\begin{array}{l}\text { Donor } \\
\text { Code }\end{array}$ & Group & Age & Sex & Test Method \\
\hline 1 & C080467 & B & 84 & $\mathrm{~F}$ & Lateral Distraction \\
\hline 2 & C080516 & A & 70 & $\mathrm{M}$ & Lateral Distraction \\
\hline 3 & S080889 & C & 61 & $\mathrm{M}$ & Lateral Distraction \\
\hline 4 & S080883 & C & 64 & $\mathrm{~F}$ & Lateral Distraction \\
\hline 5 & S080811 & $B$ & 65 & $F$ & Lateral Distraction \\
\hline 6 & C080621 & $B$ & 63 & $\mathrm{~F}$ & Lateral Distraction \\
\hline 7 & S080849 & A & 73 & $M$ & Lateral Distraction \\
\hline 8 & C080571 & $B$ & 59 & $M$ & Lateral Distraction \\
\hline 9 & S080874 & A & 73 & $\mathrm{~F}$ & Lateral Distraction \\
\hline 10 & S080963 & $\mathrm{B}$ & 65 & $M$ & Lateral Distraction \\
\hline 11 & C080547 & C & 64 & $\mathrm{~F}$ & Lateral Distraction \\
\hline 12 & S080826 & A & 82 & $M$ & Lateral Distraction \\
\hline 13 & C080684 & $\mathrm{B}$ & 59 & $\mathrm{~F}$ & Lateral Distraction \\
\hline 14 & S082064 & C & 68 & $\mathrm{M}$ & Lateral Distraction \\
\hline 15 & C080542 & $\mathrm{C}$ & 88 & $\mathrm{~F}$ & Lateral Distraction \\
\hline 16 & S080719 & A & 69 & $\mathrm{~F}$ & Longitudinal Shear \\
\hline 17 & S080900 & $B$ & 65 & $M$ & Longitudinal Shear \\
\hline 18 & C080189 & $B$ & 65 & $M$ & Longitudinal Shear \\
\hline 19 & S080782 & A & 81 & $\mathrm{~F}$ & Longitudinal Shear \\
\hline 20 & S080902 & A & 79 & $\mathrm{~F}$ & Longitudinal Shear \\
\hline 21 & S080882 & $\mathrm{B}$ & 82 & $\mathrm{~F}$ & Longitudinal Shear \\
\hline 22 & S080938 & C & 67 & $M$ & Longitudinal Shear \\
\hline 23 & S080879 & $\mathrm{C}$ & 70 & $\mathrm{~F}$ & Longitudinal Shear \\
\hline 24 & S081057 & C & 72 & $\mathrm{~F}$ & Longitudinal Shear \\
\hline 25 & C080709 & A & 70 & $\mathrm{~F}$ & Longitudinal Shear \\
\hline 26 & S080129 & $\mathrm{B}$ & 62 & $\mathrm{~F}$ & Longitudinal Shear \\
\hline 27 & S080988 & A & & $\mathrm{F}$ & Longitudinal Shear \\
\hline 28 & C080570 & $\mathrm{B}$ & 70 & $\mathrm{~F}$ & Longitudinal Shear \\
\hline 29 & S080535 & C & 81 & $\mathrm{M}$ & Longitudinal Shear \\
\hline 30 & S080923 & C & 84 & $M$ & Longitudinal Shear \\
\hline 31 & S080850 & A & 76 & $M$ & Transverse Shear \\
\hline 32 & S080450 & A & 65 & $\mathrm{~F}$ & Transverse Shear \\
\hline 33 & C080582 & $\mathrm{B}$ & 80 & $\mathrm{~F}$ & Transverse Shear \\
\hline 34 & C080526 & A & 82 & $\mathrm{M}$ & Transverse Shear \\
\hline 35 & S081013 & $\mathrm{B}$ & 68 & $M$ & Transverse Shear \\
\hline 36 & S081047 & C & 69 & $M$ & Transverse Shear \\
\hline 37 & S080029 & $\mathrm{B}$ & 50 & $\mathrm{~F}$ & Transverse Shear \\
\hline 38 & $\mathrm{C} 060260$ & $\mathrm{~B}$ & 77 & $\mathrm{~F}$ & Transverse Shear \\
\hline 39 & S081007 & A & 89 & $M$ & Transverse Shear \\
\hline 40 & S080950 & $\mathrm{A}$ & 79 & $\mathrm{~F}$ & Transverse Shear \\
\hline 41 & $\mathrm{C} 080345$ & $B$ & 85 & $\mathrm{~F}$ & Transverse Shear \\
\hline 42 & S060167 & C & 80 & $M$ & Transverse Shear \\
\hline
\end{tabular}




\section{Results}

Each of the desired biomechanical parameters will be evaluated separately for each of the methods. Each of the main factor plots will include an asterisk if the differences are significant. Interaction plots will be shown to elucidate trends, even if the interaction is not significant. In all of the models, age is not a significant factor. The average age of cadaveric samples was calculated to be 72 years with a standard deviation of $9.43 \%$ of all the specimen tested are male.

\subsection{Lateral Distraction}

Table 6.1: Description of the sample group tested in lateral distraction with values for each biomechanical property.

\begin{tabular}{|r|l|l|r|l|r|r|r|r|}
\hline \multicolumn{1}{|r|}{$\#$} & $\begin{array}{c}\text { Donor } \\
\text { Code }\end{array}$ & Group & Age & Sex & Stiffness & $\begin{array}{c}\text { Yield } \\
\text { Load }\end{array}$ & $\begin{array}{c}\text { Ultimate } \\
\text { Load }\end{array}$ & $\begin{array}{l}\text { Post-Yield } \\
\text { Disp }\end{array}$ \\
\hline 1 & C080516 & A & 70 & M & 927.801 & 378.401 & 838.020 & 0.412 \\
\hline 4 & 5080897 & A & 67 & M & 255.660 & 262.000 & 309.000 & 1.957 \\
\hline 7 & 5080849 & A & 73 & M & 612.116 & 493.012 & 691.694 & 0.868 \\
\hline 12 & S080826 & A & 82 & M & 453.284 & 333.094 & 435.287 & 0.741 \\
\hline 9 & S080874 & A & 73 & F & 532.608 & 207.072 & 606.784 & 1.341 \\
\hline 8 & C080571 & B & 59 & M & 1515.230 & 1020.005 & 1082.848 & 0.099 \\
\hline 10 & S080963 & B & 65 & M & 3671.435 & 638.667 & 736.665 & 0.099 \\
\hline 5 & S080811 & B & 65 & F & 3181.039 & 228.047 & 617.691 & 0.983 \\
\hline 6 & C080621 & B & 63 & F & 4609.300 & 526.070 & 612.825 & 0.005 \\
\hline 13 & C080684 & B & 59 & F & 2160.049 & 546.039 & 696.224 & 0.130 \\
\hline 2 & S080889 & C & 61 & M & 3062.800 & 730.000 & 816.000 & 0.000 \\
\hline 14 & 5082064 & C & 68 & M & 4840.485 & 550.737 & 633.297 & 0.008 \\
\hline 3 & S080883 & C & 64 & F & 680.077 & 168.393 & 436.462 & 1.200 \\
\hline 11 & C080547 & C & 64 & F & 650.084 & 492.760 & 656.454 & 0.247 \\
\hline 15 & C080542 & C & 88 & F & 7200.000 & 510.000 & 553.000 & 0.000 \\
\hline
\end{tabular}

Testing in lateral distraction, 5 samples were used from each sternal-closure technique.

The average age of this set of cadaveric sternum is 68 years, a total of 8 males and 7

females were tested. 4 males and 1 female closed with peristernal wires, 2 males and 3 
females closed with Sternalock using an "L" plate at the manubrium, and 2 males and 3 females closed with Sternalock using a box-plate to stabilize the manubrium. The use of only 1 female specimen closed with peristernal wires was identified as a potential statistical weakness of the model.

\subsubsection{Stiffness}

Table 6.2: Mean stiffness values for each sternal-closure technique tested in lateral distraction, separated by gender.

\begin{tabular}{|c|c|c|c|c|}
\hline \multicolumn{5}{|c|}{ Stiffness } \\
\hline \multirow{2}{*}{ Group } & \multicolumn{2}{|c|}{ Averages } & \multicolumn{2}{c|}{ Standard Dev } \\
\cline { 2 - 5 } & $\mathrm{M}$ & $\mathrm{F}$ & $\mathrm{M}$ & $\mathrm{F}$ \\
\hline A & 562.215 & 366.627 & 284.010 & 0.000 \\
\hline B & 2593.332 & 3316.796 & 1524.668 & 1230.256 \\
\hline C & 3951.642 & 2843.387 & 1257.013 & 3772.967 \\
\hline
\end{tabular}

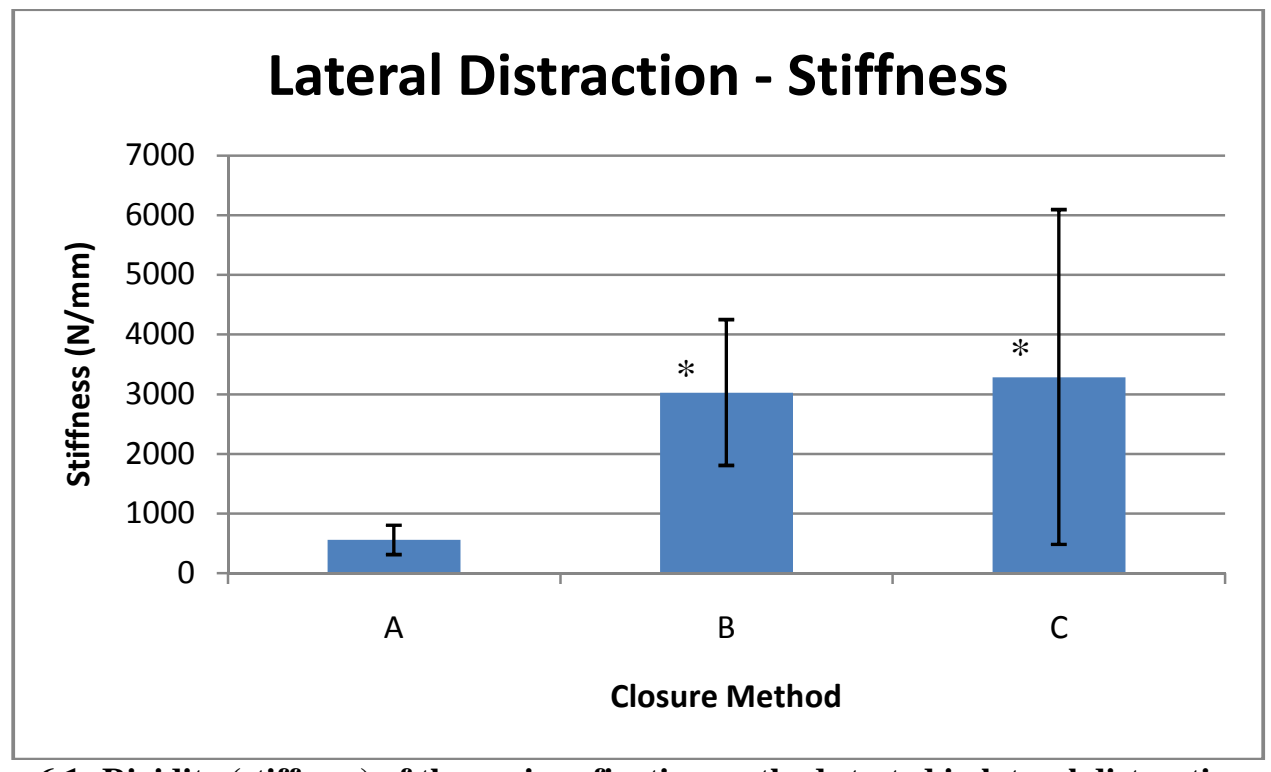

Figure 6.1: Rigidity (stiffness) of the various fixation methods tested in lateral distraction. Data denoted by an asterisk are significant $(p<0.05)$. Columns denote mean values. Stiffness is measured in newtons of force per millimeter displacement. Error bars indicate one standard deviation.

Closure methods B and C were both found to be statistically significant when compared to group $\mathrm{A}(\mathrm{p}=0.002$ and $\mathrm{p}=0.004$, respectively). Meaning that both plate configurations 
were significantly stiffer when compared to sterna closed by peristernal wires.

Sternalock systems using L-plates were found to have a $2471 \mathrm{~N} / \mathrm{mm}$ higher mean stiffness of over peristernal wires while plate systems using box-plates had $2730 \mathrm{~N} / \mathrm{mm}$ more than wires. Sternalock constructs were approximately six times stiffer than wire closures.

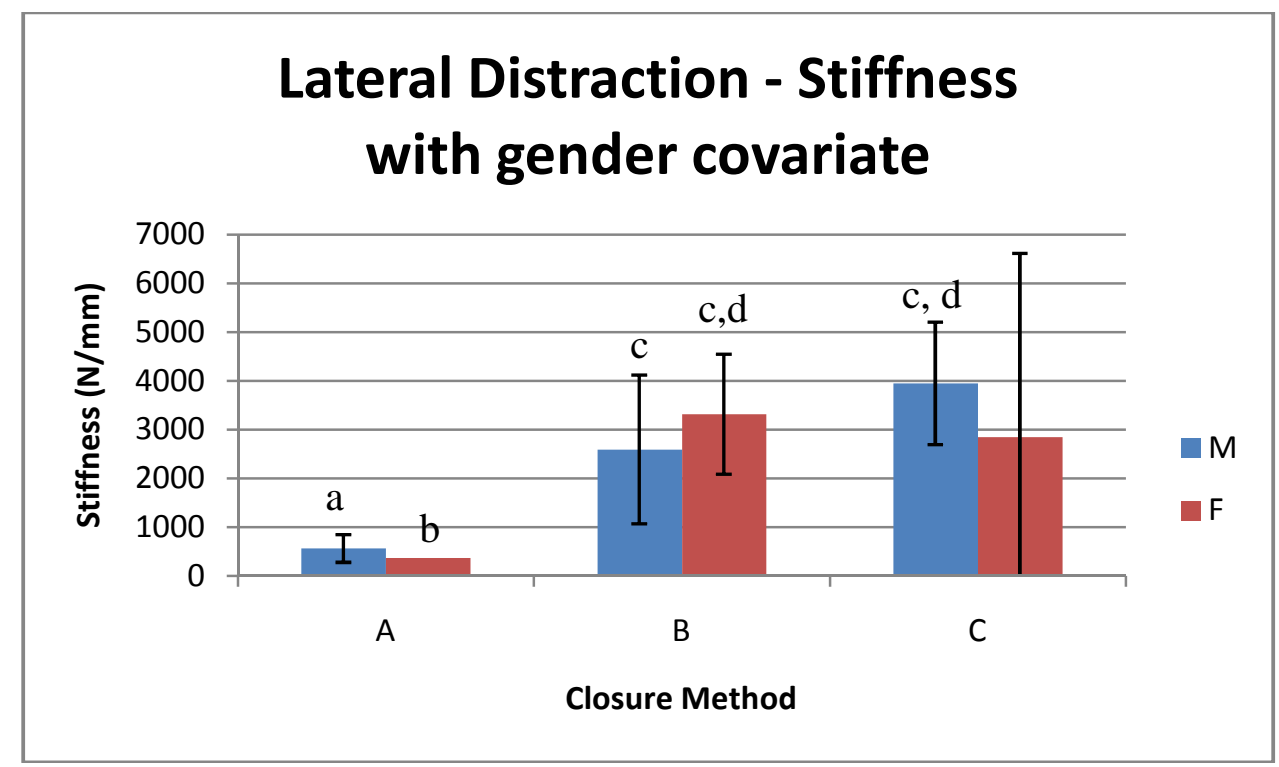

Figure 6.2: Rigidity (stiffness) of the various fixation methods tested in lateral distraction separated by gender. Columns denote mean values. Stiffness is measured in newtons of force per millimeter

displacement. Error bars indicate one standard deviation. Columns denoted with letter 'c' are statistically different $(p<0.05)$ than columns denoted with the letter ' $a$,' likewise ' $b$ ' is different than 'd.'

When analyzed further with gender considered as a covariate, it was found that males from group $\mathrm{B}(\mathrm{p}=0.03)$, females from group $\mathrm{B}(\mathrm{p}=0.008)$ and males from group $\mathrm{C}$ $(\mathrm{p}=0.009)$ were statistically different when compared to female group A sterna; females from group $\mathrm{C}$ were found to be almost significant ( $\mathrm{p}=0.12)$. When compared to male group A sterna, females from group $\mathrm{B}$, and males from group $\mathrm{C}$ were found to be significantly different ( $\mathrm{p}=0.04$ in both examples); males from group B were almost significant $(\mathrm{p}=0.11)$. No difference was found between any of the sternum closed with Sternalock devices when compared to each other. Females in group $\mathrm{C}$ had a very high 
amount of variability due to a combination of unusually high and low outliers. This explains the higher variability seen in all group $\mathrm{C}$ sternum in Figure 6.2.

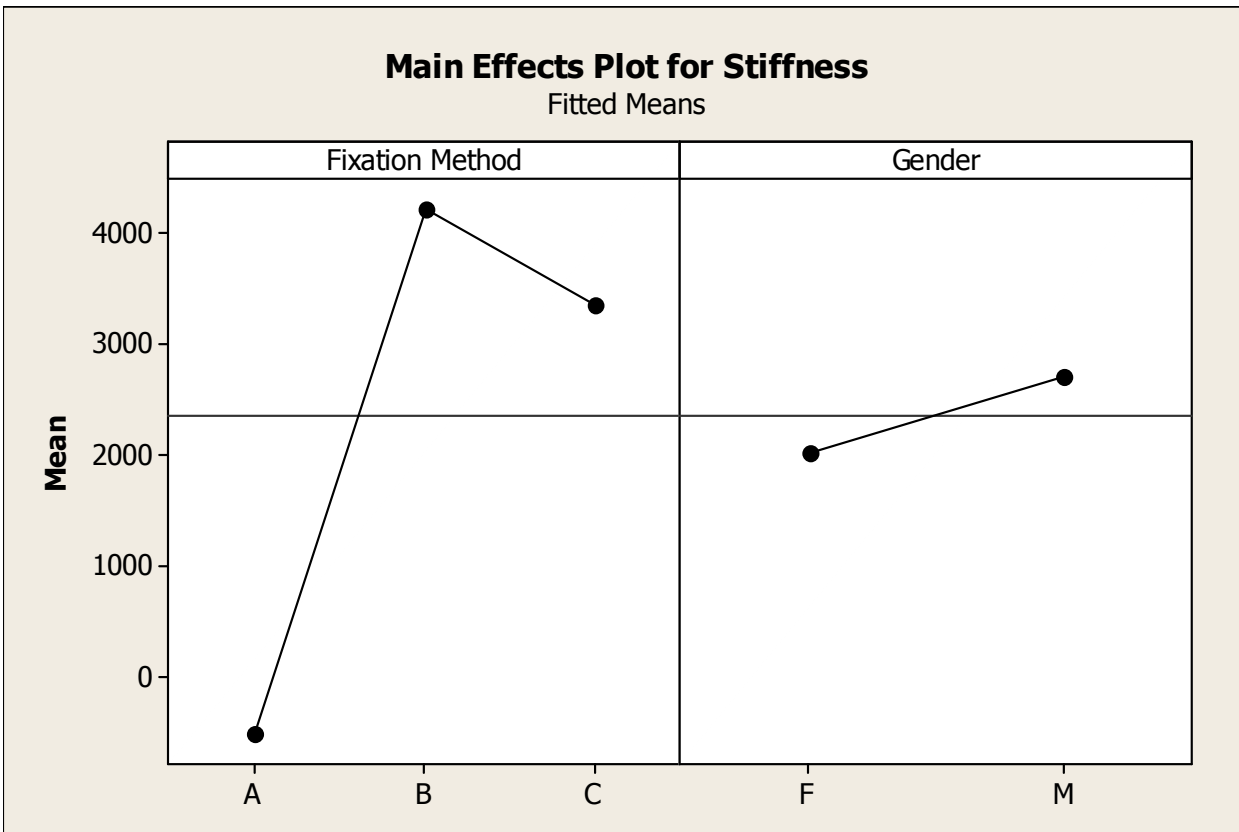

Figure 6.3: Side by side comparison plot of main effects with regards to construct stiffness tested in lateral distraction.

Figure 6.3 illustrates that though gender had an effect on the data, fixation method had bar far the most dramatic effect on stiffness. Both groups B and C sterna show dramatically higher values of stiffness. Gender exhibited a limited influence on the constructs stiffness. 


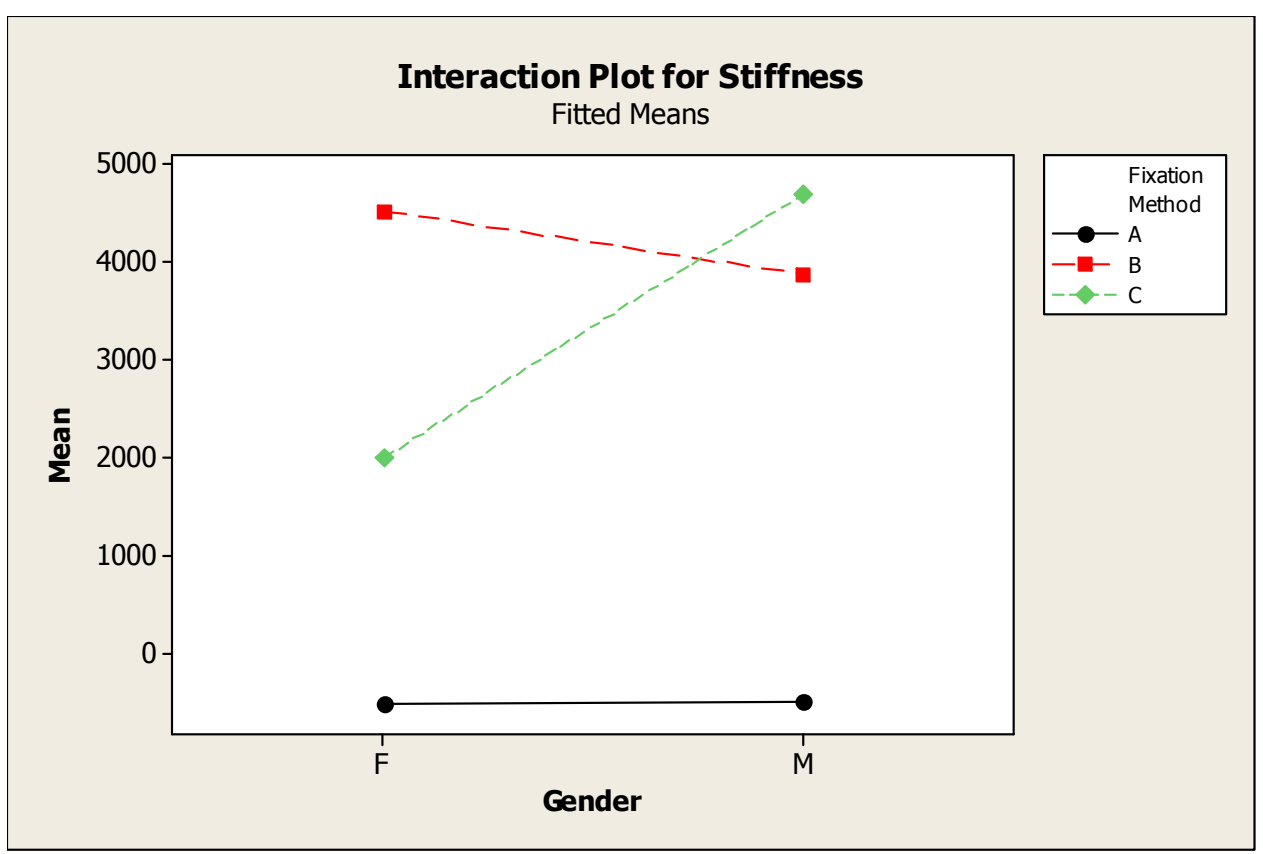

Figure 6.4: Interaction plot describing the effect of gender on each construct in regards to stiffness tested in lateral distraction.

Due to much smaller values, very little change in stiffness was observed (Figure 6.4)

when comparing group A sternum. A substantially higher stiffness in group C males versus females is found during this test and proves to be a trend among all biomechanical characteristics. In an unusual case, group B sternum showed a slight but statistically insignificant decrease in males versus females.

\subsubsection{Yield Load}

Table 6.3: Mean yield values for each sternal-closure technique tested in lateral distraction, separated by gender.

\begin{tabular}{|l|c|c|c|c|}
\hline \multicolumn{5}{|c|}{ Yield Load } \\
\hline \multirow{2}{*}{ Group } & \multicolumn{2}{|c|}{ Averages } & \multicolumn{2}{c|}{ Standard Dev } \\
\cline { 2 - 5 } & $\mathrm{M}$ & $\mathrm{F}$ & $\mathrm{M}$ & $\mathrm{F}$ \\
\hline A & 366.627 & 207.072 & 96.925 & 0.000 \\
\hline B & 829.336 & 433.385 & 269.646 & 178.108 \\
\hline C & 640.369 & 390.384 & 126.758 & 192.444 \\
\hline
\end{tabular}




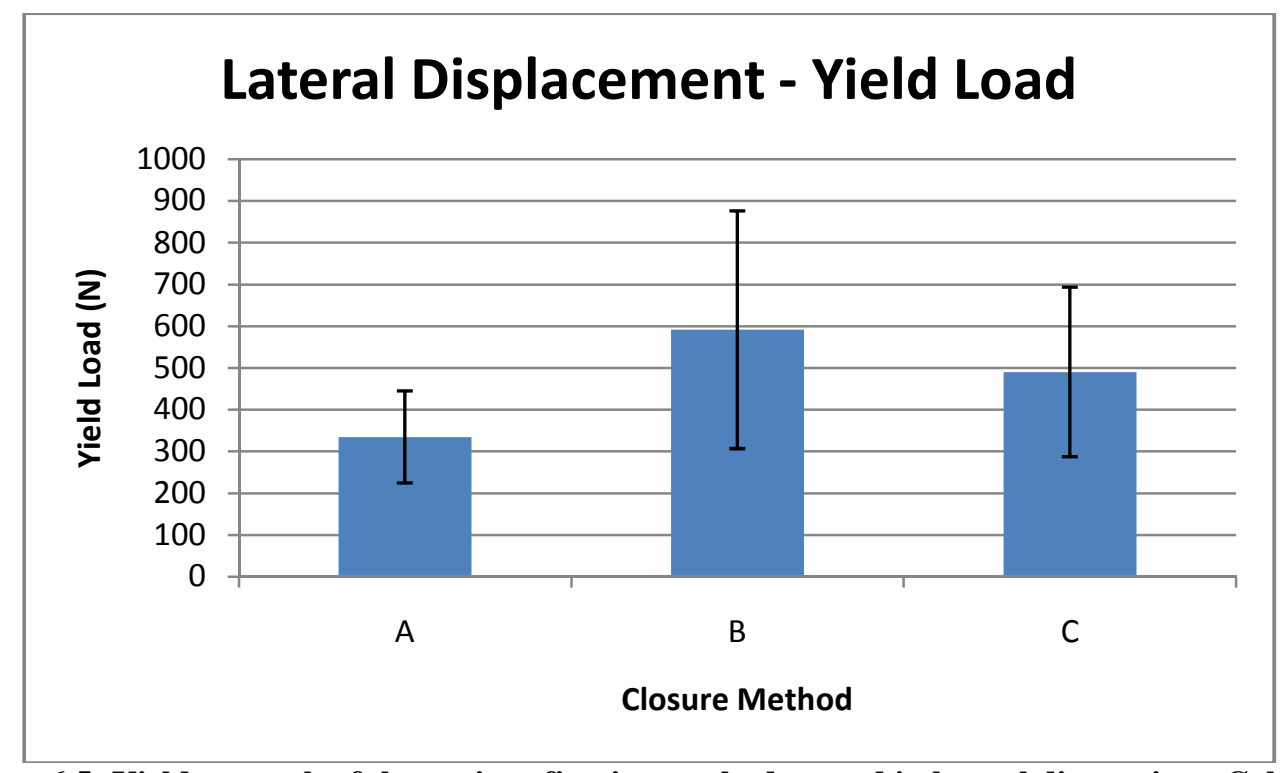

Figure 6.5: Yield strength of the various fixation methods tested in lateral distraction. Columns denote mean values. Yield strength is measured in newtons of force. Error bars indicate one standard deviation.

Closure methods B and C both consistently displayed higher yield loads than group A.

This trend did not prove to be statistically significant $(\mathrm{p}=0.10$ and $\mathrm{p}=0.24$, respectively) when compared with group A, but it showed a trend towards higher yield strengths for sternum closed with Sternalock devices. Group B showed $257 \mathrm{~N}$ higher mean yield strength when compared to group A specimen, group $\mathrm{C}$ was observed to have a higher mean of $156 \mathrm{~N}$. More indicative results may be revealed from testing larger sample sizes. 


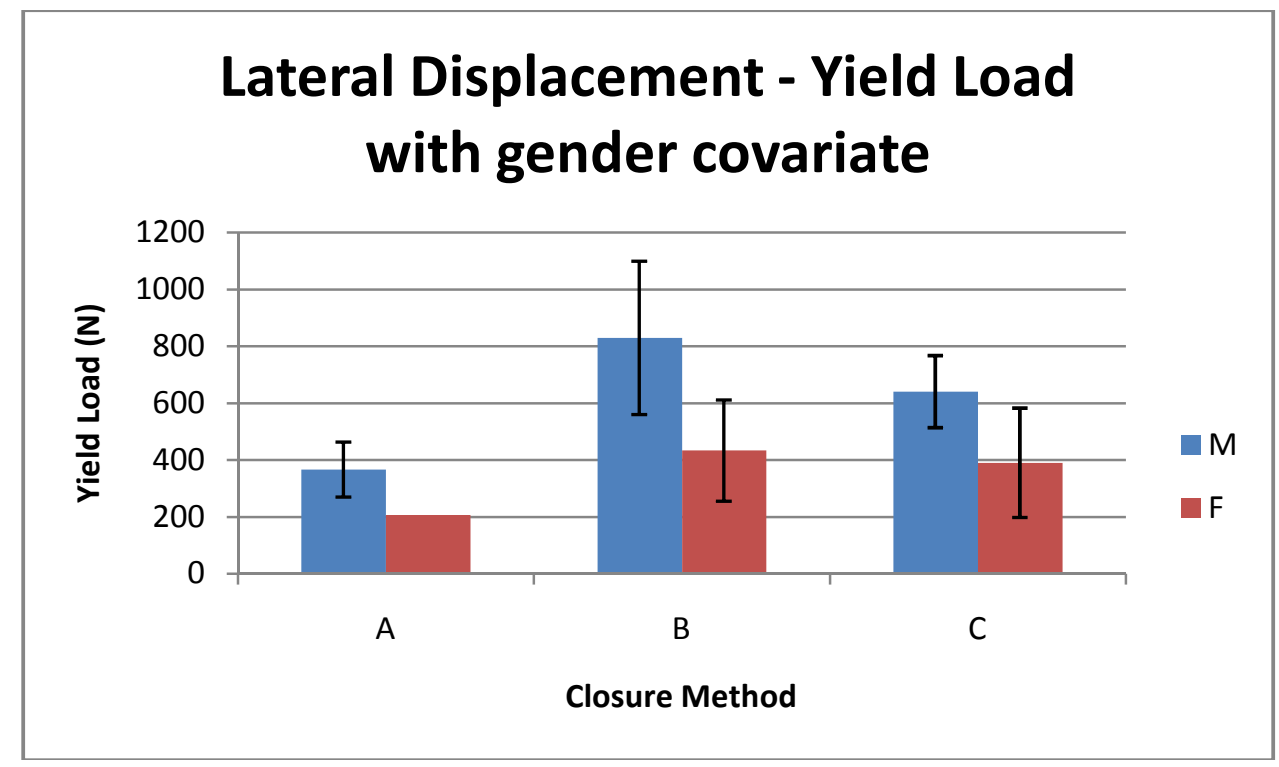

Figure 6.6: Yield strength of the various fixation methods tested in lateral distraction separated by gender. Columns denote mean values. Yield strength is measured in newtons of force. Error bars indicate one standard deviation.

No statistically significant differences were found between any closure methods. Group B males were found to be almost statistically different ( $\mathrm{p}=0.17$ in both cases) when compared to both males and females from group A. From this graph, we can begin to see a trend in the model that male specimen exhibited larger yield strengths than females. This may provide an underlying cause for lower yield strengths and a possible link between gender and yield strength. 


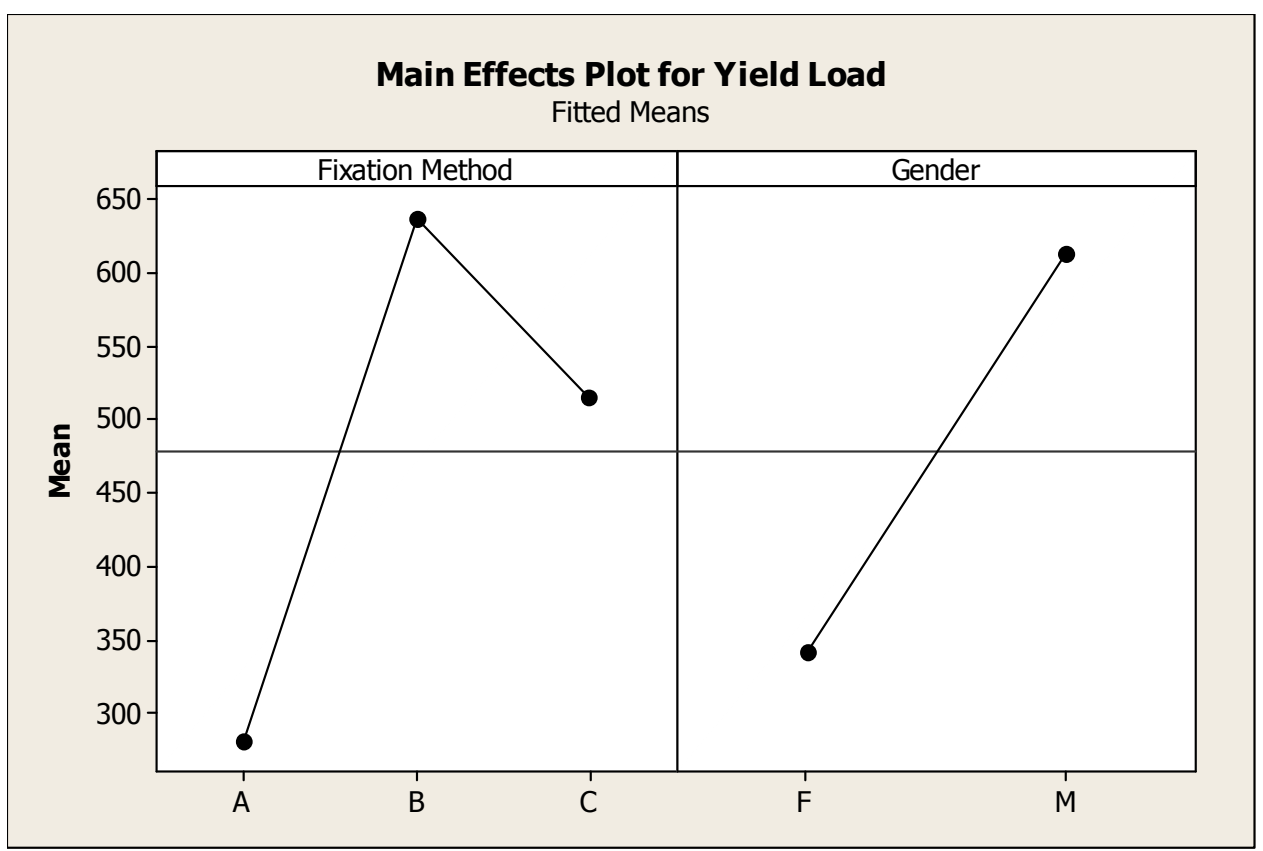

Figure 6.7: Side by side comparison plot of main effects with regards to yield strength tested in lateral distraction.

Figure 6.7 illustrates the effect of fixation method and gender on the mean stiffness of the sternal construct. Much like its effect on stiffness, fixation method contributes a primary influence on construct yield strength. Gender has a more pronounced effect on yield strength than it did on the stiffness of the model, showing higher strength values for males than females. Although not found to be statistically significant, the figure illustrates a possible trend in the data. 


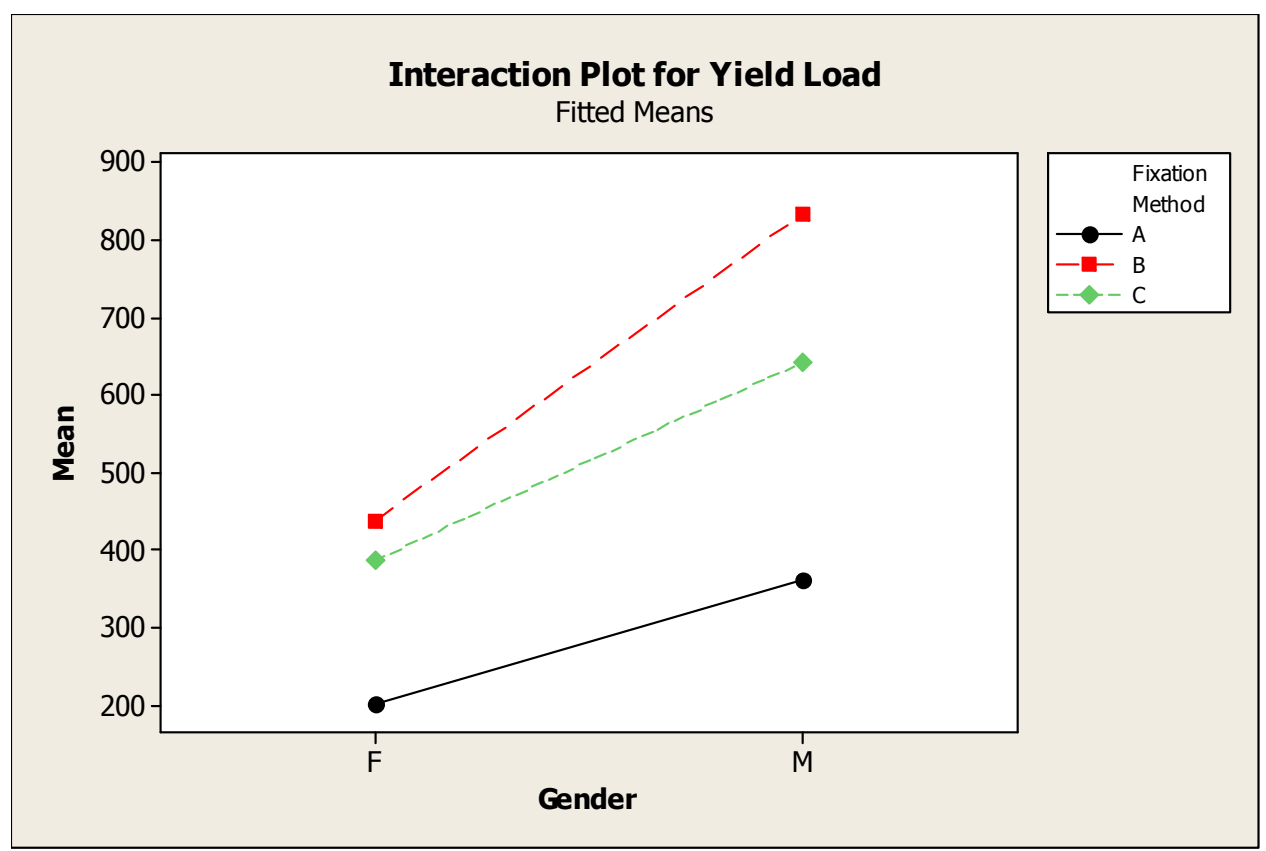

Figure 6.8: Interaction plot describing the effect of gender on each construct in regards to yield strength tested in lateral distraction.

Considerable effects of gender are found to influence yield strength of sternal constructs.

Figure 6.8 breaks down how gender affects each sternal closure technique. These affects are larger in sternum closed with Sternalock device than models closed with peristernal wires, similar to effects on stiffness (Figure 6.4). In all closure methods, closures of male cadavers exhibited a higher tolerance of load before plastically deforming.

\subsubsection{Maximum Load}

Table 6.4: Mean maximum-load values for each sternal-closure technique tested in lateral distraction, separated by gender.

\begin{tabular}{|c|c|c|c|r|}
\hline \multicolumn{5}{|c|}{ Ultimate Load } \\
\hline \multirow{2}{*}{ Group } & \multicolumn{2}{|c|}{ Averages } & \multicolumn{2}{c|}{ Standard Dev } \\
\cline { 2 - 5 } & $\mathrm{M}$ & $\mathrm{F}$ & $\mathrm{M}$ & $\mathrm{F}$ \\
\hline A & 568.500 & 606.784 & 240.072 & 0.000 \\
\hline B & 909.756 & 642.247 & 244.788 & 46.809 \\
\hline C & 724.649 & 548.639 & 129.190 & 110.061 \\
\hline
\end{tabular}




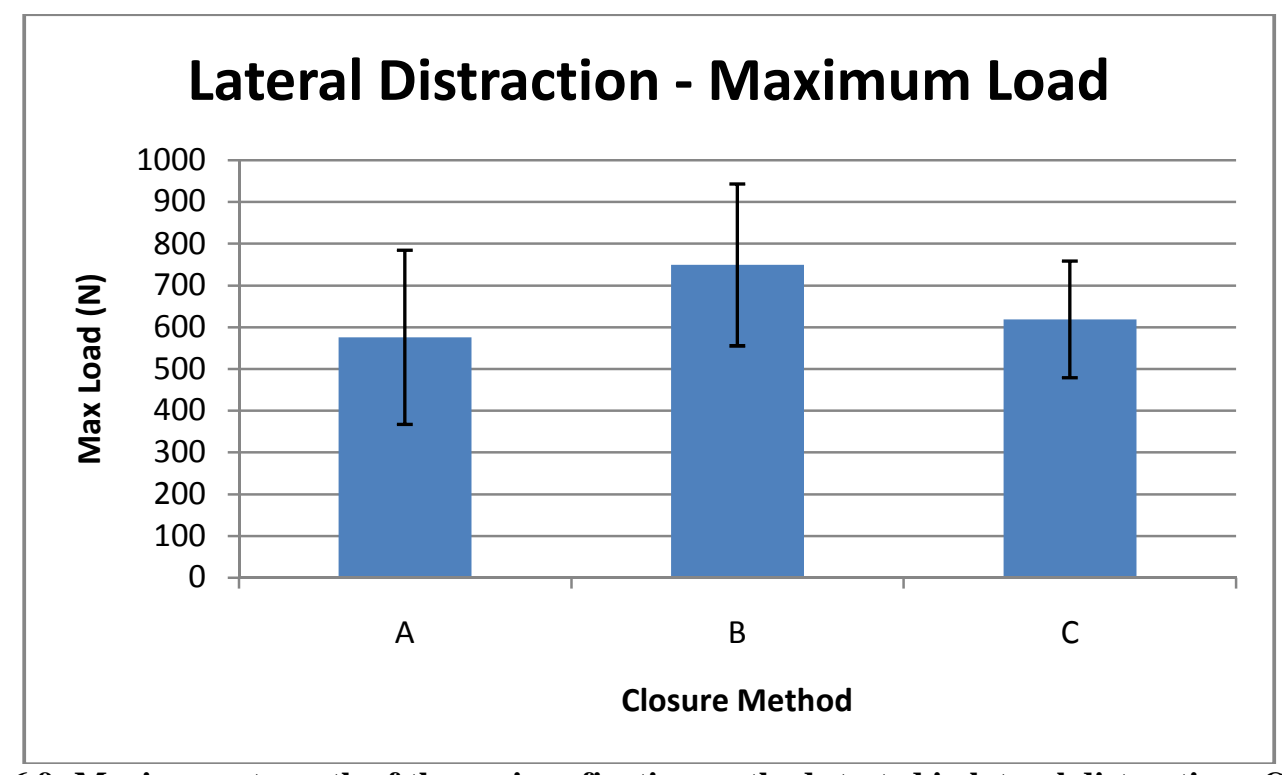

Figure 6.9: Maximum strength of the various fixation methods tested in lateral distraction. Columns denote mean values. Maximum strength is measured in newtons of force. Error bars indicate one standard deviation.

No differences were statistically found between the maximum strengths of the different closure methods tested. Very slight changes between the different test groups can be observed in Figure 6.9. Group $\mathrm{C}$ sterna had a mean maximum load only $43 \mathrm{~N}$ higher than group A while group B showed a mean $173 \mathrm{~N}$ higher. Although differences were found to be small and insignificant, this fits an overall model illustrating the advantages of Sternalock plates over conventional peristernal wire closures. 


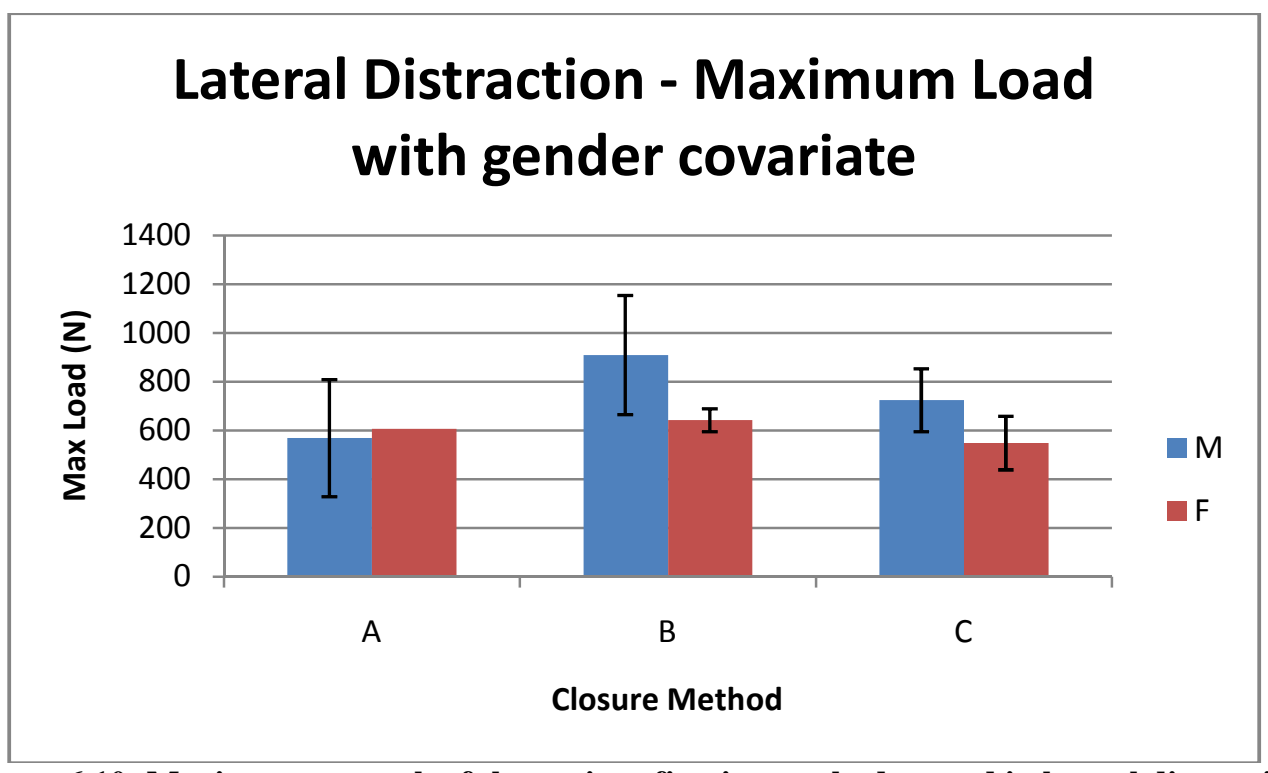

Figure 6.10: Maximum strength of the various fixation methods tested in lateral distraction separated by gender. Columns denote mean values. Maximum strength is measured in newtons of force. Error bars indicate one standard deviation.

Implementing gender as a covariate, the same insignificant result was found for maximum strength. There was virtually no difference found between male and female genders in group A samples, while it can be observed that female specimen in groups B and $\mathrm{C}$ catastrophically fail at lower loads. Given the slight differences in values, variability, and overall statistical power when comparing this biomechanical property, very little can be concluded from Figure 6.9 and Figure 6.10. 


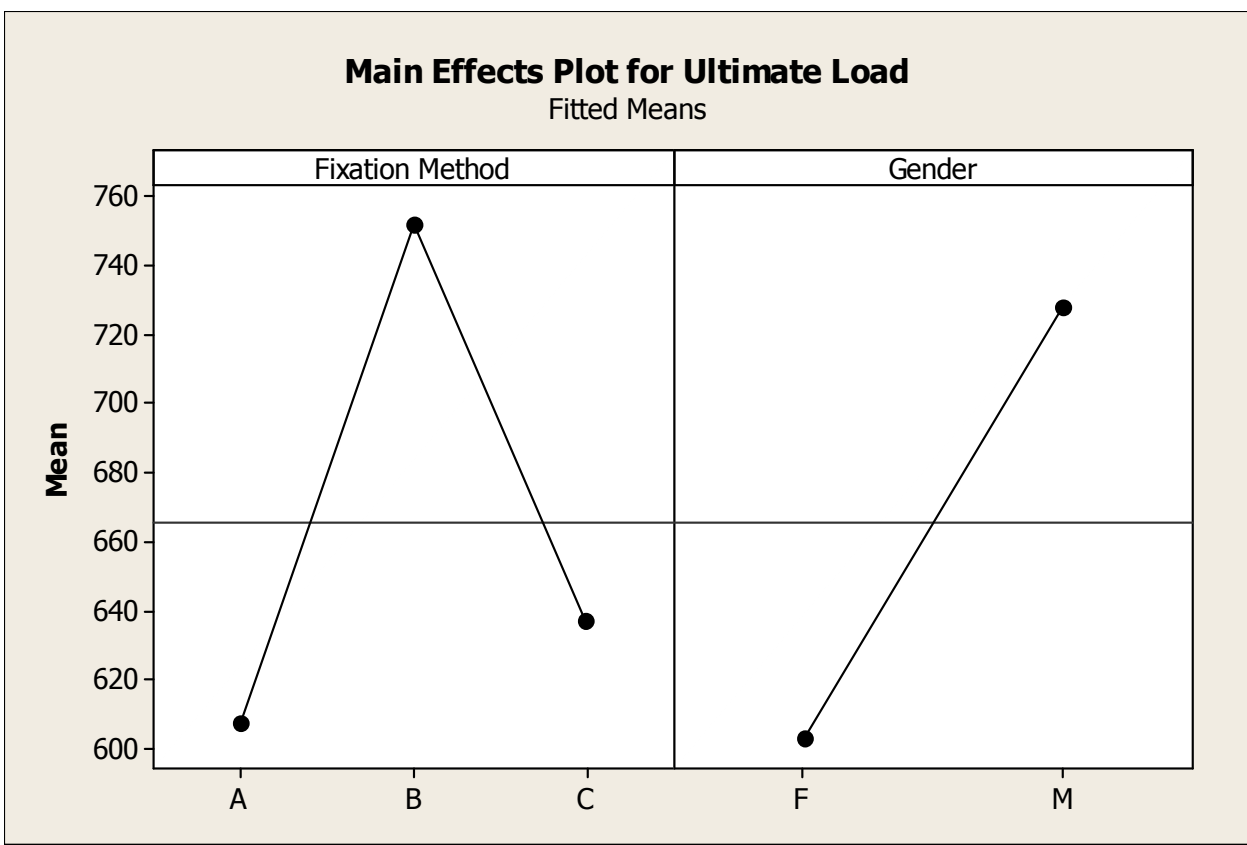

Figure 6.11: Side by side comparison plot of main effects with regards to maximum strength tested in lateral distraction.

Figure 6.11 shows that the overall effect of different fixation methods and genders on the mean ultimate load is similar. Although as large changes on the plot, the scaling is such that the actual range is only 160 newtons. This small difference when comparing larger numbers amplifies the changes seen in this model. Figure 6.11 shows the relative influence found in the two primary factors in biomechanical behavior - fixation method and gender. 


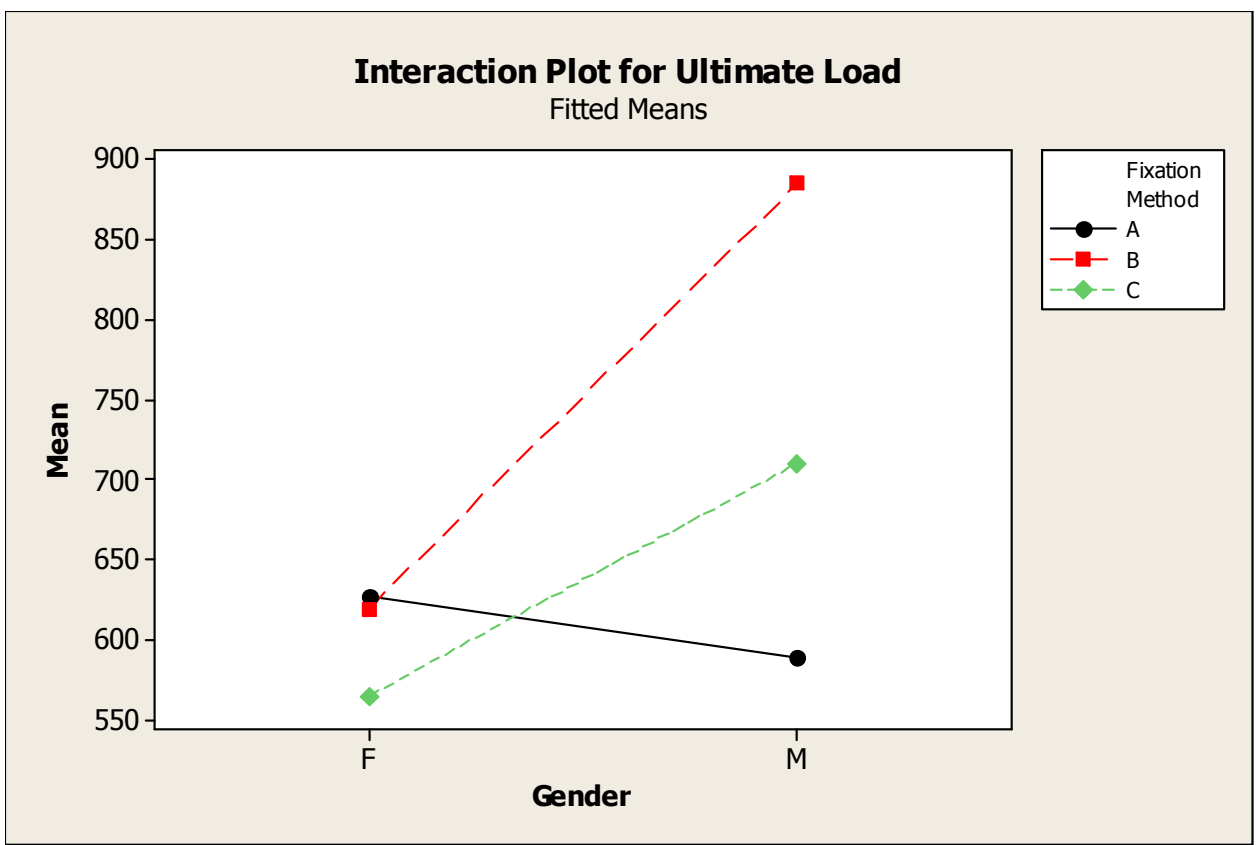

Figure 6.12: Interaction plot describing the effect of gender on each construct in regards to yield strength tested in lateral distraction.

Gender has little, if any, effect on group A specimen (Figure 6.12), a result shared with stiffness and yield strength in Figure 6.4 and Figure 6.8, respectively. The influence of gender on ultimate strength has a much larger consequence in sternum closed with Sternalock plates. Male specimens were found to withstand larger loads before catastrophically failing.

\subsubsection{Post-Yield Displacement}

Table 6.5: Mean post-yield values for each sternal-closure technique tested in lateral distraction, separated by gender.

\begin{tabular}{|l|c|c|c|c|}
\hline \multicolumn{4}{|c|}{ Post-Yield Displacement } \\
\hline \multirow{2}{*}{ Group } & \multicolumn{2}{|c|}{ Averages } & \multicolumn{2}{c|}{ Standard Dev } \\
\cline { 2 - 5 } & $\mathrm{M}$ & $\mathrm{F}$ & $\mathrm{M}$ & $\mathrm{F}$ \\
\hline $\mathrm{A}$ & 0.994 & 1.341 & 0.670 & 0.000 \\
\hline B & 0.099 & 0.373 & 0.000 & 0.532 \\
\hline C & 0.004 & 0.482 & 0.006 & 0.633 \\
\hline
\end{tabular}




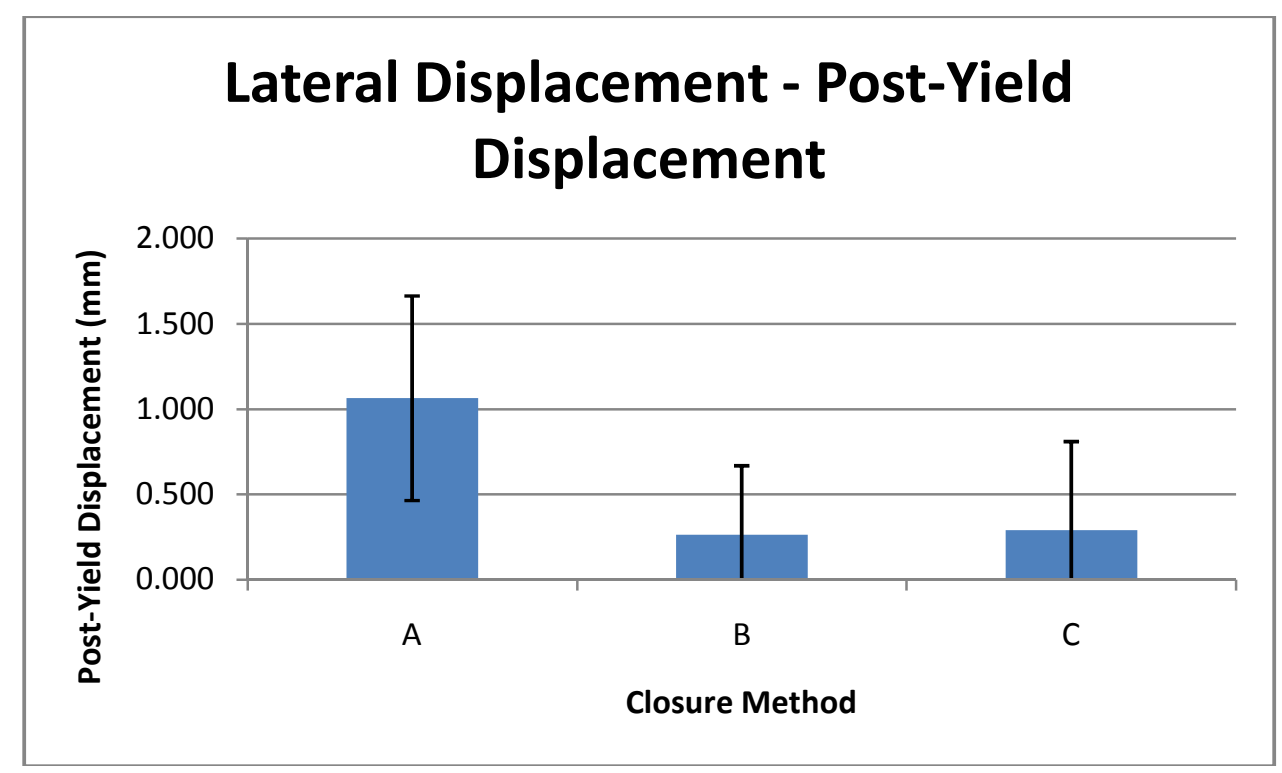

Figure 6.13: Post-yield behavior of the various fixation methods tested in lateral distraction.

Columns denote mean values. Post-yield displacement is measured in millimeters. Error bars indicate one standard deviation.

Peristernal wire-sternum constructs exhibited higher displacement after yielding (Figure 6.13). This translates to movement at the midline between point at which yield was met and catastrophic failure occurred. High post-yield displacement values are undesirable in a sternal construct because it is often symptomatic of physiologic damage occurring before complete failure takes place. Both Sternalock systems were found to be almost significantly different when compared to wire closures $(p=0.06$ for group $B$ and $p=0.07$ for group C). 


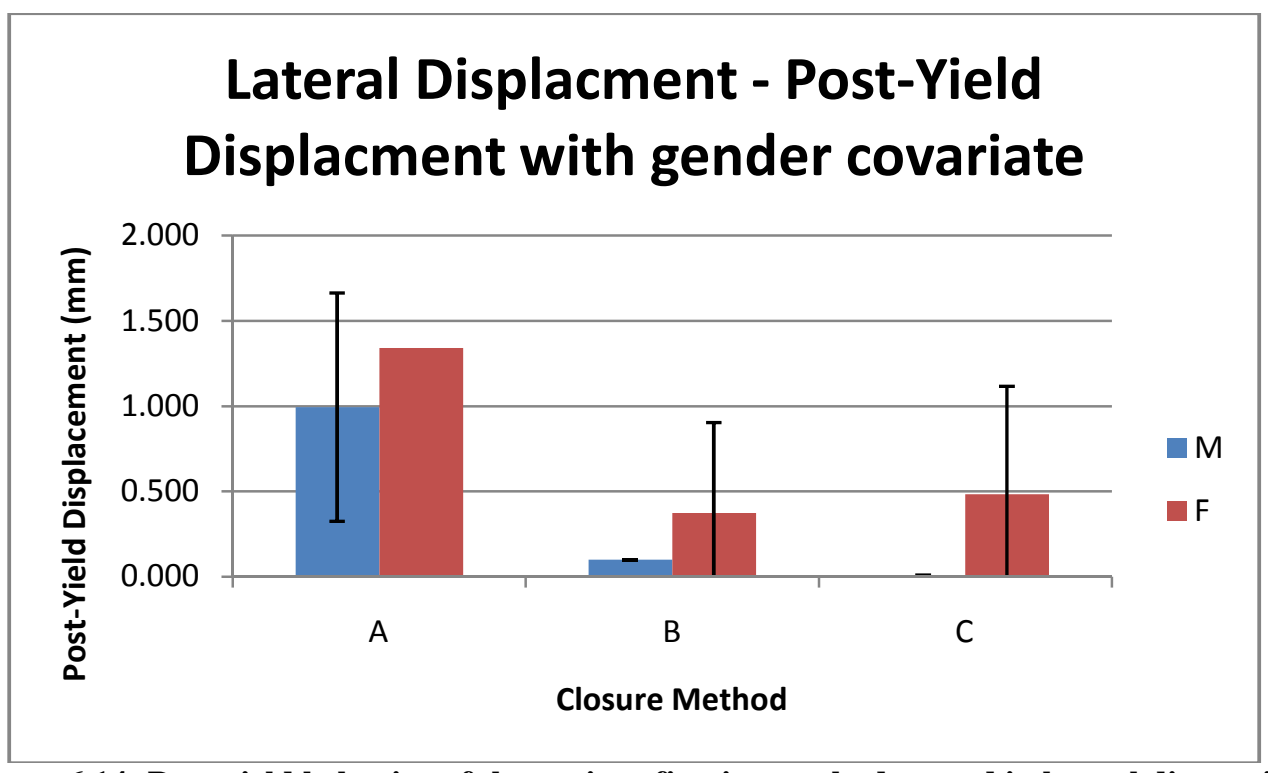

Figure 6.14: Post-yield behavior of the various fixation methods tested in lateral distraction separated by gender. Columns denote mean values Post-yield displacement is measured in millimeters. Error bars indicate one standard deviation.

No statistical evidence was found to support the differences seen due to small sample sizes associated with this study. Though hard to see in Figure 6.14, the 2 male group C specimen had a mean post-yield displacement of $0.002 \mathrm{~mm}$.

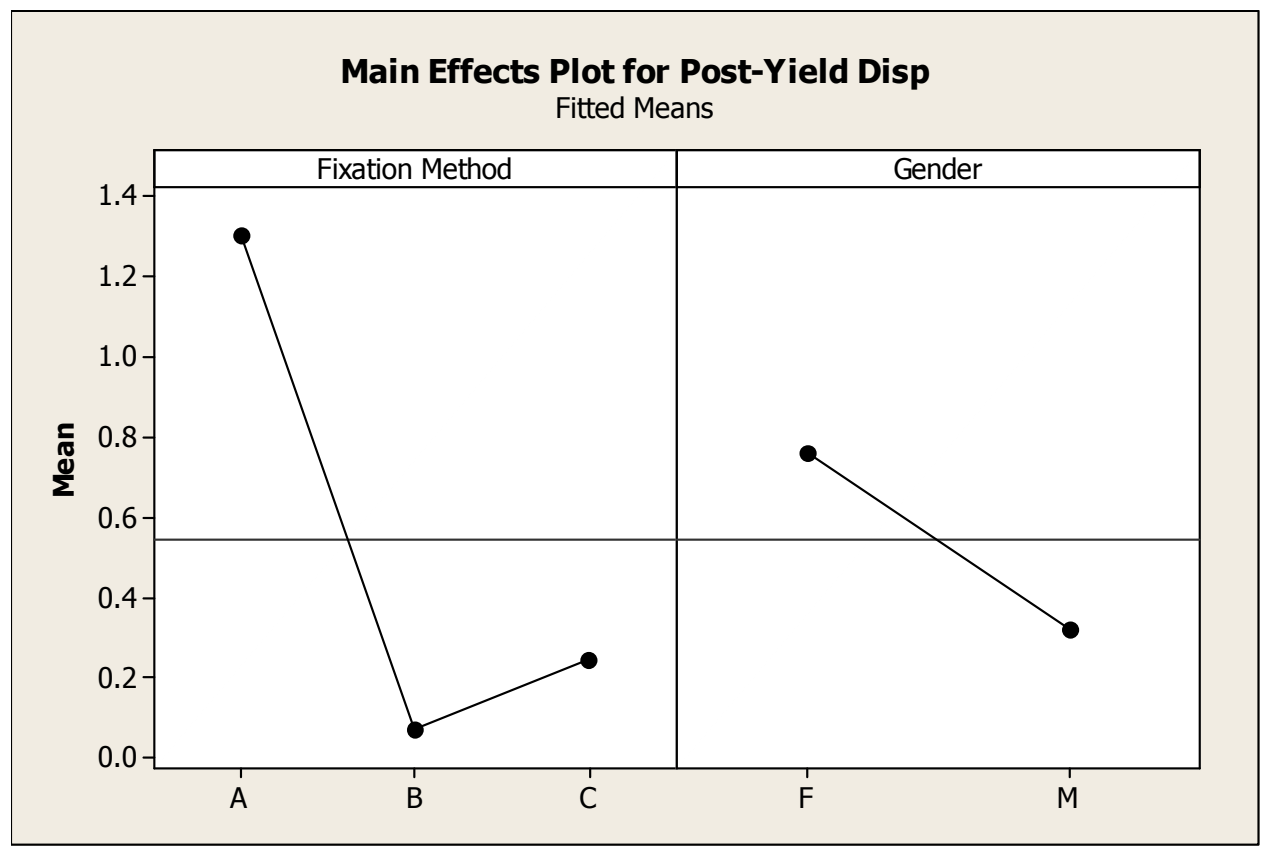

Figure 6.15: Side by side comparison plot of main effects with regards to post-yield displacement tested in lateral distraction. 
Illustrated by the comparison plot in Figure 6.15, fixation method has a dramatic effect on post-yield displacement. Figure 6.13 and Figure 6.14 show evidence for large but statistically insignificant support of Sternalock systems providing advantageous performance. Figure 6.15 also shows that gender has a smaller influence on post-yield displacement when compared to the device used for closure. Overall, male specimens were found to displace less after yielding and leading up to complete failure.

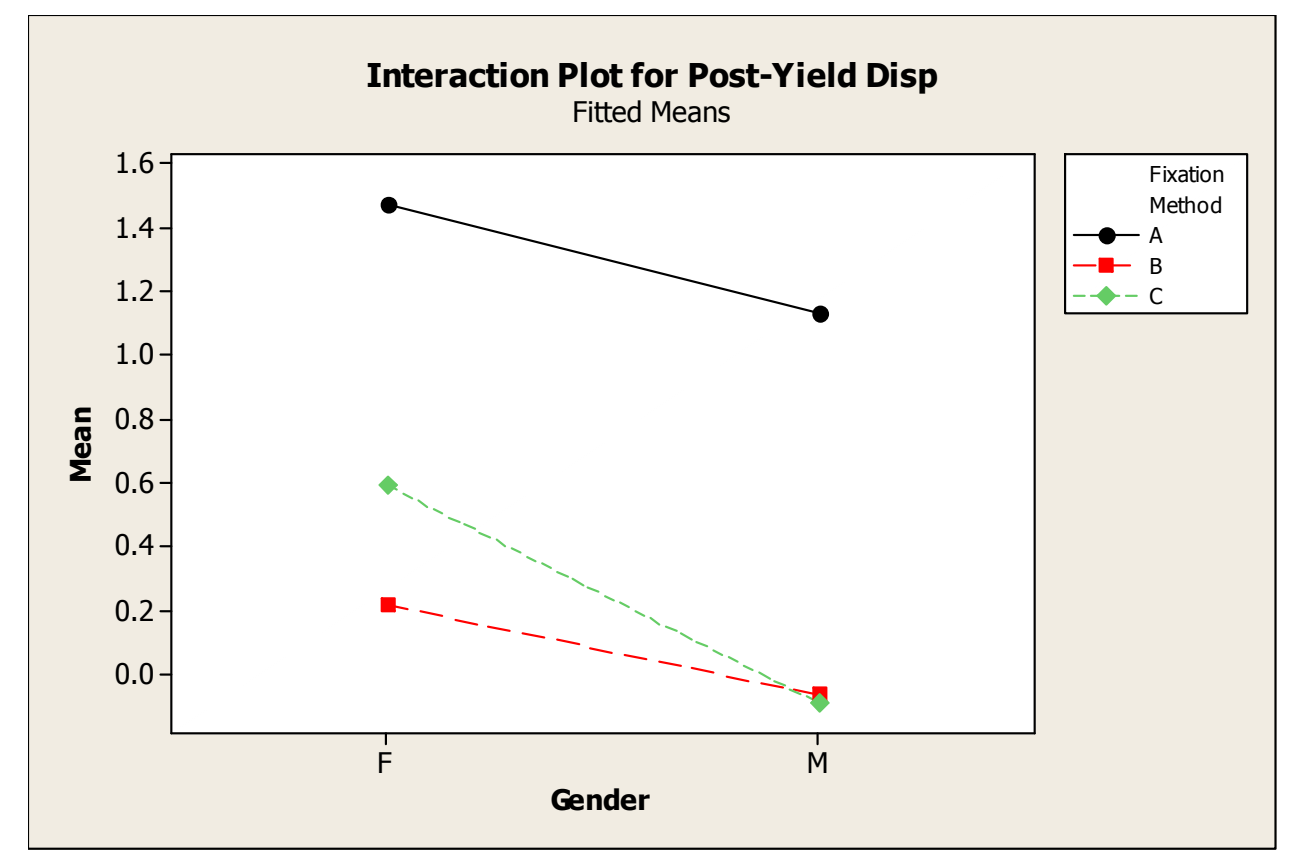

Figure 6.16: Interaction plot describing the effect of gender on each construct in regards to post-yield displacement tested in lateral distraction.

Evidence shown in Figure 6.16 displays the effect of gender on post-yield displacement for each fixation method. Males consistently had less post-yield displacement in every sternal closure technique. 


\subsection{Rostro-Caudal Shear}

Table 6.6: Description of the sample group tested in the longitudinal distraction with values for each biomechanical property.

\begin{tabular}{|l|l|l|r|l|r|r|r|r|}
\hline$\#$ & $\begin{array}{c}\text { Donor } \\
\text { Code }\end{array}$ & Group & Age & Sex & Stiffness & \multicolumn{1}{|l}{$\begin{array}{l}\text { Yield } \\
\text { Load }\end{array}$} & \multicolumn{1}{l}{$\begin{array}{l}\text { Ultimate } \\
\text { Load }\end{array}$} & $\begin{array}{l}\text { Post- } \\
\text { Yield } \\
\text { Disp }\end{array}$ \\
\hline 16 & S080719 & A & 69 & F & 129.790 & 85.581 & 328.731 & 328.155 \\
\hline 19 & S080782 & A & 81 & F & 50.726 & 126.022 & 356.586 & 355.338 \\
\hline 20 & S080902 & A & 79 & F & 161.004 & 83.399 & 216.301 & 215.923 \\
\hline 25 & C080709 & A & 70 & F & 48.732 & 194.486 & 497.878 & 495.103 \\
\hline 27 & S080988 & A & & F & 32.963 & 147.669 & 312.454 & 308.572 \\
\hline 17 & S080900 & B & 65 & M & 1184.349 & 178.041 & 373.031 & 372.879 \\
\hline 18 & C080189 & B & 65 & M & 1746.441 & 90.111 & 335.946 & 335.899 \\
\hline 21 & S080882 & B & 82 & F & 1740.698 & 60.578 & 216.637 & 216.600 \\
\hline 26 & S080129 & B & 62 & F & 2157.580 & 119.645 & 344.001 & 343.955 \\
\hline 28 & C080570 & B & 70 & F & 580.690 & 40.609 & 157.401 & 157.363 \\
\hline 22 & S080938 & C & 67 & M & 539.953 & 178.125 & 381.254 & 380.988 \\
\hline 29 & S080535 & C & 81 & M & 1946.021 & 348.448 & 745.895 & 745.588 \\
\hline 30 & S080923 & C & 84 & M & 776.952 & 133.237 & 285.269 & 284.901 \\
\hline 23 & S080879 & C & 70 & F & 687.114 & 171.581 & 379.576 & 379.372 \\
\hline 24 & S081057 & C & 72 & F & 248.068 & 127.700 & 171.833 & 171.372 \\
\hline
\end{tabular}

The average age of specimen tested in the rostro-caudal direction is 73 years, 5 males and 10 females were included in this group. A total of 15 specimen were used and separated into groups of 5 to represent each sternal-closure technique. 5 females closed with peristernal wires, 2 males and 3 females closed with Sternalock using an L-plate at the manubrium, and 3 males and 2 females closed with Sternalock using a box-plate to stabilize the manubrium. No male specimen were available to use in group A, this weakens the comprehensive outlook on the study. 


\subsubsection{Stiffness}

Table 6.7: Mean stiffness values for each sternal-closure technique tested in longitudinal shear, separated by gender.

\begin{tabular}{|c|c|r|c|c|}
\hline \multicolumn{5}{|c|}{ Stiffness } \\
\hline \multirow{2}{*}{ Group } & \multicolumn{2}{|c|}{ Averages } & \multicolumn{2}{c|}{ Standard Dev } \\
\cline { 2 - 5 } & $\mathrm{M}$ & \multicolumn{1}{c|}{$\mathrm{F}$} & $\mathrm{M}$ & $\mathrm{F}$ \\
\hline A & - & 84.643 & - & 56.965 \\
\hline B & 1465.395 & 1492.989 & 397.459 & 817.108 \\
\hline C & 1087.642 & 467.591 & 752.763 & 310.452 \\
\hline
\end{tabular}

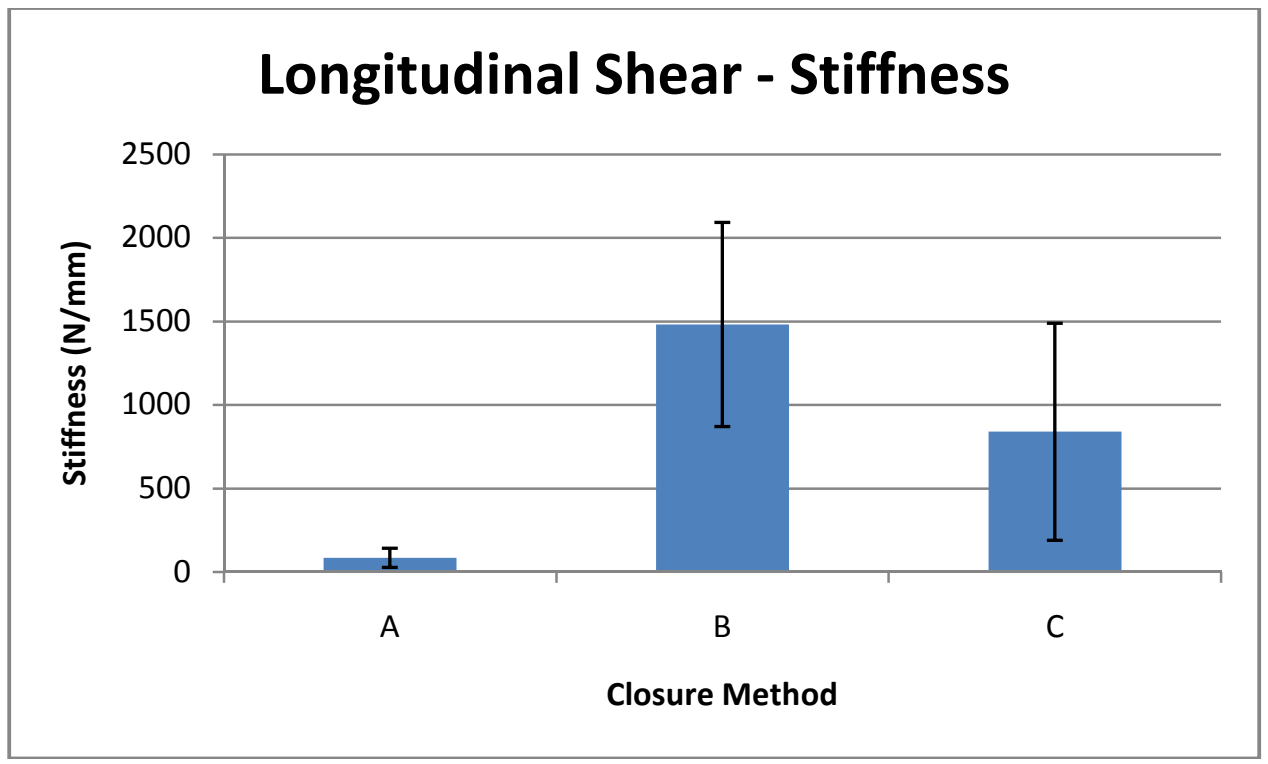

Figure 6.17: Rigidity (stiffness) of the various fixation methods tested in longitudinal shear. Columns denote mean values. Stiffness is measured in newtons of force per millimeter displacement. Error bars indicate one standard deviation.

As shown by Figure 6.17, both Sternalock configurations exhibited higher stiffness values. Though not statistically significant, these advantages in stiffness can be observed from this graph. Sternum closed with peristernal wires was tested to have a mean stiffness of $84 \mathrm{~N} / \mathrm{mm}$ with a standard deviation of $45 \mathrm{~N} / \mathrm{mm}$ in the longitudinal direction - virtually no resistance to displacement. Group B's test results show almost a 1400 $\mathrm{N} / \mathrm{mm}$ increase in stiffness when compared to peristernal wires, group $\mathrm{C}$ sterna showed a $755 \mathrm{~N} / \mathrm{mm}$ gain in rigidity when compared to wires. 


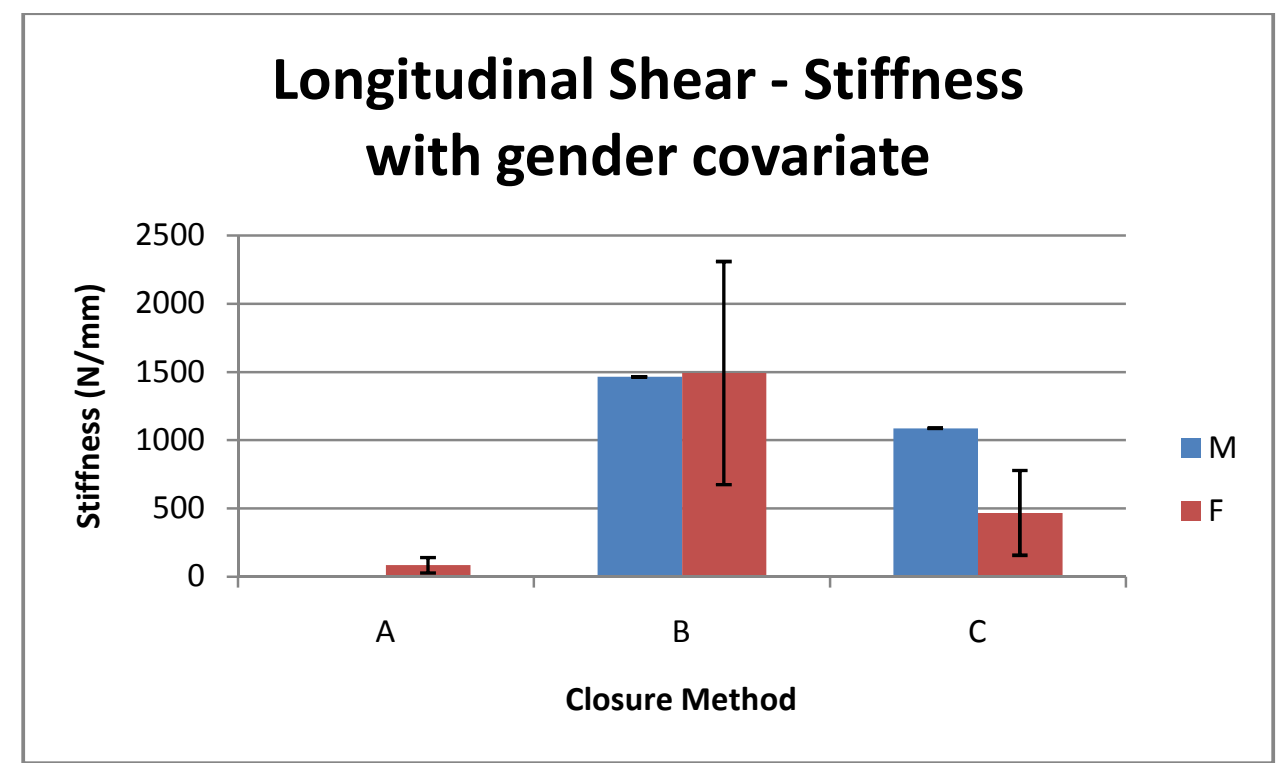

Figure 6.18: Rigidity (stiffness) of the various fixation methods tested in longitudinal shear separated by gender. Columns denote mean values. Stiffness is measured in newtons of force per millimeter displacement. Error bars indicate one standard deviation.

No males in group A were tested in this direction. In the test group that was tested in rostro-caudal shear, they were found to have a stiffness of $84 \mathrm{~N} / \mathrm{mm}$ (Figure 6.18). Group B females we found to be statistically different when compared to group A females. Group B specimen had very similar mean stiffness values when compared to each other, while female group $\mathrm{C}$ specimen had a mean stiffness much lower than males in that group. 


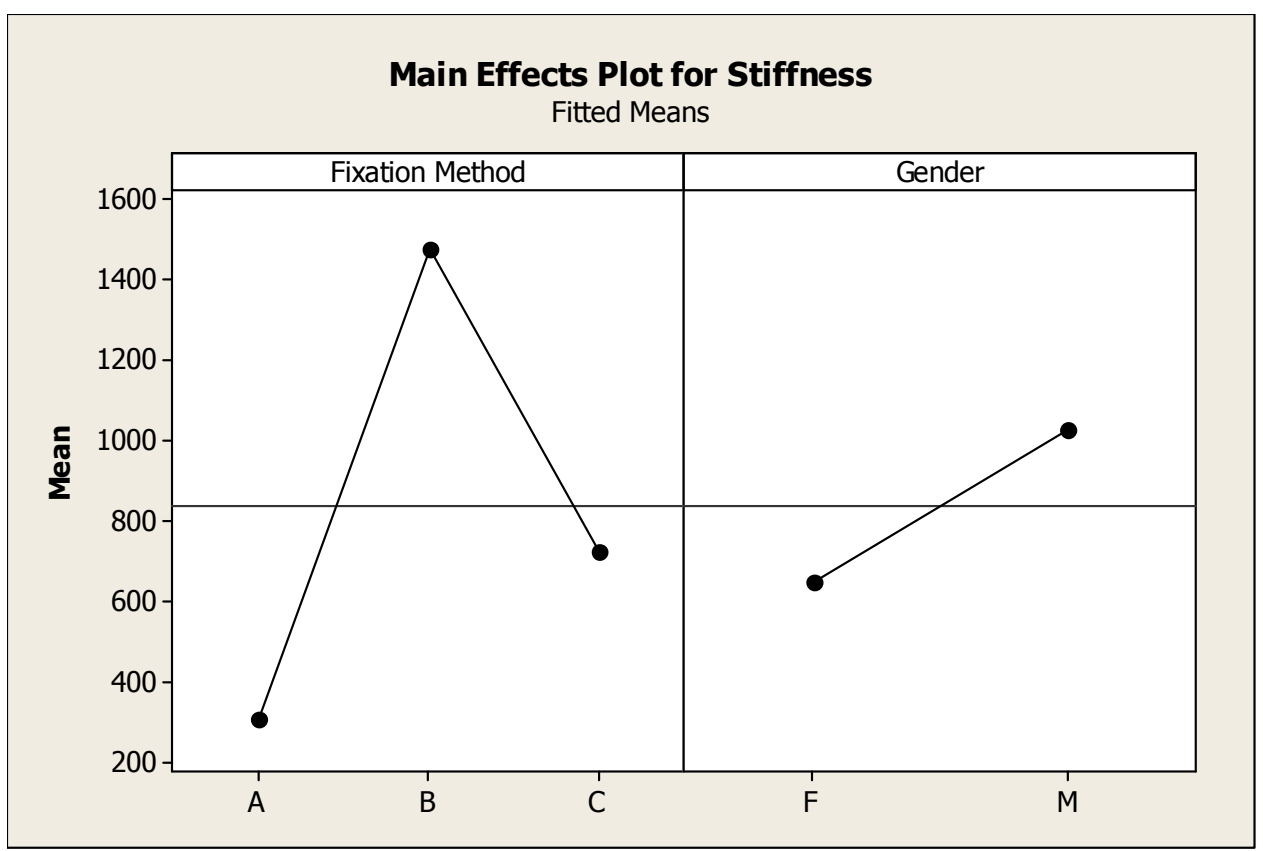

Figure 6.19: Side by side comparison plot of main effects with regards to stiffness tested in longitudinal shear.

Fixation method was found to be the primary effect on stiffness when looking at mean values (Figure 6.19). Group B had the largest mean stiffness out of the three closure techniques, $1481 \mathrm{~N} / \mathrm{mm}$. Group $\mathrm{C}$ was found to have a lower than expected stiffness value, $839 \mathrm{~N} / \mathrm{mm}$. Figure 6.18 cites the source of this low value from the 2 female specimens tested in this group. Group C sterna tested still had over a $750 \mathrm{~N} / \mathrm{mm}$ gain in stiffness over sterna closed with wires. Gender also had an influence, with males testing $655 \mathrm{~N} / \mathrm{mm}$ stiffer than female counterparts. 


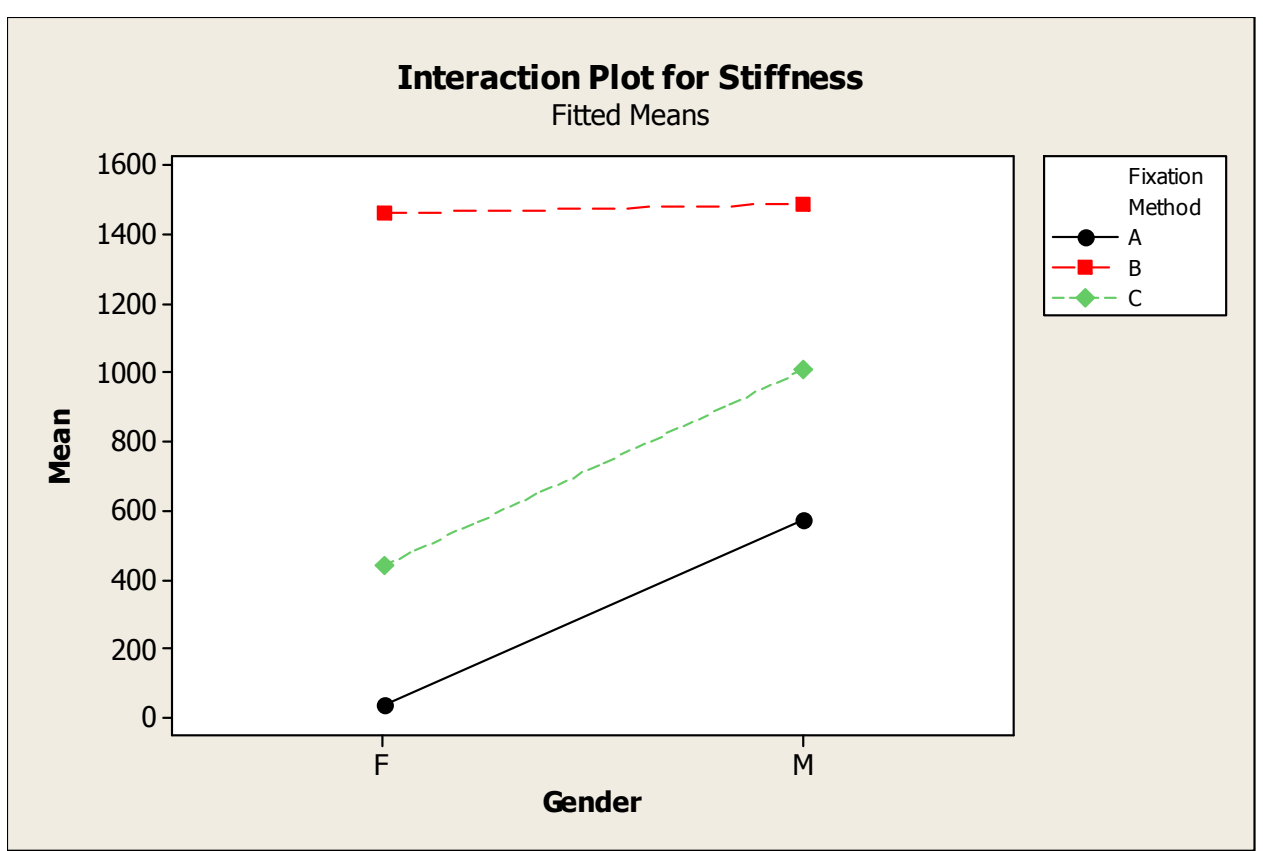

Figure 6.20: Interaction plot describing the effect of gender on each construct in regards stiffness tested in longitudinal shear.

I $n$ all examples, male specimen were found to exhibit higher stiffness values than female (Figure 6.20). Similar to findings illustrated by Figure 6.18, gender had a minimal effect on mean stiffness in group B. The interaction plot for gender in group A should be disregarded as no male specimen was tested in this direction. A difference of over 600 $\mathrm{N} / \mathrm{mm}$ was recorded in the mean stiffness of subjects closed with Sternalock using boxplates.

\subsubsection{Yield Load}

Table 6.8: Mean yield values for each sternal-closure technique tested in longitudinal shear, separated by gender.

\begin{tabular}{|l|c|c|c|c|}
\hline \multicolumn{5}{|c|}{ Yield Load } \\
\hline \multirow{2}{*}{ Group } & \multicolumn{2}{|c|}{ Averages } & \multicolumn{2}{c|}{ Standard Dev } \\
\cline { 2 - 5 } & $\mathrm{M}$ & $\mathrm{F}$ & $\mathrm{M}$ & $\mathrm{F}$ \\
\hline $\mathrm{A}$ & - & 127.431 & - & 46.363 \\
\hline B & 134.076 & 73.611 & 62.176 & 41.098 \\
\hline C & 219.937 & 149.640 & 113.534 & 31.029 \\
\hline
\end{tabular}




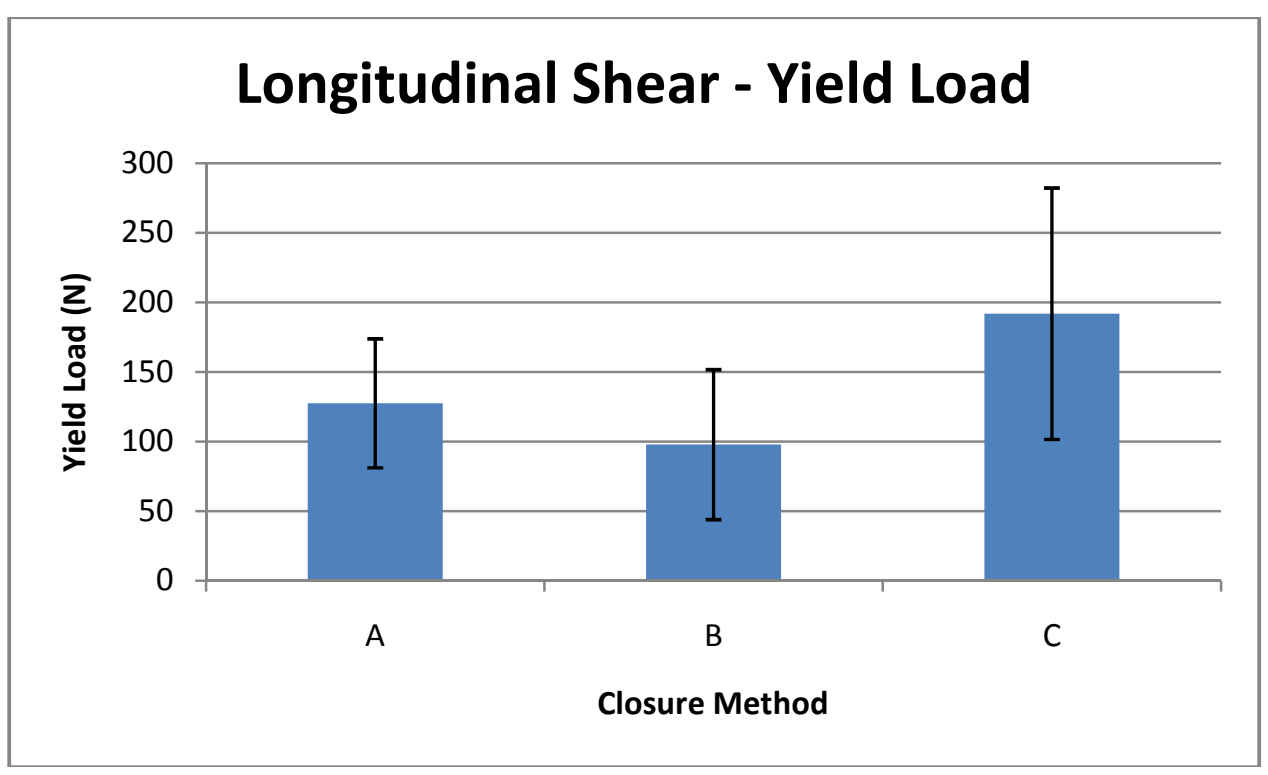

Figure 6.21: Yield strength of the various fixation methods tested in longitudinal shear. Columns denote mean values. Yield strength is measured in newtons of force. Error bars indicate one standard deviation.

Figure 6.21 reveals very little differences of mean yield strength values between the three fixation methods. The range of mean yield strength is only $94 \mathrm{~N}$, the range of all the individual specimen is approximately 300 N. No statistically significance was found.

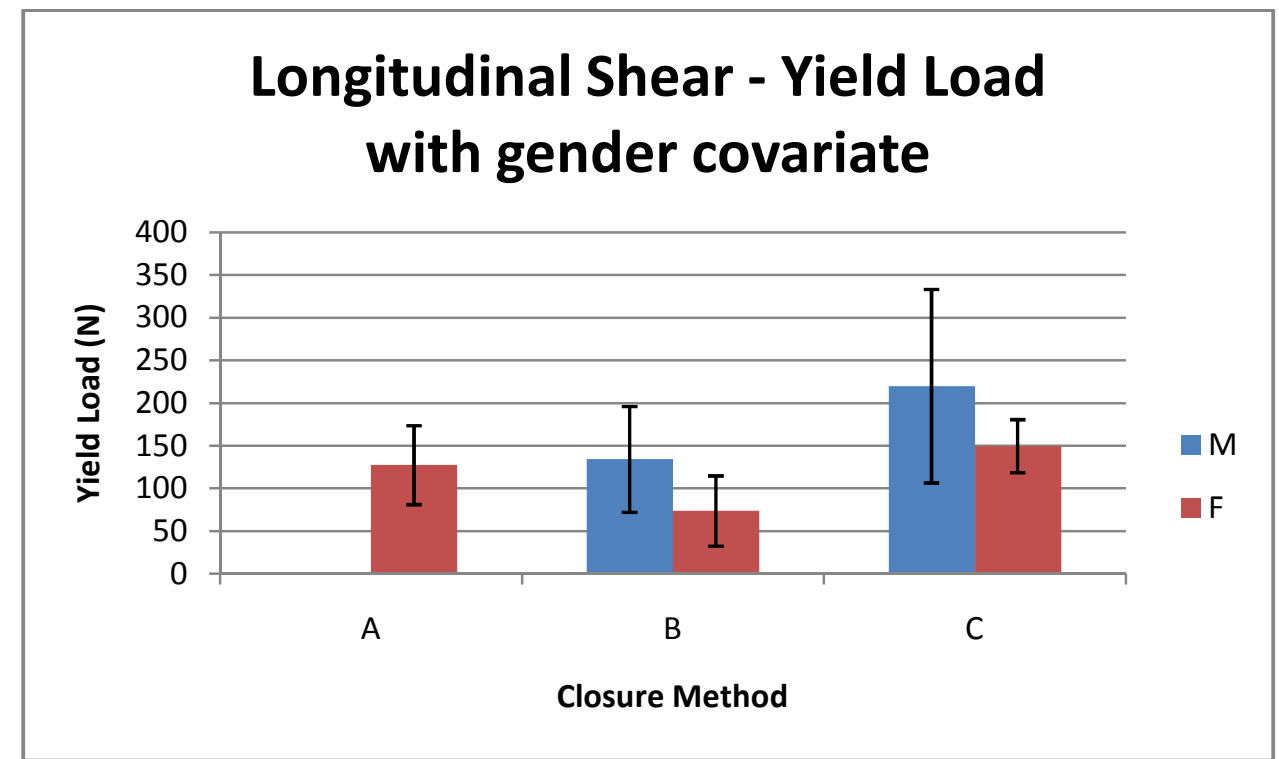

Figure 6.22: Yield strength of the various fixation methods tested in longitudinal shear separated by gender. Columns denote mean values. Yield strength is measured in newtons of force. Error bars indicate one standard deviation. 
No male specimen was tested in group A (Figure 6.22). Testing of female specimen resulted in lower mean yield strength when compared to similar male specimen for groups B and C. Analogous to results found without consideration of gender, no statistical significance was found when comparing this biomechanical property.

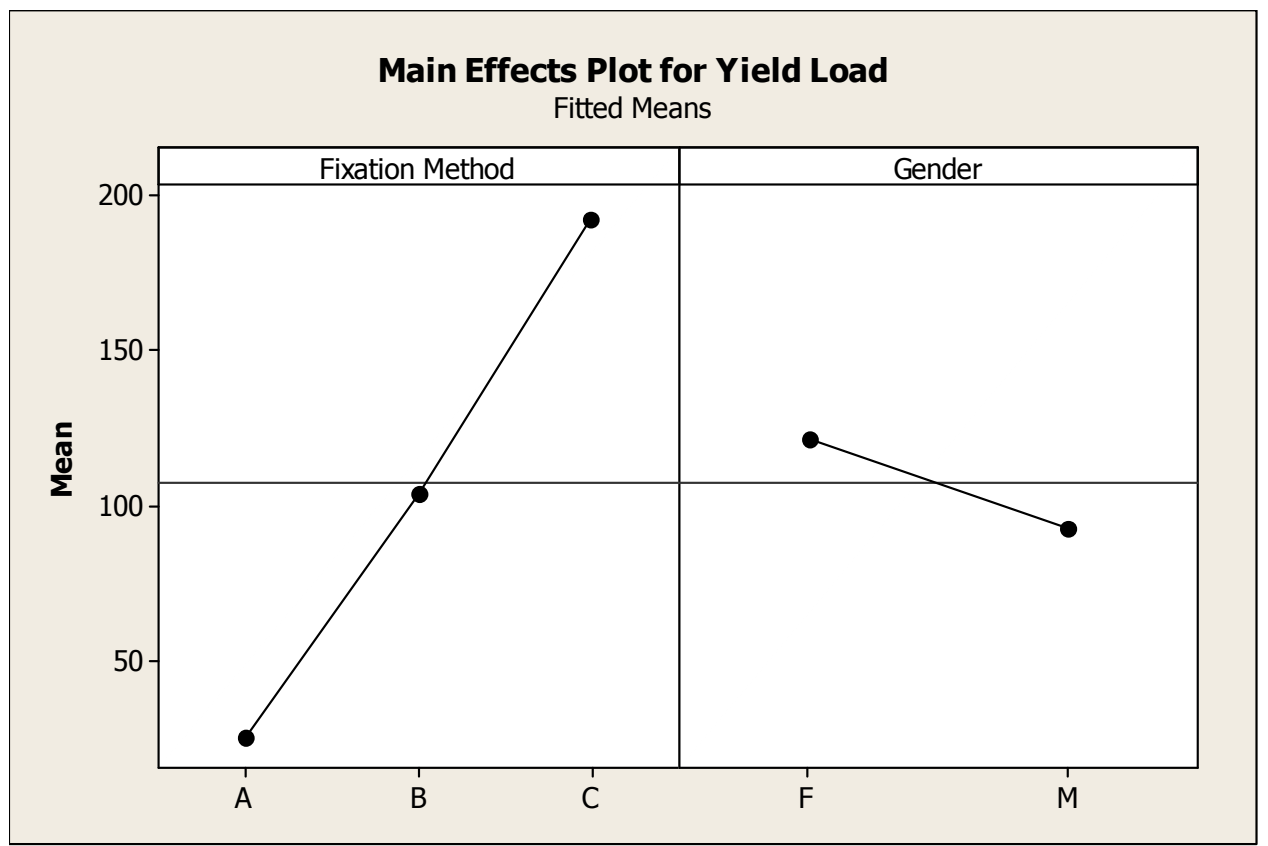

Figure 6.23: Side by side comparison plot of main effects with regards to yield strength tested in longitudinal shear.

Primary effect on mean yield strength was found to be a dependence on the fixation method applied to the sternal construct. Gender was not found to have an influential effect on the amount of load the construct can withstand before yielding (Figure 6.23). 


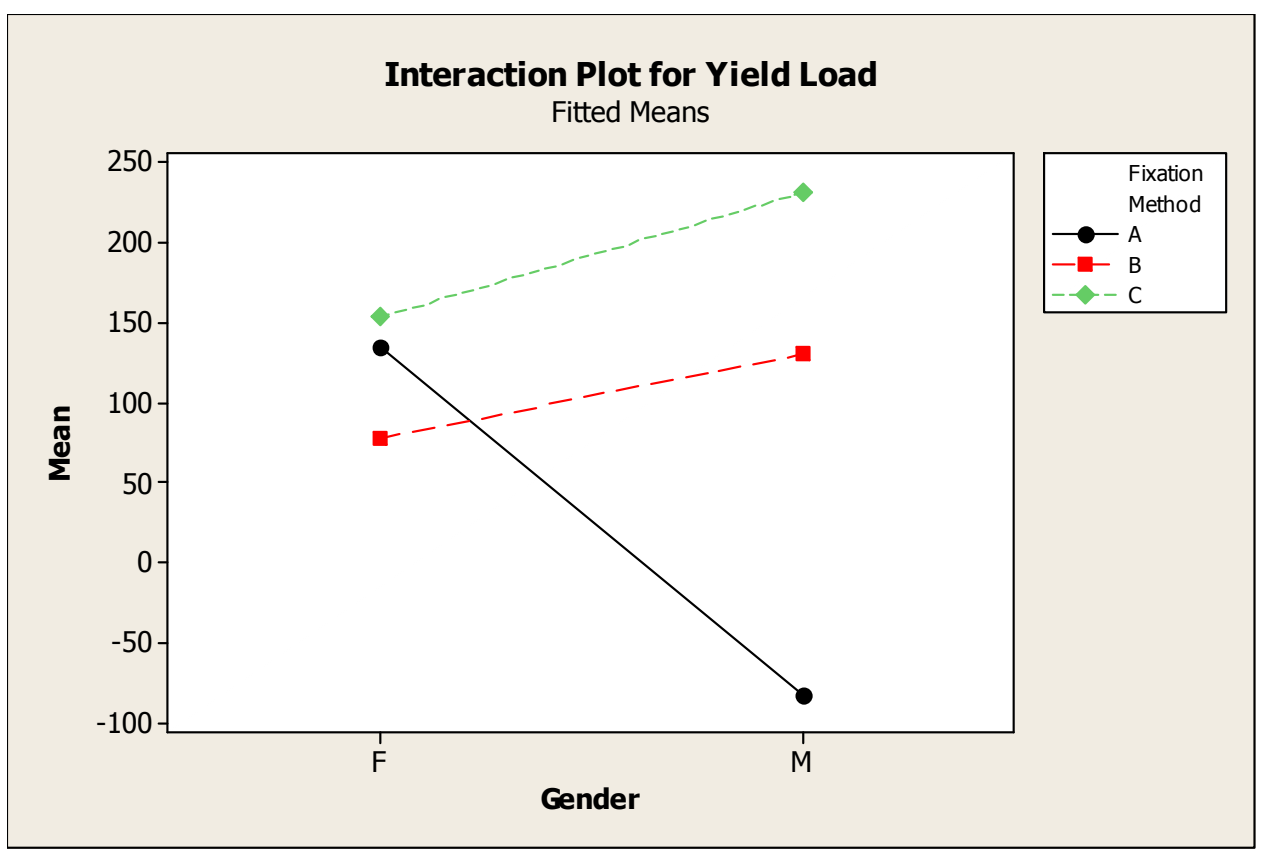

Figure 6.24: Interaction plot describing the effect of gender on each construct in regards yield strength tested in longitudinal shear.

The plot for group A should be disregarded since there were no male specimen tested.

Sternal constructs in groups B and C showed larger capacities for load before plastically deforming for males (Figure 6.24). This difference was not large and was ultimately found to be statistically insignificant.

\subsubsection{Maximum Load}

Table 6.9: Mean maximum-load values for each sternal-closure technique tested in longitudinal shear, separated by gender.

\begin{tabular}{|c|c|c|c|r|}
\hline \multicolumn{5}{|c|}{ Ultimate Load } \\
\hline \multirow{2}{*}{ Group } & \multicolumn{2}{|c|}{ Averages } & \multicolumn{2}{c|}{ Standard Dev } \\
\cline { 2 - 5 } & $\mathrm{M}$ & $\mathrm{F}$ & $\mathrm{M}$ & $\mathrm{F}$ \\
\hline A & - & 342.390 & - & 101.685 \\
\hline B & 354.489 & 239.346 & 26.223 & 95.350 \\
\hline C & 470.806 & 275.704 & 243.020 & 146.896 \\
\hline
\end{tabular}




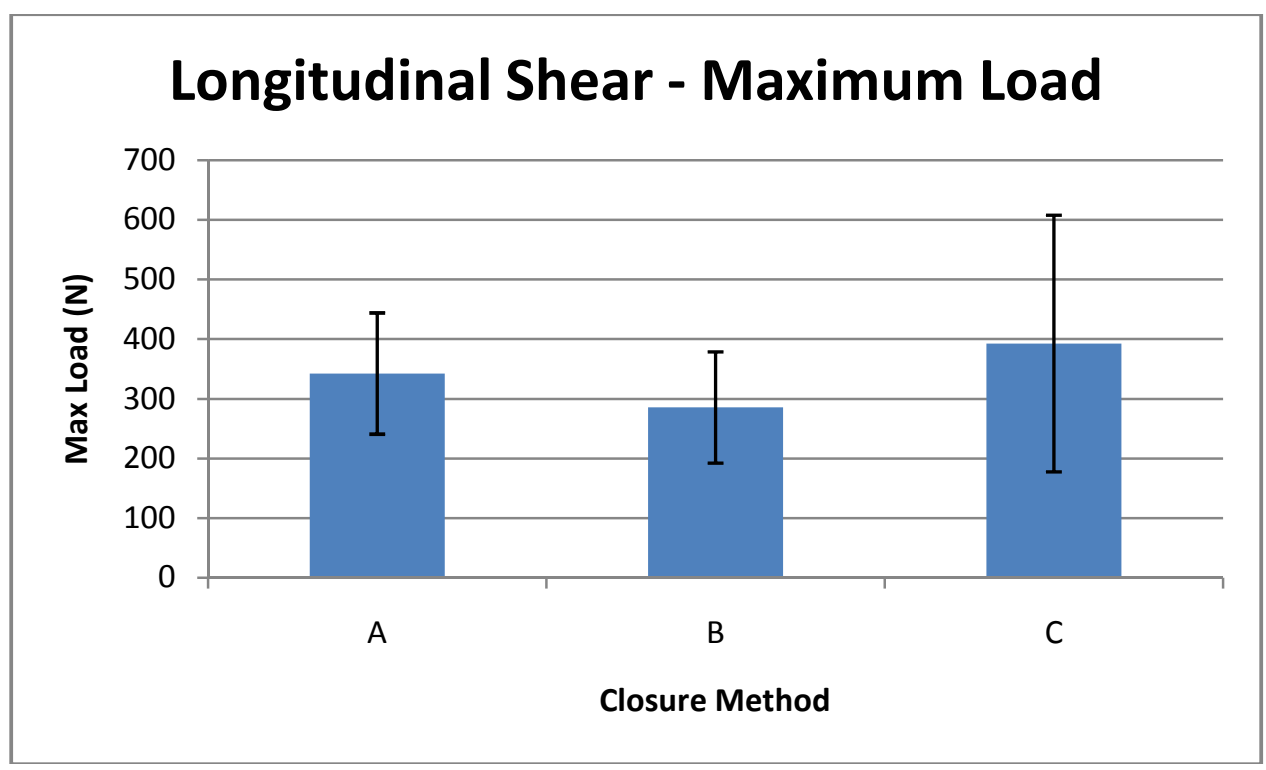

Figure 6.25: Maximum strength of the various fixation methods tested in longitudinal shear.

Columns denote mean values. Maximum strength is measured in newtons of force. Error bars indicate one standard deviation.

Much like results found for yield strength in longitudinal shear, differences in maximum strength for the three fixation methods were found to be minimal (Figure 6.25). The range for mean ultimate strengths is $107 \mathrm{~N}$. No statistical significance was found, and there did not seem to be any type of correlation between the fixation method and the amount of force the construct was able to endure before completely failing.

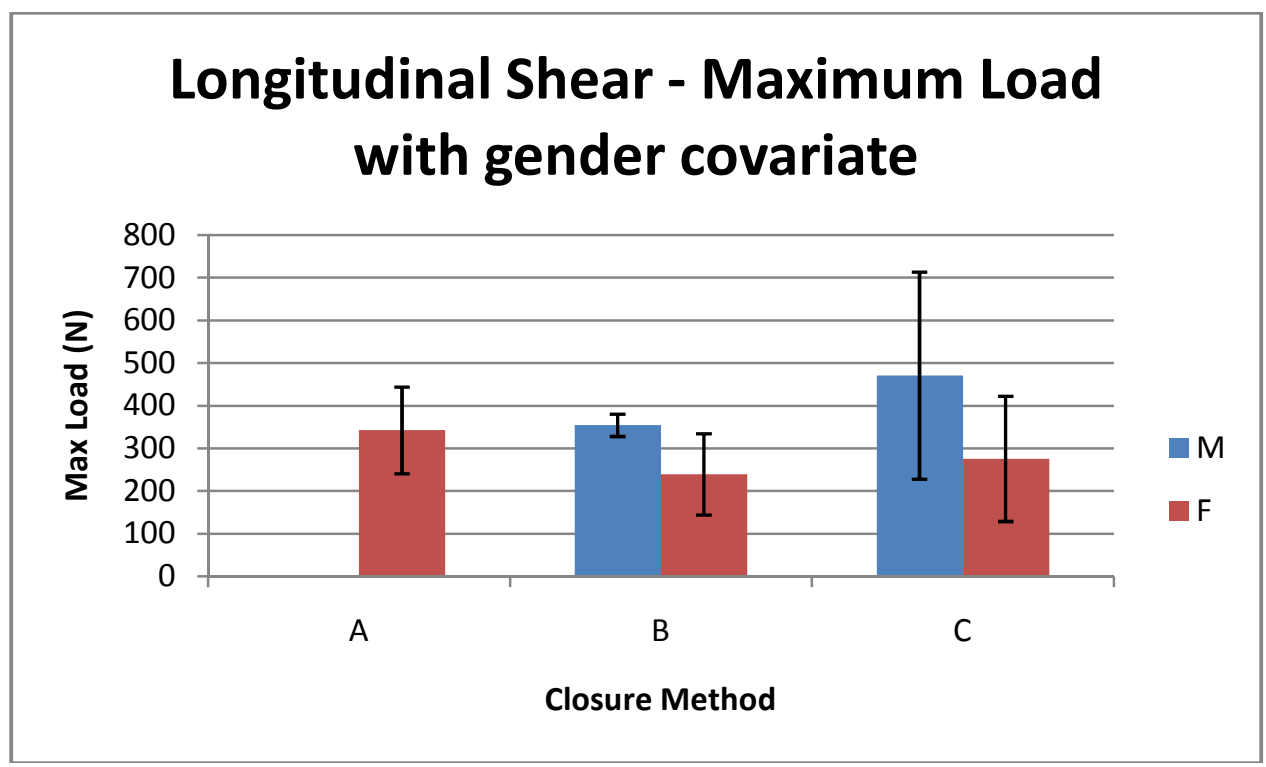


Figure 6.26: Maximum strength of the various fixation methods tested in longitudinal shear separated by gender. Columns denote mean values. Maximum strength is measured in newtons of force. Error bars indicate one standard deviation.

No sterna closed with peristernal wires taken from male cadavers were tested. Figure 6.26 shows that very little differences were observed in mean ultimate strength. A slight trend showing weakness in female specimen is observed again. Overall, the capacity a sternal construct is able to withstand before catastrophic failure occurs is approximately $300 \mathrm{~N}$ in the longitudinal direction. No correlation has been found that would show evidence of a fixation method having an advantage over others.

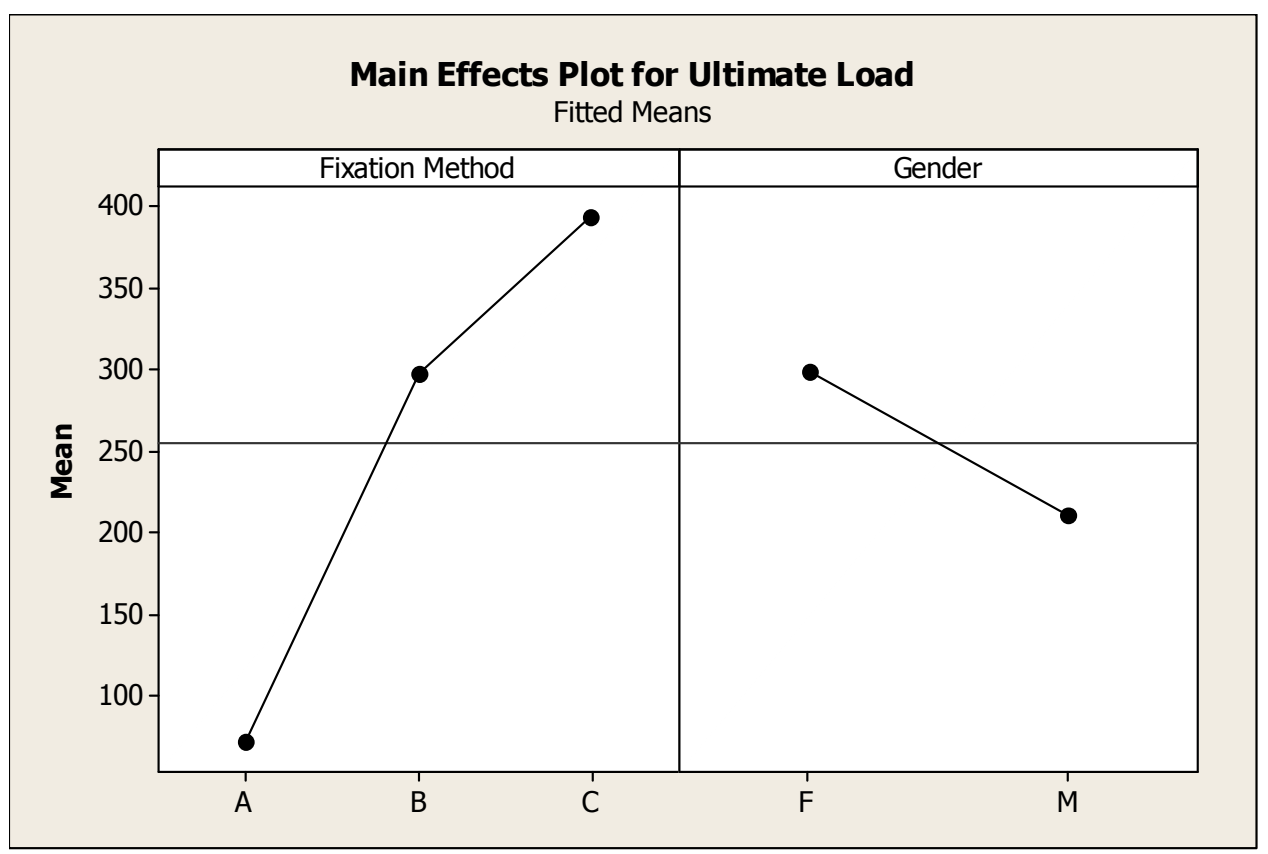

Figure 6.27: Side by side comparison plot of main effects with regards to maximum strength tested in longitudinal shear.

Gender was shown to not have as much of an impact on mean ultimate load capacity when compared to fixation method (Figure 6.27). 


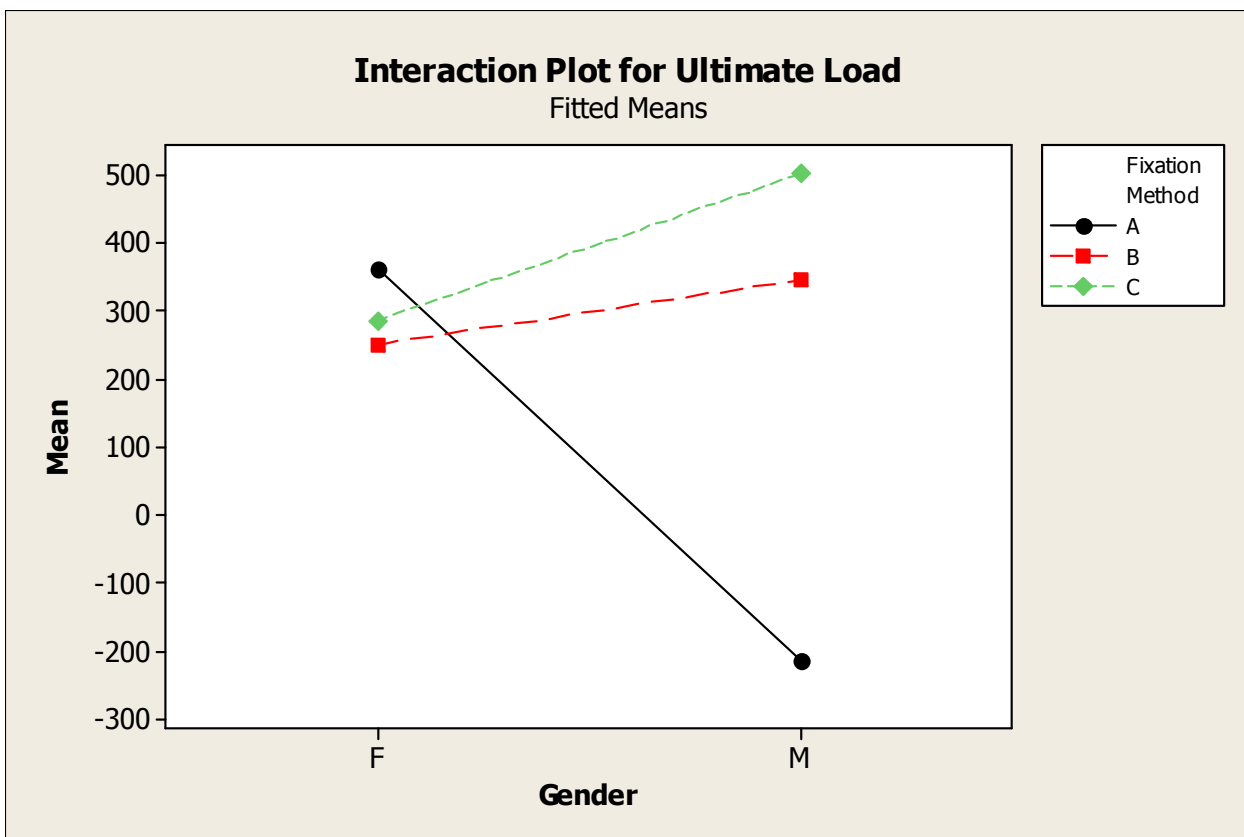

Figure 6.28: Interaction plot describing the effect of gender on each construct in regards maximum strength tested in longitudinal shear.

The interaction plot for group A should be disregarded because no male specimen was tested with that fixation method (Figure 6.28). Male specimens were found to have a larger capacity for stress in Sternalock constructs. However, this was a small amount and found to be statistically insignificant.

\subsubsection{Post-Yield Displacement}

Table 6.10: Mean post-yield values for each sternal-closure technique tested in longitudinal shear, separated by gender.

\begin{tabular}{|l|c|c|c|c|}
\hline \multicolumn{5}{|c|}{ Post-Yield Displacement } \\
\hline \multirow{2}{*}{ Group } & \multicolumn{2}{|c|}{ Averages } & \multicolumn{2}{c|}{ Standard Dev } \\
\cline { 2 - 5 } & $\mathrm{M}$ & $\mathrm{F}$ & $\mathrm{M}$ & $\mathrm{F}$ \\
\hline $\mathrm{A}$ & - & 8.295 & - & 3.986 \\
\hline $\mathrm{B}$ & 0.785 & 0.643 & 0.398 & 0.564 \\
\hline C & 2.733 & 1.885 & 2.390 & 2.345 \\
\hline
\end{tabular}




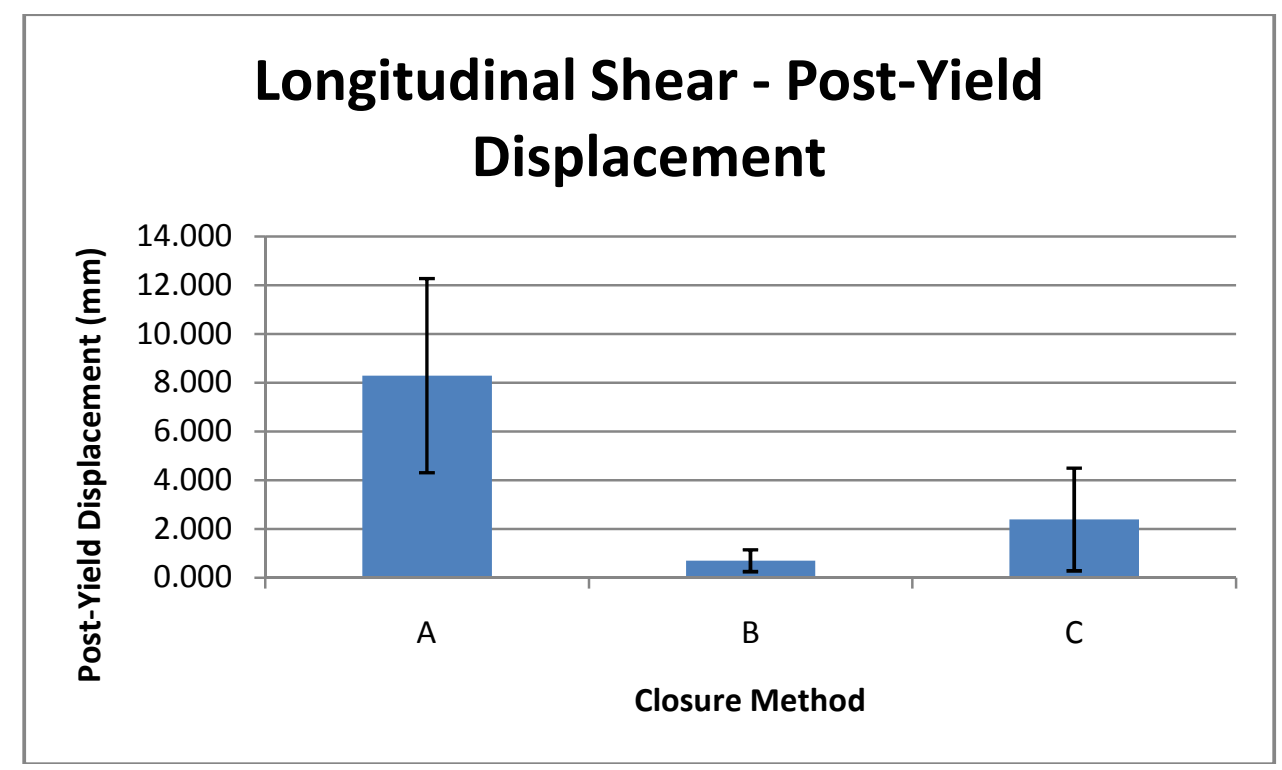

Figure 6.29: Post-yield behavior of the various fixation methods tested in longitudinal shear.

Columns denote mean values. Post-yield displacement is measured in millimeters. Error bars indicate one standard deviation.

A very clear trend links sternum closed with peristernal wires with high post-yield

displacement. This trend is not statistically significant, but a difference can easily be seen from Figure 6.29. Sternalock systems using L-plates were found to displace just 1 millimeter before failing. A similar system using box-plates were found to displace as much as 5 millimeters. Sternum closed with peristernal wires were observed to displace as much as 15 millimeters before catastrophic failure was reached.

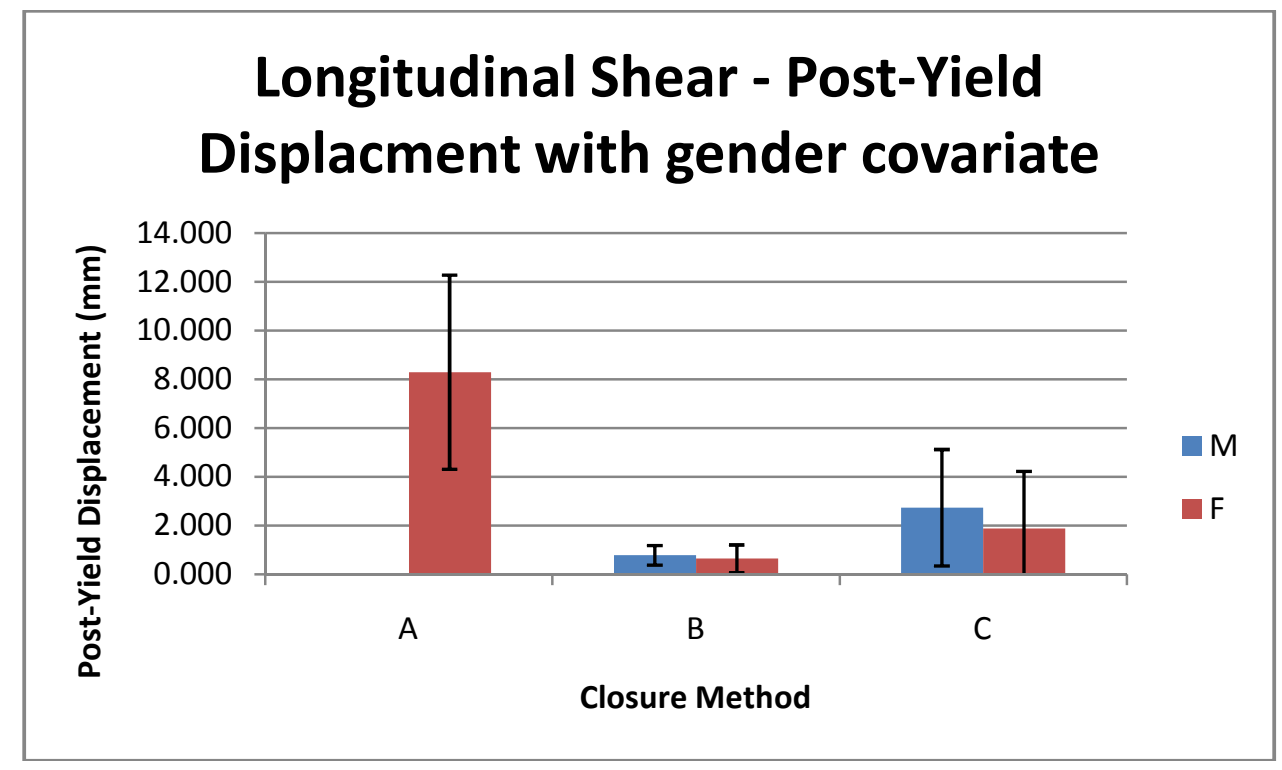


Figure 6.30: Post-yield of the various fixation methods tested in longitudinal shear separated by gender. Columns denote mean values. Post-yield displacement is measured in millimeters. Error bars indicate one standard deviation.

A gender comparison for group A sterna was unavailable. Negligible differences

between male and female specimen were found in fixation methods that we were able to make this comparison (Figure 6.30).

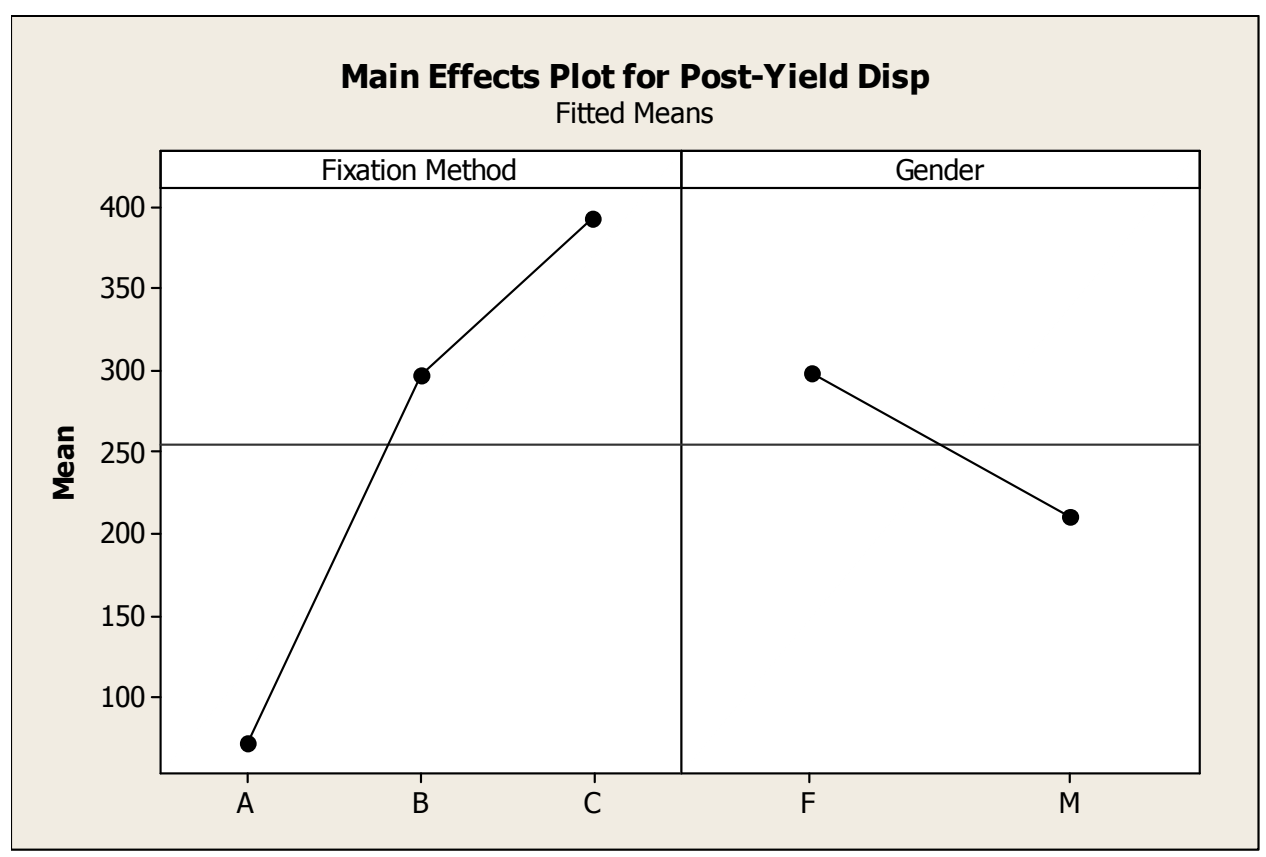

Figure 6.31: Side by side comparison plot of main effects with regards to post-yield displacement tested in longitudinal shear.

Fixation method had the larger effect on mean post-yield displacement; gender provided a secondary influence on this biomechanical behavior (Figure 6.31). 


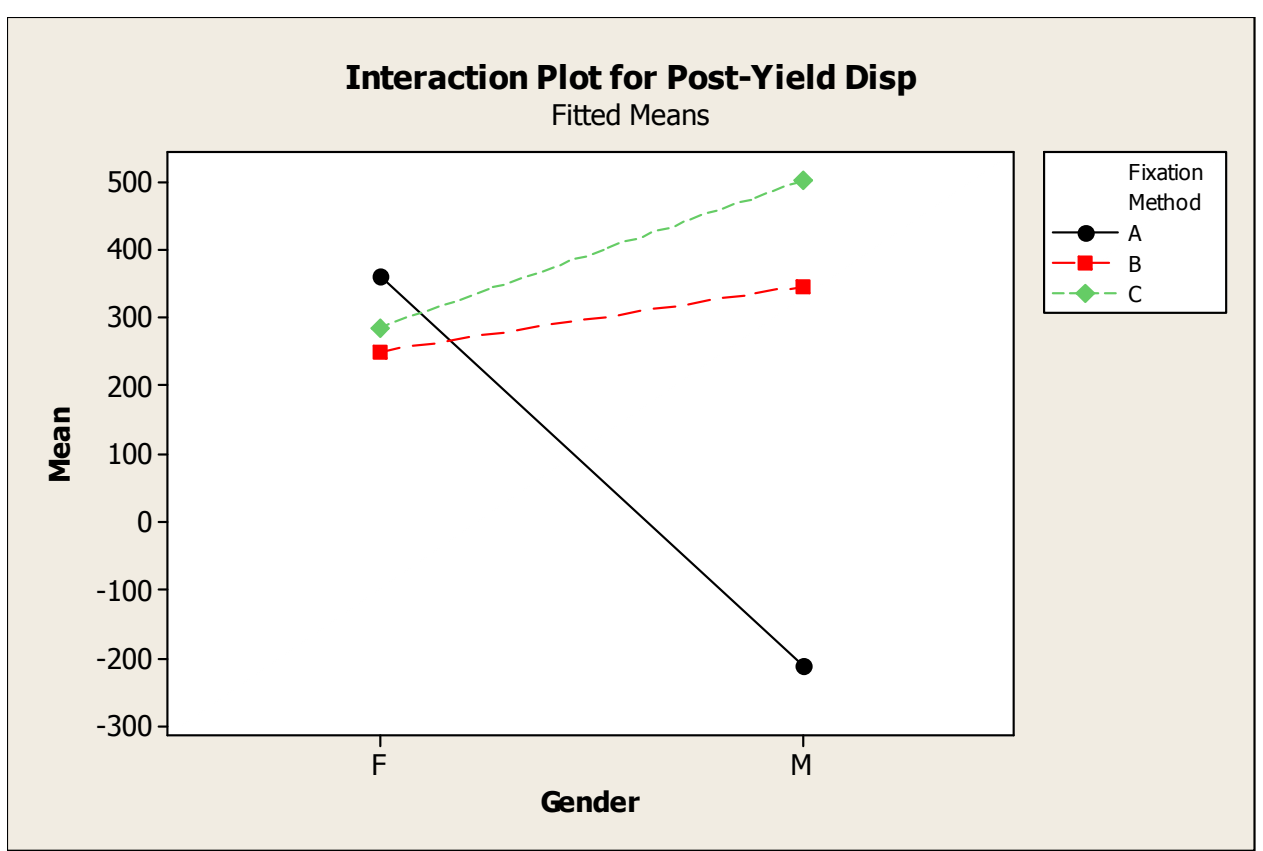

Figure 6.32: Interaction plot describing the effect of gender on each construct in regards post-yield displacement tested in longitudinal shear.

The line depicting the interaction of gender in group A sternum should be disregarding since no males were tested in this group (Figure 6.32). Gender had a minimal effect on this biomechanical behavior.

\subsection{Anterior-Posterior Shear}

Table 6.11: Description of the sample group tested in the transverse distraction with values for each biomechanical property.

\begin{tabular}{|l|l|l|r|l|r|c|}
\hline$\#$ & $\begin{array}{c}\text { Donor } \\
\text { Code }\end{array}$ & Group & Age & Sex & Stiffness & $\begin{array}{c}\text { Yield } \\
\text { Load }\end{array}$ \\
\hline 31 & S080850 & A & 76 & M & 110.823 & 48.999 \\
\hline 34 & C080526 & A & 82 & M & 66.350 & - \\
\hline 39 & S081007 & A & 89 & M & - & - \\
\hline 32 & S080450 & A & 65 & F & 34.507 & 23.493 \\
\hline 40 & S080950 & A & 79 & F & 46.401 & 22.989 \\
\hline 35 & S081013 & B & 68 & M & 32.570 & - \\
\hline 33 & C080582 & B & 80 & F & 113.650 & - \\
\hline 37 & S080029 & B & 50 & F & 8.857 & 129.042 \\
\hline 38 & C060260 & B & 77 & F & 117.158 & 51.684 \\
\hline 41 & C080345 & B & 85 & F & - & - \\
\hline 36 & S081047 & C & 69 & M & 107.317 & 104.039 \\
\hline 42 & S060167 & C & 80 & M & 132.657 & 55.879 \\
\hline
\end{tabular}


Of specimen tested in the anterior-posterior shear direction, the average age was 75 years with 6 males and 6 females. 12 sternums were tested. 5 samples using peristernal wires, 5 samples using Sternalock with L-plates, and 2 using Sternalock with box-plates. No female specimen was tested with box-plates.

Table 12 shows several weaknesses in data collection. Calculating biomechanical behaviors of the cadaveric constructs was very difficult when stressing in the transverse direction. The cadaver-device constructs had a very large amount of compliance due to the length of the ribs and presence of intercostal muscles, this made it difficult to apply force to the midline of the sternum.

\subsubsection{Stiffness}

Table 6.12: Mean stiffness values for each sternal-closure technique tested in transverse shear, separated by gender.

\begin{tabular}{|c|r|r|r|c|}
\hline \multicolumn{4}{|c|}{ Stiffness } \\
\hline \multirow{2}{*}{ Group } & \multicolumn{2}{|c|}{ Averages } & \multicolumn{2}{c|}{ Standard Dev } \\
\cline { 2 - 5 } & $\mathrm{M}$ & $\mathrm{F}$ & $\mathrm{M}$ & $\mathrm{F}$ \\
\hline $\mathrm{A}$ & 88.586 & 40.454 & 31.447 & 8.410 \\
\hline B & 32.570 & 79.888 & 0.000 & 61.540 \\
\hline C & 119.987 & - & 17.918 & - \\
\hline
\end{tabular}




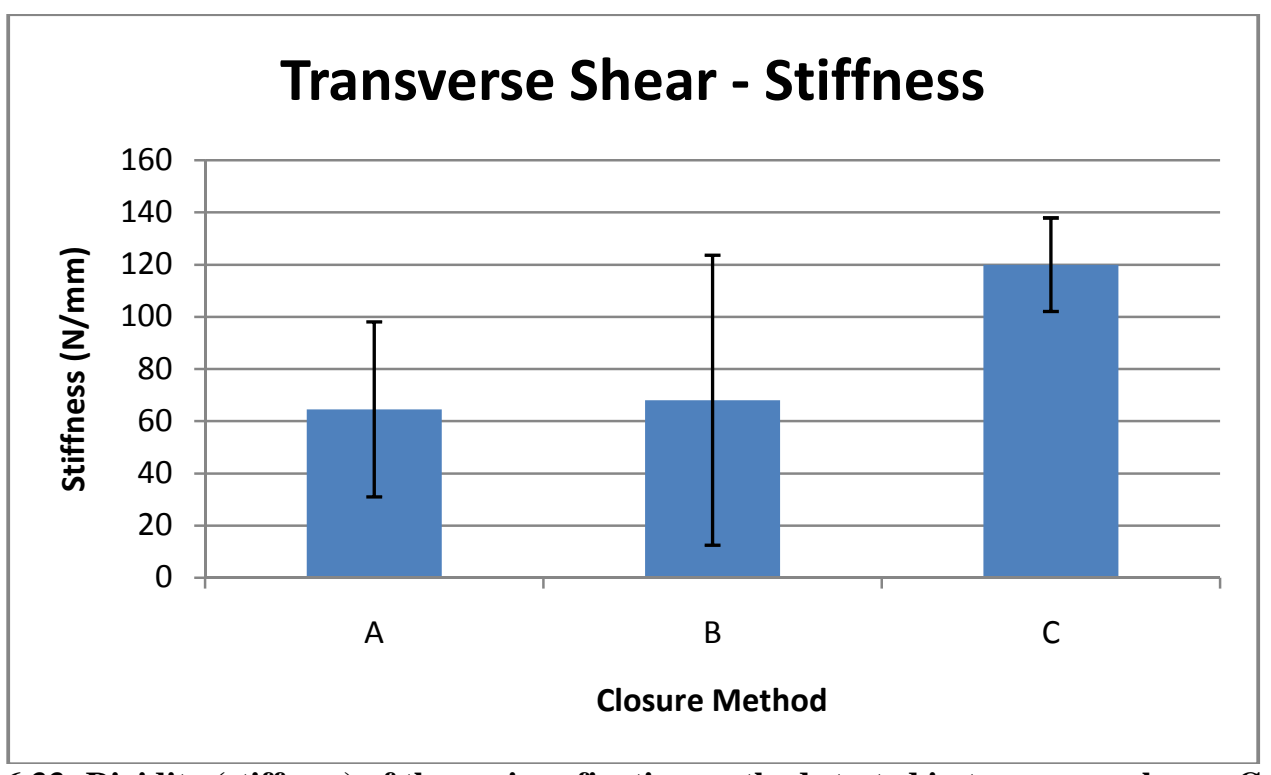

Figure 6.33: Rigidity (stiffness) of the various fixation methods tested in transverse shear. Columns denote mean values. Stiffness is measured in newtons of force per millimeter displacement. Error bars indicate one standard deviation.

No fixation method was found to be statistically different than another (Figure 6.33).

Peristernal wires appeared to be almost identical in stiffness to Sternalock with L-plates, only a $4 \mathrm{~N} / \mathrm{mm}$ difference in mean stiffness. A moderate gain in stiffness can be observed for Sternalock with box-plates in Figure 6.33, a $55 \mathrm{~N} / \mathrm{mm}$ difference when compared to peristernal wires.

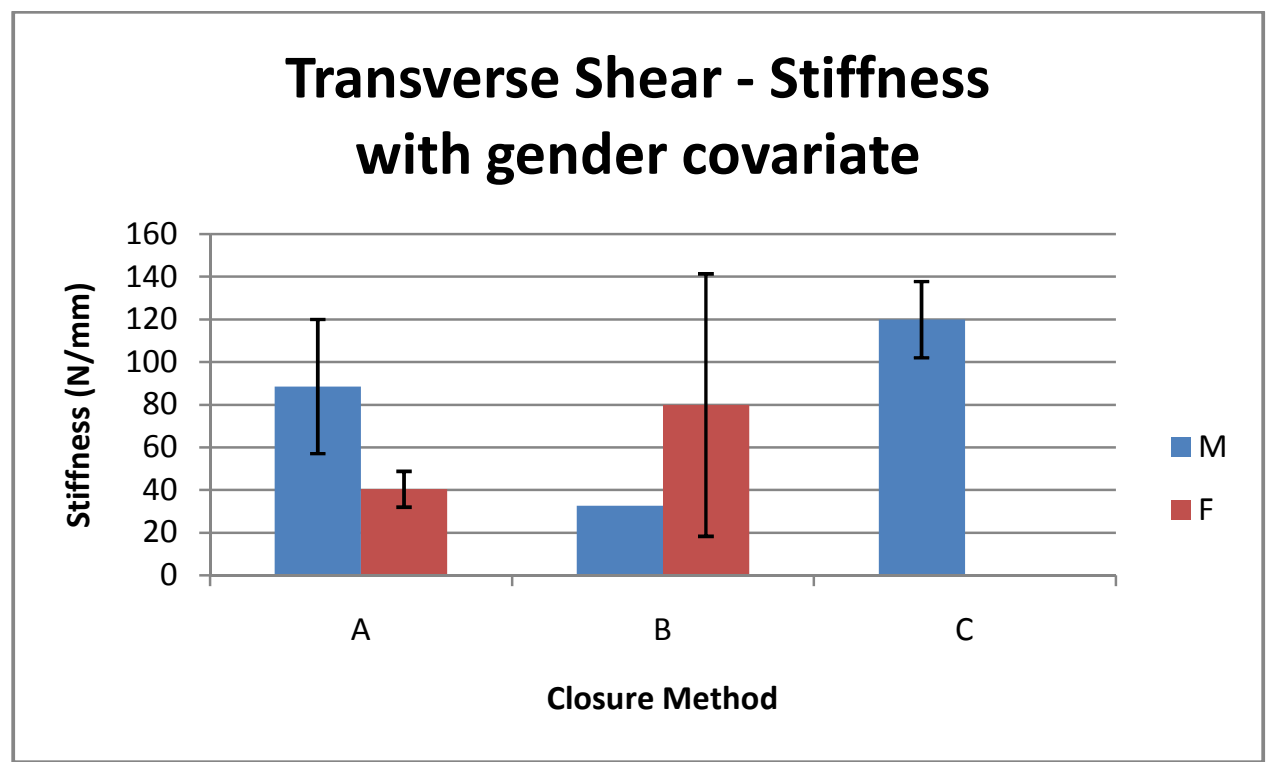


Figure 6.34: Rigidity (stiffness) of the various fixation methods tested in longitudinal shear separated by gender. Columns denote mean values. Stiffness is measured in newtons of force per millimeter displacement. Error bars indicate one standard deviation.

No female samples were tested in group C. No trends or correlations are able to be made from the data recorded and shown in Figure 6.34.

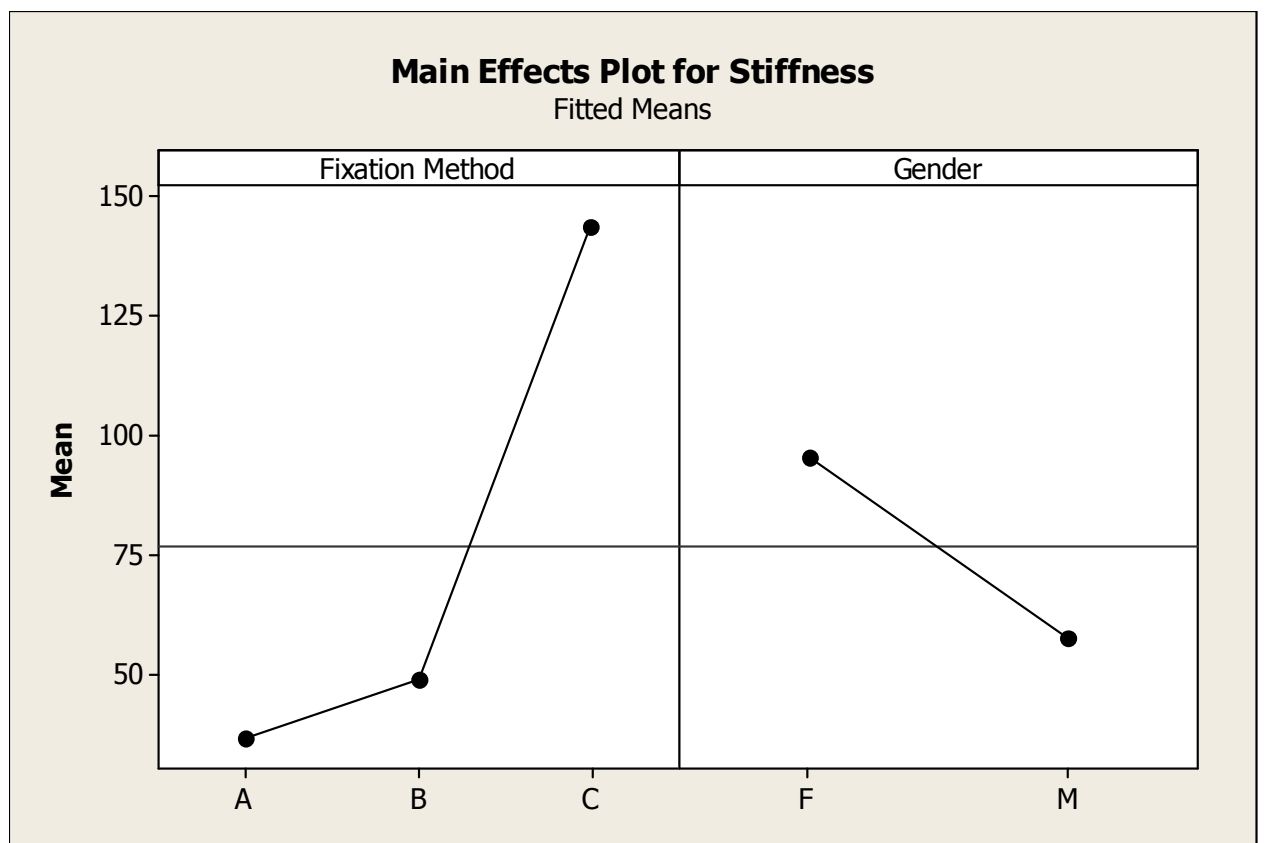

Figure 6.35: Side by side comparison plot of main effects with regards to stiffness tested in transverse shear.

Fixation method is shown to be the primary influence on mean stiffness of the construct.

Gender has a secondary effect on this biomechanical property. The overall scale of

Figure 6.35 allows us to analyze the source of different stiffness values, but the small difference of overall values does not provide enough statistical power to draw any direct relationships between fixation method, gender, and mean stiffness. 


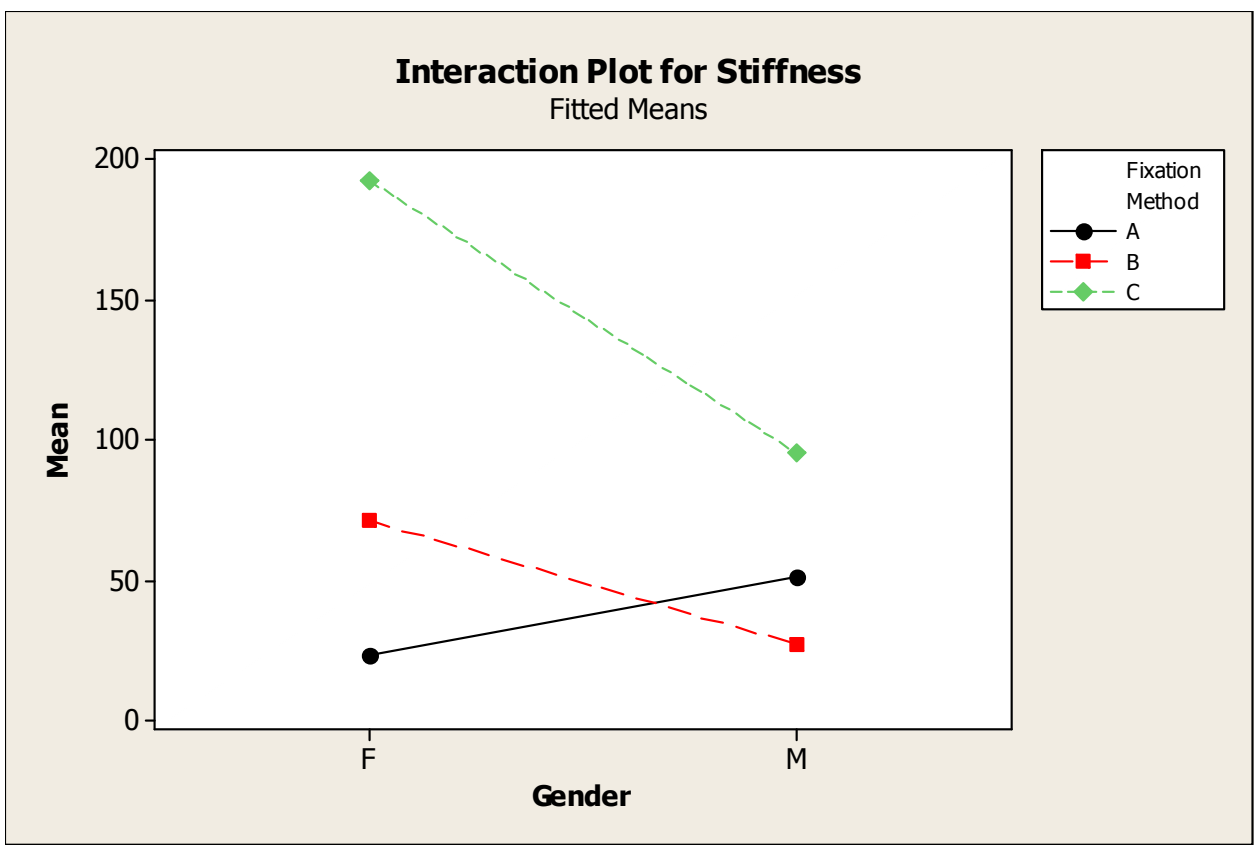

Figure 6.36: Interaction plot describing the effect of gender on each construct in regards stiffness tested in transverse shear.

The interaction plot describing fixation method $\mathrm{C}$ should be disregarding because no female samples were tested in this group. Figure 6.36 shows very little effect of different genders to both sternums closed with peristernal wires and Sternalock systems using Lplates.

\subsubsection{Yield Load}

Table 6.13: Mean yield values for each sternal-closure technique tested in transverse shear, separated by gender.

\begin{tabular}{|l|c|c|c|c|}
\hline \multicolumn{4}{|c|}{ Yield Load } \\
\hline \multirow{2}{*}{ Group } & \multicolumn{2}{|c|}{ Averages } & \multicolumn{2}{c|}{ Standard Dev } \\
\cline { 2 - 5 } & $\mathrm{M}$ & $\mathrm{F}$ & $\mathrm{M}$ & $\mathrm{F}$ \\
\hline $\mathrm{A}$ & 48.999 & 23.241 & 0.000 & 0.356 \\
\hline B & - & 90.363 & - & 54.701 \\
\hline C & 79.959 & - & 34.054 & - \\
\hline
\end{tabular}


Table 6.14: Mean yield values for each sternal-closure technique tested in transverse shear.

\begin{tabular}{|l|r|r|}
\hline \multicolumn{3}{|c|}{ Yield Load } \\
\hline Group & Average & \multicolumn{1}{c|}{ Std Dev } \\
\hline A & 31.827 & 14.874 \\
\hline B & 90.363 & 54.701 \\
\hline C & 79.959 & 34.054 \\
\hline
\end{tabular}

Table 15 was included because there are so many vacancies in table 14 . Weaknesses in table 14 make it difficult to read no conclusions can be drawn from analyzing gender.

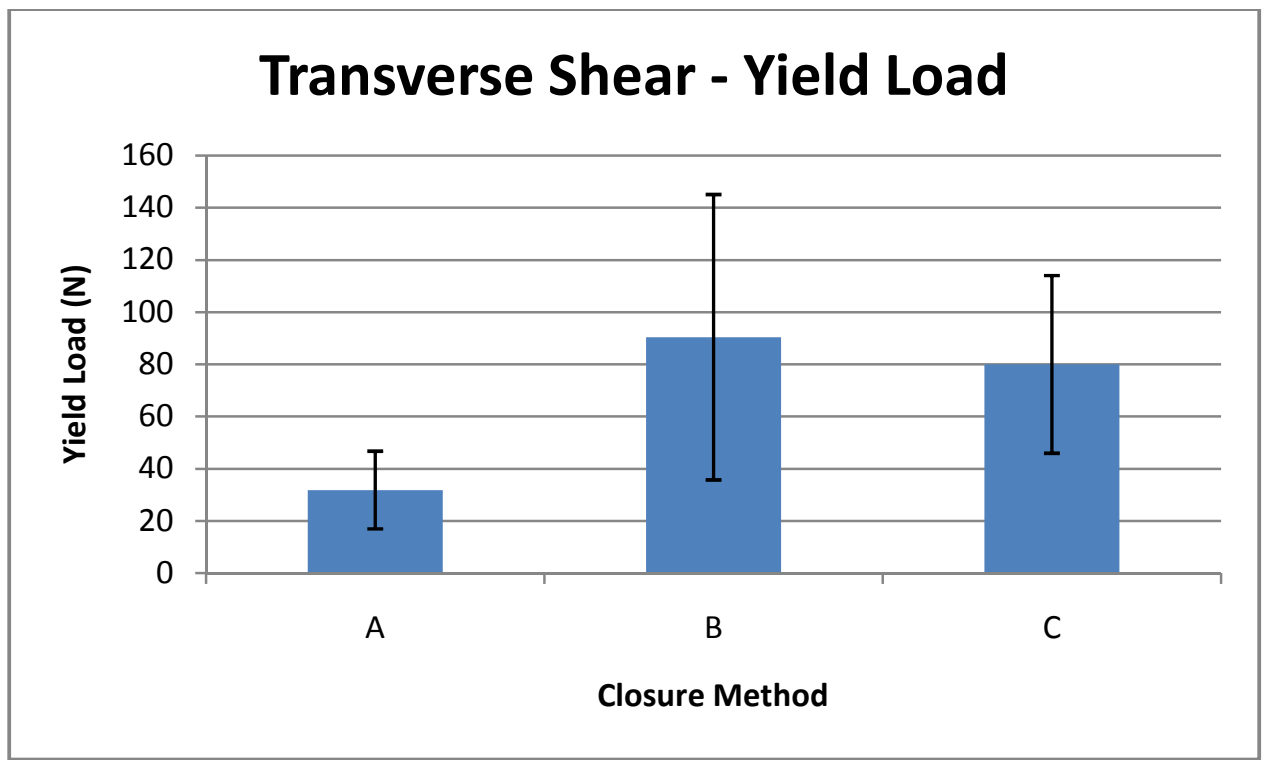

Figure 6.37: Yield strength of the various fixation methods tested in longitudinal shear. Columns denote mean values. Yield strength is measured in newtons of force. Error bars indicate one standard deviation.

No fixation method was found to have statistically different yield strength when compared to each other. The constructs capacity for stress before plastically deforming did appear to be influence by different closure techniques in the anterior-posterior direction. A trend of Sternalock systems having a higher yield strength can be observed from Figure 6.37, however, this trend was not found to be statistically significant. The largest change, the difference between group B and group A was only found to be $59 \mathrm{~N}$. 


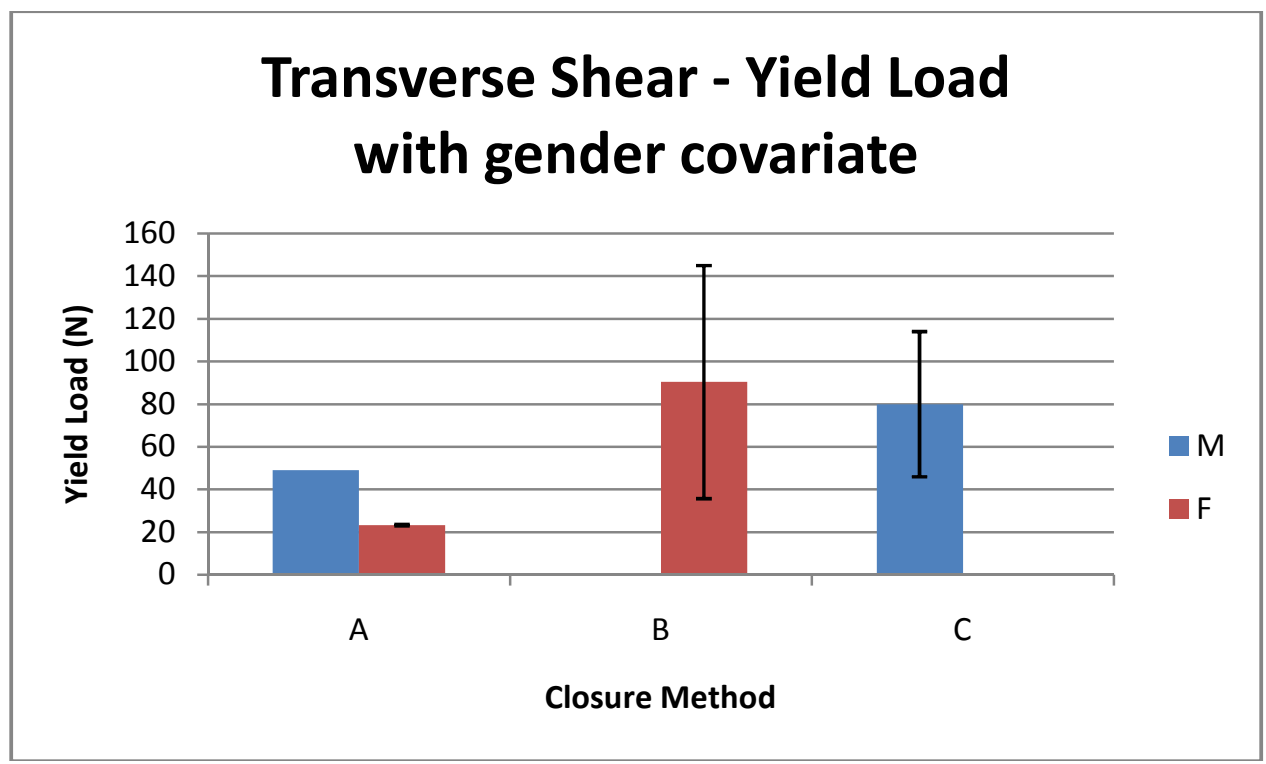

Figure 6.38: Yield strength of the various fixation methods tested in longitudinal shear separated by gender. Columns denote mean values. Yield strength is measured in newtons of force. Error bars indicate one standard deviation.

No data was recorded for males in group B and no females were tested from group C.

This shows weaknesses in the study for transverse shear. The one thing Figure 6.38 reveals is that females had a slightly lower stiffness when compared to males in group A.

\subsubsection{Maximum Load}

Data was unavailable for the maximum strength when tested in the anterior-posterior direction. The maximum displacement of the load frame was approximately 3 inches. At maximum displacement, failure was not achieved for the sternal construct. Cited in section 7.3, force was very inefficiently transferred to the sternum using the test fixtures for the anterior-posterior direction. The high compliance of the sternum makes it extremely difficult to collect viable data in this direction. 


\subsubsection{Post-Yield Displacement}

Because catastrophic failure was never reached for this test group, a post-yield displacement was unavailable for each construct.

\subsection{Males versus Females}

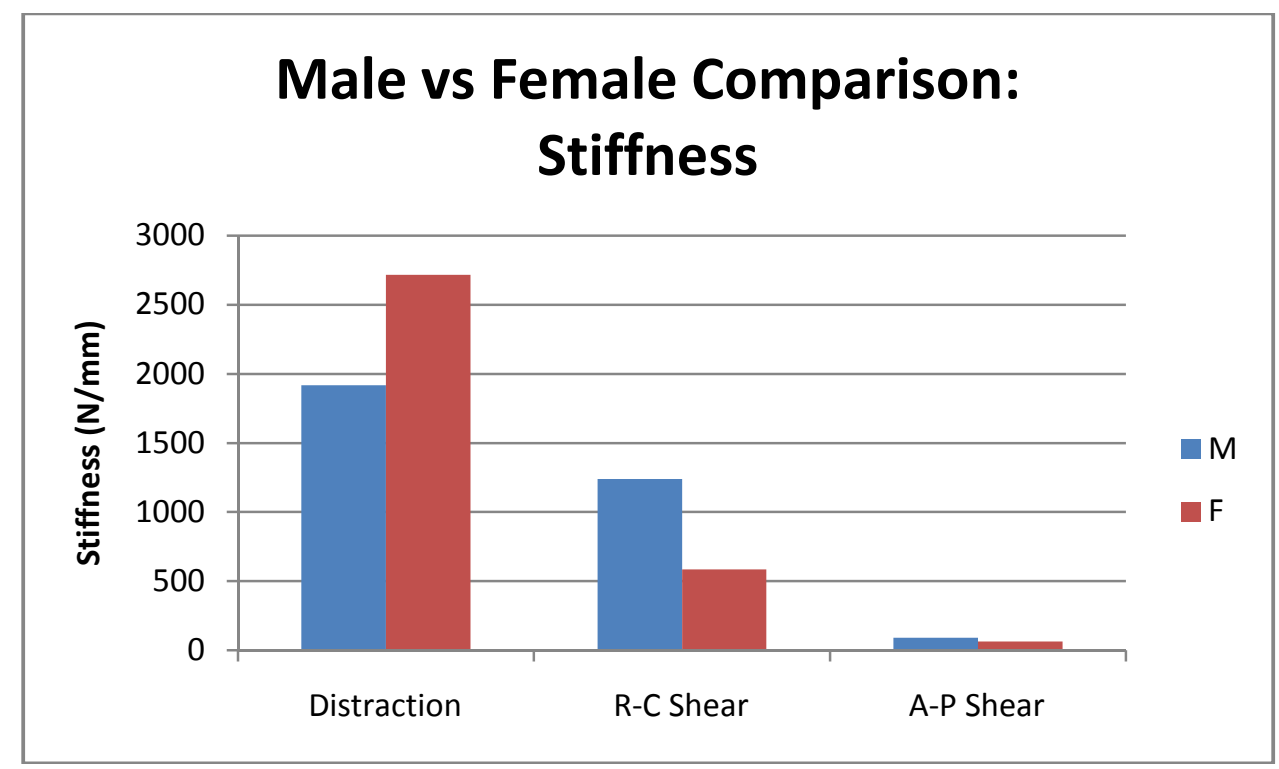

Figure 6.39: Comparing stiffness between male and female specimen. Columns denote cumulative values for all fixation methods.

Trends have been noted that link gender and mean stiffness for groups organized by

fixation method. Overall no statistical differences can be observed from Figure 6.39. In Figure 6.39, all fixation methods were averaged to produce the graph. This may not be the best way to analyze the gender relationship since plated fixation methods tended to exhibit higher stiffness values, skewing the averaged values in Figure 6.39 towards the behavior of groups B and C. 


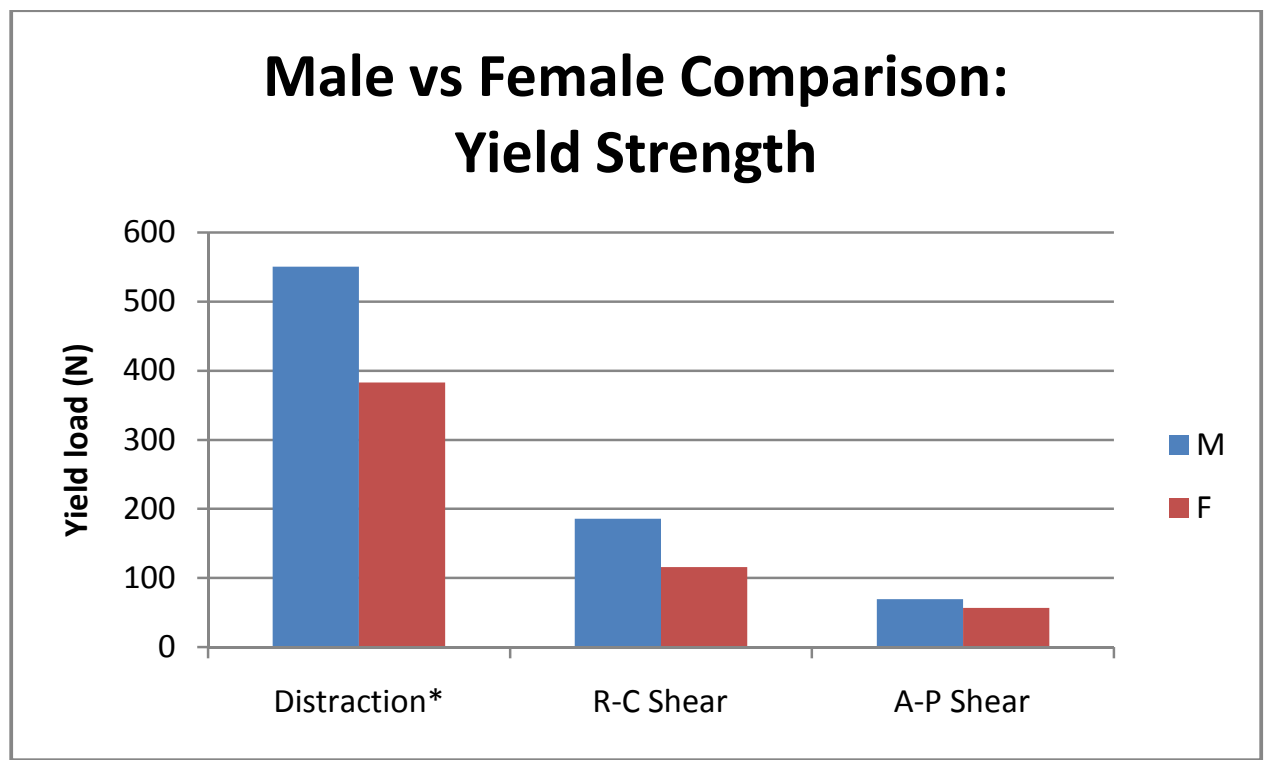

Figure 6.40: Comparing yield strength between male and female specimen. Columns denote cumulative values for all fixation methods. An asterisk indicates statistically significance between male and female specimen.

A trend can be seen associating male specimen with a higher capacity for stress before plastically deforming (Figure 6.40). When tested in lateral distraction, males were found to be statistically different $(\mathrm{p}=0.03)$ when compared to similarly tested females; males had a mean stiffness of $550 \mathrm{~N}$ while females were tested to have $382 \mathrm{~N}$. Statistical differences were not found in rostro-caudal shear and anterior-posterior shear, however, a trend can be observed showing higher yield strengths for male specimen. This data suggests that males can be associated with larger yield-strengths. 


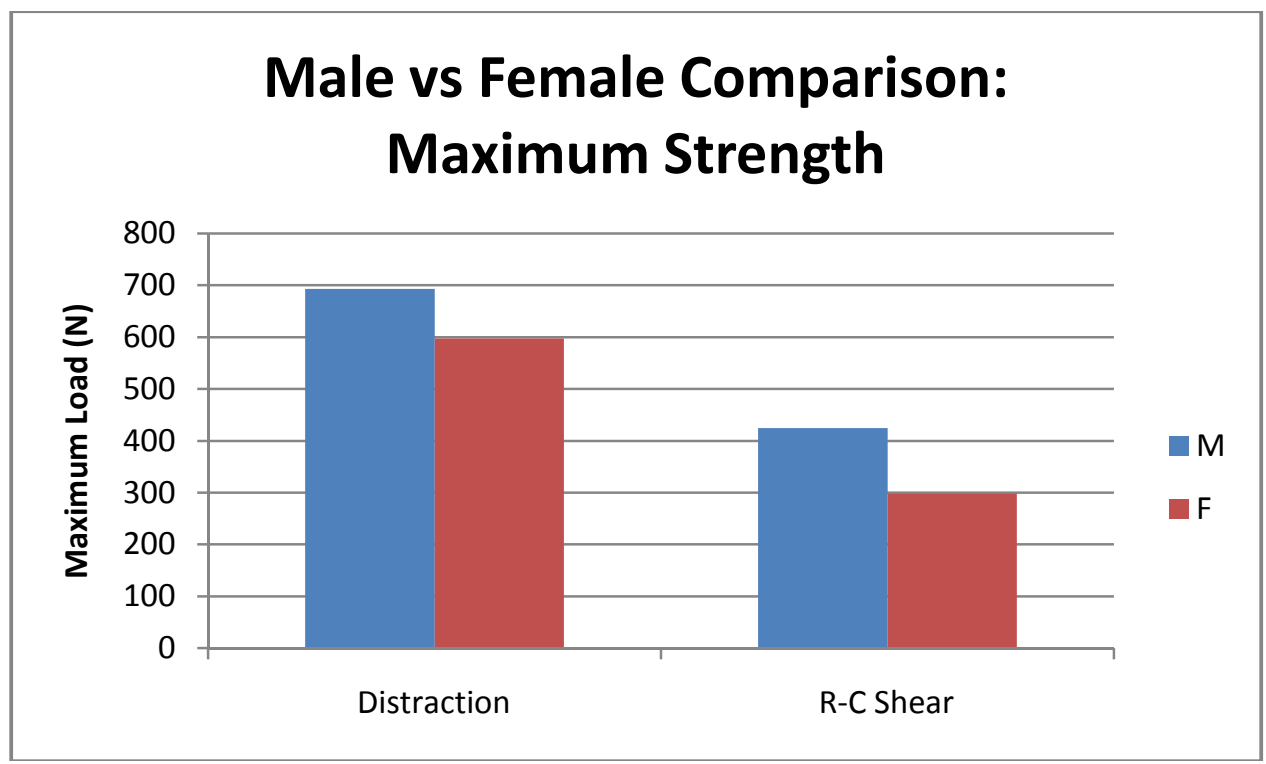

Figure 6.41: Comparing maximum strength between male and female specimen. Columns denote cumulative values for all fixation methods.

No statistical differences were found when comparing similarly tested males and females (Figure 6.41). Male specimens were consistently stronger, able to withstand larger amounts of stress before reaching catastrophic failure. However, these differences were small, $95 \mathrm{~N}$ and $126 \mathrm{~N}$ for distraction and longitudinal shear, respectively. This data suggests that males are associated with larger maximum-strengths.

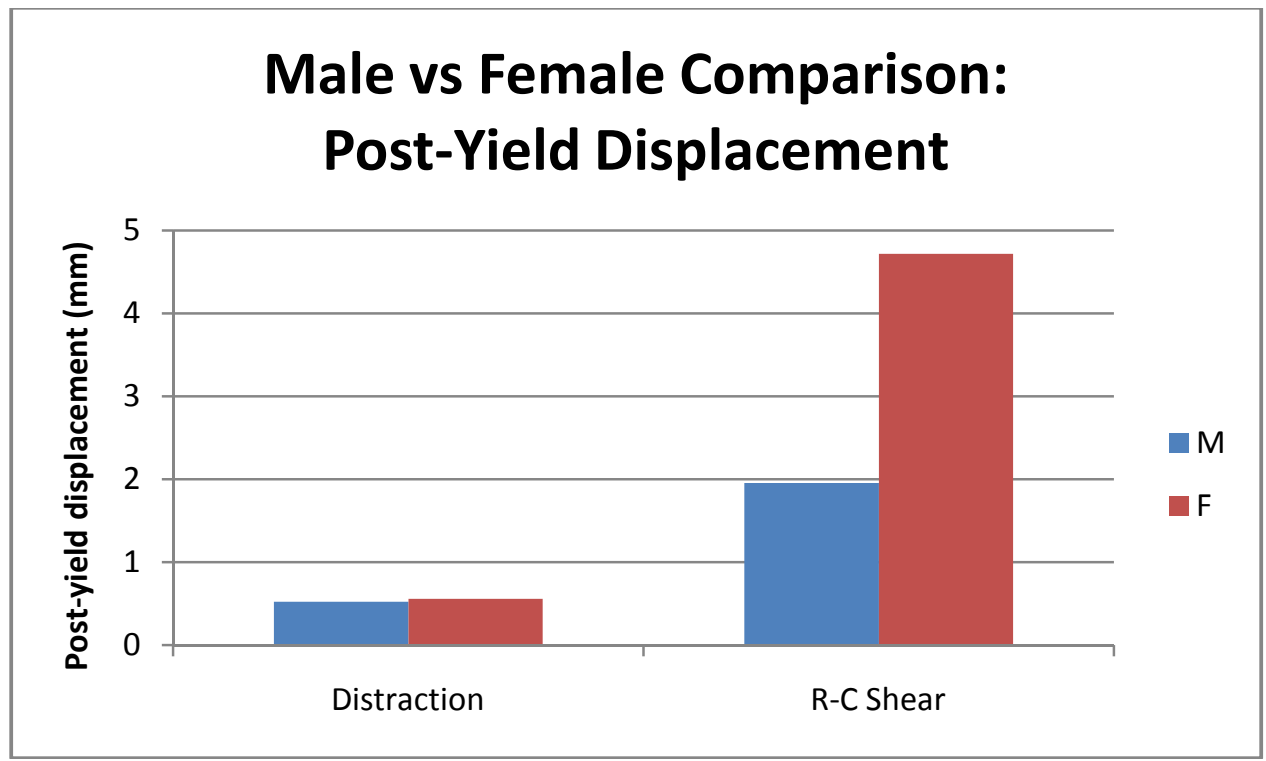

Figure 6.42: Comparing post-yield displacement between male and female specimen. Columns denote cumulative values for all fixation methods. 
Difference in male versus female specimen when tested in lateral distraction was found to be almost statistically significant $(\mathrm{p}=0.19)$. When tested in rostro-caudal shear, females displaced much more after yielding when compared to males. This difference did not prove to be statistically different.

\subsection{Additional Graphs}

Figures 6.43-6.46 bring perspective to the findings of this study. The magnitude of the differences found can be compared to other fixation methods, other directions of applied stress, and the opposite gender.

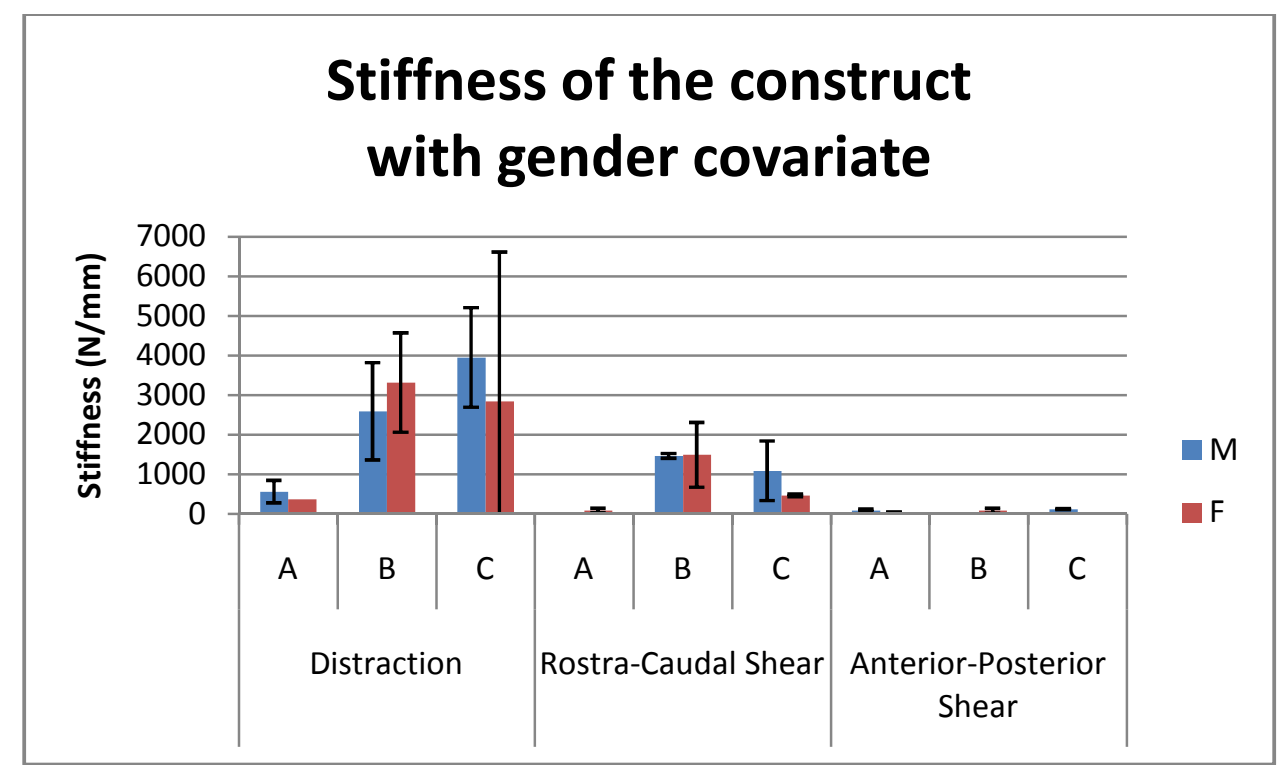

Figure 6.43: Rigidity (stiffness) of the various fixation methods tested in various directions and separated by gender. Columns denote mean values. Stiffness is measured in newtons of force per millimeter displacement. Error bars indicate one standard deviation. 


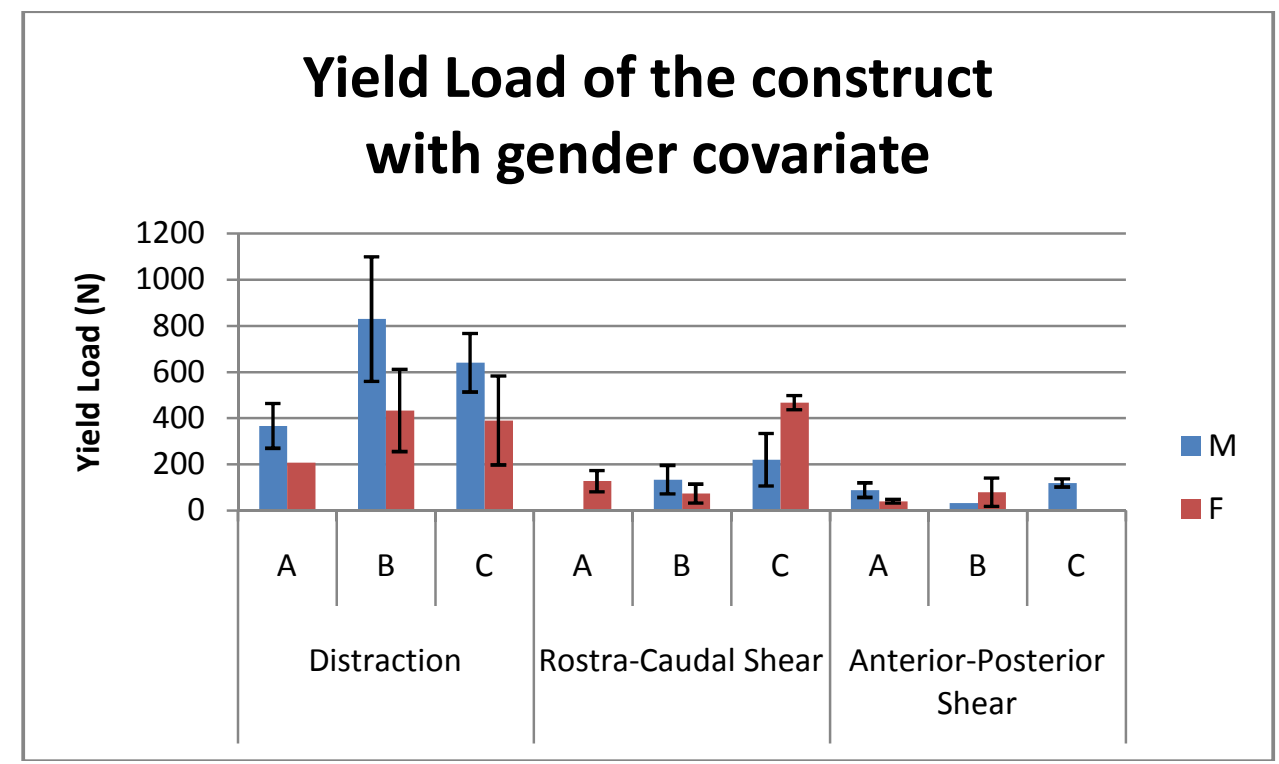

Figure 6.44: Yield strength of the various fixation methods tested in various directions and separated by gender. Columns denote mean values. Yield strength is measured in newtons of force. Error bars indicate one standard deviation.

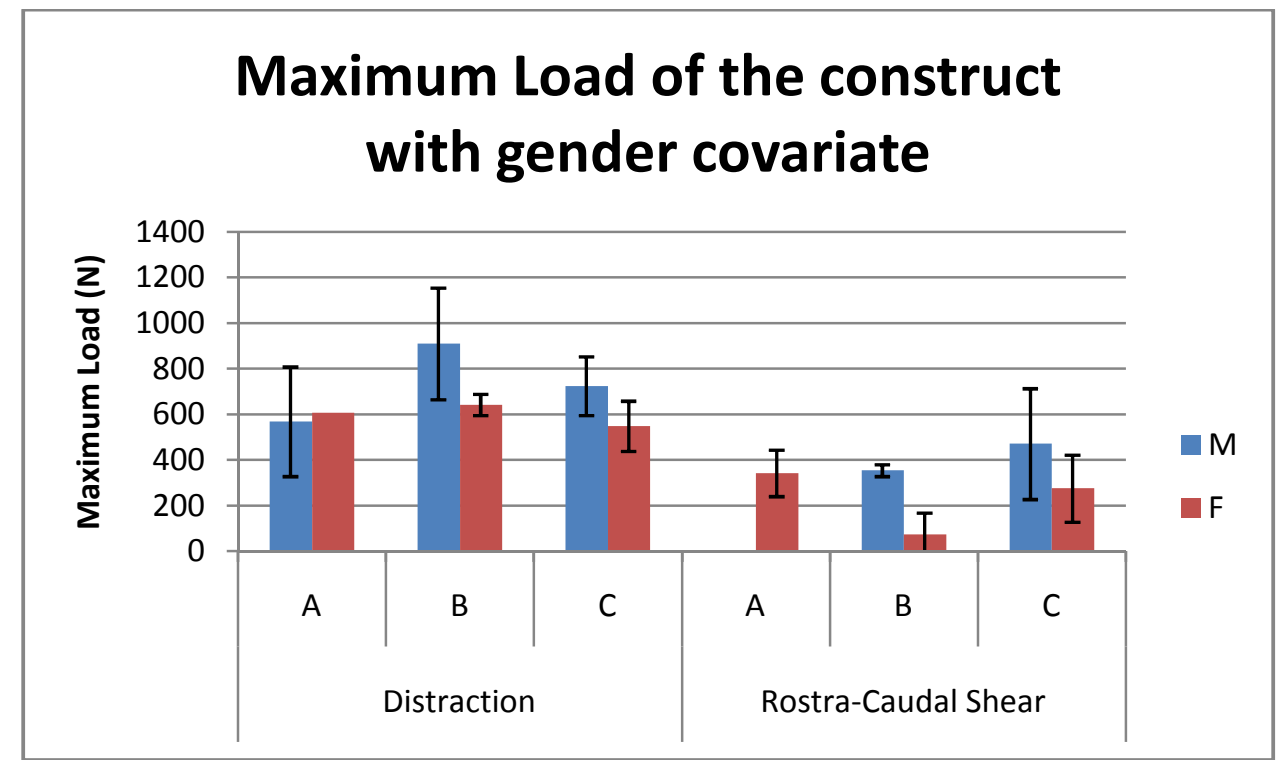

Figure 6.45: Maximum strength of the various fixation methods tested in various directions and separated by gender. Columns denote mean values. Maximum strength is measured in newtons of force. Error bars indicate one standard deviation. 


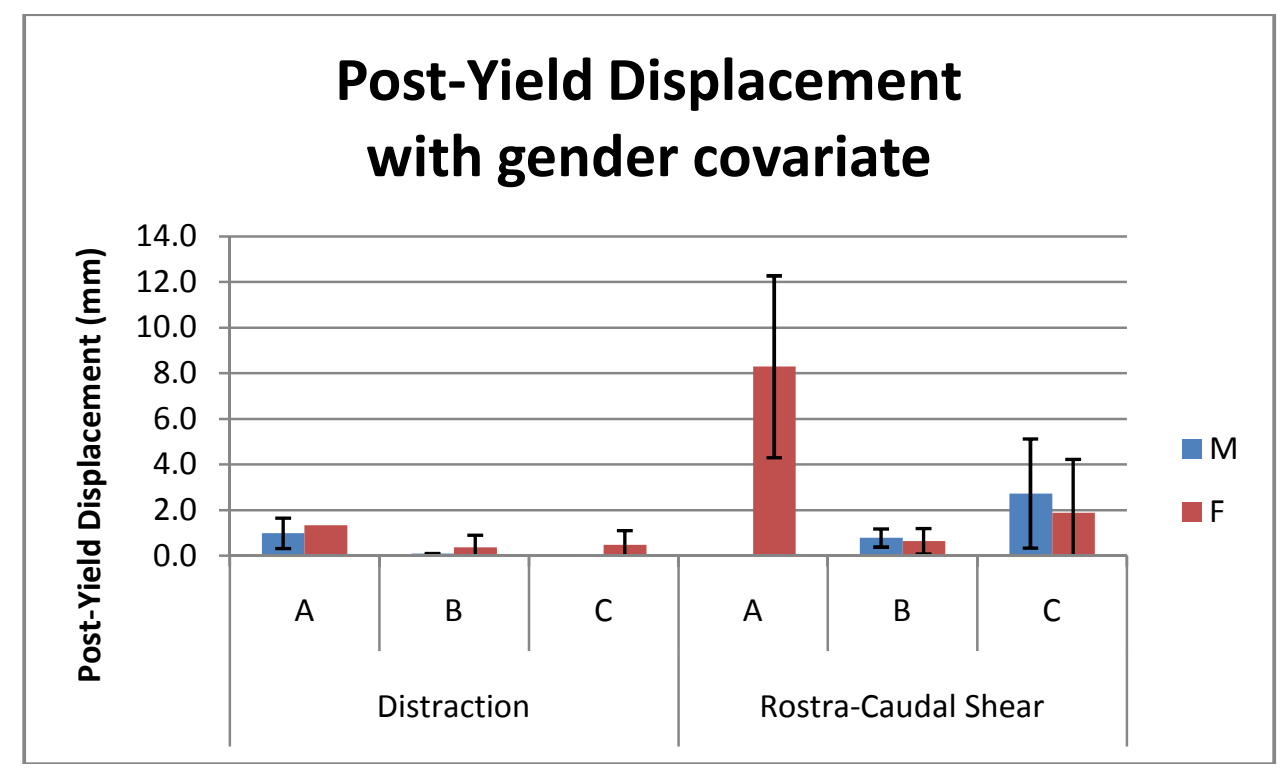

Figure 6.46: Post-yield displacement of the various fixation methods tested in various directions and separated by gender. Columns denote mean values. Post-yield displacement is measured millimeters. Error bars indicate one standard deviation.

\section{Discussion}

\subsection{Lateral distraction}

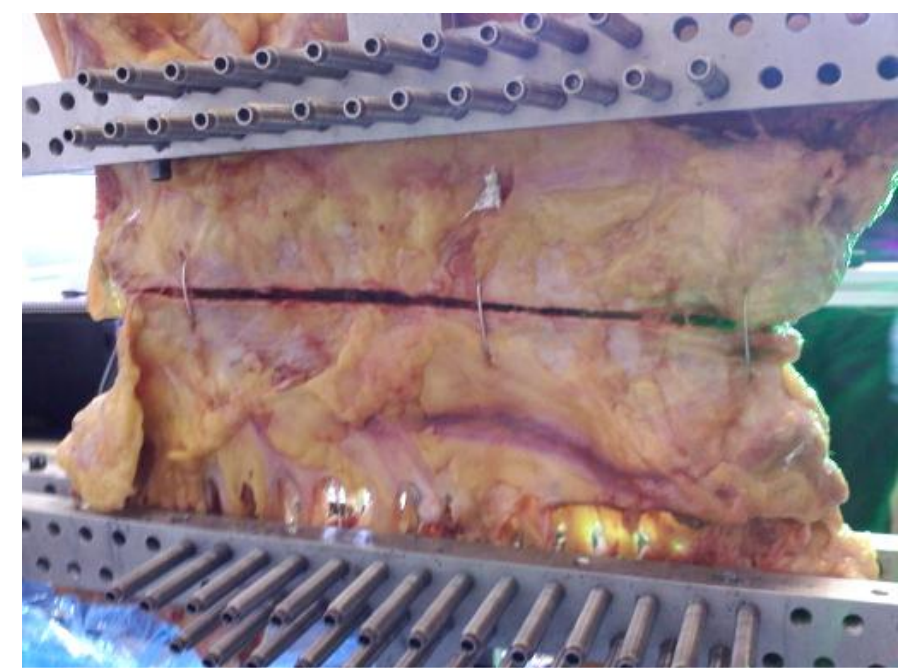

Figure 7.1: Picture taken at maximum displacement in the lateral distraction direction. Separation can be observed at the midline and rib fractures can be seen along the bottom clamp.

It was found that both Sternalock configurations were statistically different $(\mathrm{p}<0.05)$

when comparing stiffness to sternum closed with peristernal wires. A loose trend was found for the same when analyzing yield strength $(\mathrm{p}<0.23)$. No conclusions could be 
drawn from each tested fixation method with regards to maximum strength. A loose trend was also found when analyzing data for post-yield displacement, Sternalock systems were found to be more superior to peristernal wires $(\mathrm{p}<0.07)$.

Substantial advantages in performance were observed from all the biomechanical properties analyzed for Sternalock devices when compared to peristernal wires, excluding maximum strength. Overall, displacement at the midline for sternum involving Sternalock devices was almost not detectable. When stressed in lateral distraction, Sternalock plates were very efficient at transferring load to the sternum without allowing elastic or inelastic deformation at the osteotomy site. Figure 18a shows a coloration map of stress concentrations for a sternum closed with peristernal wires. Red color indicates high stress areas, these areas were seen to be more likely to displace at higher rates. A peristernal wire closure was not sufficient to stabilize the xiphoid region when increased loads were applied to the construct.

Lateral distraction is the biomechanical property most commonly discussed in literature. A very large amount of data has been compiled on stiffness - cadaver models[11], bone analogues [49], porcine models [50], canine models [15]. No new information is being reported in this study on the lateral distraction of cadaveric models except the validation of the Sternalock device. 


\subsection{Rostro-caudal shear}

Longitudinal shear is not widely used in evaluating new median sternotomy closure devices. However, this can be an important metric to further understand the limits and failure modes in devices very commonly implanted in a very wide patient-group. An older and more mature procedure, median sternotomy closures have become sufficiently capable of resisting motion during lateral distraction but little progress has been made to resist load in directions that are physiologically known to occur. The test fixtures used to apply stress in the rostro-caudal direction were very effective to transferring load through the midline of the construct. Minimal rotation was seen to occur and viable data recorded during testing.

Peristernal wires are not well suited to resist motion in the longitudinal direction. Due to the inherent nature of this fixation method, this wire configuration can only resist load in one direction. Wires are tightened to provide a compressive force around the cortical bone of the sternal body; this provides the action in resisting forces in lateral distraction. Resistance in the longitudinal or transverse direction is completely dependent on friction between the sternal halves, as the halves are merely being compressed together. Even in the one mode of resistance capable by peristernal wire closures, load is not efficiently transferred to the construct. Multiple point loads are created around cortical bone that tend to concentrate stress in small areas. This often leads to stainless steel wires cutting through the sternal body and is very commonly observed in clinical settings. 


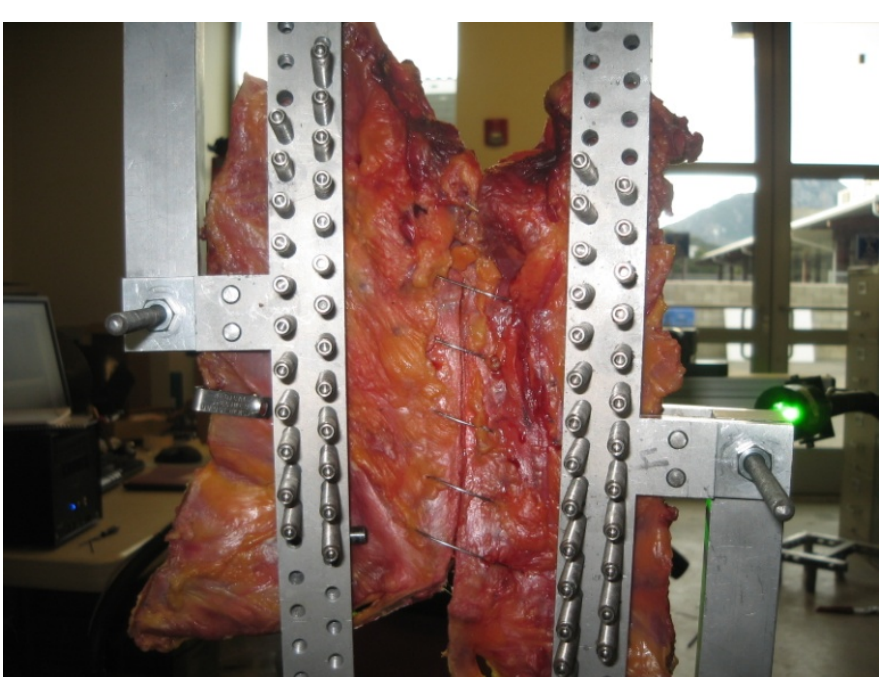

Figure 7.2: Picture taken at maximum displacement in the longitudinal direction. Slanted wires indicate plastic deformation at the midline.

Figure 7.2 shows a sternal construct closed with peristernal wires after testing. Wires wrapped around the sternal body are applied perpendicular to the midline of the sternotomy. Figure 7.2 shows the peristernal wires slanted after maximum displacement was achieved by the load frame and catastrophic failure had occurred. This suggests that after the construct had gone through a phase of elastic deformation and began to yield, the two sternal halves began sliding across each other. The sternum has permanently displaced relative to each other. This is the mode for post-yield behavior in peristernal wires when subjected to load in the longitudinal direction.

Only one statistical difference was found when testing in the rostro-caudal direction. When comparing females in groups $\mathrm{A}$ and $\mathrm{B}$, the difference their stiffness was found to be statistically significant. Noticeable trends that Sternalock devices possessed advantageous properties were observed in the evaluation of stiffness and post-yield displacement (Figure 6.17 and Figure 6.29). Otherwise, no statistically significant data 
was calculated. No separation in yield strength and maximum strength performance could be drawn from the data.

\subsection{Anterior-posterior shear}

Anterior-posterior, or transverse shear is also an important metric in evaluation median sternotomy closure techniques. Forces identical to this are seen in a clinical setting when a patient might roll on his or her back or bend in a particular direction.

Very little data was gathered from testing in this direction. Several obstacles existed that prevented us from recording meaningful data. No female specimen were available that were closed with Sternalock devices using box-plates (group C). Several data points were omitted due to Vic-3d being unable to process information.

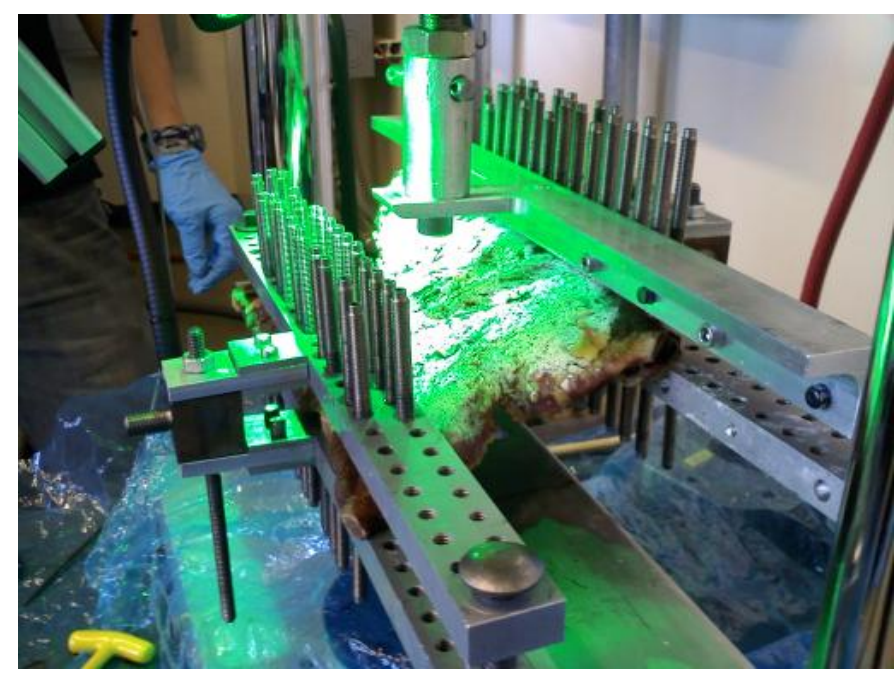

Figure 7.3: Picture taken at maximum displacement in the transverse direction. Failure did not occur during this test.

A very large amount of physiological compliance was present. This was due to the length of the ribs, presence of intercostal muscles, and cumbersome nature of the testfixtures used. Additional test fixtures were created and added to the system shown in 
Figure 7.3. This additional fixturing is difficult to see in the photograph, it involved bars that would apply force on the sternum closer to the midline of the construct. This attempt to avoid compliance was not sufficient to cause catastrophic failure in the device.

Due to the nature of the optical cameras, very little data was able to be captured during the tests. The positioning required that would allow an unobstructed view of the midline involved very close placement of the cameras to the sample, shown in Figure 7.4. This provided difficulties for the correlation software, and was not always able to extract meaningful data.

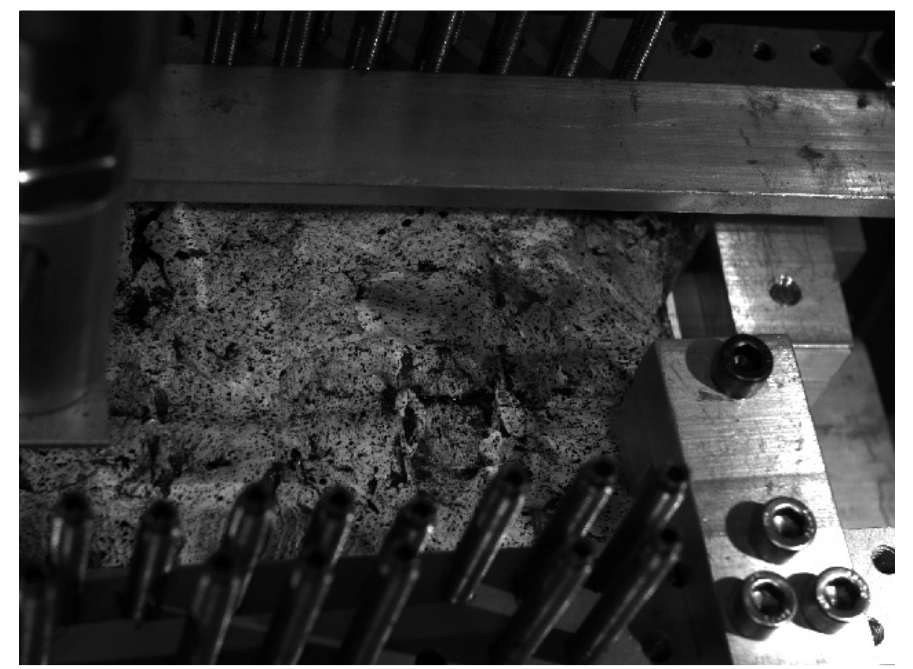

Figure 7.4: Picture taken from a camera used in the digital image correlation capture system.

You can also see issues in the camera's perspective from Figure 7.4. Deformation occurring due to the displacement of the test frame is neither vertical of the frame ( $\mathrm{y}$ axis), nor towards the camera (z-axis). Analysis of motion in one of these conventional directions is what Vic-3D is set up to do, one at a time. 
It may not be critical to evaluate this test mode in depth, as it is expected that the high compliance seen in our test fixture will also be experienced to a larger extent in any clinical setting. The combination of low expected forces with high compliance of the system may prevent yield or maximum strength to be reached for the construct.

\subsection{Texture correlation}

The force versus displacement graph obtained by a load read-out given by the load frame is often the data gathered in similar studies. This references the overall stress experienced by the load cell against the displacement measured by the load frame. Three dimensional texture correlation (Correlated Solutions Inc, Columbia, SC) was seen as an opportunity to comprehensively analyze biomechanical properties. Overall load experienced by the system could be referenced to the displacement at the midline of the construct, more accurately characterizing the properties of the model.

A three-dimensional map was created using Vic-3D (Correlated Solutions Inc, Columbia, SC) that revealed high stress areas, rates of strain, and videos to analyze the mode of failure. This system is capable of more analysis than what was utilized for this study and the use of it is recommended for future studies.

\subsection{Increased healing rate}

During the early post-operative phase after a median sternotomy, a very fragile fibrocartilage callus will form over the osteotomy site. This is the beginning of bone healing and ultimately leads to woven bone and mineralized bone. Beginning several 
weeks after surgery until 3 months post-operation, the fibrocartilage callus and woven bone provide the primary action for the healing process. This phase requires protection, as revascularization occurs. Complete immobilization of the area is critical to prevent severed blood vessels or damaging the woven bone. Sufficient immobilization may lead to faster healing times when compared to the insufficient immobilization achieved by wire closure methods [6].

A high stiffness or rigidity of the device-thorax construct will prevent any motion at the osteotomy site. Since the devices tested possessed maximum strength values in excess of what is typically experienced in-vivo, stiffness is seen as the most important and most practical factor in improving a sternal closure device.

\subsection{Blood supply}

As shown in Figure 3.14, internal mammary arteries run parallel to the sternal body and lead to branches that run across the sternum. The existence of blood vessels yields the possibility of interrupting blood flow to the area with any device that will wrap around the sternal body [28]. Any disruption of this blood flow may have the serious consequences of sternal ischemia, delayed wound healing and an increased sternal complication rate $[28,43,51]$. Ozaki et al. speculated that rigid plate fixation does not circumferentially compress the sternum and will not likely damage local sternal blood supply and subsequently lower the risk of sternal complications [28]. This is something that this study was not able to measure or evaluate, but is surely an advantage of the Sternalock device. 


\subsection{Gender differences}

The only statistically significance found showing the difference between the biomechanical properties of males and females was data for yield strength when tested under longitudinal distraction. Consistent trends were found for each property that was analyzed with the exception of stiffness data tested in distraction (a difference opposite of the trend was found). Differences were repeatedly noted in all tests. Maximum strength and post-yield displacement both showed statistically insignificant trends towards higher performance for male specimen. However, this study lacked the statistical power to prove this difference.

\subsection{Nature of failure}

An important note from this study is the location and nature of failures during testing. Failure modes for particular devices can give important insight to its weaknesses.

Classification of these failures can be put into two categories: device or physiologic failure. 


\subsubsection{Type of failure}

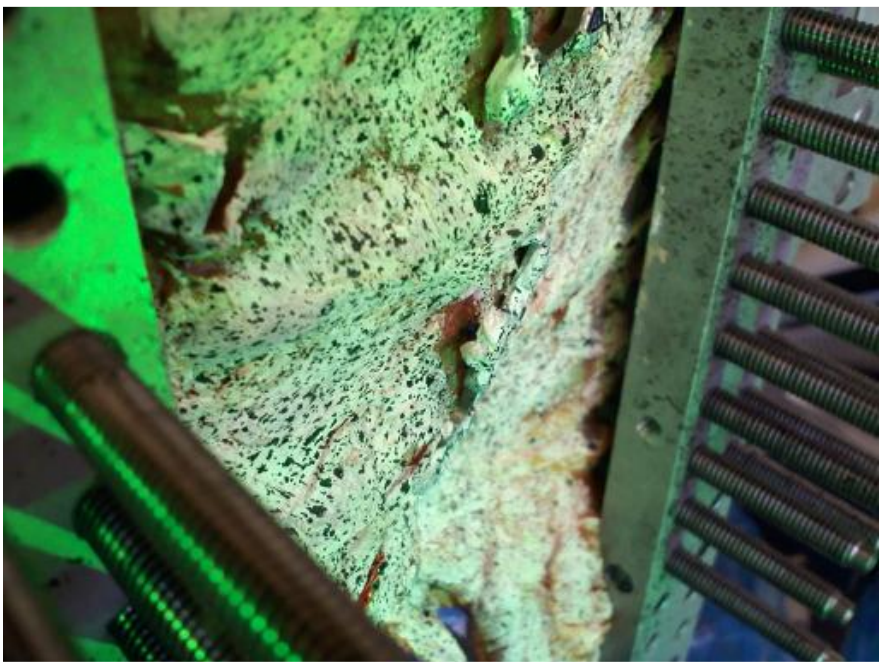

Figure 7.5: Picture taken after failure of the device occurred. A screw that fastened the plate to the sternum became dislodged.

Device failure was not often observed during this study. One case recorded was a Sternalock device in which the first X-plate had a screw that became dislodged from the sternum. The screw popped out, losing traction from its threads during catastrophic failure. This screw can be seen in Figure 7.5 in the middle of the photograph.

Examples of device failures that were seen in this study could be wire fracture, plate fracture, or untwisting of wires. However, device failures were extremely rare in this study and are not expected to be common in a clinical setting.

Physiologic failure was commonly noted in sternum closed by Sternalock devices.

Sternal union was so much stiffer than it would be normally in a healthy sternum that rib fracture and intercostals muscle tearing was often seen. Examples of this are in Figure 7.1 and Figure 7.6. In Figure 7.1, light can be seen protruding through the cadaver in the area of the lower clamp, this indicates rib fracture and separation. Physiologic failure 
may suggest that the true biomechanical properties of yield and maximum strength may be beyond what we were capable of measuring in this model.

\subsubsection{Location of failure}

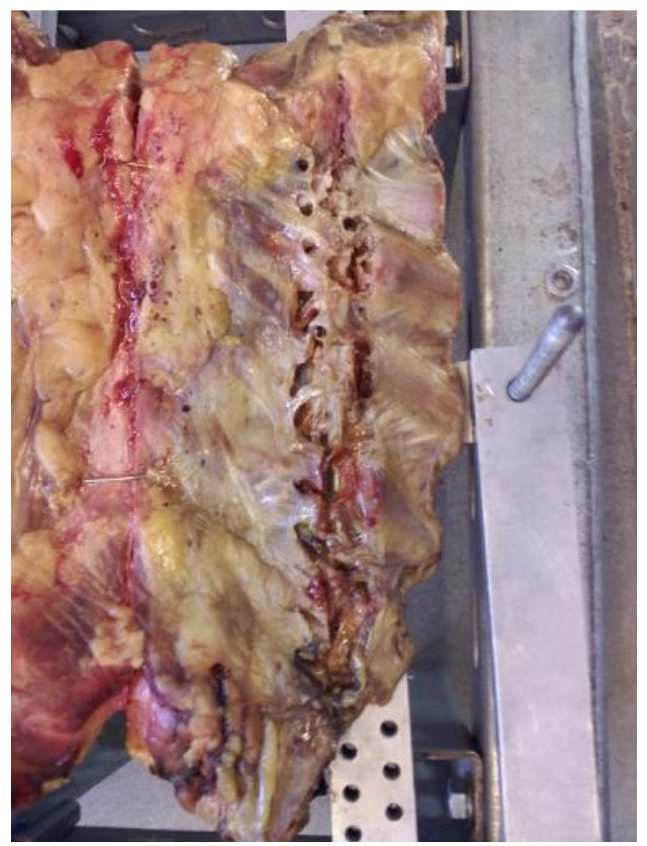

Figure 7.6: Picture taken after clamps were removed from the sternum. Obvious tearing of the intercostal muscles had taken place, as well as fracture of associated ribs in the area.

Using wire circlage as a closure method, failures were observed with wires began to cut through cortical bone. This is consistent with results published by previous studies, and have been seen to cause healing complications. The failure mode observed in Sternalock systems occurred away from the midline of the sternum. Rib fractures and intercostals muscle tear along the grip line of the clamps were often noted with minimal separation at the midline (Figure 7.6). Although we found significantly higher stiffness values and trends towards higher yield strengths for these Sternalock constructs, it can be inferred that the yield strengths and maximum strengths found are not completely representative of the device-sternum interface; the data found is a representation of the mechanical 
properties of the interaction between the clamps and cadaveric ribs. Because the closure at the midline was so rigid, stress fields were shifted further away from midline and resulted in catastrophic failure. This is more evidence supporting better performance of Sternalock devices.

\subsection{Statistical power}

42 cadaver models were used for this study. 3 fixation methods were tested to catastrophic failure in 3 different directions. Gender was also found to moderately influence biomechanical properties. The 42 specimen were divided into 9 groups, leaving 4.6 specimens per group - approximately 5. Considering gender in each of these groups, statistical analysis was often only left with 2 or 3 specimen in each group evaluated. In most cases, statistical power could not be achieved and sample sizes could not provide statistically significant differences between the three fixation methods. Trends were observed and interpreted in the data, but a future study with a larger sample size or more narrow focus could be done to verify these findings. Larger quantities could not be obtained for this study due to the large cost of cadavers.

A weakness in this study was the inability to test both male and female specimen in each group for every direction. Only 5 male specimens were available in group B and 5 female specimens for group C. An attempt was made to include at least 2 samples of each gender in each fixation method but this was not possible due to uneven proportions of samples. To further analyze the role of gender on biomechanical properties, a sufficient number of samples from each gender should be tested in each direction. 


\subsection{Post-Yield Displacement}

Post-yield displacement is an indicator of damage to the bone in a cadaver model. This may translate into very undesirable outcomes in clinical settings. In the case of sternum closed with peristernal wires, this is usually characterized by wire cutting through bone. This has been cited for the reason for sternal mal-union or non-union, dehiscence, and mediastinitis. Therefore, wire cutting through bone, or any damage to bone should be avoided at all costs. Due to the minimal displacement associated with sternum closed with Sternalock devices, very little post-yield displacement occurred. This is evidence for limited damage to the bone before catastrophic failure.

\section{Conclusions}

1) Overall, Sternalock is less likely to fail under both lateral distraction and longitudinal shear. This rigid plate fixation device demonstrates superior rigidity, and shows promise for larger yield load and maximum load values. Rigid plate fixation is more equipped to provide support in all directions that might occur in a clinical setting, where peristernal wires only support a sternal construct in one direction.

2) Post-sternotomy constructs require a high resistance to movement. A completely immobilized union can allow for uninterrupted osseous healing and correlated with decreased healing times. 
3) Directly linked to bone damage, post-yield displacement occurred in limited amounts with Sternalock devices. This may prevent healing complications such as sternal mal-union, non-union, dehiscence, or mediastinitis.

4) Evidence has been shown that revealed differences in mechanical behavior between cadaveric models of male and female subjects.

5) Sternalock plates were found to be stiffer and stronger than the native physiology of the thorax. Under high loads, sternum closed with Sternalock devices failed due to weaknesses in native tissue rather than related to the device. 


\section{References}

1. The-American-Heart-Association. Open-Heart Surgery Statistics. Available from: http://www.americanheart.org/presenter.jhtml?identifier=4674.

2. Losanoff, J.E., B.W. Richman, and J.W. Jones, Disruption and infection of median sternotomy: a comprehensive review. Eur J Cardiothorac Surg, 2002. 21(5): p. 831-9.

3. Julian, O.C., et al., The median sternal incision in intracardiac surgery with extracorporeal circulation; a general evaluation of its use in heart surgery. Surgery, 1957. 42(4): p. 753-61.

4. Sargent, L.A., et al., The healing sternum: a comparison of osseous healing with wire versus rigid fixation. Ann Thorac Surg, 1991. 52(3): p. 490-4.

5. Sarr, M.G., V.L. Gott, and T.R. Townsend, Mediastinal infection after cardiac surgery. Ann Thorac Surg, 1984. 38(4): p. 415-23.

6. Iriz, E., et al., Corpus sterni reinforcement improves the stability of primary sternal closure in high-risk patients. Surg Today, 2007. 37(3): p. 197-201.

7. Bitkover, C.Y. and B. Gardlund, Mediastinitis after cardiovascular operations: a case-control study of risk factors. Ann Thorac Surg, 1998. 65(1): p. 36-40.

8. $\quad$ Casha, A.R., et al., Fatigue testing median sternotomy closures. Eur J Cardiothorac Surg, 2001. 19(3): p. 249-53.

9. McGregor, W.E., D.R. Trumble, and J.A. Magovern, Mechanical analysis of midline sternotomy wound closure. J Thorac Cardiovasc Surg, 1999. 117(6): p. 1144-50.

10. Losanoff, J.E., et al., Biomechanical comparison of median sternotomy closures. Ann Thorac Surg, 2004. 77(1): p. 203-9.

11. Cheng, W., et al., Biomechanical study of sternal closure techniques. Ann Thorac Surg, 1993. 55(3): p. 737-40.

12. Sanfelippo, P.M. and G.K. Danielson, Complications associated with median sternotomy. J Thorac Cardiovasc Surg, 1972. 63(3): p. 419-23. 
13. Losanoff, J.E., et al., Single wire versus double wire loops for median sternotomy closure: experimental biomechanical study using a human cadaveric model. Ann Thorac Surg, 2007. 84(4): p. 1288-93.

14. Schimmer, C., W. Reents, and O. Elert, Primary closure of median sternotomy: a survey of all German surgical heart centers and a review of the literature concerning sternal closure technique. Thorac Cardiovasc Surg, 2006. 54(6): p. 408-13.

15. Davis, K.M., et al., Median sternotomy closure in dogs: a mechanical comparison of technique stability. Vet Surg, 2006. 35(3): p. 271-7.

16. Tavilla, G., et al., Modified Robicsek technique for complicated sternal closure. Ann Thorac Surg, 1991. 52(5): p. 1179-80.

17. Timmes, J.J., et al., A new method of sternal approximation. Ann Thorac Surg, 1973. 15(5): p. 544-6.

18. Losanoff, J.E., J.W. Jones, and B.W. Richman, Primary closure of median sternotomy: techniques and principles. Cardiovasc Surg, 2002. 10(2): p. 102-10.

19. Rubio, P.A., et al., Median sternotomy closure with running wire: a simplified method. J Thorac Cardiovasc Surg, 1977. 74(4): p. 651-2.

20. Di Marco, R.F., Jr., et al., Interlocking figure-of-8 closure of the sternum. Ann Thorac Surg, 1989. 47(6): p. 927-9.

21. Murray, K.D. and M.K. Pasque, Routine sternal closure using six overlapping figure-of-8 wires. Ann Thorac Surg, 1997. 64(6): p. 1852-4.

22. McGregor, W.E., et al., Improvement of sternal closure stability with reinforced steel wires. Ann Thorac Surg, 2003. 76(5): p. 1631-4.

23. Zeitani, J., et al., Performance of a novel sternal synthesis device after median and faulty sternotomy: mechanical test and early clinical experience. Ann Thorac Surg, 2008. 85(1): p. 287-93.

24. Hoffman, G.R. and F.B. Moloney, The stability of facial osteotomies. 1. The evolution of maxillary, mandibular and chin osteotomies. Aust Dent J, 1995. 40(3): p. 182-5. 
25. Rohrich, R.J. and D. Watumull, Comparison of rigid plate versus wire fixation in the management of zygoma fractures: a long-term follow-up clinical study. Plast Reconstr Surg, 1995. 96(3): p. 570-5.

26. Zachariades, N., I. Papademetriou, and G. Rallis, Complications associated with rigid internal fixation of facial bone fractures. J Oral Maxillofac Surg, 1993. 51(3): p. 275-8; discussion 278-9.

27. Thaller, S.R., D. Reavie, and A. Daniller, Rigid internal fixation with miniplates and screws: a cost-effective technique for treating mandible fractures? Ann Plast Surg, 1990. 24(6): p. 469-74.

28. Ozaki, W., et al., Biomechanical study of sternal closure using rigid fixation techniques in human cadavers. Ann Thorac Surg, 1998. 65(6): p. 1660-5.

29. Raman, J., D. Straus, and D.H. Song, Rigid plate fixation of the sternum. Ann Thorac Surg, 2007. 84(3): p. 1056-8.

30. Shih, C.C., et al., Potential risk of sternal wires. Eur J Cardiothorac Surg, 2004. 25(5): p. 812-8.

31. Cohen, D.J. and L.V. Griffin, A biomechanical comparison of three sternotomy closure techniques. Ann Thorac Surg, 2002. 73(2): p. 563-8.

32. Serry, C., et al., Sternal wound complications. Management and results. J Thorac Cardiovasc Surg, 1980. 80(6): p. 861-7.

33. Stoney, W.S., et al., Median sternotomy dehiscence. Ann Thorac Surg, 1978. 26(5): p. 421-6.

34. Strecker, T., et al., Sternal wound infections following cardiac surgery: risk factor analysis and interdisciplinary treatment. Heart Surg Forum, 2007. 10(5): p. E36671.

35. Shumacker, H.B., Jr. and I. Mandelbaum, Continuous antibiotic irrigation in the treatment of infection. Arch Surg, 1963. 86: p. 384-7.

36. Song, D.H., et al., Primary sternal plating in high-risk patients prevents mediastinitis. Eur J Cardiothorac Surg, 2004. 26(2): p. 367-72.

37. Sirivella, S., et al., Improved technique for closure of median sternotomy incision. Mersilene tapes versus standard wire closure. J Thorac Cardiovasc Surg, 1987. 94(4): p. 591-5. 
38. Goldman, G., et al., Effective technique of sternum closure in high-risk patients. Arch Surg, 1988. 123(3): p. 386-7.

39. Zacharias, A. and R.H. Habib, Factors predisposing to median sternotomy complications. Deep vs superficial infection. Chest, 1996. 110(5): p. 1173-8.

40. Jutley, R.S., et al., Calculating stress magnitude between sternotomy closures and sternum. Eur J Cardiothorac Surg, 2001. 20(5): p. 1071-3.

41. El Oakley, R.M. and J.E. Wright, Postoperative mediastinitis: classification and management. Ann Thorac Surg, 1996. 61(3): p. 1030-6.

42. Molina, J.E., E.C. Nelson, and R.R. Smith, Treatment of postoperative sternal dehiscence with mediastinitis: twenty-four-year use of a single method. J Thorac Cardiovasc Surg, 2006. 132(4): p. 782-7.

43. Arnold, M., The surgical anatomy of sternal blood supply. J Thorac Cardiovasc Surg, 1972. 64(4): p. 596-610.

44. Szivek, J.A., M. Thomas, and J.B. Benjamin, Characterization of a synthetic foam as a model for human cancellous bone. J Appl Biomater, 1993. 4(3): p. 269-72.

45. Bruhin, R., et al., Numerical simulation techniques to study the structural response of the human chest following median sternotomy. Ann Thorac Surg, 2005. 80(2): p. 623-30.

46. Bay, B.K., Texture correlation: a method for the measurement of detailed strain distributions within trabecular bone. J Orthop Res, 1995. 13(2): p. 258-67.

47. McNeill, S.R., ESTIMATION OF STRESS INTENSITY FACTOR BY DIGITAL IMAGE CORRELATION. Engineering Fracture Mechanics, 1987. 28(1): p. 101112.

48. Russell, S.S., STRAIN FIELD ANALYSIS ACQUIRED THROUGH CORRELATION OF X-RAY RADIOGRAPHS OF FIBER-REINFORCED COMPOSITE LAMINATES. Soc for Experimental Mechanics Inc, 1986.

49. Casha, A.R., et al., A biomechanical study of median sternotomy closure techniques. Eur J Cardiothorac Surg, 1999. 15(3): p. 365-9.

50. Losanoff, J.E., et al., Biomechanical porcine model of median sternotomy closure. J Surg Res, 2002. 107(1): p. 108-12. 
Biomechanical Comparison of Wire Circlage and Rigid Plate Fixation for Median Sternotomy Closure in Human Cadaver Specimens

51. Seyfer, A.E., et al., Sternal blood flow after median sternotomy and mobilization of the internal mammary arteries. Surgery, 1988. 104(5): p. 899-904. 


\title{
Appendix A: Statistical Analysis - Lateral distraction
}

\author{
General Linear Model: Stiffness, Yield Load, ... versus Fixation Met, Gender

$\begin{array}{llrl}\text { Factor } & \text { Type } & \text { Levels } & \text { Values } \\ \text { Fixation Method } & \text { fixed } & 3 \text { A, B, C } \\ \text { Gender } & 2 \text { fixed } & 2 & \text { F M }\end{array}$

Analysis of Variance for Stiffness, using Adjusted SS for Tests

\begin{tabular}{|c|c|c|c|c|c|c|c|c|c|}
\hline Source & & & $\mathrm{DF}$ & Seq & SS & Adj SS & Adj MS & F & P \\
\hline Age & & & 1 & 2879 & 103 & 25789181 & 25789181 & 20.93 & 0.002 \\
\hline Fixation & Method & & 2 & 39360 & 861 & 35164464 & 17582232 & 14.27 & 0.002 \\
\hline Gender & & & 1 & 1480 & 229 & 1429128 & 1429128 & 1.16 & 0.313 \\
\hline Fixation & Method*Ge & ende & er & 6886 & 150 & 6886150 & 3443075 & 2.79 & 0.120 \\
\hline Error & & & 8 & 9855 & 121 & 9855121 & 1231890 & & \\
\hline Total & & & 14 & 60461 & 464 & & & & \\
\hline$S=1109$ & $\mathrm{R}-\mathrm{SC}$ & $q=$ & $83.70 \%$ & $R-S$ & $q(\operatorname{adj})$ & )$=71.48 \%$ & & & \\
\hline Term & Coef & $\mathrm{SE}$ & Coef & $\mathrm{T}$ & $\mathrm{P}$ & $P$ & & & \\
\hline Constant & -12108 & & 3165 & -3.83 & 0.005 & & & & \\
\hline Age & 212.49 & 4 & 46.44 & 4.58 & 0.002 & & & & \\
\hline
\end{tabular}

$\begin{array}{rrrrrr}\text { Obs } & \text { Stiffness } & \text { Fit } & \text { SE Fit } & \text { Residual } & \text { St Resid } \\ 4 & 453.28 & 2474.62 & 694.75 & -2021.34 & -2.34 \mathrm{R} \\ 5 & 532.61 & 532.61 & 1109.91 & 0.00 & \text { * X }\end{array}$

$R$ denotes an observation with a large standardized residual.

$\mathrm{X}$ denotes an observation whose $\mathrm{X}$ value gives it large leverage.

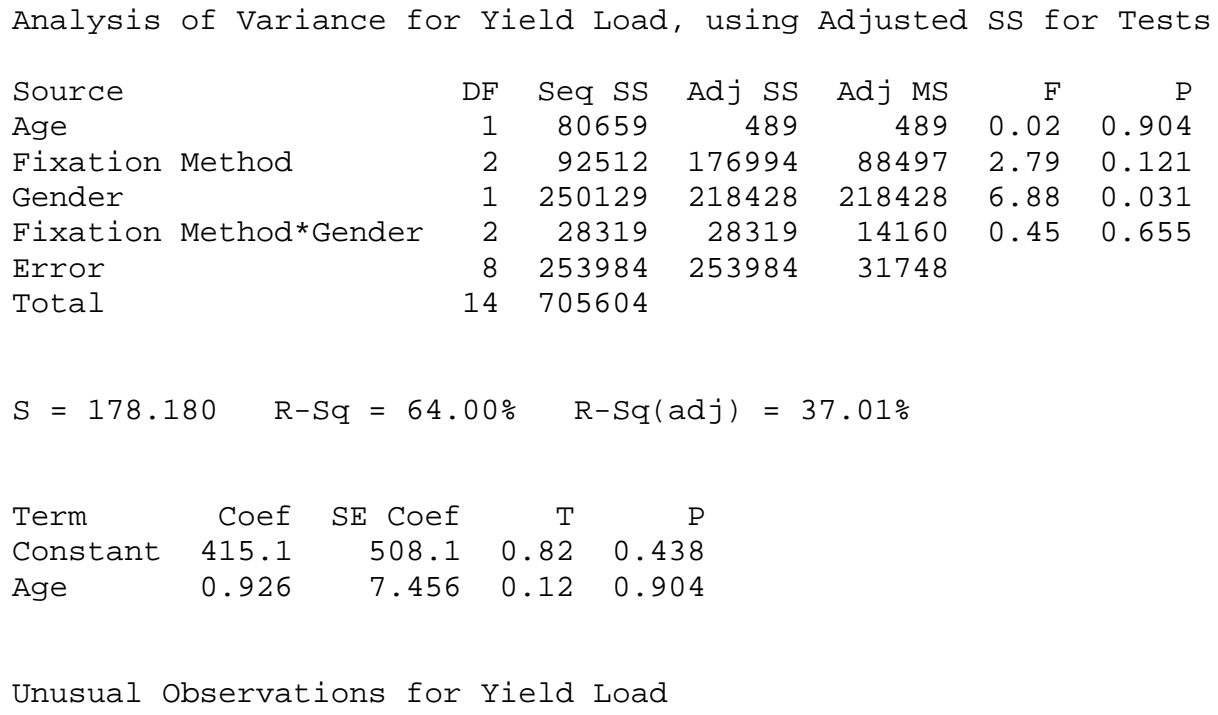


Biomechanical Comparison of Wire Circlage and Rigid Plate Fixation for Median Sternotomy Closure in Human Cadaver Specimens

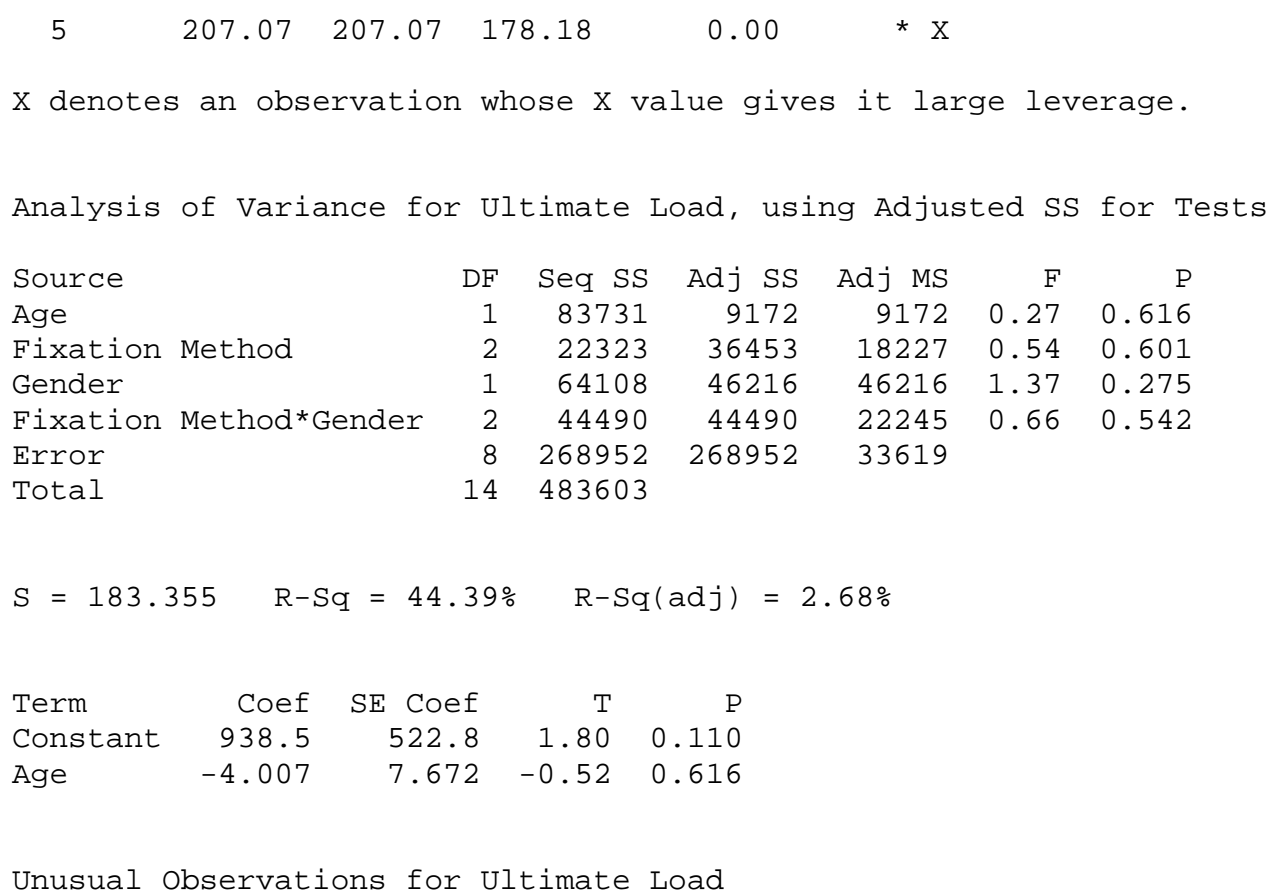

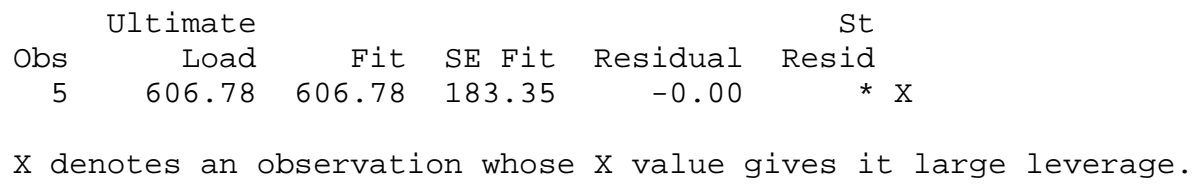

Analysis of Variance for Post-Yield Disp, using Adjusted SS for Tests

\begin{tabular}{|c|c|c|c|c|c|c|c|c|}
\hline Source & & & $\mathrm{DF}$ & Seq SS & Adj SS & Adj MS & $\mathrm{F}$ & $\mathrm{P}$ \\
\hline Age & & & 1 & 0.0794 & 0.4297 & 0.4297 & 1.51 & 0.255 \\
\hline Fixation Met & hod & & 2 & 2.1831 & 2.4930 & 1.2465 & 4.37 & 0.052 \\
\hline Gender & & & 1 & 0.5907 & 0.5700 & 0.5700 & 2.00 & 0.195 \\
\hline Fixation Met & hod*Genc & der & 2 & 0.1009 & 0.1009 & 0.0505 & 0.18 & 0.841 \\
\hline Error & & & 8 & 2.2839 & 2.2839 & 0.2855 & & \\
\hline Total & & & 14 & 5.2380 & & & & \\
\hline$S=0.534307$ & $\mathrm{R}-\mathrm{Sq}$ & $=5$ & $56.40 \%$ & $\mathrm{R}-\mathrm{Sq}$ & $(\operatorname{adj})$ & $23.70 \%$ & & \\
\hline Term & Coef & $\mathrm{SE}$ & Coef & $\mathrm{T}$ & $\mathrm{P}$ & & & \\
\hline Constant & 2.409 & & 1.524 & 1.58 & 0.153 & & & \\
\hline Age & .02743 & 0.0 & 02236 & -1.23 & 0.255 & & & \\
\hline
\end{tabular}

Unusual Observations for Post-Yield Disp

\begin{tabular}{rrrrrr}
\multicolumn{9}{c}{ Post-Yield } & & & & St \\
Obs & Disp & Fit & SE Fit & Residual & Resid \\
5 & 1.34083 & 1.34083 & 0.53431 & 0.00000 & * X
\end{tabular}

$\mathrm{X}$ denotes an observation whose $\mathrm{X}$ value gives it large leverage.

Tukey 95.0\% Simultaneous Confidence Intervals

Response Variable Stiffness 
Biomechanical Comparison of Wire Circlage and Rigid Plate Fixation for Median Sternotomy Closure in Human Cadaver Specimens

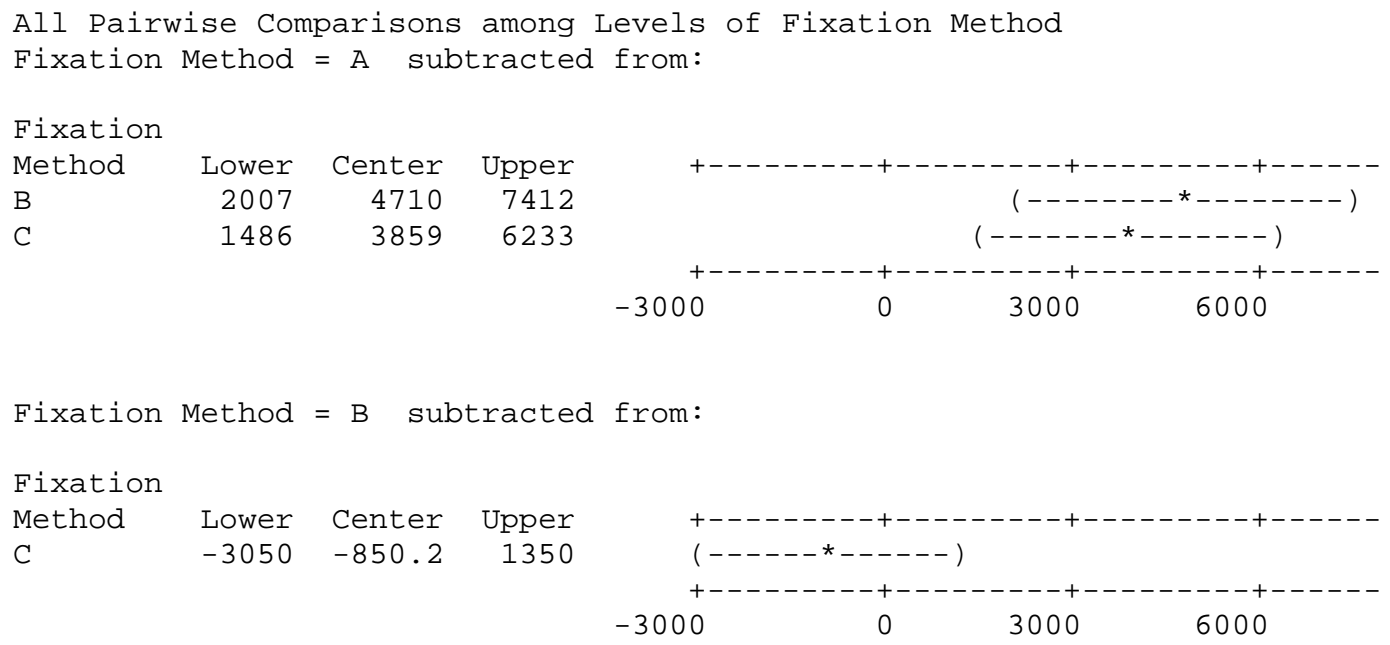

Tukey Simultaneous Tests

Response Variable Stiffness

All Pairwise Comparisons among Levels of Fixation Method

Fixation Method = A subtracted from:

$\begin{array}{lrrrr}\text { Fixation } & \text { Difference } & \text { SE of } & \text { Adjusted } \\ \text { Method } & \text { of Means } & \text { Difference } & \text { T-Value } & \text { P-Value } \\ \text { B } & 4710 & 945.9 & 4.979 & 0.0027 \\ \text { C } & 3859 & 830.8 & 4.645 & 0.0042\end{array}$

Fixation Method = B subtracted from:

$\begin{array}{lrrrr}\text { Fixation } & \text { Difference } & \text { SE of } & & \text { Adjusted } \\ \text { Method } & \text { of Means } & \text { Difference } & \text { T-Value } & \text { P-Value } \\ \text { C } & -850.2 & 770.1 & -1.104 & 0.5382\end{array}$

Tukey 95.0\% Simultaneous Confidence Intervals Response Variable Stiffness

All Pairwise Comparisons among Levels of Gender

Gender $=\mathrm{F}$ subtracted from:

Gender Lower Center Upper

$\begin{array}{lrrr}\text { M } & -790.7 & 693.0 & 2177\end{array}$

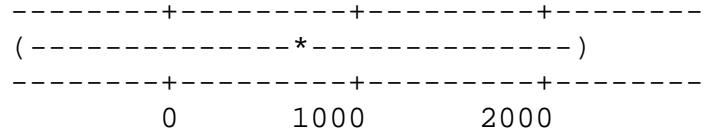

Tukey Simultaneous Tests

Response Variable Stiffness

All Pairwise Comparisons among Levels of Gender

Gender $=\mathrm{F}$ subtracted from:

$\begin{array}{lrrrr} & \text { Difference } & \text { SE of } & & \text { Adjusted } \\ \text { Gender } & \text { of Means } & \text { Difference } & \text { T-Value } & \text { P-Value } \\ \text { M } & 693.0 & 643.4 & 1.077 & 0.3129\end{array}$

Tukey 95.0\% Simultaneous Confidence Intervals

Response Variable Stiffness

All Pairwise Comparisons among Levels of Fixation Method*Gender

Fixation Method $=\mathrm{A}$ 
Biomechanical Comparison of Wire Circlage and Rigid Plate Fixation for Median Sternotomy Closure in Human Cadaver Specimens

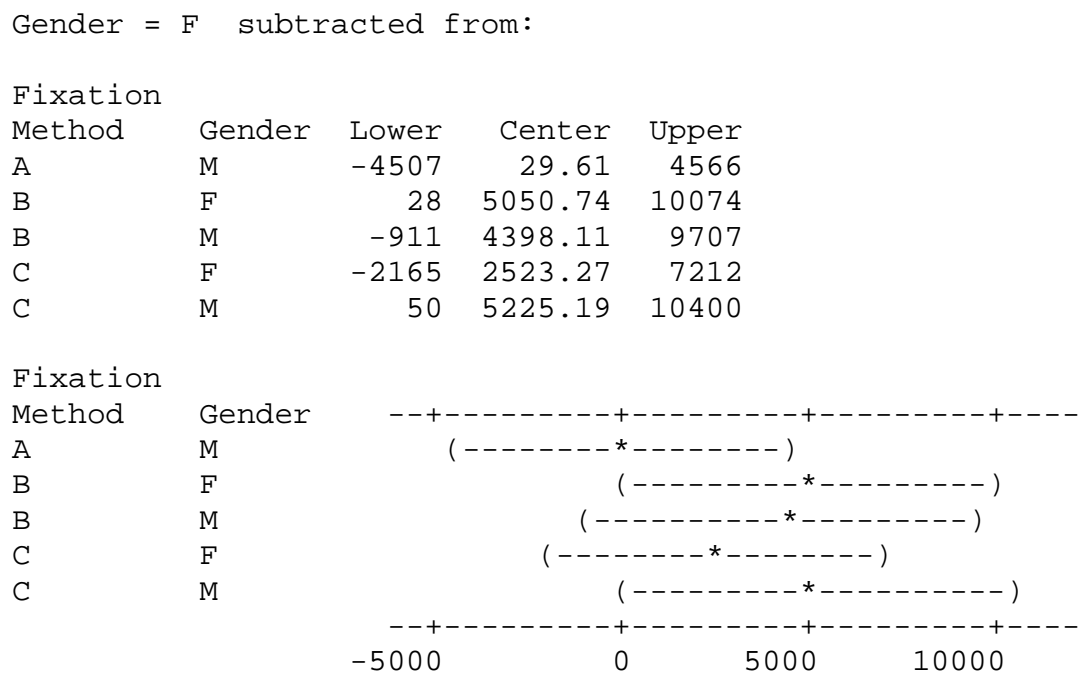

Fixation Method $=\mathrm{A}$

Gender $=\mathrm{M}$ subtracted from:

$\begin{array}{llrrr}\text { Fixation } & & & \\ \text { Method } & \text { Gender } & \text { Lower } & \text { Center } & \text { Upper } \\ \text { B } & \text { F } & 1431.8 & 5021 & 8610 \\ \text { B } & \text { M } & 389.1 & 4369 & 8348 \\ \text { C } & \text { F } & -610.0 & 2494 & 5597 \\ \text { C } & \text { M } & 1396.9 & 5196 & 8994\end{array}$

Fixation

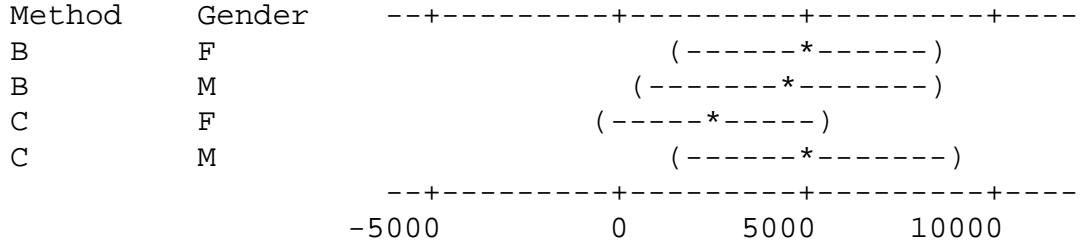

Fixation Method $=\mathrm{B}$

Gender $=F$ subtracted from:

Fixation

$\begin{array}{llrrr}\text { Method } & \text { Gender } & \text { Lower } & \text { Center } & \text { Upper } \\ \text { B } & \text { M } & -4357 & -653 & 3052 \\ \text { C } & \text { F } & -6225 & -2527 & 1170 \\ \text { C } & \text { M } & -3548 & 174 & 3897\end{array}$

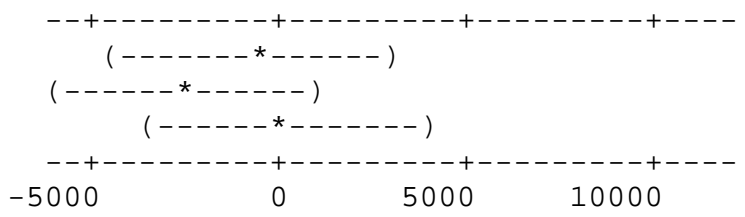

Fixation Method $=\mathrm{B}$

Gender $=M$ subtracted from:

Fixation

$\begin{array}{llrrr}\text { Method } & \text { Gender } & \text { Lower } & \text { Center } & \text { Upper } \\ \text { C } & \text { F } & -5949 & -1875 & 2200 \\ \text { C } & \text { M } & -3253 & 827 & 4907\end{array}$

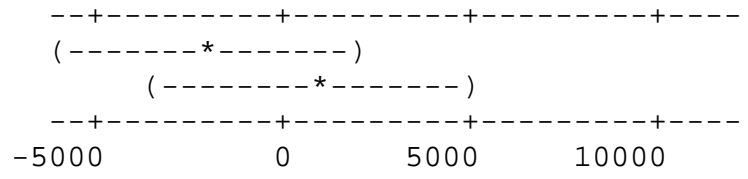


Biomechanical Comparison of Wire Circlage and Rigid Plate Fixation for Median Sternotomy Closure in Human Cadaver Specimens
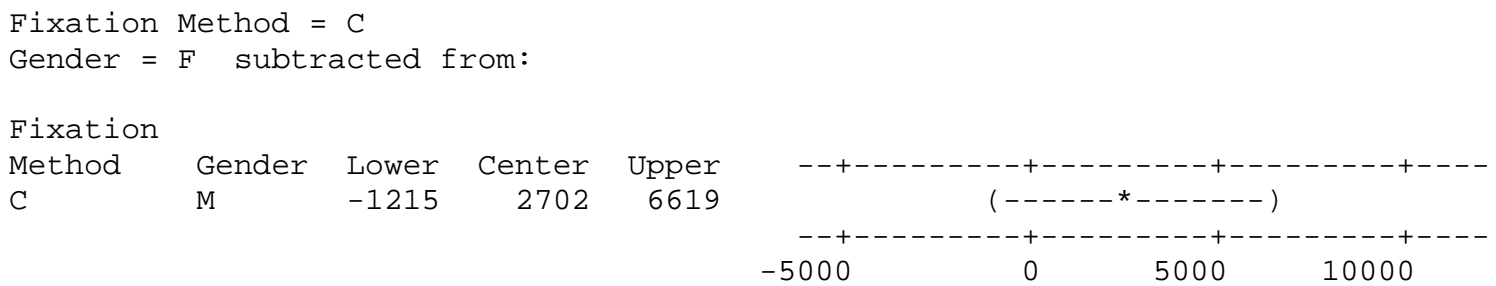

Tukey Simultaneous Tests Response Variable Stiffness

All Pairwise Comparisons among Levels of Fixation Method*Gender Fixation Method = A

Gender $=\mathrm{F}$ subtracted from:

$\begin{array}{llrrrr}\text { Fixation } & \text { Difference } & \text { SE of } & & \text { Adjusted } \\ \text { Method } & \text { Gender } & \text { of Means } & \text { Difference } & \text { T-Value } & \text { P-Value } \\ \text { A } & \text { M } & 29.61 & 1241 & 0.02386 & 1.0000 \\ \text { B } & \text { F } & 5050.74 & 1374 & 3.67590 & 0.0486 \\ \text { B } & \text { M } & 4398.11 & 1452 & 3.02864 & 0.1149 \\ \text { C } & \text { F } & 2523.27 & 1282 & 1.96754 & 0.4313 \\ \text { C } & \text { M } & 5225.19 & 1416 & 3.69139 & 0.0476\end{array}$

Fixation Method $=\mathrm{A}$

Gender $=M$ subtracted from:

\begin{tabular}{|c|c|c|c|c|c|}
\hline Fixation & & Difference & SE of & & Adjusted \\
\hline lethod & Gender & of Means & Difference & T-Value & P-Value \\
\hline 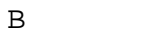 & $\mathrm{F}$ & 5021 & 981.8 & 5.114 & 0.0080 \\
\hline B & M & 4369 & 1088.5 & 4.013 & 0.0312 \\
\hline & $\mathrm{F}$ & 2494 & 849.0 & 2.937 & 0.1297 \\
\hline$\Omega_{2}$ & M & 5196 & 1039.1 & 5.000 & 0.0091 \\
\hline
\end{tabular}

Fixation Method $=\mathrm{B}$

Gender $=\mathrm{F}$ subtracted from:

\begin{tabular}{llrrrr} 
Fixation & \multicolumn{2}{c}{ Difference } & SE of & Adjusted \\
Method & Gender & Of Means & Difference & T-Value & P-Value \\
B & M & -653 & 1013 & -0.644 & 0.9837 \\
C & F & -2527 & 1011 & -2.499 & 0.2293 \\
C & M & 174 & 1018 & 0.171 & 1.0000
\end{tabular}

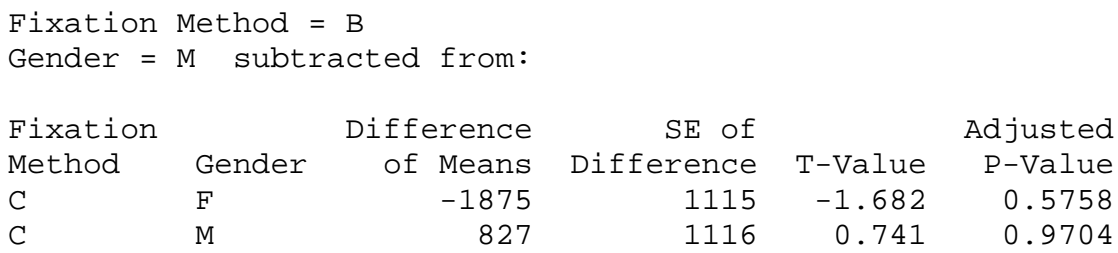


Biomechanical Comparison of Wire Circlage and Rigid Plate Fixation for Median Sternotomy Closure in Human Cadaver Specimens

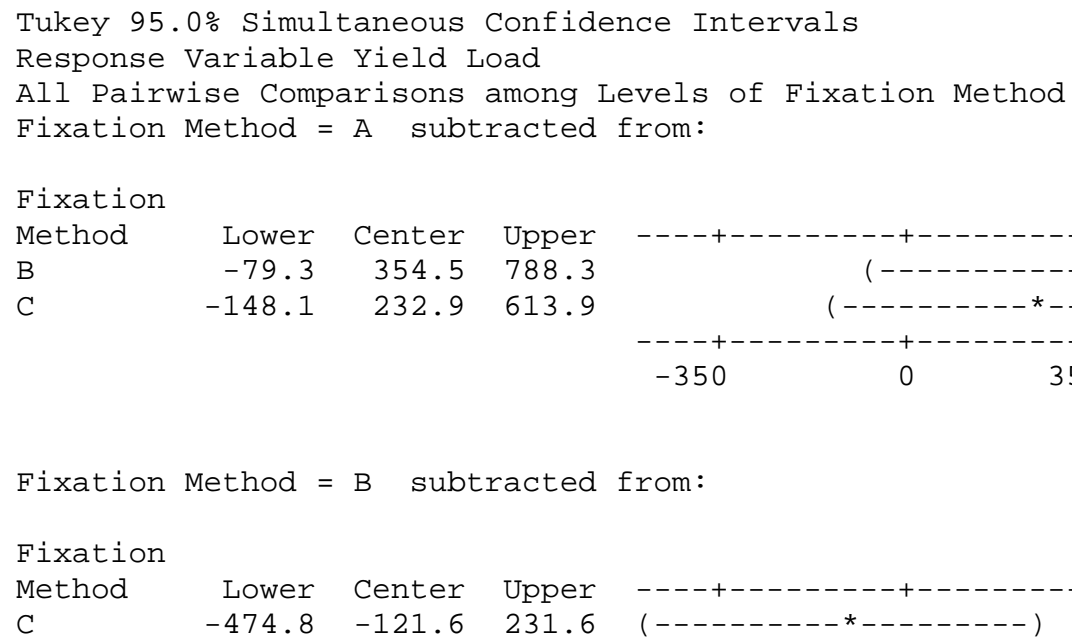

Fixation Method $=B$ subtracted from:

Fixation

Method

$\begin{array}{rrr}\text { Lower } & \text { Center } & \text { Upper } \\ -474.8 & -121.6 & 231.6\end{array}$

Tukey Simultaneous Tests

Response Variable Yield Load

All Pairwise Comparisons among Levels of Fixation Method

Fixation Method = A subtracted from:

$\begin{array}{lrrrr}\text { Fixation } & \text { Difference } & \text { SE of } & \text { Adjusted } \\ \text { Method } & \text { of Means } & \text { Difference } & \text { T-Value } & \text { P-Value } \\ \text { B } & 354.5 & 151.9 & 2.335 & 0.1077 \\ \text { C } & 232.9 & 133.4 & 1.746 & 0.2473\end{array}$

Fixation Method = B subtracted from:

$\begin{array}{lrrrr}\text { Fixation } & \text { Difference } & \text { SE of } & \text { Adjusted } \\ \text { Method } & \text { of Means } & \text { Difference } & \text { T-Value } & \text { P-Value } \\ \text { C } & -121.6 & 123.6 & -0.9837 & 0.6067\end{array}$

Tukey 95.0\% Simultaneous Confidence Intervals Response Variable Yield Load

All Pairwise Comparisons among Levels of Gender

Gender $=F$ subtracted from:

$\begin{array}{lrrr}\text { Gender } & \text { Lower Center Upper } \\ \text { M } & 32.74 & 270.9 & 509.1\end{array}$

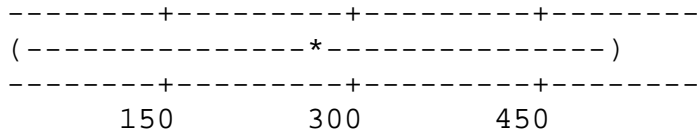

Tukey Simultaneous Tests

Response Variable Yield Load

All Pairwise Comparisons among Levels of Gender

Gender $=F$ subtracted from:

$\begin{array}{rrrrr} & \text { Difference } & \text { SE of } & \text { Adjusted } \\ \text { Gender } & \text { of Means } & \text { Difference } & \text { T-Value } & \text { P-Value } \\ \text { M } & 270.9 & 103.3 & 2.623 & 0.0305\end{array}$

Tukey 95.0\% Simultaneous Confidence Intervals

Response Variable Yield Load 
Biomechanical Comparison of Wire Circlage and Rigid Plate Fixation for Median Sternotomy Closure in Human Cadaver Specimens

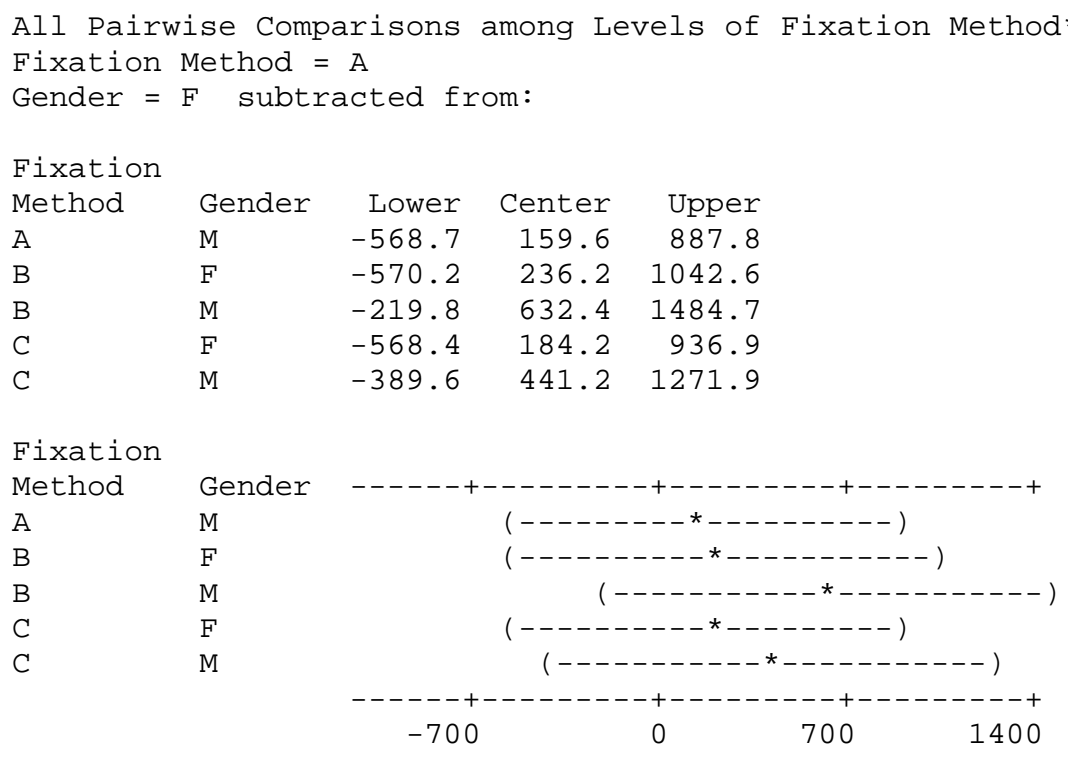

Fixation Method $=\mathrm{A}$

Gender $=M$ subtracted from:

$\begin{array}{llrrr}\begin{array}{llrr}\text { Fixation } \\ \text { Method }\end{array} & \text { Gender } & \text { Lower } & \text { Center } & \text { Upper } \\ \text { B } & \text { F } & -499.6 & 76.63 & 652.8 \\ \text { B } & \text { M } & -165.9 & 472.89 & 1111.7 \\ \text { C } & \text { F } & -473.6 & 24.68 & 522.9 \\ \text { C } & \text { M } & -328.2 & 281.61 & 891.4\end{array}$

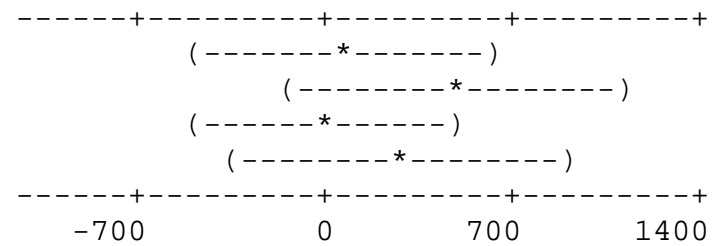

Fixation Method $=\mathrm{B}$

Gender $=F$ subtracted from:

Fixation

$\begin{array}{llrrr}\text { Method } & \text { Gender } & \text { Lower } & \text { Center } & \text { Upper } \\ \text { B } & \text { M } & -198.4 & 396.26 & 991.0 \\ \text { C } & \text { F } & -645.5 & -51.95 & 541.6 \\ \text { C } & \text { M } & -392.6 & 204.98 & 802.5\end{array}$

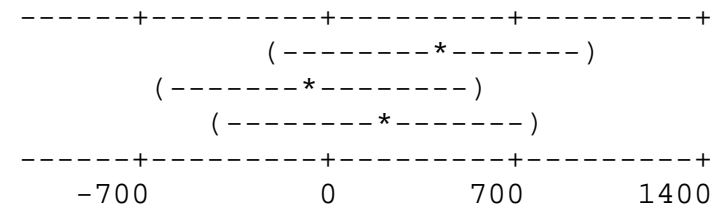

Fixation Method $=\mathrm{B}$

Gender $=M$ subtracted from:

$\begin{array}{llrrr}\text { Fixation } & & & & \\ \text { Method } & \text { Gender } & \text { Lower } & \text { Center } & \text { Upper } \\ \text { C } & \text { F } & -1102 & -448.2 & 205.9 \\ \text { C } & \text { M } & -846 & -191.3 & 463.7\end{array}$

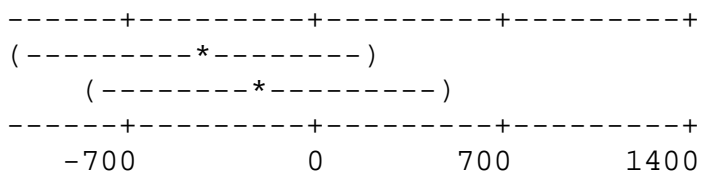

Fixation Method $=\mathrm{C}$

Gender $=\mathrm{F}$ subtracted from:

Fixation 
Biomechanical Comparison of Wire Circlage and Rigid Plate Fixation for Median Sternotomy Closure in Human Cadaver Specimens

\begin{tabular}{|c|c|c|c|c|c|}
\hline $\begin{array}{l}\text { Method } \\
\text { C }\end{array}$ & $\begin{array}{l}\text { Gender } \\
\text { M }\end{array}$ & $\begin{array}{r}\text { Lower } \\
-371.9\end{array}$ & $\begin{array}{r}\text { Center } \\
256.9\end{array}$ & $\begin{array}{l}\text { Upper } \\
885.7\end{array}$ & $\begin{array}{c}-----++-------++---------+---------+ \\
(--------\star--------)\end{array}$ \\
\hline & & & & & -700 \\
\hline
\end{tabular}

Tukey Simultaneous Tests

Response Variable Yield Load

All Pairwise Comparisons among Levels of Fixation Method*Gender Fixation Method = A

Gender $=F$ subtracted from:

\begin{tabular}{llrrrr} 
Fixation & \multicolumn{2}{c}{ Difference } & SE of & Adjusted \\
Method & Gender & of Means & Difference & T-Value & P-Value \\
A & M & 159.6 & 199.2 & 0.8009 & 0.9594 \\
B & F & 236.2 & 220.6 & 1.0708 & 0.8801 \\
B & M & 632.4 & 233.1 & 2.7129 & 0.1742 \\
C & F & 184.2 & 205.9 & 0.8949 & 0.9374 \\
C & M & 441.2 & 227.2 & 1.9414 & 0.4437
\end{tabular}

Fixation Method $=\mathrm{A}$

Gender $=M$ subtracted from:

\begin{tabular}{llrrrr} 
Fixation & \multicolumn{2}{c}{ Difference } & SE of & Adjusted \\
Method & Gender & of Means & Difference & T-Value & P-Value \\
B & F & 76.63 & 157.6 & 0.4862 & 0.9954 \\
B & M & 472.89 & 174.7 & 2.7061 & 0.1758 \\
C & F & 24.68 & 136.3 & 0.1811 & 1.0000 \\
C & M & 281.61 & 166.8 & 1.6882 & 0.5726
\end{tabular}

Fixation Method $=\mathrm{B}$

Gender $=\mathrm{F}$ subtracted from:

\begin{tabular}{|c|c|c|c|c|c|}
\hline Fixation & & Difference & SE of & & Adjusted \\
\hline Method & Gender & of Means & Difference & T-Value & P-Value \\
\hline$B$ & $\mathrm{M}$ & 396.26 & 162.7 & 2.4359 & 0.2483 \\
\hline C & $\mathrm{F}$ & -51.95 & 162.4 & -0.3200 & 0.9994 \\
\hline & M & 204.98 & 163.5 & 1.2540 & 0.8007 \\
\hline
\end{tabular}

Fixation Method $=\mathrm{B}$

Gender $=M$ subtracted from:

\begin{tabular}{llrrrr} 
Fixation & \multicolumn{2}{c}{ Difference } & SE of & Adjusted \\
Method & Gender & of Means & Difference & T-Value & P-Value \\
C & F & -448.2 & 178.9 & -2.505 & 0.2276 \\
C & M & -191.3 & 179.2 & -1.068 & 0.8813
\end{tabular}

\begin{tabular}{|c|c|c|c|c|c|}
\hline Fixation & & Difference & SE of & & Adjusted \\
\hline Method & Gender & of Means & Difference & T-Value & P-Value \\
\hline $\mathrm{C}$ & $\mathrm{M}$ & 256.9 & 172.0 & 1.494 & 0.6774 \\
\hline
\end{tabular}

Tukey 95.0\% Simultaneous Confidence Intervals Response Variable Ultimate Load

All Pairwise Comparisons among Levels of Fixation Method

Fixation Method = A subtracted from: 
Biomechanical Comparison of Wire Circlage and Rigid Plate Fixation for Median Sternotomy Closure in Human Cadaver Specimens

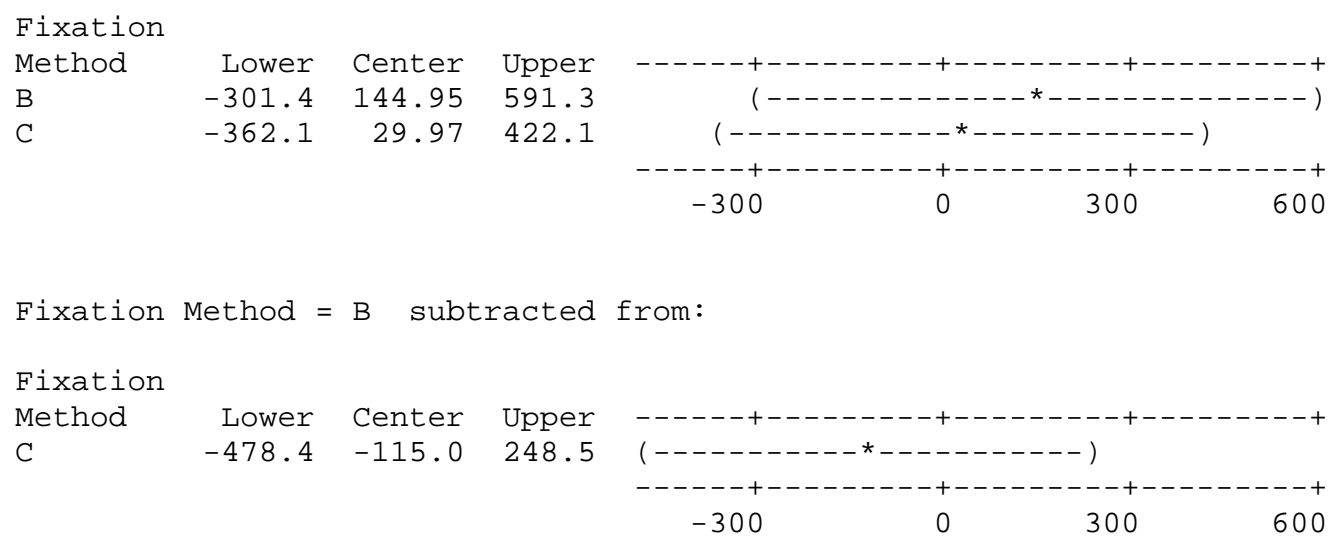

Tukey Simultaneous Tests

Response Variable Ultimate Load

All Pairwise Comparisons among Levels of Fixation Method

Fixation Method = A subtracted from:

$\begin{array}{lrrrr}\text { Fixation } & \text { Difference } & \text { SE of } & \text { Adjusted } \\ \text { Method } & \text { of Means } & \text { Difference } & \text { T-Value } & \text { P-Value } \\ \text { B } & 144.95 & 156.3 & 0.9276 & 0.6393 \\ \text { C } & 29.97 & 137.3 & 0.2183 & 0.9741\end{array}$

Fixation Method = B subtracted from:

$\begin{array}{lrrrr}\text { Fixation } & \text { Difference } & \text { SE of } & & \text { Adjusted } \\ \text { Method } & \text { of Means } & \text { Difference } & \text { T-Value } & \text { P-Value } \\ \text { C } & -115.0 & 127.2 & -0.9038 & 0.6532\end{array}$

Tukey 95.0\% Simultaneous Confidence Intervals Response Variable Ultimate Load

All Pairwise Comparisons among Levels of Gender Gender $=\mathrm{F}$ subtracted from:

Gender Lower Center Upper

$\begin{array}{llll}\text { M } & -120.5 & 124.6 & 369.7\end{array}$

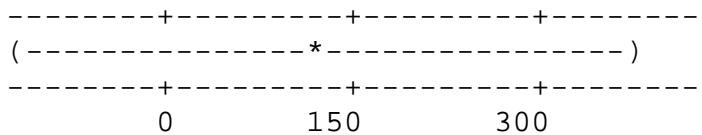

Tukey Simultaneous Tests

Response Variable Ultimate Load

All Pairwise Comparisons among Levels of Gender

Gender $=F$ subtracted from:

$\begin{array}{lrrrr} & \text { Difference } & \text { SE of } & & \text { Adjusted } \\ \text { Gender } & \text { of Means } & \text { Difference } & \text { T-Value } & \text { P-Value } \\ \text { M } & 124.6 & 106.3 & 1.172 & 0.2747\end{array}$

Tukey 95.0\% Simultaneous Confidence Intervals

Response Variable Ultimate Load

All Pairwise Comparisons among Levels of Fixation Method*Gender

Fixation Method = A

Gender $=F$ subtracted from:

Fixation 
Biomechanical Comparison of Wire Circlage and Rigid Plate Fixation for Median Sternotomy Closure in Human Cadaver Specimens

$\begin{array}{llrrr}\text { Method } & \text { Gender } & \text { Lower } & \text { Center } & \text { Upper } \\ \text { A } & \text { M } & -787.7 & -38.28 & 711.1 \\ \text { B } & \text { F } & -837.1 & -7.28 & 822.5 \\ \text { B } & \text { M } & -618.1 & 258.89 & 1135.9 \\ \text { C } & \text { F } & -836.7 & -62.15 & 712.3 \\ \text { C } & \text { M } & -771.1 & 83.80 & 938.7\end{array}$

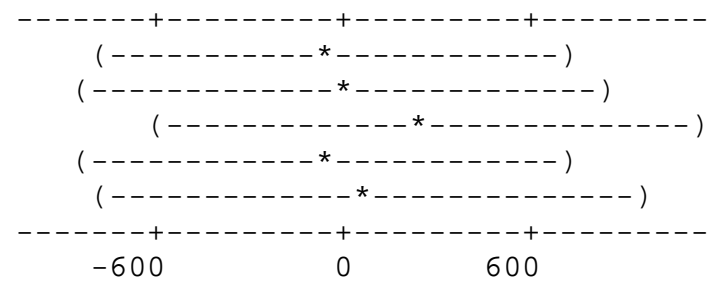

Fixation Method $=\mathrm{A}$

Gender $=$ M subtracted from:

$\begin{array}{llrrr}\text { Fixation } & & & & \\ \text { Method } & \text { Gender } & \text { Lower } & \text { Center } & \text { Upper } \\ \text { B } & \text { F } & -562.0 & 31.00 & 624.0 \\ \text { B } & \text { M } & -360.2 & 297.18 & 954.6 \\ \text { C } & \text { F } & -536.6 & -23.87 & 488.8 \\ \text { C } & \text { M } & -505.5 & 122.09 & 749.6\end{array}$

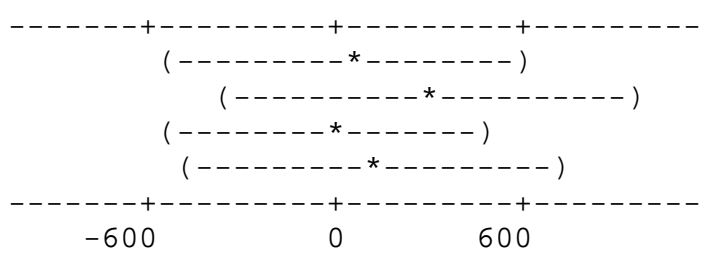

Fixation Method $=\mathrm{B}$

Gender $=\mathrm{F}$ subtracted from:

$\begin{array}{llrrr}\text { Fixation } & & & & \\ \text { Method } & \text { Gender } & \text { Lower } & \text { Center } & \text { Upper } \\ \text { B } & \text { M } & -345.8 & 266.17 & 878.1 \\ \text { C } & \text { F } & -665.6 & -54.87 & 555.9 \\ \text { C } & \text { M } & -523.8 & 91.08 & 706.0\end{array}$

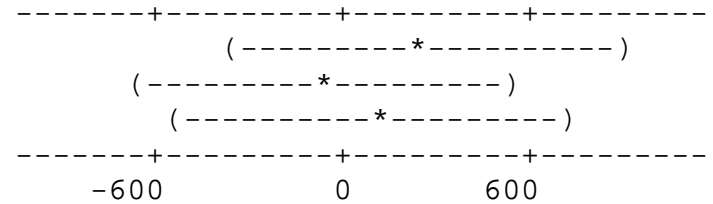

Fixation Method $=\mathrm{B}$

Gender $=M$ subtracted from:

Fixation

Method Gender Lower Center Upper

$\begin{array}{lllll}C & F & -994.2 & -321.0 & 352.1\end{array}$

$\begin{array}{lllll}\text { C } & \text { M } & -849.0 & -175.1 & 498.9\end{array}$

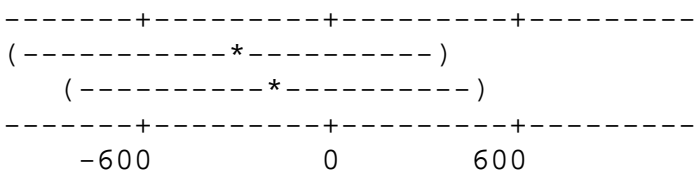

Fixation Method $=\mathrm{C}$

Gender $=\mathrm{F}$ subtracted from:

Fixation

Method

$\mathrm{C}$

$\begin{array}{lrrr}\text { Gender } & \text { Lower } & \text { Center } & \text { Upper } \\ \text { M } & -501.1 & 146.0 & 793.0\end{array}$

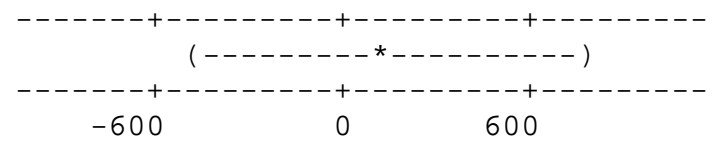

Tukey Simultaneous Tests

Response Variable Ultimate Load

All Pairwise Comparisons among Levels of Fixation Method*Gender

Fixation Method = A

Gender $=F$ subtracted from:

Fixation

Difference

SE of

Adjusted 
Biomechanical Comparison of Wire Circlage and Rigid Plate Fixation for Median Sternotomy Closure in Human Cadaver Specimens

$\begin{array}{llrrrr}\text { Method } & \text { Gender } & \text { of Means } & \text { Difference } & \text { T-Value } & \text { P-Value } \\ \text { A } & \text { M } & -38.28 & 205.0 & -0.1868 & 1.0000 \\ \text { B } & \text { F } & -7.28 & 227.0 & -0.0321 & 1.0000 \\ \text { B } & \text { M } & 258.89 & 239.9 & 1.0792 & 0.8769 \\ \text { C } & \text { F } & -62.15 & 211.9 & -0.2934 & 0.9996 \\ \text { C } & \text { M } & 83.80 & 233.8 & 0.3584 & 0.9989\end{array}$

Fixation Method $=\mathrm{A}$

Gender $=M$ subtracted from:

\begin{tabular}{|c|c|c|c|c|c|}
\hline Fixation & & Difference & $S E$ of & & Adjusted \\
\hline $\mathrm{Me}$ & Gender & of Means & Difference & T-Value & P-Value \\
\hline B & $\mathrm{F}$ & 31.00 & 162.2 & 0.1911 & 0.9999 \\
\hline B & M & 297.18 & 179.8 & 1.6526 & 0.5916 \\
\hline C & $\mathrm{F}$ & -23.87 & 140.2 & -0.1702 & 1.0000 \\
\hline & M & 122.09 & 171.7 & 0.7112 & 0.9751 \\
\hline
\end{tabular}

Fixation Method $=\mathrm{B}$

Gender $=\mathrm{F}$ subtracted from:

\begin{tabular}{|c|c|c|c|c|c|}
\hline Fixation & & Difference & $S E$ of & & Adjusted \\
\hline Method & Gender & of Means & Difference & T-Value & P-Value \\
\hline B & $\mathrm{M}$ & 266.17 & 167.4 & 1.5901 & 0.6253 \\
\hline $\mathrm{C}$ & $\mathrm{F}$ & -54.87 & 167.1 & -0.3284 & 0.9993 \\
\hline $\mathrm{C}$ & $\mathrm{M}$ & 91.08 & 168.2 & 0.5415 & 0.9924 \\
\hline
\end{tabular}

Fixation Method $=\mathrm{B}$

Gender $=M$ subtracted from:

\begin{tabular}{llrrrr} 
Fixation & \multicolumn{2}{c}{ Difference } & SE of & Adjusted \\
Method & Gender & Of Means & Difference & T-Value & P-Value \\
C & F & -321.0 & 184.1 & -1.744 & 0.5432 \\
C & M & -175.1 & 184.4 & -0.950 & 0.9218
\end{tabular}

Fixation Method $=\mathrm{C}$

Gender $=\mathrm{F}$ subtracted from:

\begin{tabular}{llrrrr} 
Fixation & \multicolumn{2}{c}{ Difference } & SE of & Adjusted \\
Method & Gender & of Means & Difference & T-Value & P-Value \\
C & M & 146.0 & 177.0 & 0.8246 & 0.9544
\end{tabular}

Tukey 95.0\% Simultaneous Confidence Intervals Response Variable Post-Yield Disp

All Pairwise Comparisons among Levels of Fixation Method

Fixation Method = A subtracted from:

$\begin{array}{lrrr}\text { Fixation } & & & \\ \text { Method } & \text { Lower } & \text { Center } & \text { Upper } \\ \text { B } & -2.530 & -1.229 & 0.07185 \\ \text { C } & -2.197 & -1.055 & 0.08797\end{array}$

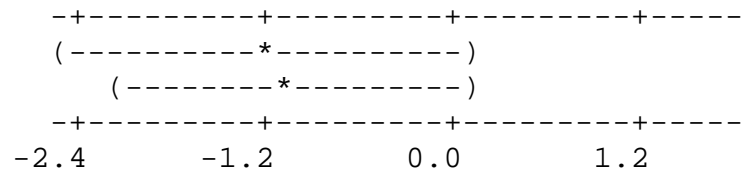

Fixation Method = B subtracted from:

Fixation

Method

Lower Center Upper 
Biomechanical Comparison of Wire Circlage and Rigid Plate Fixation for Median Sternotomy Closure in Human Cadaver Specimens

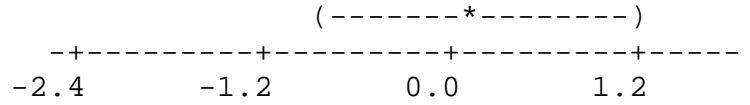

Tukey Simultaneous Tests Response Variable Post-Yield Disp All Pairwise Comparisons among Levels of Fixation Method Fixation Method = A subtracted from:

\begin{tabular}{|c|c|c|c|c|}
\hline Fixation & Difference & $S E$ of & & Adjusted \\
\hline Method & of Means & Difference & T-Value & P-Value \\
\hline B & -1.229 & 0.4554 & -2.699 & 0.0631 \\
\hline C & -1.055 & 0.4000 & -2.637 & 0.0692 \\
\hline ix & Method $=\mathrm{B}$ & subtracted & rom: & \\
\hline ixa & Difference & $S E$ of & & Adjus \\
\hline t+ & of Means & Difference & T-Value & $\mathrm{P}-\mathrm{Valu}$ \\
\hline & 0.1744 & 0.3707 & 0.4703 & 0.88 \\
\hline
\end{tabular}

Tukey 95.0\% Simultaneous Confidence Intervals Response Variable Post-Yield Disp

All Pairwise Comparisons among Levels of Gender Gender $=F$ subtracted from:

\begin{tabular}{|c|c|c|c|c|}
\hline $\begin{array}{l}\text { Gender } \\
\text { M }\end{array}$ & $\begin{array}{r}\text { Lower } \\
-1.152\end{array}$ & $\begin{array}{r}\text { Center } \\
-0.4377\end{array}$ & $\begin{array}{r}\text { Upper } \\
0.2766\end{array}$ & $\begin{array}{c}---------+---------+---------+------- \\
(-----------------\star-----------------)\end{array}$ \\
\hline & & & & $\begin{array}{c}------++---- \\
-0.80\end{array}$ \\
\hline
\end{tabular}

Tukey Simultaneous Tests Response Variable Post-Yield Disp

All Pairwise Comparisons among Levels of Gender Gender $=\mathrm{F}$ subtracted from:

$\begin{array}{lrrrr} & \text { Difference } & \text { SE of } & & \text { Adjusted } \\ \text { Gender } & \text { of Means } & \text { Difference } & \text { T-Value } & \text { P-Value } \\ \text { M } & -0.4377 & 0.3097 & -1.413 & 0.1954\end{array}$

Tukey 95.0\% Simultaneous Confidence Intervals Response Variable Post-Yield Disp

All Pairwise Comparisons among Levels of Fixation Method*Gender Fixation Method $=\mathrm{A}$

Gender $=F$ subtracted from:

Fixation

$\begin{array}{llrrr}\text { Method } & \text { Gender } & \text { Lower } & \text { Center } & \text { Upper } \\ \text { A } & \text { M } & -2.530 & -0.346 & 1.8375 \\ \text { B } & \text { F } & -3.679 & -1.261 & 1.1573 \\ \text { B } & \text { M } & -4.099 & -1.544 & 1.0121 \\ \text { C } & \text { F } & -3.143 & -0.886 & 1.3711 \\ \text { C } & \text { M } & -4.061 & -1.570 & 0.9214\end{array}$

Fixation

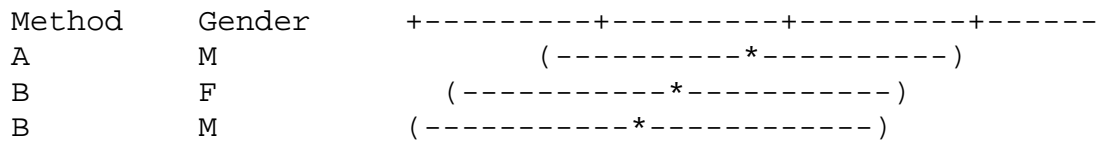


Biomechanical Comparison of Wire Circlage and Rigid Plate Fixation for Median Sternotomy Closure in Human Cadaver Specimens

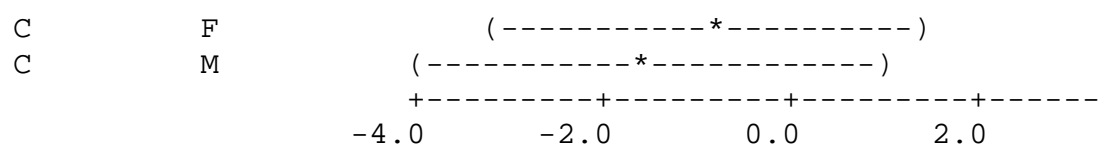

Fixation Method $=\mathrm{A}$

Gender $=M$ subtracted from:

$\begin{array}{llrrr}\begin{array}{llrr}\text { Fixation } \\ \text { Method }\end{array} & \text { Gender } & \text { Lower } & \text { Center } & \text { Upper } \\ \text { B } & \text { F } & -2.642 & -0.914 & 0.8135 \\ \text { B } & \text { M } & -3.113 & -1.197 & 0.7185 \\ \text { C } & \text { F } & -2.034 & -0.539 & 0.9546 \\ \text { C } & \text { M } & -3.052 & -1.223 & 0.6054\end{array}$
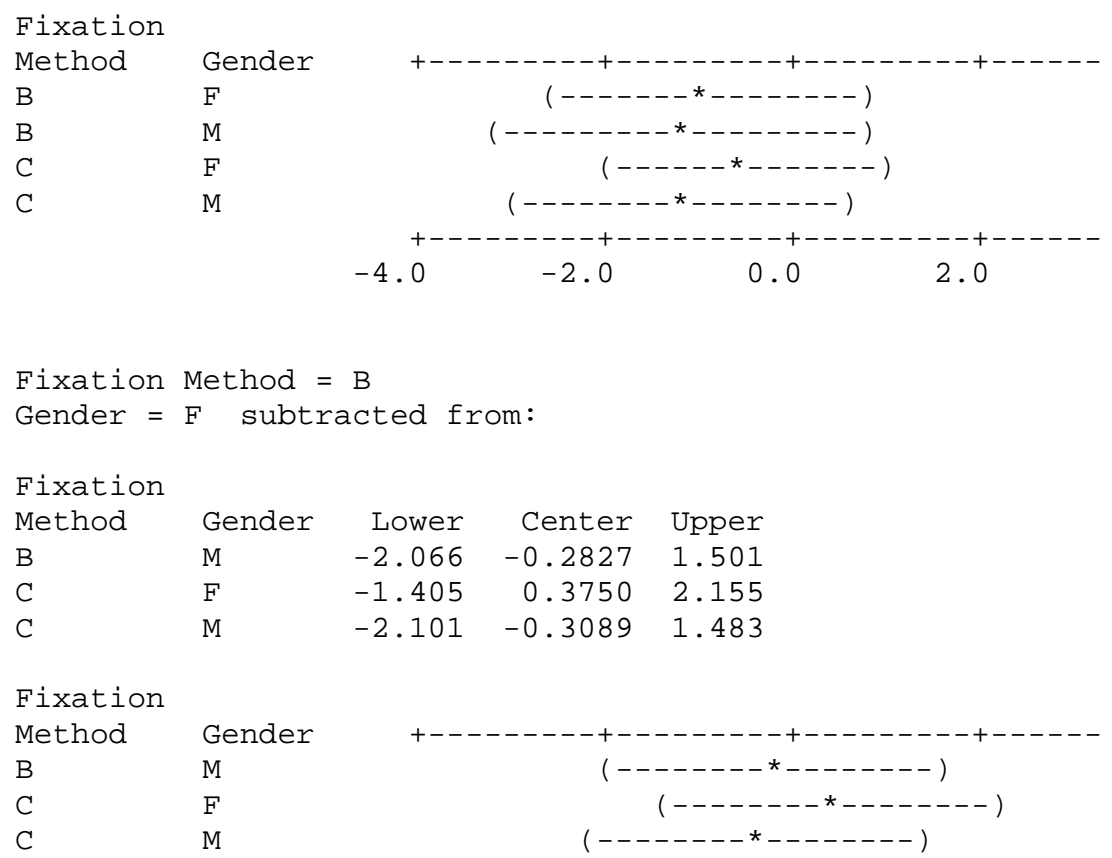

F

Fixation Method $=\mathrm{B}$

Gender $=M$ subtracted from:

Fixation

$\begin{array}{llrrr}\text { Method } & \text { Gender } & \text { Lower } & \text { Center } & \text { Upper } \\ \text { C } & \text { F } & -1.304 & 0.65766 & 2.619 \\ \text { C } & \text { M } & -1.990 & -0.02620 & 1.938\end{array}$

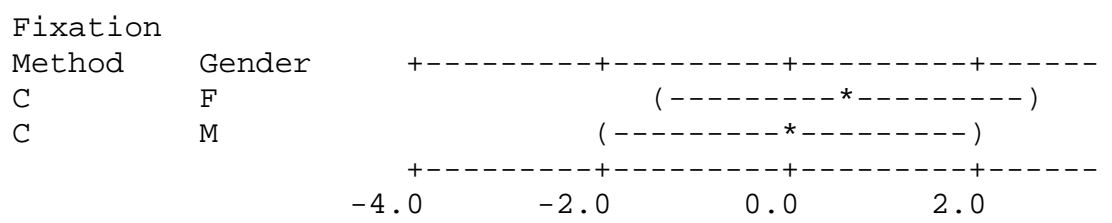

Fixation Method $=\mathrm{C}$

Gender $=\mathrm{F}$ subtracted from: 
Biomechanical Comparison of Wire Circlage and Rigid Plate Fixation for Median Sternotomy Closure in Human Cadaver Specimens

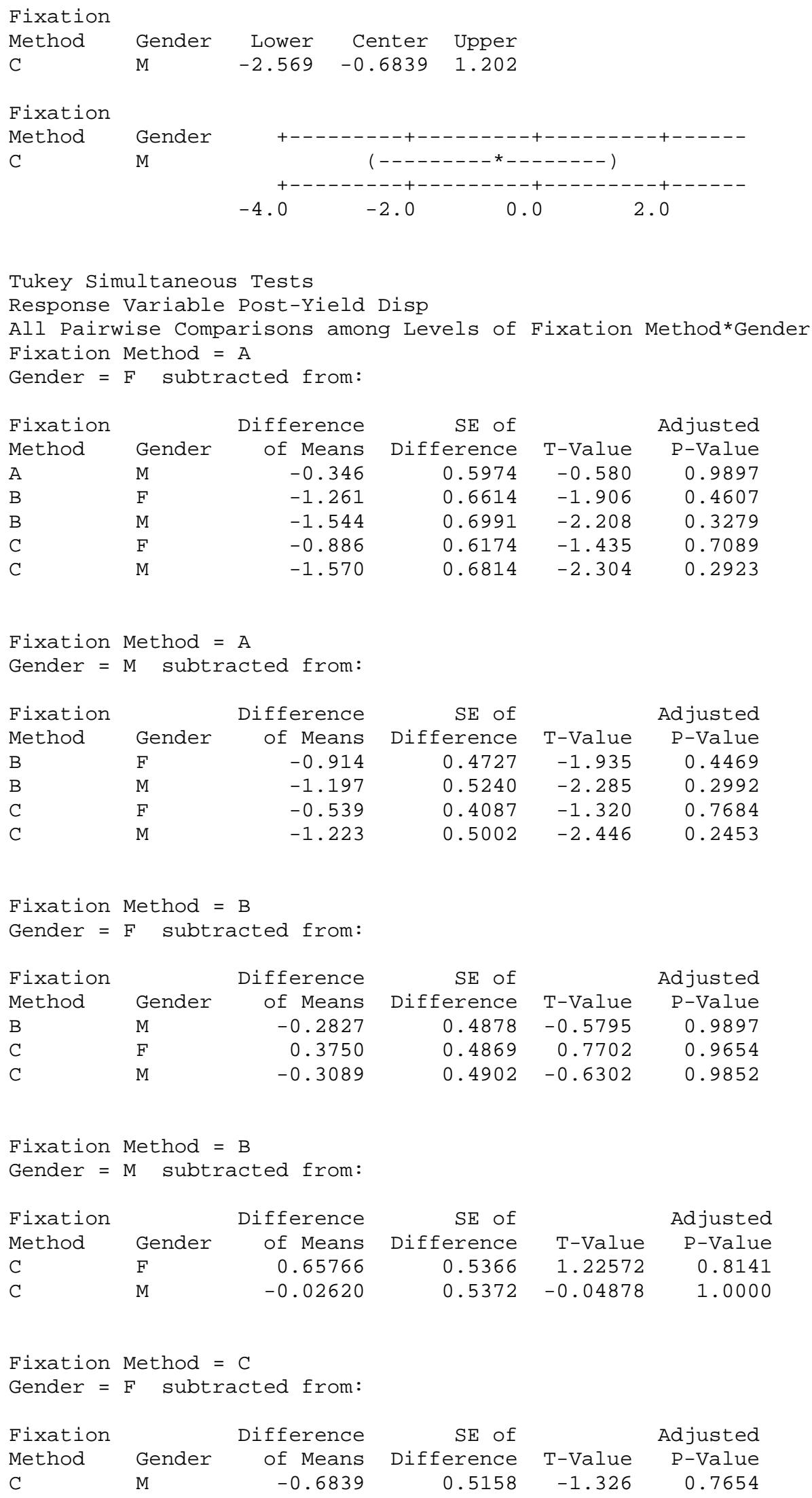




\section{Appendix B: Statistical Analysis - Rostro-caudal shear \\ General Linear Model: Stiffness, Yield Load, ... versus Fixation Met, Gender

$\begin{array}{llrl}\text { Factor } & \text { Type } & \text { Levels } & \text { Values } \\ \text { Fixation Method } & \text { fixed } & 3 & \text { A, B, } \\ \text { Gender } & \text { fixed } & 2 & \text { F, M }\end{array}$

Analysis of Variance for Stiffness, using Adjusted ss for Tests

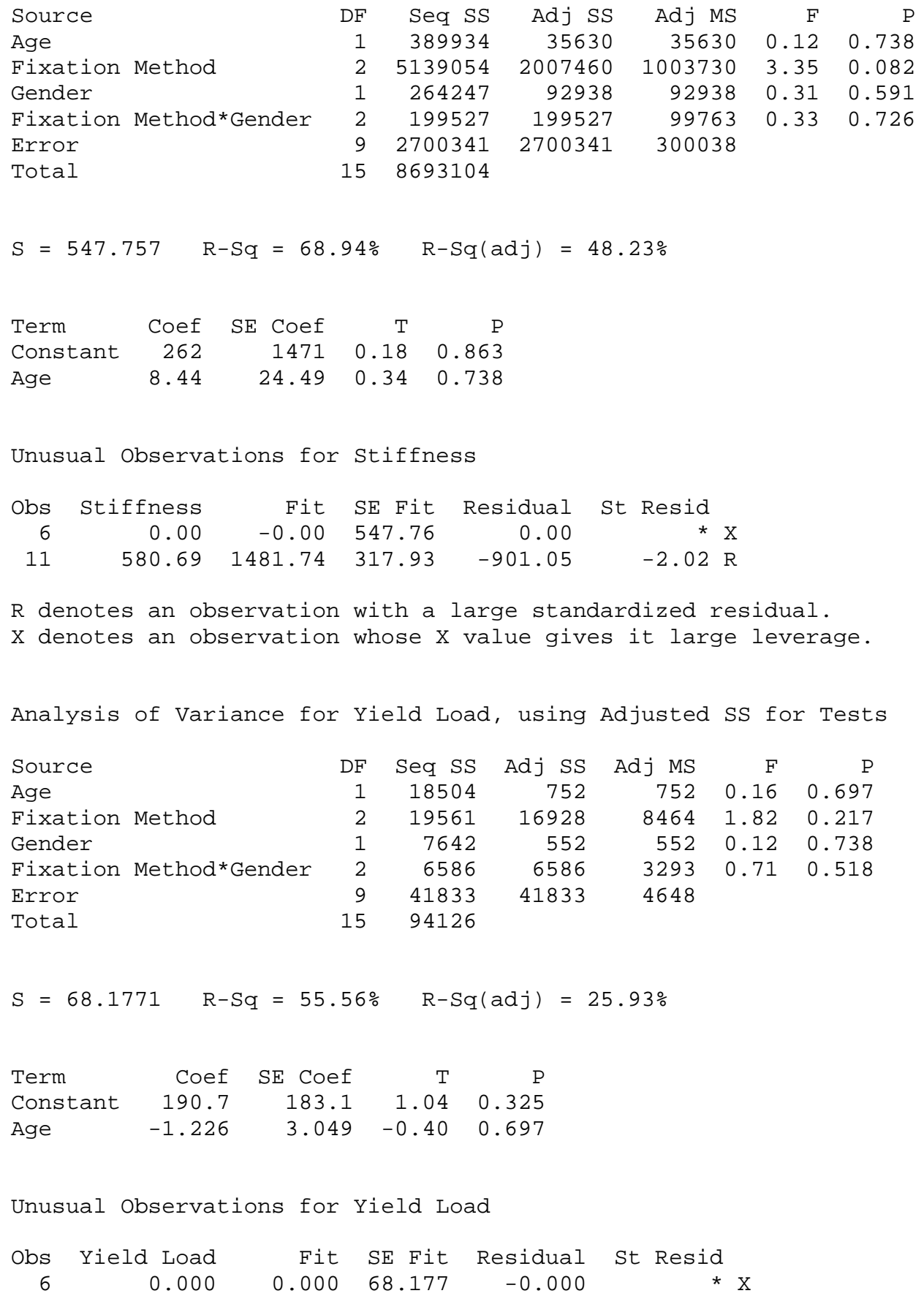


Biomechanical Comparison of Wire Circlage and Rigid Plate Fixation for Median Sternotomy Closure in Human Cadaver Specimens

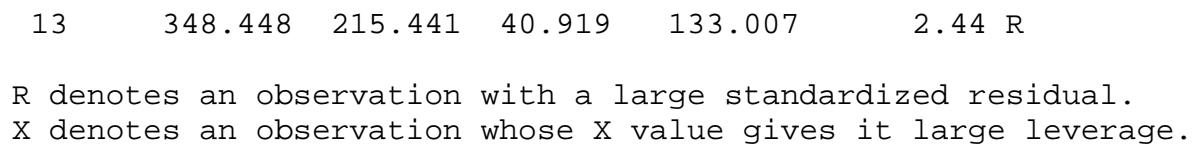


Biomechanical Comparison of Wire Circlage and Rigid Plate Fixation for Median Sternotomy Closure in Human Cadaver Specimens

$\mathrm{X}$ denotes an observation whose $\mathrm{X}$ value gives it large leverage.

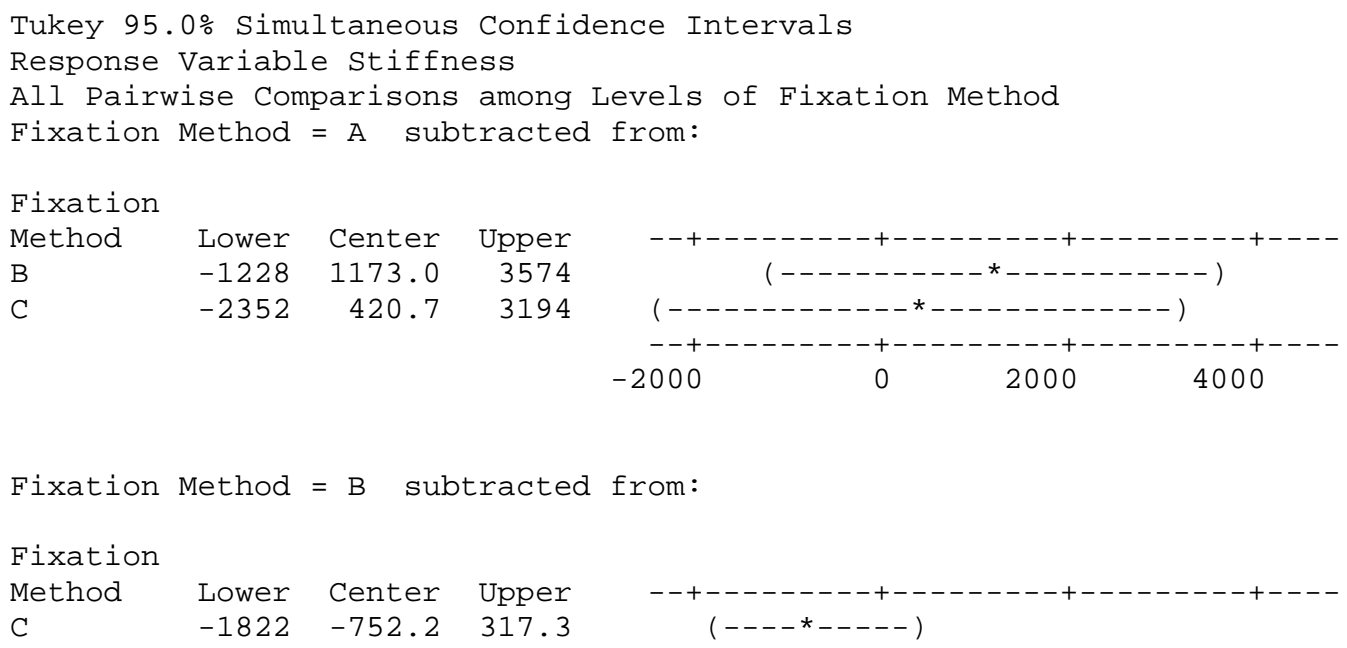

Tukey Simultaneous Tests

Response Variable Stiffness

All Pairwise Comparisons among Levels of Fixation Method

Fixation Method = A subtracted from:

$\begin{array}{lrrrr}\text { Fixation } & \text { Difference } & \text { SE of } & \text { Adjusted } \\ \text { Method } & \text { of Means } & \text { Difference } & \text { T-Value } & \text { P-Value } \\ \text { B } & 1173.0 & 859.7 & 1.3645 & 0.3980 \\ \text { C } & 420.7 & 992.8 & 0.4238 & 0.9067\end{array}$

Fixation Method = B subtracted from:

$\begin{array}{lrrrr}\text { Fixation } & \text { Difference } & \text { SE of } & \text { Adjusted } \\ \text { Method } & \text { of Means } & \text { Difference } & \text { T-Value } & \text { P-Value } \\ \text { C } & -752.2 & 382.9 & -1.965 & 0.1768\end{array}$

Tukey 95.0\% Simultaneous Confidence Intervals Response Variable Stiffness

All Pairwise Comparisons among Levels of Gender

Gender $=F$ subtracted from:

Gender Lower Center Upper

M $\quad-1155 \quad 376.9 \quad 1909$

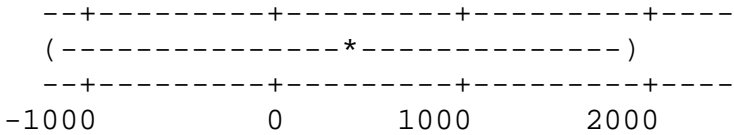

Tukey Simultaneous Tests

Response Variable Stiffness

All Pairwise Comparisons among Levels of Gender

Gender $=F$ subtracted from:

$\begin{array}{lrrrr} & \text { Difference } & \text { SE of } & \text { Adjusted } \\ \text { Gender } & \text { of Means } & \text { Difference } & \text { T-Value } & \text { P-Value } \\ \text { M } & 376.9 & 677.2 & 0.5566 & 0.5914\end{array}$


Biomechanical Comparison of Wire Circlage and Rigid Plate Fixation for Median Sternotomy Closure in Human Cadaver Specimens

Tukey 95.0\% Simultaneous Confidence Intervals Response Variable Stiffness

All Pairwise Comparisons among Levels of Fixation Method*Gender Fixation Method = A

Gender $=\mathrm{F}$ subtracted from:

$\begin{array}{llrrr}\text { Fixation } & & & & \\ \text { Method } & \text { Gender } & \text { Lower } & \text { Center } & \text { Upper } \\ \text { A } & \text { M } & -6222 & 538.3 & 7299 \\ \text { B } & \text { F } & -7 & 1429.2 & 2865 \\ \text { B } & \text { M } & -343 & 1455.0 & 3253 \\ \text { C } & \text { F } & -1238 & 406.6 & 2051 \\ \text { C } & \text { M } & -480 & 973.2 & 2426\end{array}$

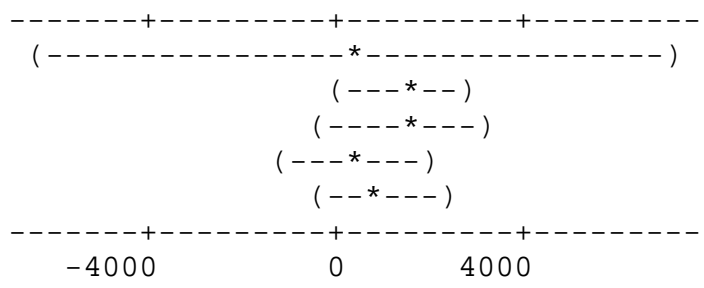

Fixation Method $=\mathrm{A}$

Gender $=M$ subtracted from:

$\begin{array}{llrrr}\text { Fixation } & & & & \\ \text { Method } & \text { Gender } & \text { Lower } & \text { Center } & \text { Upper } \\ \text { B } & \text { F } & -5705 & 890.9 & 7487 \\ \text { B } & \text { M } & -5216 & 916.8 & 7049 \\ \text { C } & \text { F } & -6748 & -131.7 & 6485 \\ \text { C } & \text { M } & -6654 & 434.9 & 7523\end{array}$

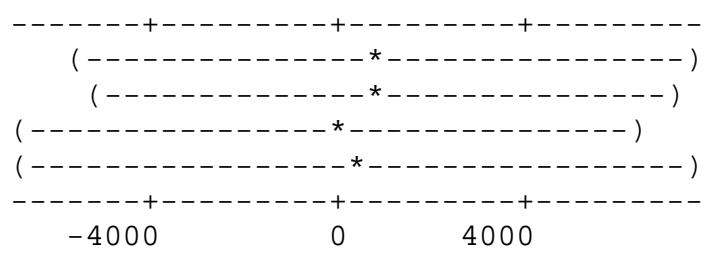

Fixation Method $=\mathrm{B}$

Gender $=\mathrm{F}$ subtracted from:

Fixation

Method

B

C

C

$\begin{array}{lrr}\text { Gender } & \text { Lower } & \text { Center } \\ \text { M } & -1833 & 26 \\ F & -2798 & -1023 \\ \text { M } & -2127 & -456\end{array}$

Fixation Method $=\mathrm{B}$

Gender $=$ M subtracted from:

Fixation

Method

C

C

Gender Lower

$\mathrm{F}$

$\mathrm{M}$

-3062
-2556

Center
-1048
-482

Upper

964.7

1591.9

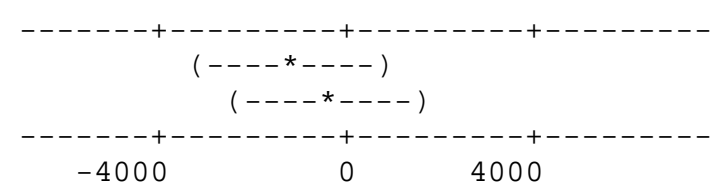

Fixation Method $=\mathrm{C}$

Gender $=\mathrm{F}$ subtracted from:

Fixation

Method

C

\section{Gender}

$\mathrm{M}$
Lower

$-1292$

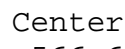

566.6
Upper
1884.3
752.6
1215.1

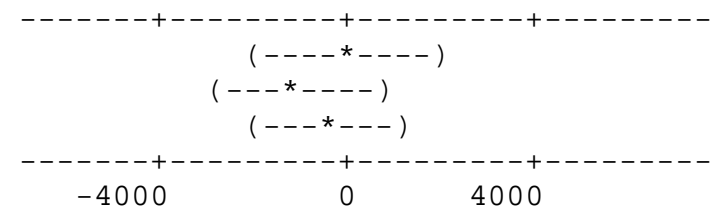

Upper

2425

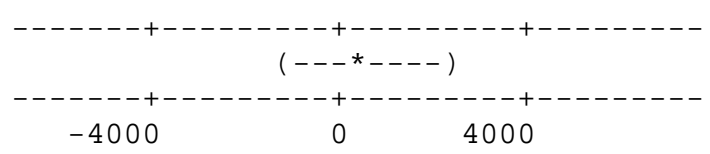


Biomechanical Comparison of Wire Circlage and Rigid Plate Fixation for Median Sternotomy Closure in Human Cadaver Specimens

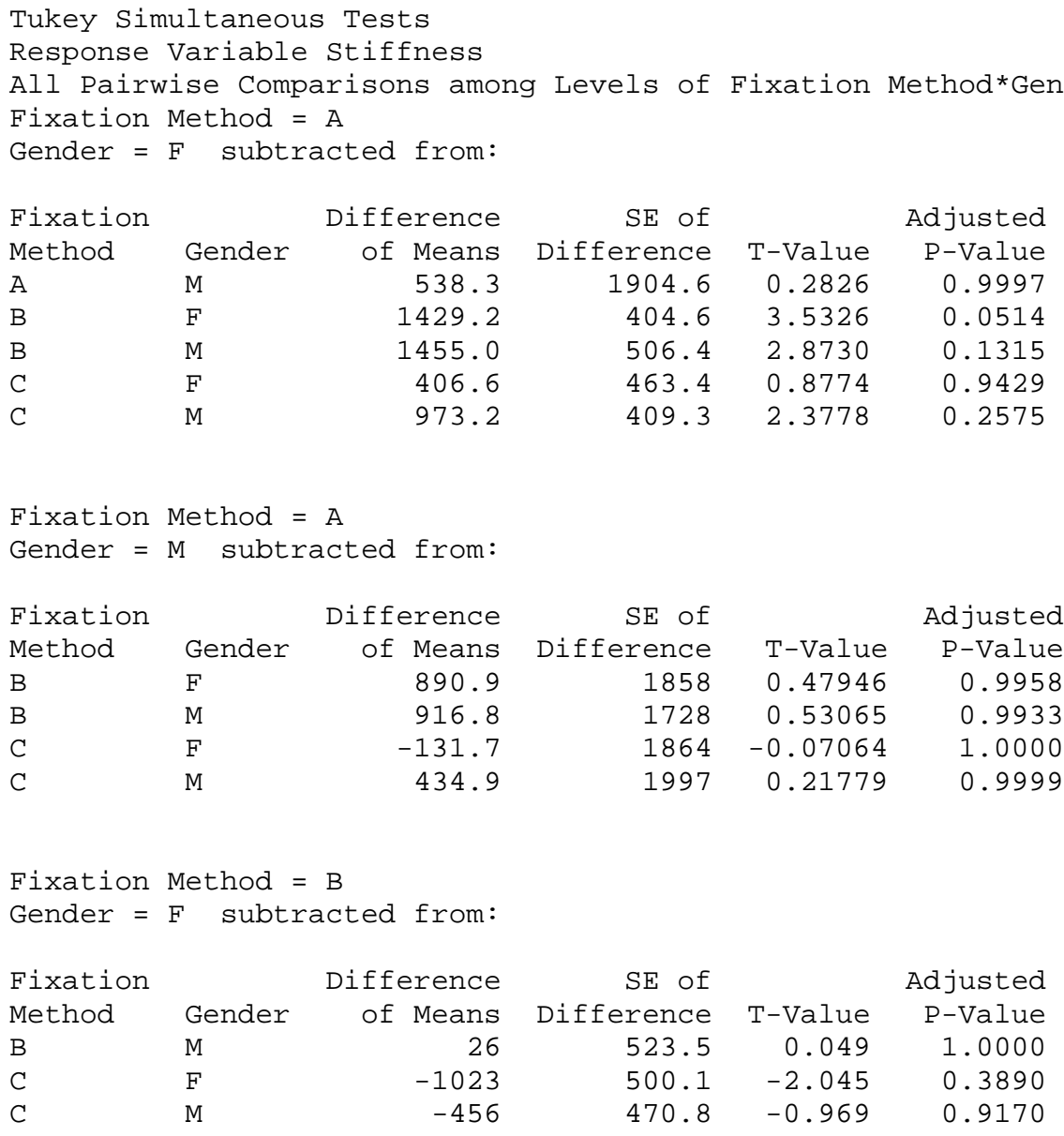

Fixation Method $=\mathrm{B}$

Gender $=M$ subtracted from:

\begin{tabular}{llrrrr} 
Fixation & \multicolumn{2}{c}{ Difference } & SE of & Adjusted \\
Method & Gender & of Means & Difference & T-Value & P-Value \\
C & F & -1048 & 567.1 & -1.849 & 0.4842 \\
C & M & -482 & 584.2 & -0.825 & 0.9553
\end{tabular}

Fixation Method $=\mathrm{C}$

Gender $=\mathrm{F}$ subtracted from:

\begin{tabular}{llrrrr} 
Fixation & \multicolumn{1}{r}{ Difference } & SE of & Adjusted \\
Method & Gender & of Means & Difference & T-Value & P-Value \\
C & M & 566.6 & 523.5 & 1.082 & 0.8769
\end{tabular}

Tukey 95.0\% Simultaneous Confidence Intervals

Response Variable Yield Load

All Pairwise Comparisons among Levels of Fixation Method

Fixation Method = A subtracted from:

$\begin{array}{lrrr}\text { Fixation } & & & \\ \text { Method } & \text { Lower } & \text { Center } & \text { Upper } \\ \text { B } & -220.4 & 78.47 & 377.3 \\ \text { C } & -178.4 & 166.77 & 511.9\end{array}$

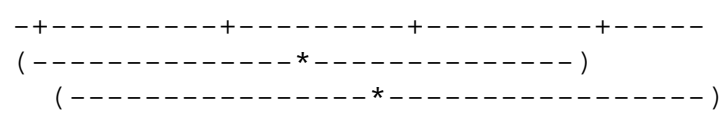


Biomechanical Comparison of Wire Circlage and Rigid Plate Fixation for Median Sternotomy Closure in Human Cadaver Specimens
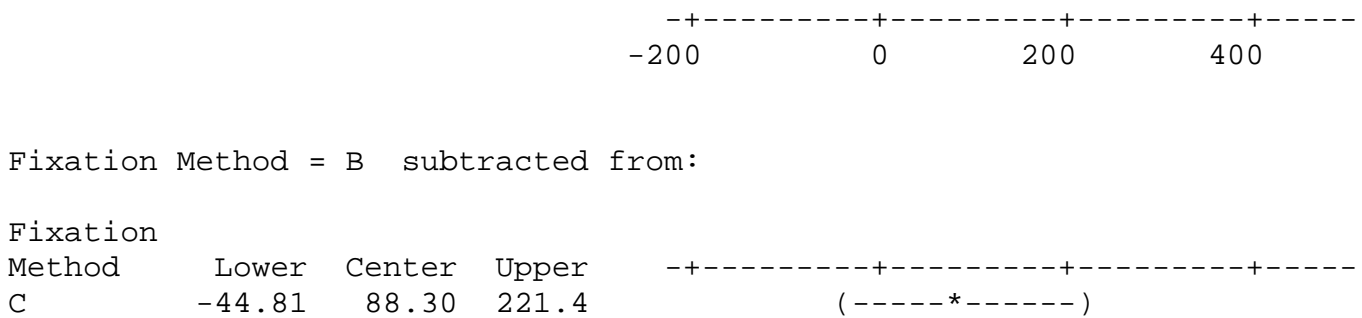

Tukey Simultaneous Tests Response Variable Yield Load All Pairwise Comparisons among Levels of Fixation Method Fixation Method = A subtracted from:

$\begin{array}{lrrrr}\text { Fixation } & \text { Difference } & \text { SE of } & \text { Adjusted } \\ \text { Method } & \text { of Means } & \text { Difference } & \text { T-Value } & \text { P-Value } \\ \text { B } & 78.47 & 107.0 & 0.7333 & 0.7507 \\ \text { C } & 166.77 & 123.6 & 1.3496 & 0.4052\end{array}$

Fixation Method = B subtracted from:

$\begin{array}{lrrrr}\text { Fixation } & \text { Difference } & \text { SE of } & & \text { Adjusted } \\ \text { Method } & \text { of Means } & \text { Difference } & \text { T-Value } & \text { P-Value } \\ \text { C } & 88.30 & 47.66 & 1.853 & 0.2077\end{array}$

Tukey 95.0\% Simultaneous Confidence Intervals Response Variable Yield Load

All Pairwise Comparisons among Levels of Gender Gender $=\mathrm{F}$ subtracted from:

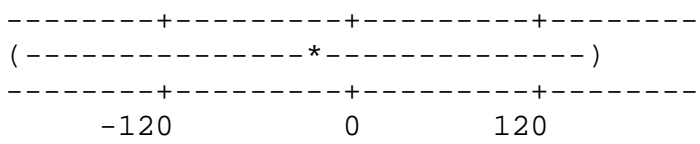

Tukey Simultaneous Tests Response Variable Yield Load

All Pairwise Comparisons among Levels of Gender Gender $=\mathrm{F}$ subtracted from:

$\begin{array}{lrrrr} & \text { Difference } & \text { SE of } & & \text { Adjusted } \\ \text { Gender } & \text { of Means } & \text { Difference } & \text { T-Value } & \text { P-Value } \\ \text { M } & -29.05 & 84.29 & -0.3447 & 0.7383\end{array}$

Tukey 95.0\% Simultaneous Confidence Intervals Response Variable Yield Load

All Pairwise Comparisons among Levels of Fixation Method*Gender Fixation Method $=\mathrm{A}$

Gender $=\mathrm{F}$ subtracted from:

Fixation

$\begin{array}{llrrrc}\text { Method } & \text { Gender } & \text { Lower } & \text { Center } & \text { Upper } & -----+-----1---+---------+--------+- \\ \text { A } & \text { M } & -1059 & -217.9 & 623.6 & \left(----------{ }_{-1}--------\right) \\ \text { B } & \text { F } & -236 & -56.8 & 121.9 & (-\star--) \\ \text { B } & \text { M } & -228 & -4.1 & 219.6 & (--\star--)\end{array}$


Biomechanical Comparison of Wire Circlage and Rigid Plate Fixation for Median Sternotomy Closure in Human Cadaver Specimens

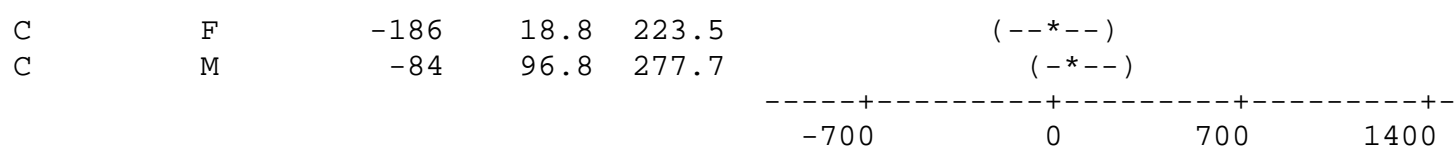

Fixation Method $=\mathrm{A}$

Gender $=M$ subtracted from:

Fixation

Method

$\begin{array}{lll}F & -659.9 & 161.1\end{array}$

B $\quad \mathrm{M}$

$-549.5213 .8$

Upper

982.0

$\mathrm{M}$

$\begin{array}{lll}-586.8 & 236.7 & 1060.2\end{array}$

$\begin{array}{ll}\mathrm{C} & \mathrm{F} \\ \mathrm{C} & \mathrm{M}\end{array}$

$-567.5$

314.81197 .0

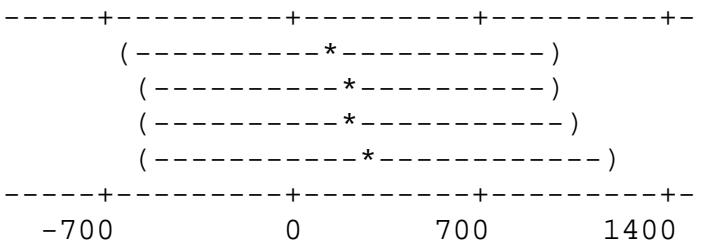

Fixation Method $=\mathrm{B}$

Gender $=\mathrm{F}$ subtracted from:

Fixation

Method

B

$\begin{array}{lrr}\text { Gender } & \text { Lower } & \text { Center } \\ M & -178.6 & 52.70 \\ F & -145.3 & 75.62 \\ M & -54.3 & 153.68\end{array}$

Upper

284.0

C

C

$-54.3 \quad 153.68$

296.6

361.7

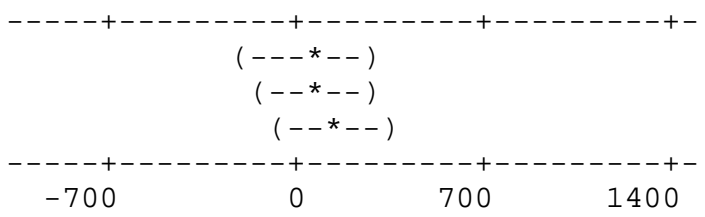

Fixation Method $=\mathrm{B}$

Gender $=M$ subtracted from:

$\begin{array}{llrrr}\text { Fixation } & & & & \\ \text { Method } & \text { Gender } & \text { Lower } & \text { Center } & \text { Upper } \\ \text { C } & \text { F } & -227.6 & 22.92 & 273.5 \\ \text { C } & \text { M } & -157.1 & 100.98 & 359.1\end{array}$

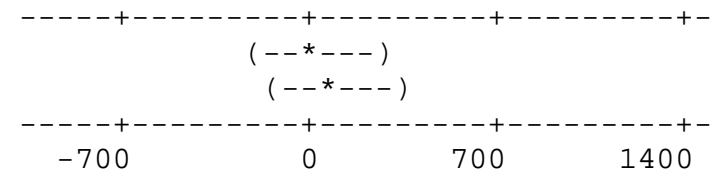

Fixation Method $=\mathrm{C}$

Gender $=F$ subtracted from:

Fixation

Method

Gender

Lower

Center

Upper

C

$\mathrm{M}$

$-153.2$

78.06

309.4

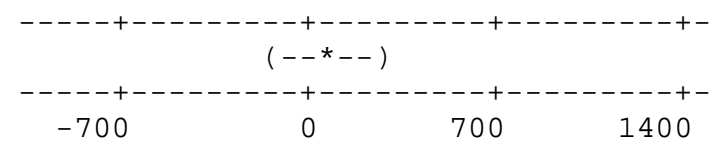

Tukey Simultaneous Tests

Response Variable Yield Load

All Pairwise Comparisons among Levels of Fixation Method*Gender

Fixation Method $=\mathrm{A}$

Gender $=\mathrm{F}$ subtracted from:

\begin{tabular}{|c|c|c|c|c|c|}
\hline Fixation & & Difference & $S E$ of & & Adjusted \\
\hline Method & Gender & of Means & Difference & T-Value & P-Value \\
\hline A & M & -217.9 & 237.06 & -0.919 & 0.9318 \\
\hline B & F & -56.8 & 50.35 & -1.129 & 0.8580 \\
\hline B & M & -4.1 & 63.03 & -0.066 & 1.0000 \\
\hline
\end{tabular}


Biomechanical Comparison of Wire Circlage and Rigid Plate Fixation for Median Sternotomy Closure in Human Cadaver Specimens

$\begin{array}{llllll}C & \text { F } & 18.8 & 57.68 & 0.326 & 0.9993 \\ C & \text { M } & 96.8 & 50.94 & 1.901 & 0.4577\end{array}$

Fixation Method $=\mathrm{A}$

Gender $=M$ subtracted from:

Fixation

Method

B $\mathrm{F}$

B $M$

C $\quad \mathrm{F}$

C M
Difference

of Means

Fixation Method $=\mathrm{B}$

Gender $=F$ subtracted from:

Fixation

Method

B

C $\quad$ F

Fixation Method $=\mathrm{B}$

Gender $=M$ subtracted from:

Fixation

Method

Gender
M

Difference of Means

22.92

100.98

C M

Fixation Method $=\mathrm{C}$

Gender $=\mathrm{F}$ subtracted from:

Fixation

Method

C

Gender

Difference
of Means
78.06

$\mathrm{M}$
161.1

213.8

236.7

314.8

SE of
Difference
231.3
215.0
232.0
248.6

T-Value

0.6965

0.9942

1.0203

1.2664

SE of

Difference

65.16

62.25

58.59

153.68

T-Value

0.8087

1. 2149

2. 6228

Adjusted

P-Value

0.9587

0.8199

0.1858

A-Value

0.9777

0.8998

0.7954

Tukey 95.0\% Simultaneous Confidence Intervals

Response Variable Ultimate Load

All Pairwise Comparisons among Levels of Fixation Method

Fixation Method = A subtracted from:

Fixation

Method

$\begin{array}{rrr}\text { Lower } & \text { Center } & \text { Upper } \\ -420.2 & 224.8 & 869.9 \\ -424.8 & 320.2 & 1065.2\end{array}$

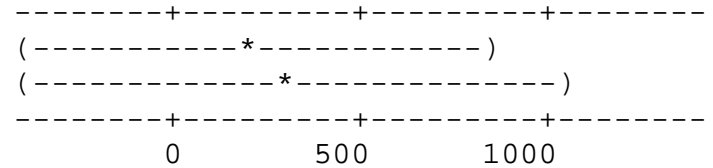

Fixation Method = B subtracted from:

Fixation

Method

$\mathrm{C}$

$\begin{array}{rrr}\text { Lower Center Uppe } & \\ -192.0 & 95.36 & 382.7\end{array}$

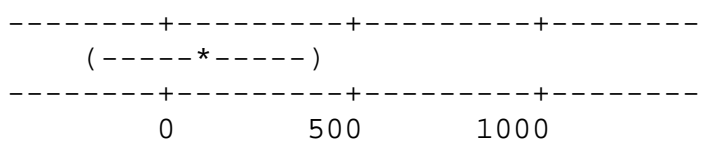

Adjusted

P-Value

0.9993

0.7330

SE of

Adjusted

P-Value

$\begin{array}{lll}65.16 & 1.198 & 0.8277\end{array}$

$\begin{array}{rrr}\text { SE of } & & \begin{array}{r}\text { Adjusted } \\ \text { P-Value }\end{array} \\ \text { Difference } & \text { T-Value } & 0.9993 \\ 70.59 & 0.3247 & 0.7330\end{array}$


Biomechanical Comparison of Wire Circlage and Rigid Plate Fixation for Median Sternotomy Closure in Human Cadaver Specimens

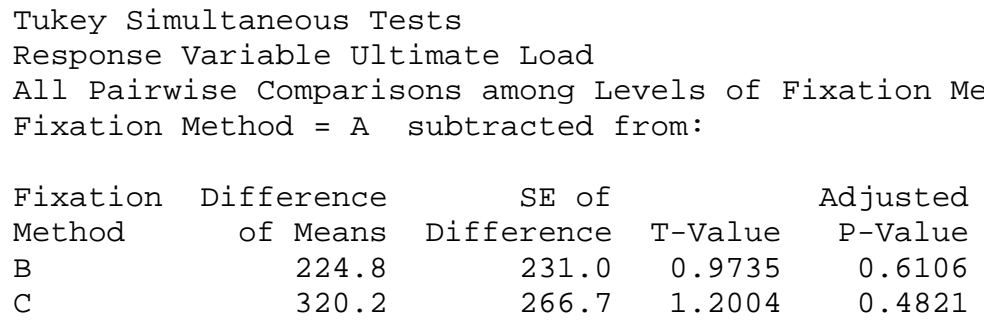

Fixation Method = B subtracted from:

$\begin{array}{lrrrr}\text { Fixation } & \text { Difference } & \text { SE of } & \text { Adjusted } \\ \text { Method } & \text { of Means } & \text { Difference } & \text { T-Value } & \text { P-Value } \\ \text { C } & 95.36 & 102.9 & 0.9270 & 0.6379\end{array}$

Tukey 95.0\% Simultaneous Confidence Intervals Response Variable Ultimate Load

All Pairwise Comparisons among Levels of Gender

Gender $=\mathrm{F}$ subtracted from:

Gender Lower Center Upper

M $\quad-500.3 \quad-88.69 \quad 322.9$

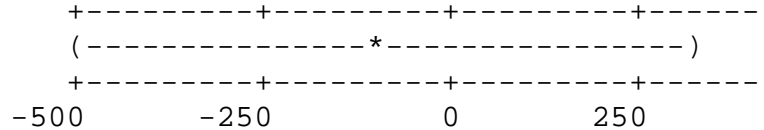

Tukey Simultaneous Tests

Response Variable Ultimate Load

All Pairwise Comparisons among Levels of Gender

Gender $=\mathrm{F}$ subtracted from:

$\begin{array}{lrrrr} & \text { Difference } & \text { SE of } & \text { Adjusted } \\ \text { Gender } & \text { of Means } & \text { Difference } & \text { T-Value } & \text { P-Value } \\ \text { M } & -88.69 & 181.9 & -0.4875 & 0.6376\end{array}$

Tukey 95.0\% Simultaneous Confidence Intervals

Response Variable Ultimate Load

All Pairwise Comparisons among Levels of Fixation Method*Gender

Fixation Method $=\mathrm{A}$

Gender $=\mathrm{F}$ subtracted from:

Fixation

Method

Gender Lower

M $\quad-2393$

$-497$

$-499$

$-517$

$-251$

Center
-576.3
-110.9
-15.8
-75.6
139.6
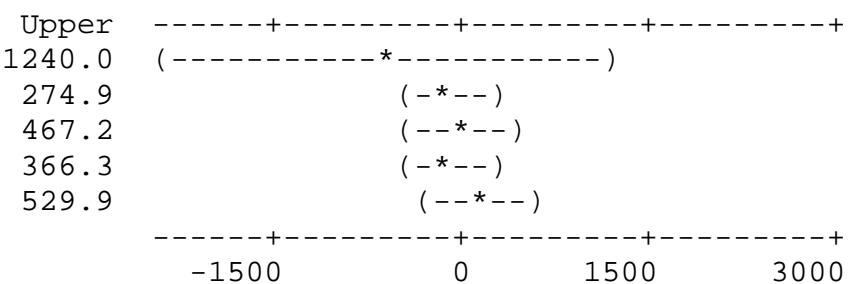

Fixation Method $=\mathrm{A}$

Gender $=\mathrm{M}$ subtracted from:

Fixation

Method

$\mathrm{B}$

Gender Lower

F

$-1307$

Center Upper

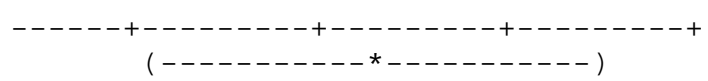


Biomechanical Comparison of Wire Circlage and Rigid Plate Fixation for Median Sternotomy Closure in Human Cadaver Specimens

$\begin{array}{lllll}B & M & -1087 & 560.5 & 2208 \\ C & \text { F } & -1277 & 500.8 & 2278 \\ C & \text { M } & -1188 & 715.9 & 2620\end{array}$

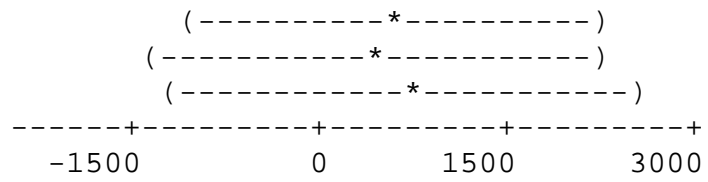

Fixation Method $=\mathrm{B}$

Gender $=F$ subtracted from:

$\begin{array}{llrrr}\text { Fixation } & & & & \\ \text { Method } & \text { Gender } & \text { Lower } & \text { Center } & \text { Upper } \\ \text { B } & \text { M } & -404.2 & 95.07 & 594.3 \\ \text { C } & \text { F } & -441.6 & 35.30 & 512.2 \\ \text { C } & \text { M } & -198.5 & 250.48 & 699.4\end{array}$

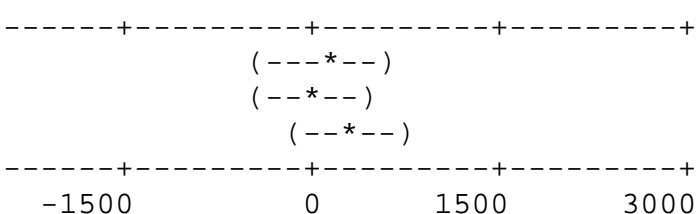

Fixation Method $=\mathrm{B}$

Gender $=\mathrm{M}$ subtracted from:

Fixation

Method

$\mathrm{C}$

Gender
M

$\begin{array}{rr}\text { Lower } & \text { Center } \\ -600.6 & -59.77 \\ -401.7 & 155.41\end{array}$

Upper

481.1

C

$\begin{array}{lll}-401.7 & 155.41 & 712.5\end{array}$

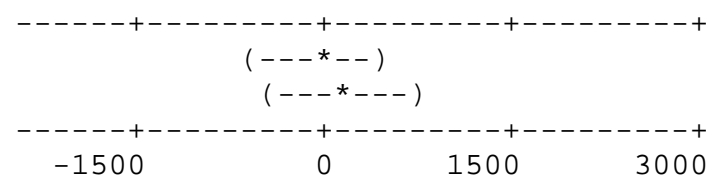

Fixation Method $=\mathrm{C}$

Gender $=\mathrm{F}$ subtracted from:

Fixation

Method

C

Gender

Lower

Center Upper

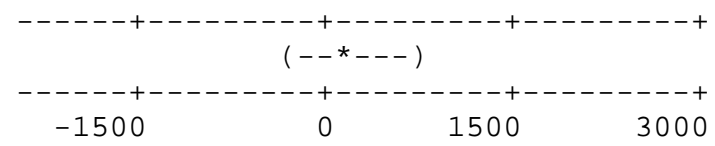

Tukey Simultaneous Tests

Response Variable Ultimate Load

All Pairwise Comparisons among Levels of Fixation Method*Gender

Fixation Method = A

Gender $=F$ subtracted from:

\begin{tabular}{llrrrr} 
Fixation & \multicolumn{2}{c}{ Difference } & SE of & Adjusted \\
Method & Gender & of Means & Difference & T-Value & P-Value \\
A & M & -576.3 & 511.7 & -1.126 & 0.8590 \\
B & F & -110.9 & 108.7 & -1.020 & 0.8999 \\
B & M & -15.8 & 136.1 & -0.116 & 1.0000 \\
C & F & -75.6 & 124.5 & -0.607 & 0.9877 \\
C & M & 139.6 & 110.0 & 1.270 & 0.7938
\end{tabular}

Fixation Method $=\mathrm{A}$

Gender $=M$ subtracted from:

$\begin{array}{llrrrr}\text { Fixation } & & \text { Difference } & \text { SE of } & & \text { Adjusted } \\ \text { Method } & \text { Gender } & \text { Of Means } & \text { Difference } & \text { T-Value } & \text { P-Value } \\ \text { B } & \text { F } & 465.5 & 499.2 & 0.9324 & 0.9280 \\ \text { B } & \text { M } & 560.5 & 464.1 & 1.2077 & 0.8233 \\ \text { C } & \text { F } & 500.8 & 500.8 & 1.0000 & 0.9068\end{array}$


Biomechanical Comparison of Wire Circlage and Rigid Plate Fixation for Median Sternotomy Closure in Human Cadaver Specimens

\begin{tabular}{|c|c|c|c|c|c|c|}
\hline C & $\mathrm{M}$ & & 715.9 & 536.5 & 1.3345 & 0.7613 \\
\hline $\begin{array}{l}\text { Fixation } \\
\text { Gender = }\end{array}$ & $\begin{array}{l}\text { Method = } \\
\text { F subtr }\end{array}$ & $\begin{array}{l}\text { B } \\
\text { acted }\end{array}$ & from: & & & \\
\hline Fixation & & $\operatorname{Diff}$ & erence & SE of & & Adjusted \\
\hline Method & Gender & of & Means & Difference & T-Value & P-Value \\
\hline B & M & & 95.07 & 140.7 & 0.6759 & 0.9804 \\
\hline $\mathrm{C}$ & $\mathrm{F}$ & & 35.30 & 134.4 & 0.2627 & 0.9998 \\
\hline C & $\mathrm{M}$ & & 250.48 & 126.5 & 1.9805 & 0.4189 \\
\hline
\end{tabular}
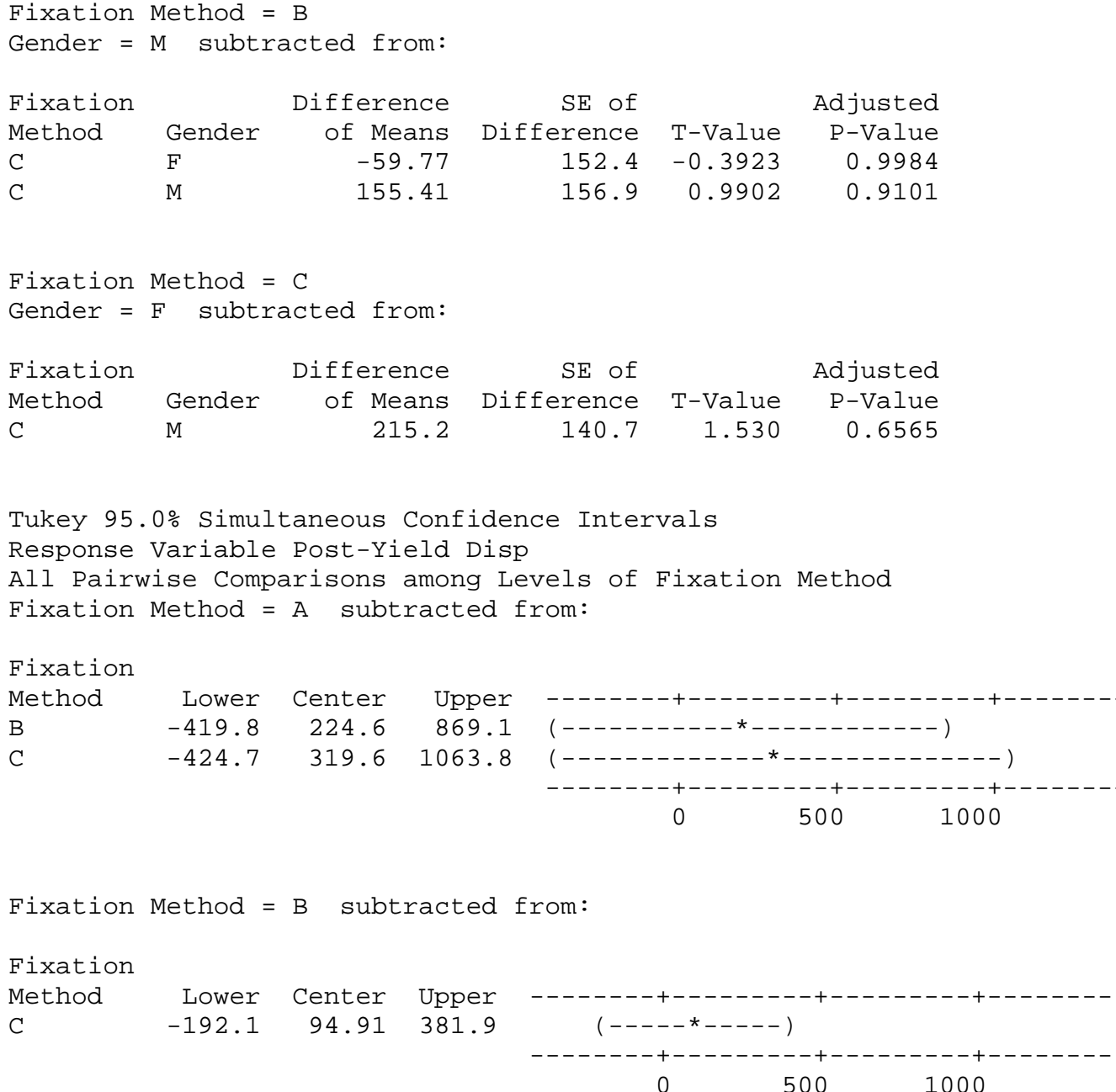

Tukey Simultaneous Tests

Response Variable Post-Yield Disp

All Pairwise Comparisons among Levels of Fixation Method

Fixation Method = A subtracted from:

$\begin{array}{lrrrr}\text { Fixation } & \text { Difference } & \text { SE of } & \text { Adjusted } \\ \text { Method } & \text { of Means } & \text { Difference } & \text { T-Value } & \text { P-Value } \\ \text { B } & 224.6 & 230.7 & 0.9736 & 0.6105 \\ \text { C } & 319.6 & 266.5 & 1.1992 & 0.4828\end{array}$


Biomechanical Comparison of Wire Circlage and Rigid Plate Fixation for Median Sternotomy Closure in Human Cadaver Specimens

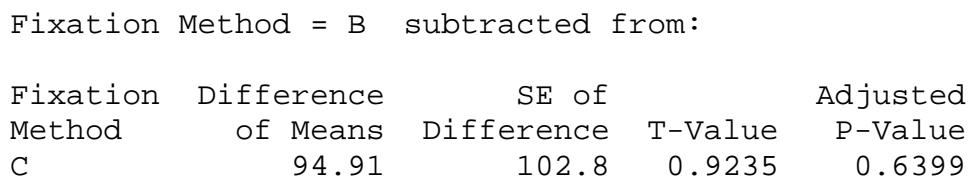

Tukey 95.0\% Simultaneous Confidence Intervals Response Variable Post-Yield Disp

All Pairwise Comparisons among Levels of Gender Gender $=F$ subtracted from:

Gender Lower Center Upper $\begin{array}{llll}\text { M } & -498.5 & -87.32 & 323.8\end{array}$

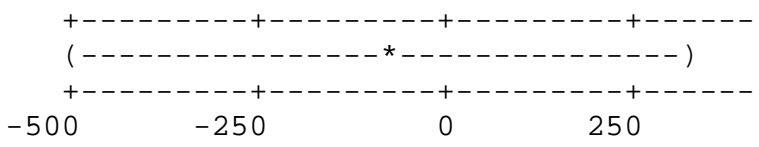

Tukey Simultaneous Tests Response Variable Post-Yield Disp

All Pairwise Comparisons among Levels of Gender Gender $=\mathrm{F}$ subtracted from:

$\begin{array}{lrrrr} & \text { Difference } & \text { SE of } & \text { Adjusted } \\ \text { Gender } & \text { of Means } & \text { Difference } & \text { T-Value } & \text { P-Value } \\ \text { M } & -87.32 & 181.8 & -0.4804 & 0.6424\end{array}$

Tukey 95.0\% Simultaneous Confidence Intervals Response Variable Post-Yield Disp

All Pairwise Comparisons among Levels of Fixation Method*Gender Fixation Method = A

Gender $=F$ subtracted from:

Fixation

$\begin{array}{llrrr}\text { Method } & \text { Gender } & \text { Lower } & \text { Center } & \text { Uppe } \\ \text { A } & \text { M } & -2387 & -572.2 & 1242 . \\ \text { B } & \text { F } & -494 & -109.1 & 276 . \\ \text { B } & \text { M } & -496 & -13.8 & 468 . \\ \text { C } & \text { F } & -516 & -74.0 & 367 . \\ \text { C } & \text { M } & -249 & 141.0 & 530 .\end{array}$

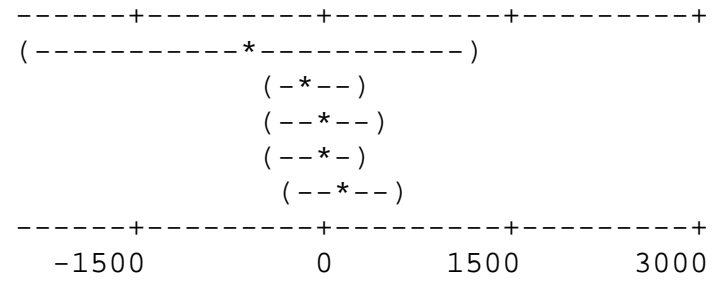

Fixation Method $=\mathrm{A}$

Gender $=M$ subtracted from:

$\begin{array}{llrrr}\text { Fixation } & & & & \\ \text { Method } & \text { Gender } & \text { Lower } & \text { Center } & \text { Upper } \\ \text { B } & \text { F } & -1307 & 463.1 & 2233 \\ \text { B } & \text { M } & -1088 & 558.3 & 2204 \\ \text { C } & \text { F } & -1278 & 498.1 & 2274 \\ \text { C } & \text { M } & -1189 & 713.1 & 2616\end{array}$

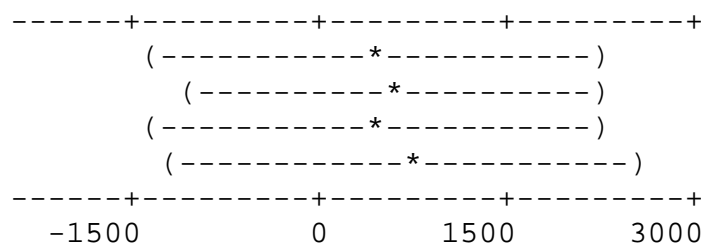

Fixation Method $=\mathrm{B}$

Gender $=F$ subtracted from:

Fixation

Method

Gender Lower Center Upper 
Biomechanical Comparison of Wire Circlage and Rigid Plate Fixation for Median Sternotomy Closure in Human Cadaver Specimens

$\begin{array}{llrrr}B & M & -403.6 & 95.21 & 594 . \\ C & F & -441.4 & 35.02 & 511 . \\ C & M & -198.5 & 250.01 & 698 .\end{array}$

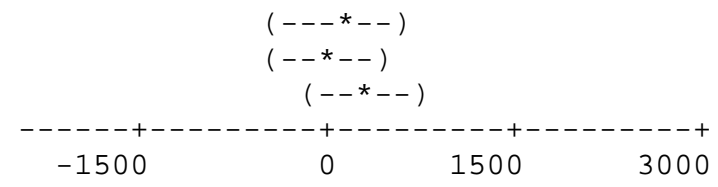

Fixation Method $=\mathrm{B}$

Gender $=$ M subtracted from:

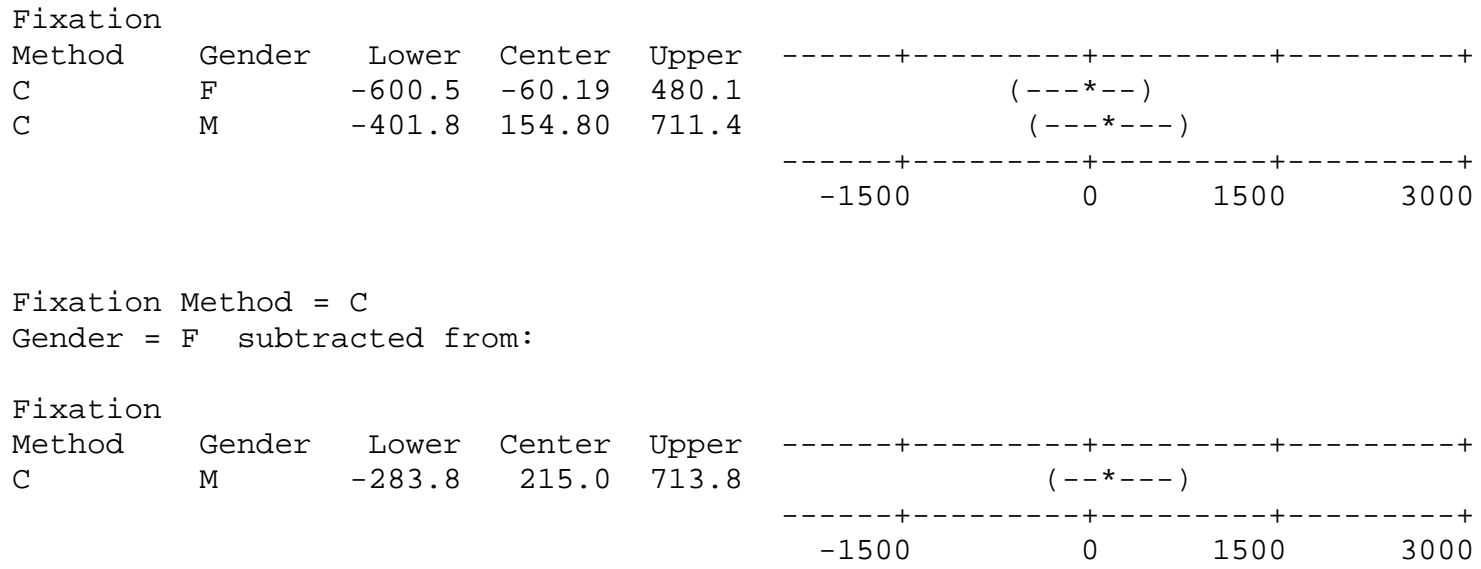

Tukey Simultaneous Tests

Response Variable Post-Yield Disp

All Pairwise Comparisons among Levels of Fixation Method*Gender

Fixation Method = A

Gender $=\mathrm{F}$ subtracted from:

\begin{tabular}{|c|c|c|c|c|c|}
\hline Fixation & & Difference & $S E$ of & & Adjusted \\
\hline Method & Gender & of Means & Difference & T-Value & P-Value \\
\hline A & M & -572.2 & 511.2 & -1.119 & 0.8620 \\
\hline B & $\mathrm{F}$ & -109.1 & 108.6 & -1.004 & 0.9053 \\
\hline$R$ & M & -13.8 & 135.9 & -0.102 & 1.0000 \\
\hline C & $\mathrm{F}$ & -74.0 & 124.4 & -0.595 & 0.9888 \\
\hline 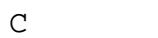 & M & 141.0 & 109.8 & 1.283 & 0.7871 \\
\hline
\end{tabular}

Fixation Method $=\mathrm{A}$

Gender $=$ M subtracted from:

\begin{tabular}{|c|c|c|c|c|c|}
\hline Fixation & & Difference & $S E$ of & & Adjusted \\
\hline Method & Gender & of Means & Difference & T-Value & P-Value \\
\hline B & F & 463.1 & 498.7 & 0.9286 & 0.9291 \\
\hline B & M & 558.3 & 463.7 & 1.2041 & 0.8249 \\
\hline $\mathrm{C}$ & F & 498.1 & 500.3 & 0.9958 & 0.9082 \\
\hline C & M & 713.1 & 536.0 & 1.3306 & 0.7633 \\
\hline
\end{tabular}

Fixation Method $=\mathrm{B}$

Gender $=\mathrm{F}$ subtracted from:

\begin{tabular}{|c|c|c|c|c|c|}
\hline Fixation & & Difference & $S E$ of & & Adjusted \\
\hline Method & Gender & of Means & Difference & T-Value & P-Value \\
\hline B & M & 95.21 & 140.5 & 0.6776 & 0.9802 \\
\hline C & F & 35.02 & 134.2 & 0.2609 & 0.9998 \\
\hline $\mathrm{C}$ & M & 250.01 & 126.4 & 1.9787 & 0.4197 \\
\hline
\end{tabular}


Biomechanical Comparison of Wire Circlage and Rigid Plate Fixation for Median Sternotomy Closure in Human Cadaver Specimens

Fixation Method $=\mathrm{B}$

Gender $=M$ subtracted from:

$\begin{array}{llrrrr}\text { Fixation } & & \text { Difference } & \text { SE of } & & \text { Adjusted } \\ \text { Method } & \text { Gender } & \text { of Means } & \text { Difference } & \text { T-Value } & \text { P-Value } \\ \text { C } & \text { F } & -60.19 & 152.2 & -0.3954 & 0.9983 \\ \text { C } & \text { M } & 154.80 & 156.8 & 0.9873 & 0.9110\end{array}$

Fixation Method $=\mathrm{C}$

Gender $=\mathrm{F}$ subtracted from:

\begin{tabular}{llrrrr} 
Fixation & \multicolumn{1}{r}{ Difference } & SE of & Adjusted \\
Method & Gender & of Means & Difference & T-Value & P-Value \\
C & M & 215.0 & 140.5 & 1.530 & 0.6564
\end{tabular}




\section{Appendix C: Statistical Analysis - Anterior-Posterior shear General Linear Model: Stiffness versus Fixation Method, Gender}
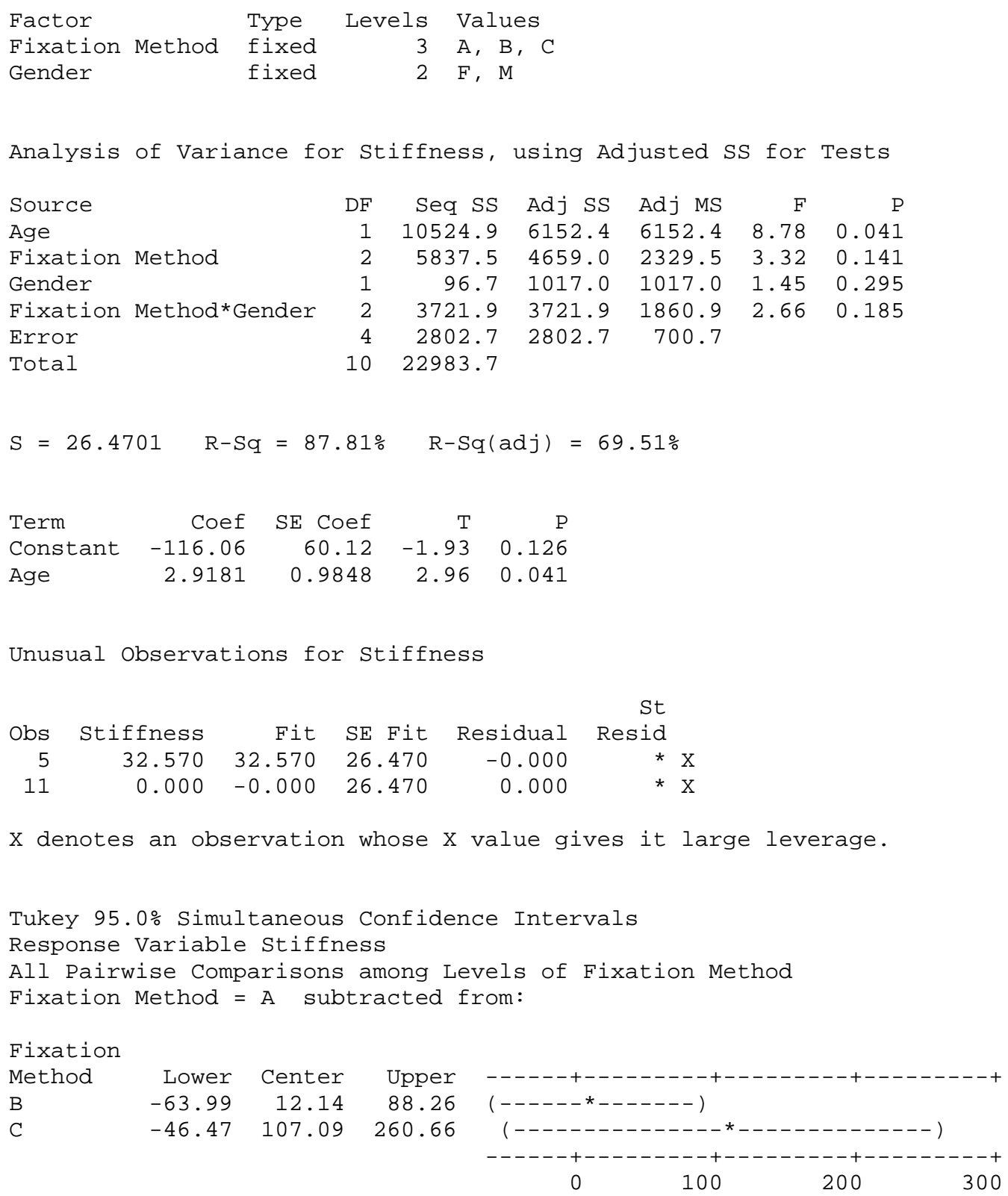

Fixation Method = B subtracted from:

Fixation

Method

C

Lower Center Upper

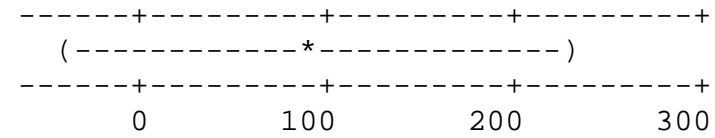

Tukey Simultaneous Tests 
Biomechanical Comparison of Wire Circlage and Rigid Plate Fixation for Median Sternotomy Closure in Human Cadaver Specimens

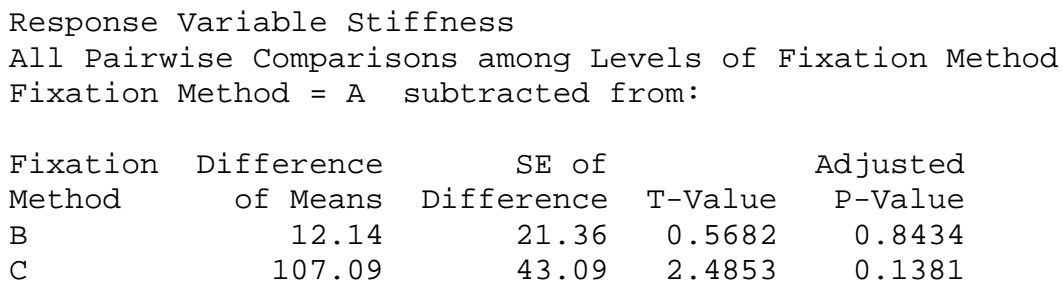

Tukey 95.0\% Simultaneous Confidence Intervals Response Variable Stiffness

All Pairwise Comparisons among Levels of Gender Gender $=\mathrm{F}$ subtracted from:

Gender Lower Center Upper -----+--------+---------+--------+-

M $-125.7-38.04 \quad 49.62 \quad(----------------\star-----------------)$

\begin{tabular}{|c|c|}
\hline-100 & -50 \\
\hline
\end{tabular}

Tukey Simultaneous Tests

Response Variable Stiffness

All Pairwise Comparisons among Levels of Gender

Gender $=\mathrm{F}$ subtracted from:

$\begin{array}{rrrrr} & \text { Difference } & \text { SE of } & & \text { Adjusted } \\ \text { Gender } & \text { of Means } & \text { Difference } & \text { T-Value } & \text { P-Value } \\ \text { M } & -38.04 & 31.57 & -1.205 & 0.2947\end{array}$

Tukey 95.0\% Simultaneous Confidence Intervals Response Variable Stiffness

All Pairwise Comparisons among Levels of Fixation Method*Gender Fixation Method $=\mathrm{A}$

Gender $=\mathrm{F}$ subtracted from:

Fixation

$\begin{array}{llrrr}\text { Method } & \text { Gender } & \text { Lower } & \text { Center } & \text { Upper } \\ \text { A } & \text { M } & -102.1 & 27.706 & 157.5 \\ \text { B } & \text { F } & -67.3 & 48.189 & 163.7 \\ \text { B } & \text { M } & -151.2 & 3.789 & 158.7 \\ \text { C } & \text { F } & -200.3 & 169.651 & 539.6 \\ \text { C } & \text { M } & -53.9 & 72.238 & 198.4\end{array}$

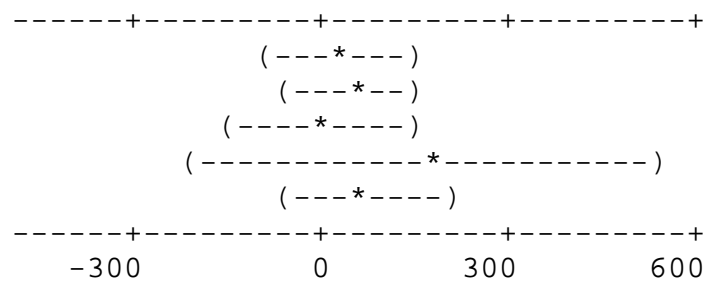

Fixation Method $=\mathrm{A}$

Gender $=M$ subtracted from:

Fixation Method

$\begin{array}{lrrr}\text { Gender } & \text { Lower } & \text { Center } & \text { Upper } \\ \text { F } & -103.3 & 20.48 & 144.3 \\ M & -186.1 & -23.92 & 138.3 \\ \text { F } & -257.9 & 141.95 & 541.8\end{array}$

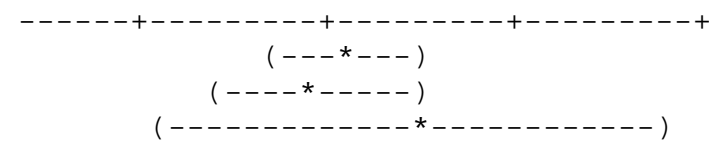


Biomechanical Comparison of Wire Circlage and Rigid Plate Fixation for Median Sternotomy Closure in Human Cadaver Specimens

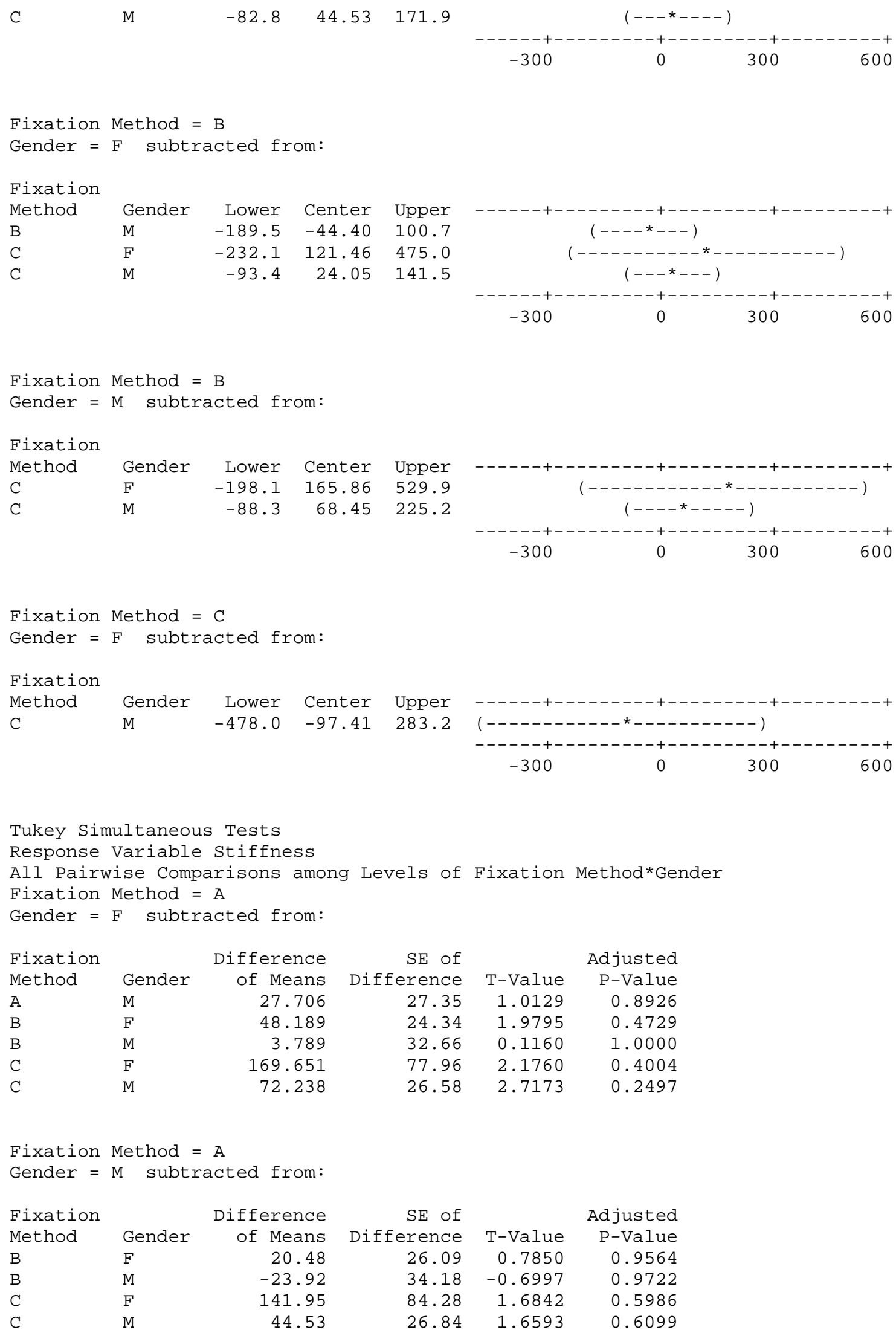


Biomechanical Comparison of Wire Circlage and Rigid Plate Fixation for Median Sternotomy Closure in Human Cadaver Specimens

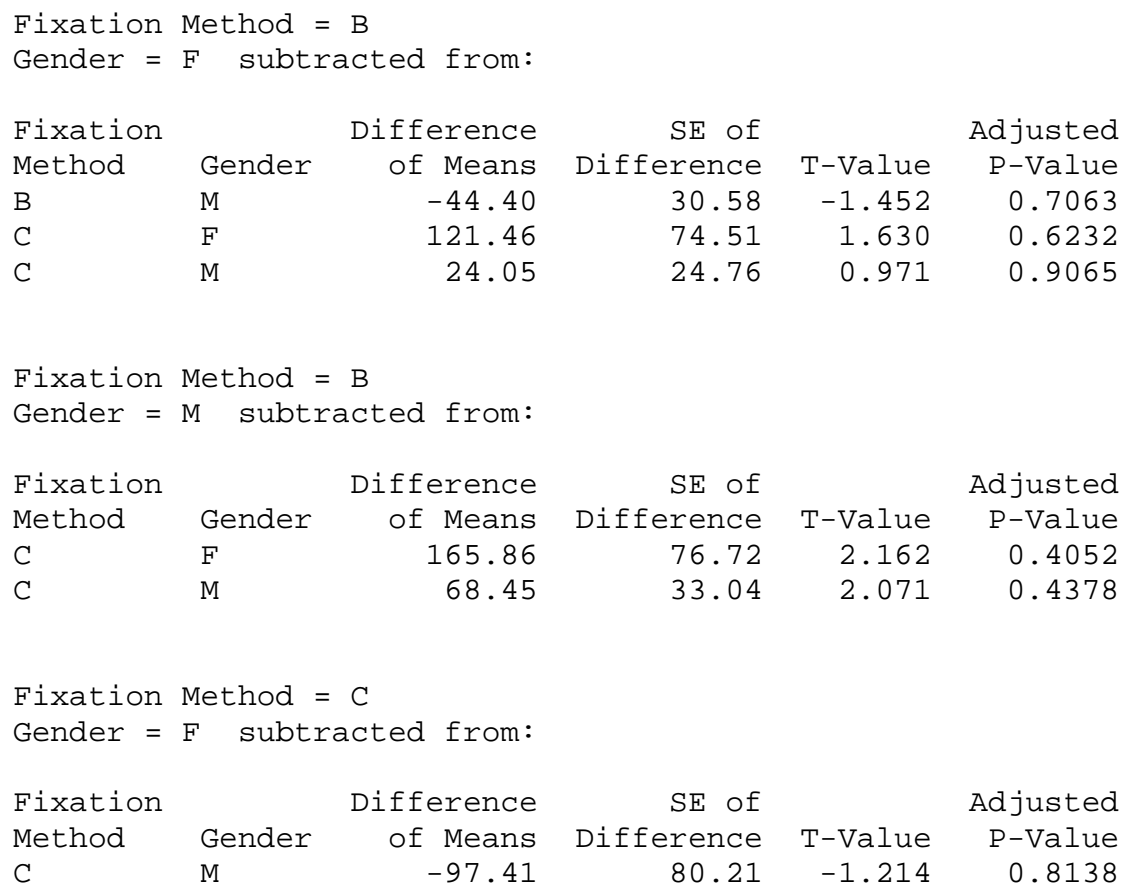

